$$
\begin{aligned}
& =\quad B N L-46856 \\
& \text { DE92 } 005024
\end{aligned}
$$

\title{
AN ORGANIZATIONAL SURVEY OF THE LOS ALAMOS SITE
}

\author{
Prepared by: \\ Deborah A. Shurberg and Sonja B. Haber \\ Engineering Technology Division \\ Department of Nuclear Energy \\ Brookhaven National Laboratory \\ Upton, New York 11973
}

November 1991

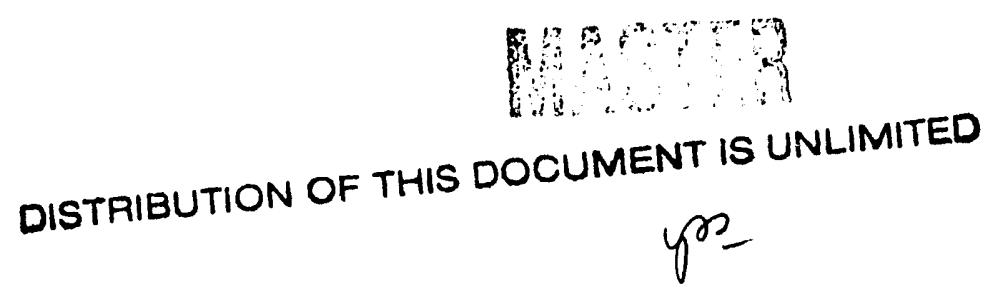

Prepared for:

U.S. Department of Energy

Washington, D.C. 20585

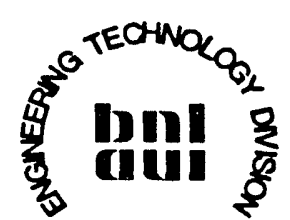

DNE 


\section{EXECUTIVE SUMMARY}

An Organizational Survey (OS) was administered at the Los Alamos Site that queried employees on the subjects of organizational culture, various aspects of communications, employee commitment, work group cohesion, coordination of work, environmental, safety, and health concerns, hazardous nature of work, safety and overall job satisfaction. The purpose of the OS is to measure in a quantitative and objective way the notion of "culture;" that is, the values, attitudes, and beliefs of the individuals working within the organization. In addition, through the OS, a broad sample of indi riduals can be reached that would probably not be interviewed or observed during the course of a typical assessment. The OS also provides a descriptive profile of the organization at one point in time that can then be compared to a profile taken at a different point in time to assess changes in the culture of the organization. While comparisons among groups are made, it is not the purpose of this report to make evaluative statements of which profile may be positive or negative. However, using the data presented in this report in conjunction with other evaluative activities, may provide useful insight into the organization.

The OS administration at the Los Alamos Site was the ninth to occur at a Department of Energy (DOE) facility. Employees of all three organizations which are at the Los Alamos Site were included in the survey administration. These three organizations are: Los Alamos National Laboratory (LANL); Johnson Controls World Services, Inc.; and Mason \& Hanger - Silas Mason Co., Inc. Of the total number of employees who work at the Los Alamos Site (approximately 9000), 2,123 employees were randomly selected to complete the survey. Of this random sarnple, 1036 actually responded to the survey, yielding a response rate of 48.8 percent, much lower than any other DOE site at which a group administered OS has been conducted. Johnson Controls had the highest response rate, with 50.9 percent. The response rate for LANL was somewhat lower at $\mathbf{4 5 . 4}$ percent. The organization with the lowest response rate was Mason \& Hanger, with a response rate of 36.2 percent. Although overall, and for both LANL and Mason \& Hanger, the obtained response rates were less than 50 percent of the total number of employees randomly selected to complete the survey, each organization's response rate represented at least ten percent of their total population, the percentage needed for statistical adequacy. All data from the OS is presented in group summaries, by organization, department or directorate within organization, supervisory level both overall and within organization, and staff classification within organization. Statistically significant differences between groups are identified and discussed.

The organizational profile which emerges from the results of the OS administration at the Los Alamos Site is that of a predominantly constructive and yet somewhat passive-defensive cultural style. This is demonstrated by the higher mean values on the constructive scales of the Organizational Culture Inventory $(\mathrm{OCI})$, Humanistic (C1), Affiliative (C2), Achievement (C11), and Self-Actualizing (C12). The passivedefensive style is represented by the mean values on the Approval (C3), Conventional (C4), Dependent (C5), and Avoidance (C6) Scales. However, it is probably more useful to examine the differences obtained between the three organizations at the Los Alamos Site: LANL, Johnson Controls, and Mason \& Hanger, as they are actually three separate organizations which work together to accomplish the mission of the overall site. They each have their own organizational structure and set of management practices and philosophies.

Only one statistically significant difference was found between the three Los Alamos Site Organizations on the OCI. This difference occurred on the Dependent (C5) Scale, with Mason \& Hanger having a statistically significantly higher mean value on this scale than either the LANL or Johnson Controls Organizations. This suggests that despite the independence of the organizations, similar cultures have been established at each. Statistically significant differences did occur between the organizations on the Communication Scales as well as on the scales relating to the perceived hazardous nature of one's work. The results suggest that communications may be less of a problematic area at LANL than at the other 
organizations, as LANL had the highest mean values on the Communication Scales. On the other hand, LANL employees perceived a significantly lower potential for hazard and environmental consequences associated with their work than either Johnson Controls or Mason \& Hanger employees.

When managers and non-managers were compared at the Los Alamos Site, the results were consistent with the literature on manager and non-manager differences as well as consistent with results obtained at other DOE facilities. Managers exhibited a more constructive, committed, and satisfied profile, while non-managers were lower on these scales but higher on scales which comprise the passive-defensive cultural style.

Only one statistically significant difference was obtained when managers from the three organizations were compared and that was on the Communication-Interaction Scale. The lack of significant differences may be due to the large discrepancy in the number of managers which are employed and conscauently, who responded to the survey, in each organization. Many statistically significant differences were obiained when the non-managers from the three organizations were compared and the differences were consistent with the results obtained when each organization overall was compared to the others.

The number of statistically significant differences found between the various groups analyzed in the LANL Organization suggest that a common culture is not shared by all groups at LANL. However, within both Johnson Controls and Mason \& Hanger, statistically significant differences between groups were few, suggesting that the culture at these organizations may be more homogeneous. Some of this may be due to differences in size and mission between the three organizations. 5oth Johnson Controls and Mason \& Hanger have fairly specific and delineated responsibilities, as well as a much smaller number of umployees than LANL. Establishing a common culture at these organizations is somewhat easier. At LANL, however, there are a variety of groups, with a much larger number of employees, working with very different issues.

In summary, the profiles of the three organizations at the Los Alamos Site indicate a predominantly constructive culture, and a tendency to deal with some issues in a more passive-defensive manner. Differences between organizations consistently occur on those scales which relate to communication processes and the hazardous nature of one's work. Within organizations, few differences are found between groups at either Mason \& Hanger or at Johnson Controls, while many differences are found between groups at LANL. This may be attributable to the different sizes and missions of each of the organizations. 


\section{CONTENTS}

\section{Page}

EXECUTIVE SUMMARY $\ldots \ldots \ldots \ldots \ldots \ldots \ldots \ldots \ldots$ iii

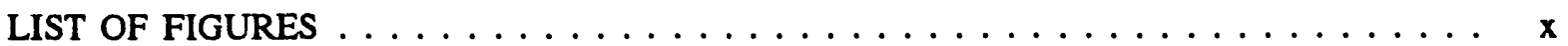

LIST OF TABLES $\ldots \ldots \ldots \ldots \ldots \ldots \ldots \ldots \ldots \ldots \ldots \ldots \ldots$

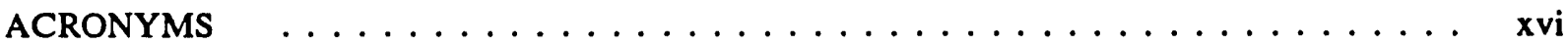

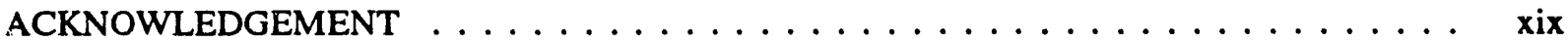

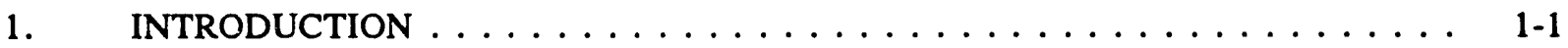

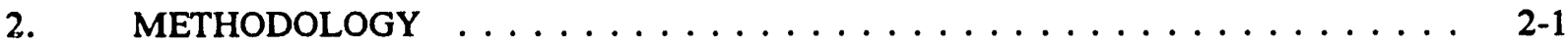

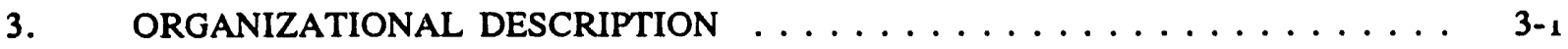

4. ORGANIZATIONAL SURVEY SCALES AND RESULTS $\ldots \ldots \ldots \ldots \ldots$. . . .

4.1 Organizational Survey Scale Descriptions . . . . . . . . . . . 4 4-1

4.1.1 Organizational Culture Inventory $\ldots \ldots \ldots \ldots \ldots \ldots . \ldots \ldots$ 4-1

4.1 .2 Communication Scales . . . . . . . . . . . . . . 4-3

4.1 .3 Commitment Scale . . . . . . . . . . . . . . . . 44-4

4.1 .4 Cohesion Scale $\ldots \ldots \ldots \ldots \ldots \ldots \ldots \ldots$ 4.4 . . . . . . . .

4.1 .5 Coordination Scale $\ldots \ldots \ldots \ldots \ldots \ldots$. . . . . . . . . .

4.1 .6 Job Satisfaction . . . . . . . . . . . . . . . . . 4 4-4

4.1 .7 Hazard Scale . . . . . . . . . . . . . . . . . . . . 4-4

4.1 .8 Safety Scale . . . . . . . . . . . . . . . . . . 4-5

4.1.9 Environment, Safety, and Health Questions . . . . . . . . 4-5

4.2 Overall Results on the OS Scales for the Los Alamos Site . . . . . . 4-5

4.2.1 Organizational Culture Inventory Results . . . . . . . . . . . . . 4-5

4.2 .2 Communication Scales Results . . . . . . . . . . . . . . 4 4-6

4.2.3 Results for Additional Scales . . . . . . . . . . . . . . . . 4 4-6

4.2.4 Envirunment, Safety and Health Questions Results . . . . . . . . . 4-7

4.2 .5 Summary . . . . . . . . . . . . . . . . . . . 4-7

4.3 Differences Between Organizations on the OS Scales $\ldots \ldots \ldots \ldots \ldots$ 4-8

4.3.1 Differences Between Organizations on the OCI . . . . . . . 4 4-8

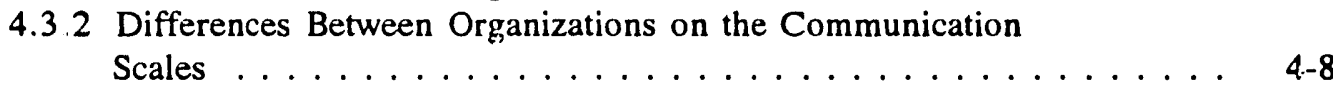

4.3.3 Differences Between Organizations on the Additional Scales . . . . 4. 4-9

4.3.4 Differences Between Organizations on the Environment, Safety, and Health Questions ................ 4-11

4.3 .5 Summary ......................... 4-13 


\section{CONTENTS (Cont'd.)}

Page

4.4 Differences Between Supervisory Levels on the OS Scales . . . . . . . . 4 4-13

4.4.1 Differences Between Managers and Non-Managers on the OCI Scales . . . . . . . . . . . . . . . . . .

4.4.2 Differences Between Managers and Non-Managers on the Communication Scales . . . . . . . . . . . . . . . . 4-16

4.4.3 Differences Between Managers and Non-Managers on the Additional Scales . . . . . . . . . . . . . . . . 4-16

4.4.4 Differences Between Managers and Non-Managers on the Environment, Safety, and Health Questions . . . . . . . . . 4-18

4.4.5 Summary . . . . . . . . . . . . . . . . . . . . . 4 4-19

4.5 Differences Between Organizations' Managerial Employees on the

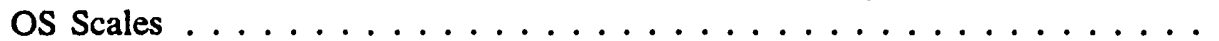

4.5.1 Differences Between Organizations' Managerial Employees on the OCI Scales . . . . . . . . . . . . . . . . .

4.5.2 Differences Between Organizations' Managerial Employees on the Communication Scales . . . . . . . . . . . . . . .

4.5.3 Differences Between Organizations' Managerial Employees on the Additional Scales . . . . . . . . . . . . . . . .

4.5.4 Differences Between Organizations' Managerial Employees on the Envirunment, Safety, and Health Questions . . . . . . . . 4-20

4.5 .5 Summary . . . . . . . . . . . . . . . . . 4 4-20

4.6 Differences Between Organizations' Non-Managerial Employees on the

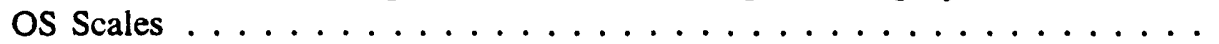

4.6.1 Differences Between Organizations' Non-Managerial Employees on the OCI Scales . . . . . . . . . . . . . . . . . . .

4.6.2 Differences Between Organizations' Non-Managerial Employees on the Communication Scales . . . . . . . . . . . . . . .

4.6.3 Differences Between Organizations' Non-Managerial Employees on the Additional Scales . . . . . . . . . . . . . .

4.6.4 Differences Between Organizations' Non-Managerial Employees on the Environment, Safety, and Health Questions . . . . . . . . 4-24

4.6 .5 Summary . . . . . . . . . . . . . . . . . . . 4-26

4.7 Differences Within the LANL Organization on the OS Scales $\ldots \ldots \ldots$. . . 4-26

4.7.1 Differences Between the LANL Directorates on the OS Scales . . . 4-26

4.7.2 Differences Between the LANL Staff Classifications on the OS Scales . . . . . . . . . . . . . . . . . . . 4 4-34

4.7.3 Differences Between the LANL Supervisory Levels on the OS Scales . . . . . . . . . . . . . . . . . . . . . 440 


\section{CONTENTS (Cont'd.)}

Page

4.8 Differences Within the Johnson Controls Organization on the OS Scales . . .

4.8.1 Differences Between the Johnson Controls Departments on the

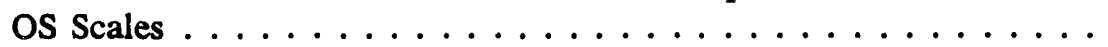

4.8.2 Differences Between Johnson Controls Staff Classifications on the os Scales $\ldots \ldots \ldots \ldots \ldots \ldots \ldots \ldots \ldots$

4.8.3 Differences Between Johnson Controls Managers and Non-Managers on the os Scales $\ldots \ldots \ldots \ldots \ldots \ldots \ldots \ldots \ldots \ldots . \ldots \ldots$

4.9 Differences Within the Mason \& Hanger Organization on the OS Scales . . 4-56

4.9.1 Differences Between the Mason \& Hanger Departments on the

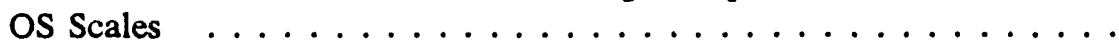

4.9.2 Differences Between Mason \& Hanger Staff Classifications on the os Scales . . . . . . . . . . . . . . . . . .

4.9.3 Differences Between Mason \& Hanger Supervisory Levels

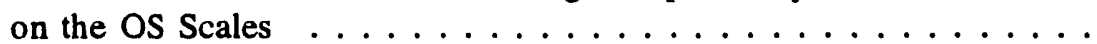

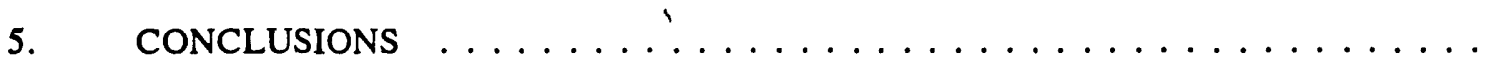

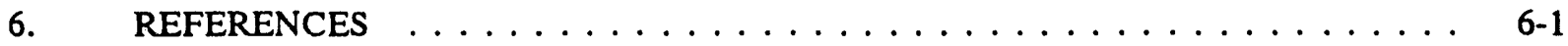

Appendix A: Overall Means on the OS Scales for the Los Alamos Site Compared to the Overall Means Obtained for Each Organization . . . . . . . . .

Appendix B: Significant Differences Between Organizations at the Los Alamos Site

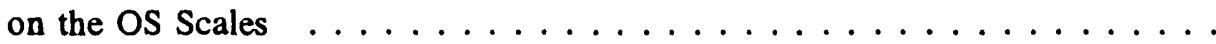

Appendix C: Significant Differences Between Managers and Non-Managers at the Los Alamos Site on the OS Scales.

Appendix D: Significant Differences Between Organizations' Managerial Employees on the OS Scales $\ldots \ldots \ldots \ldots \ldots$

Appendix E: Significant Differences Between Organizations' Non-Managerial Employees on the OS Scales

Appendix F: Significant Differences Between the LANL Organizations' Directorates on the OS Scales

Appendix G: Mean Values for the Overall LANL Organization Compared to the Mean Values Obtained for Each LANL Directorate on the OCI . . . . . . . 


\section{CONTENTS (Cont'd.)}

Appendix H: Mean Values for the Overall LANL Organization Compared to the

Mean Values Obtained for Each LANL Directorate on the

Communication Scales $\ldots \ldots \ldots \ldots \ldots \ldots \ldots \ldots \ldots \ldots \ldots \ldots$

Appendix I: Mean Values for the Overall LANL Organization Compared to the Mean Values Obtained for Each LANL Directorate on the

Appendix J: Mean Values for the Overall LANL Organization Compared to the Mean Values Obtained for Each LANL Directorate on the Environment, Safety, and Health Questions .............

Appendix K: Significant Differences Between LANL Staff Classifications on the

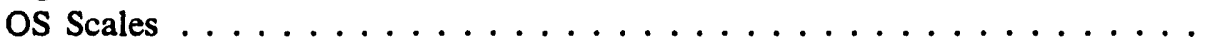

Appendix L: Significant Differences Between LANL Supervisory Levels on the

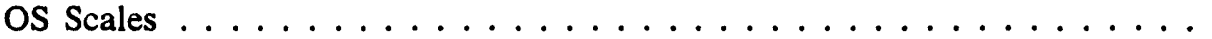

Appendix M: Significant Differences Between LANL Managers and Non-Managers on the OS Scales $\ldots \ldots \ldots \ldots \ldots \ldots \ldots \ldots \ldots \ldots \ldots$

Appendix N: Significant Differences Between Johnson Controls Departments on the OS Scales

Appendix O: Mean Values for the Overall Johnson Controls Organization Compared to the Mean Values Obtained for Each Johnson Controls Department

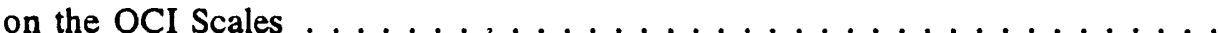

Appendix P: Mean Values for the Overall Johrsson Controls Organization Compared to the Mean Values Obtained for Each Johnson Controls Department on the Communication Scales $\ldots \ldots \ldots \ldots \ldots \ldots \ldots$

Appendix Q: $\quad$ Mean Values for the Overall Johnson Controls Organization Compared to the Mean Values Obtained for Each Johnson Controls Department

Appendix R: $\quad$ Mean Values for the Overall Johnson Controls Organization Compared to the Mean Values Obtained for Each Johnson Controls Department on the Environment, Safety, and Health Question . . . . . . . . . . . .

Appendix S: $\quad$ Significant Differences Between Johnson Con rols Staff Classifications on the os Scales $\ldots \ldots \ldots \ldots \ldots \ldots$

Appendix T: Significant Differences Between Johnson Controls Managers and Non-Managers on the os Scales .................. T-1 
CONTENTS (Cont'd.)

Page

Appendix U: Significant Differences Between Mason \& Hanger Departments

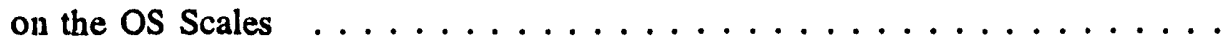

Appendix V: Mean Values for the Overall Mason \& Hanger Organization Compared to the Mean Values Obtained for Each Mason \& Hanger Department on the OCI Scales . . . . . . . . . . . . . . . . . . . . . .

Appendix W: Mean Values for the Overall Mason \& Hanger Organization Compared to the Mean Values Obtained for Each Mason \& Hanger Department on the Communication Scales $\ldots \ldots \ldots \ldots \ldots \ldots$

Appendix X: Mean Values for the Overall Mason \& Hanger Organization Compared to the Mean Values Obtained for Each Mason \& Hanger Department

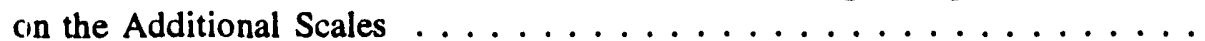

Appendix Y: Mean Values for the Overall Mason \& Hanger Organization Compared to the Mean Values Obtained for Each Mason \& Hanger Department on the Environment, Safety, and Health Questions ............

Appendix Z: Significant Differences Between Mason \& Hanger Staff

Classifications on the os Scales $\ldots \ldots \ldots \ldots \ldots \ldots \ldots$

Appendix AA: Significant Differences Between Mason \& Hanger Supervisory Levels on the OS Scales $\ldots \ldots \ldots \ldots \ldots \ldots \ldots \ldots$ 


\section{LIST OF FIGURES}

$\underline{\text { Page }}$

4.1 Overall means for the Los Alamos site on the OCI scales . . . . . . . . . . 4-5

4.2 Overall mean values for the Los Alamos site on the communication scales . . . . 4 4-6

4.3 Overall mean values for the Los Alamos site on the additional scales . . . . . . . 4 4-7

4.4 Overall mean values for the Los Alamos site on the environment, safety, and health questions $\ldots \ldots \ldots \ldots \ldots \ldots \ldots \ldots$ 4-7

4.5 Significant differences between organizations on the dependent scale $\ldots \ldots \ldots \ldots$ 4-8

4.6 Significant differences between organizations on the communicationtrust scale . . . . . . . . . . . . . . . . . . . . .

4.7 Significant differences between organizations on the communication-

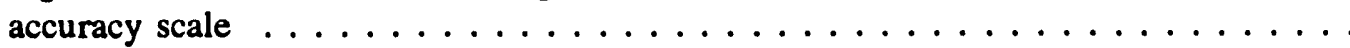

4.8 Significant differences between organizations on the communication-

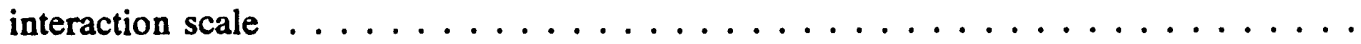

4.9 Significant differences between organizations on the commitment scale . . . . . . . 4-10

4.10 Significant differences between organizations on the hazard scale . . . . . . . . . 4-10

4.11 Significant differences between organizations at the Los Alamos site

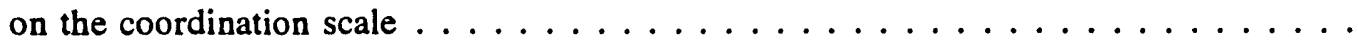

4.12 Significant differences between organizations on the offsite environmental

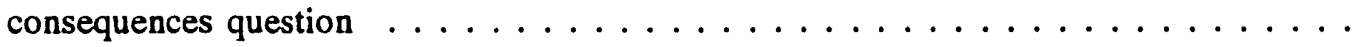

4.13 Significant differences between organizations on the onsite environmental

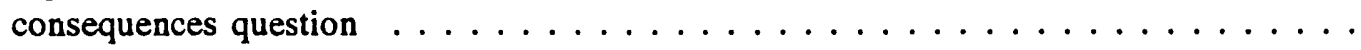

4.14 Significant differences between organizations on the management emphasis

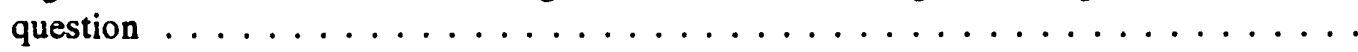

4.15 Significant differences between organizations on the employee awareness

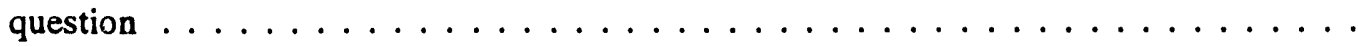

4.16 Significant differences between managers and non-managers on the humanistic-encouraging scale $\ldots \ldots \ldots \ldots \ldots \ldots$

4.17 Significant differences between managers and non-managers on the

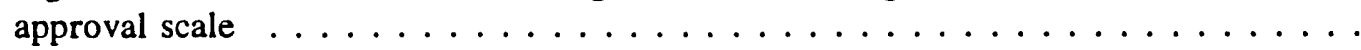

4.18 Significant differences between managers and non-managers on the

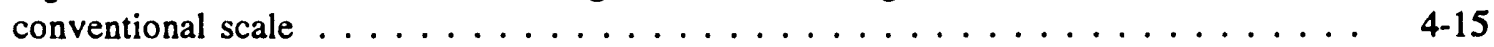

4.19 Significant differences between managers and non-managers on the dependent scale ......................... 4-15

4.20 Significant differences between managers and non-managers on the

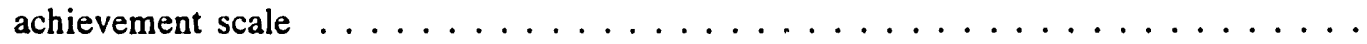

4.21 Significant differences between managers and non-managers on the

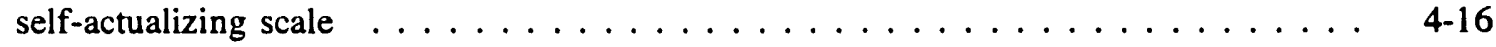

4.22 Significant differences between managers and non-managers on the

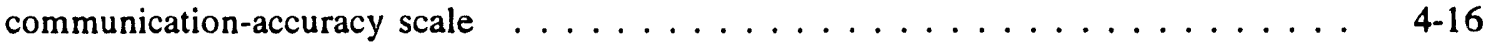

4.23 Significant differences between managers and non-managers on the communication-interaction scale 


\section{LIST OF FIGURES (Cont'd.)}

4.24 Significant differences between managers and non-managers on the commitment scale . . . . . . . . . . . . . . . . . . .

4.25 Significant differences between managers and non-managers on the

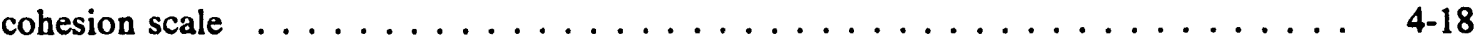

4.26 Significant differences between managers and non-managers on the

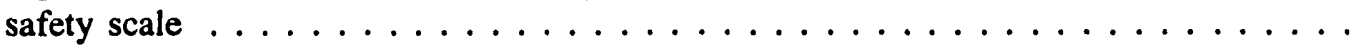

4.27 Significant differences between managers and non-managers on the management emphasis question . . . . . . . . . . . . . . .

4.28 Significant differences between managers and non-managers on the employee awareness question . . . . . . . . . . . . . . . . 4-19

4.29 Significant differences between organizations' managerial employees on the communication-interaction scale . . . . . . . . . . . . . . . . 4-20

4.30 Significant differences between organizations' non-managerial employees on the communication-trust scale $\ldots \ldots \ldots \ldots \ldots \ldots \ldots \ldots$

4.31 Significant differences between organizations' non-managerial employees on the communication-accuracy scale $\ldots \ldots \ldots \ldots \ldots \ldots \ldots$

4.32 Significant differences between organizations' non-managerial employees on the communication-interaction scale $\ldots \ldots \ldots \ldots \ldots \ldots$

4.33 Significant differences between organizations' non-managerial employees on the commitment scale . . . . . . . . . . . . . . . . . . . .

4.34 Significant differences between organizations' non-managerial employees

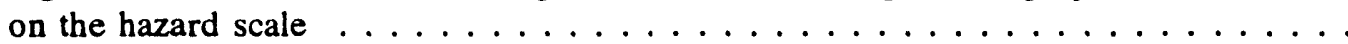

4.35 Significant differences between organizations' non-managerial employees on the coordination scale $\ldots \ldots \ldots \ldots \ldots \ldots \ldots$

4.36 Significant differences between organizations' non-managerial employees on the offsite environmental consequences question . . . . . . . . . . .

4.37 Significant differences between organizations' non-managerial employees on the onsite environmental consequences question . . . . . . . . . . .

4.38 Significant differences between organizations' non-managerial employees on the management emphasis question . . . . . . . . . . . . . . .

4.39 Significant differences between organizations' non-managerial employees on the employee awareness question . . . . . . . . . . . . . . . .

4.40 Significant differences between LANL directorates on the affiliative scale

4.41 Significant differences between LANL directorates on the approval scale . . . . . .

4.42 Significant differences between LANL directorates on the conventional

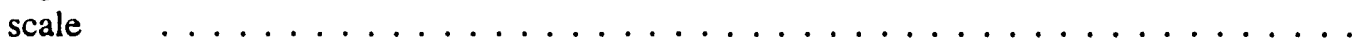

4.43 Significant differences between LANL directorates on the dependent scale . . . . . . 4-28

4.44 Significant differences between LANL directorates on the avoidance scale . . . . . . 4-29

4.45 Significant differences between LANL directorates on the power scale . . . . . . . 4-29 


\section{LIST OF FIGURES (Cont'd.)}

Page

4.46 Significant differences between LANL directorates on the communicationtrust scale . . . . . . . . . . . . . . . . . . . . . . 4-30

4.47 Significant differences between LANL directorates on the commitment

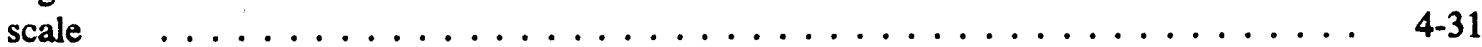

4.48 Significant differences between LANL directorates on the hazard scale . . . . . . . 4-31

4.49 Significant differences between LANL directorates on the offsite

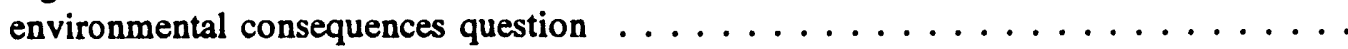

4.50 Significani differences between LANL directorates on the onsite

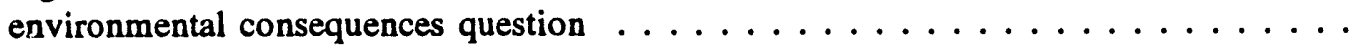

4.51 Significant differences between LANL directorates on the management emphasis question . . . . . . . . . . . . . . . . . . .

4.52 Significant differences between LANL directorates on the employee

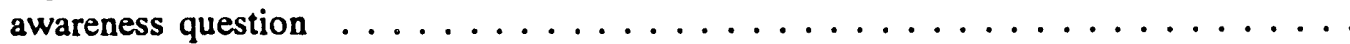

4.53 Significant differences between LANL staff classifications on the humanistic-encouraging scale $\ldots \ldots \ldots \ldots \ldots \ldots \ldots$

4.54 Significant differences between LANL staff classifications on the affiliative scale . . . . . . . . . . . . . . . . . .

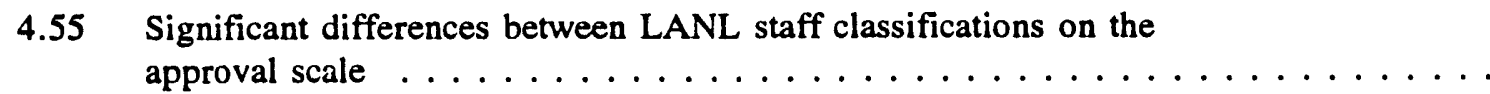
4.55 Significant differences between LANL staff classifications on the

4.56 Significant differences between LANL staff classifications on the

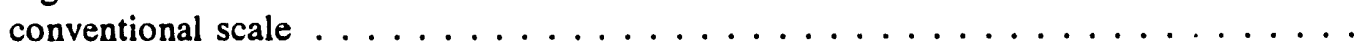

4.57 Significant differences between LANL Staff classifications on the

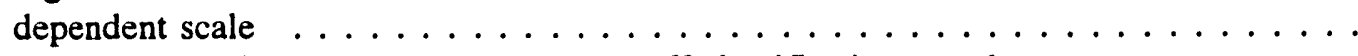

4.58 Significant differences between LANL staff classifications on the perfectionistic scale . . . . . . . . . . . . . . . . .

4.59 Significant differences between LANL staff classifications on the communication-accuracy scale $\ldots \ldots \ldots \ldots \ldots \ldots \ldots$

4.60 Significant differences between LANL staff classifications on the

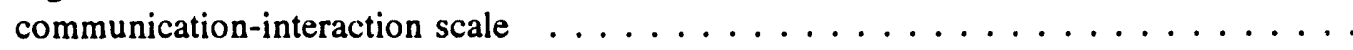

4.61 Significant differences between LANL staff classifications on the hazard scale . . .

4.62 Significant differences between LANL staff classifications on the offsite

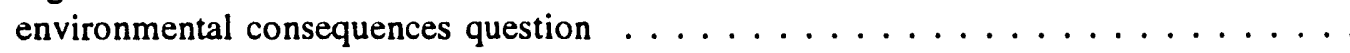

4.63 Significant differences between LANL staff classifications on the onsite environmental consequences question . . . . . . . . . . . . . . . 4-40

4.64 Significant differences between LANL supervisory levels on the humanistic-

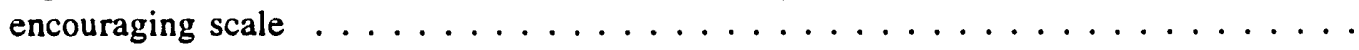

4.65 Significant differences between LANL managers and non-managers on the humanistic-encouraging scale $\ldots \ldots \ldots \ldots \ldots \ldots \ldots$

4.66 Significant differences between LANL supervisory levels on the approval scale ...

4.67 Significant differences between LANL managers and non-managers on the

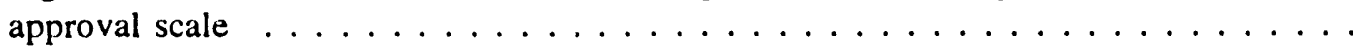




\section{LIST OF FIGURES (Cont'd.)}

$\underline{\text { Page }}$

4.68 Significant differences between LANL supervisory levels on the conventional

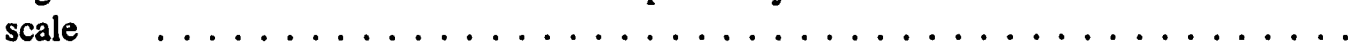

4.69 Significant differences between LANL managers and non-managers on the conventional scale . . . . . . . . . . . . . . . . . . . . . . . . 4-43

4.70 Significant differences between LANL supervisory levels on the dependent

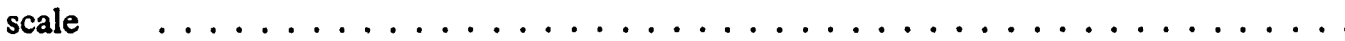

4.71 Significant differences between LANL managers and non-managers on the

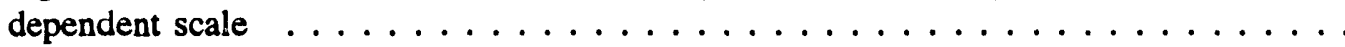

4.72 Significant differences between LANL supervisory levels on the achievement

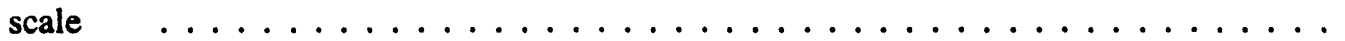

4.73 Significant differences between LANL managers and non-managers on the

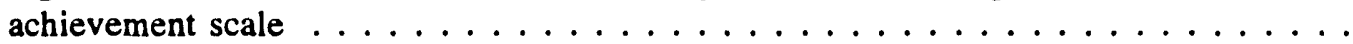

4.74 Significant differences between LANL supervisory levels on the self-

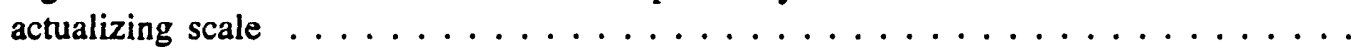

4.75 Significant differences between LANL managers and non-managers on the

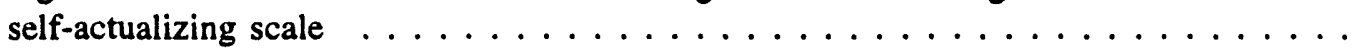

4.76 Significant differences between LANL supervisory levels on the

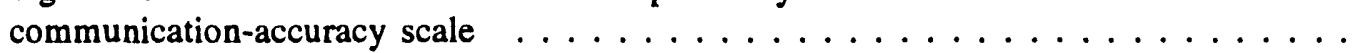

4.77 Significant differences between LANL managers and non-managers on the communication-accuracy scale $\ldots \ldots \ldots \ldots \ldots \ldots \ldots$

4.78 Significant differences between LANL supervisory levels on the

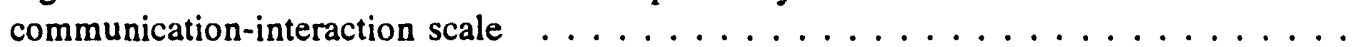

4.79 Significant differences between LANL managers and non-managers on the communication-interaction scale $\ldots \ldots \ldots \ldots \ldots$

4.80 Significant differences between LANL supervisory levels on the

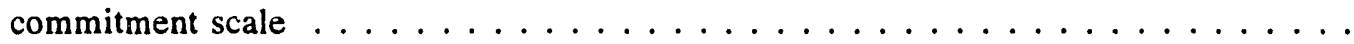

4.81 Significant differences between LANL managers and non-managers on the commitment scale . . . . . . . . . . . . . . . . . . .

4.82 Significant differences between LANL supervisory levels on the cohesion scale . .

4.83 Significant differences between LANL managers and non-managers on the

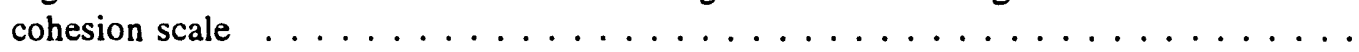

4.84 Significant differences between LANL managers and non-managers on the

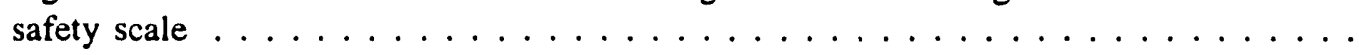

4.85 Significant differences between LANL managers and non-managers on the employee awareness question $\ldots \ldots \ldots \ldots \ldots \ldots \ldots$

4.86 Significant differences between Johnson Controls departments on the

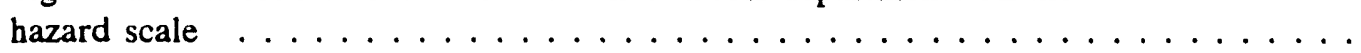

4.87 Significant differences between Johnson Controls departments on the onsite environmental consequences question . . . . . . . . . . . .

4.88 Significant differences between Johnson Controls staff classifications on the conventional scale $\ldots \ldots \ldots \ldots \ldots \ldots \ldots$ 


\section{LIST OF FIGURES (Cont'd.)}

Page

4.89 Significant differences between Johnson Controls staff classifications on the hazard scale $\ldots \ldots \ldots \ldots \ldots \ldots \ldots \ldots \ldots \ldots \ldots \ldots$. . . . . . . . . . . .

4.90 Significant differences between managers and non-managers at Johnson Controls on the Job Satisfaction Scale . . . . . . . . . . . . . . . 4-56

4.91 Significant differences between Mason \& Hanger departments on the humanistic-encouraging scale . . . . . . . . . . . . . . . . 4-57

4.92 Significant differences between Mason \& Hanger departments on the communication-trust scale $\ldots \ldots \ldots \ldots \ldots \ldots \ldots \ldots \ldots$ 4-57

4.93 Significant differences between Mason \& Hanger departments on the communication-accuracy scale $\ldots \ldots \ldots \ldots \ldots \ldots \ldots \ldots \ldots \ldots$ 4.58

4.94 Significant differences hetween Mason \& Hanger departments on the job satisfaction scale $\ldots \ldots \ldots \ldots \ldots \ldots \ldots \ldots \ldots \ldots \ldots \ldots \ldots$ 4-58 


\section{LIST OF TABLES}

Page

3.1 Response Rate by Organization and Percent of the Total Employee Population that Rate Represents for the Los Alamos Site . . . . . . . . . . . . . . . 3-1

3.2 Staff Classifications of Los Alamos National Laboratory Respondents . . . . . . . 3-2

3.3 Staff Classifications of Johnson Controls Respondents . . . . . . . . . . . . 3-2

3.4 Staff Classifications of Mason \& Hanger Respondents . . . . . . . . . . . . . 3-3

3.5 Supervisory Levels at the Los Alamos Site . . . . . . . . . . . . . . 3-3

3.6 Supervisory Levels at the Los Alamos National Laboratory . . . . . . . . . . . . . 3-3

3.7 Supervisory Levels at the Johnson Controls Los Alamos Site . . . . . . . . . . . . 3-4

3.8 Supervisory Levels at Mason \& Hanger Los Alamos Site . . . . . . . . . . . . . 3-4

3.9 Distribution of Number of Years at the Los Alamos Site . . . . . . . . . . . . 3-5

3.10 Distribution of Educational Levels at the Los Alamos Site . . . . . . . . . . 3-5

3.11 Modal Educational Level and Mean Number of Years at the Los Alamos Site

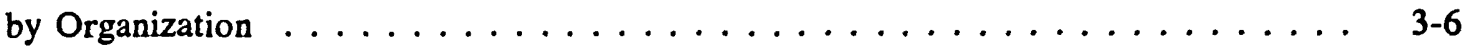




\section{ACRONYMS}

\section{Organizations}

LANL Los Alamos National Laboratory

JC

Johnson Controls

MH

Mason and Hanger

\section{LANL Directorates}

ADO

CM

CON

DRA

ET

NWT

RES

CNS

HR

DIR

CSL

OPR

ADM

FLD

STF

GEN

OST

STF

TSF

TST

CFT

EAD

ESM

ETL

NCL

NTD

Operations Directorate

Chemistry and Materials Directorate

Controller

Defense Research and Applications Directorate

Energy and Technology Directorate

Nuclear Weapons Technology Directorate

Research Directorate

At Large Directorate

Human Resources Directorate

Director's Office

\} SUP Support

Laboratory Counsel

Johnson Controls Departments

Operations

Administration

Mason \& Hanger Departments

Field

Staff

\section{LANL Staff Classifications}

General

Office Support

Specialist Staff

Technical Staff

Technical Support

\section{Johnson Controls Staff Classifications}

Craft Employee

Exempt Administrative

Exempt Supervisor/Management

Exempt Technical

Non-Exempt Clerical

Non-Exempt Technician/Drafter 
ACRONYMS (Cont'd.)

\section{Mason \& Hanger Staff Classifications}

$\begin{array}{ll}\text { ADM } & \text { Administrative Specialist } \\ \text { DHD } & \text { Department Head } \\ \text { SEC } & \text { Secretary } \\ \text { SPT } & \text { Support }\end{array}$

Managerial Level

$\begin{array}{ll}\text { MNG } & \text { Manager } \\ \text { NMN } & \text { Non-Manager }\end{array}$

LAANL Supervisory Levels

D\&A

G\&A

NMN

SL

Division and Above

Group and Above

Non-Manager

Section Leader

Johnson Controls Supervisory Levels

CFM

DMN

NMN

OAM

SPT

SUP

Mason \& Hanger Supervisory Levels

$\begin{array}{ll}\text { MNG } & \text { Manager } \\ \text { NMN } & \text { Non-Manager }\end{array}$


ACRONYMS (Cont'd.)

\section{Survey Scales}

$\begin{array}{ll}\text { C1 } & \text { Humanistic-Encouraging } \\ \text { C2 } & \text { Affiliative } \\ \text { C3 } & \text { Approval } \\ \text { C4 } & \text { Conventional } \\ \text { C5 } & \text { Dependent } \\ \text { C6 } & \text { Avoidance } \\ \text { C7 } & \text { Oppositional } \\ \text { C8 } & \text { Power } \\ \text { C9 } & \text { Competition } \\ \text { C10 } & \text { Perfectionistic } \\ \text { C11 } & \text { Achievement } \\ \text { C12 } & \text { Self-Actualizing }\end{array}$

ACCURACY (CMA)

AWARENESS (EMA)

COHESION (COH)

COMMITMT (COT)

COORD (COD)

EMPHASIS (MGE)

HAZARD (HAZ)

INTERACT (CMI)

JOBSAT (JOB)

OFFSITE (OFF)

ONSITE (ONS)

SAFETY (SAF)

SATISFAC (CMS)

TRUST (CMT)
Perceived Accuracy of Communications

Employee Awareness of Workplace Hazards

Cohesion of Work Group

Organizational Commitment

Coordination

Management Emphasis of Environmental Issues

Perceived Hazardous Nature of Work

Desirability of Interaction with Others

Overall Job Satisfaction

Consequence to Offsite Environment

Consequence to Onsite Environment

Attention to Safety

Satisfaction with Communications

Trust in Communications 


\section{ACKNOWLEDGEMENT}

The authors wish to thank the Department of Energy (DOE) staff that have been supportive and facilitative of this work, Mark Gilbertson and Larry Weiner, as well as the Los Alamos Site for their cooperation in this effort, in particular, Carol Estes and Lucy Hanson for their help in arranging the logistics and details of the survey administration.

We also extend our appreciation to the efforts of our Brookhaven National Laboratory colleagues: John Usher, for his help in administering the survey, David Stock, for his statistical assistance and expertise, Sonja Santos, for her proficiency in graph production, and Kathleen Nasta for her help in preparing this manuscript. In addition, the review, comments, and insights provided by Robert Hall were also very . sch appreciated. 


\section{INTRODUCTION}

An Organizational Survey (OS) was performed at the Los Alamos Site which queried employees on the subjects of organizational culture, various aspects of communication, employee commitment to their organization, work group cohesion, coordination of work, environmental concerns, hazardous nature of work, safety, and overall job satisfaction. A description of each of the scales used to assess these subjects is discussed below.

The primary purpose of administering the survey was to attempt to measure, in a more quantitative and objective way the notion of "organizational culture," that is, the values, attitudes, and beliefs of the individuals working within the organization. In particular, those aspects of the working environment which are believed to be important influences on the operations of a facility and on the safety issues relevant to the organization were assessed.

In addition, by conducting a survey, a broad sampling of the individuals in the organization can be obtained. This is especially important when the survey is utilized in conjunction with an assessment or inspection team which typically has only a limited amount of resources to address many issues. The OS provides a broad, but more comprehensive picture of the organization by querying a much larger number of individuals than could be reached through the assessment team alone.

Finally, the OS provides a descriptive profile of the organization at one point in time. This profile can then be used as a baseline point against which comparisons of other points in time can be made. Such comparisons may prove valuable and would help to assess changes in the organizational culture. Comparisons of the profiles can also be made across similar facilities.

While the survey does allow comparisons between various groups to be made, it is not the purpose of this report to make evaluative statements concerning the desirability of the profile of one group versus the profile of another. However, using the data provided in this report in the context of the organization and its functioning may provide useful insights. 


\section{METHODOLOGY}

The Organizational Survey (OS) was administered in large groups to the employees of the Los Alamos Site, which is comprised of the Los Alamos National Laboratory (LANL), Johnson Controls World Services, Inc., and Mason \& Hanger - Silas Mason Co., Inc., Organizations. A total of 2,123 employees from these three organizations, representing approximately twenty percent of each of the organizations' employee populations, were randomly selected to complete the survey. The surveys were administered on September 12 and $13,1991$.

Included with the survey was a cover letter explaining the purpose for the survey administration. Prior to the survey administration, a memorandum from the Director's Office was circulated to all employees selected to participate in the survey administration. This memorandum encouraged employees to complete the survey and contained the times at which various groups of employees, scheduled by the first letter of the last name, were to take the survey. A background sheet attached to the survey requested information pertaining to the organization and directorate/department in which the respondent was located, the number of years they had been working at the Los Alamos Site, their staff classification, and supervisory and educational levels.

Two subject matter experts familiar with the survey were at the Los Alamos Site during the survey administration to distribute the surveys and to answer any questions which employees may have had while taking the questionnaire. A total of 1036 surveys were completed, for a response rate of 48.8 percent. The surveys were taken from the Los Alamos Site for data entry and analysis.

Overall means, standard errors, and standard deviations were computed for each scale assessed in the OS. A one-way analysis of variance was also performed on each OS scale using the scale score as the dependent variable and separate analyses using directorate/department, staff classification, and supervisory level as the independent variables. In order to control the false positive rate (Type I error rate), the Bonferroni correction was applied to all the analyses of variance performed for each independent variable. Since there were 26 one-way analyses of variance for each independent variable, the significance level for each analysis of variance was reduced to $.05 / 26=.0019$. Where the analysis of variance showed a significant difference among the group means at the .0019 level, a Tukey HSD (Honestly Significant Difference) (Hays, 1988) procedure was applied to identify those means that were statistically significantly different from each other. Consequently, the results that are reported to be significantly different from each other represent a very conservative approach in the interpretation of the data analyses performed.

Included in this report are the overall results for the Los Alamos Site on each of the scales used in the OCS. In addition, any statistically significant differences between organizations, directorates/departments within organizations, staff classifications within organizations and supervisory levels overall and within organizations are presented. 


\section{ORGANIZATIONAL DESCRIPTION}

The Los Alamos Site is comprised of three primary organizations: the Los Alanos National Laboratory (LANL), Johnson Controls World Services, Inc., and Mason \& Hanger - Silas Mason Co., Inc. Within each of these organizations, the largest organizational units are identifird as either directorates or departments. The demographics sheet used in the administration of the Orgenizational Survey (OS) included eleven directorates for LANL, two departments for Johnson Controls, and two departments for Mason and Hanger. Due to the smaller number of employees in four of the LANL Directorates, the At Large Directorate, the Human Resources Directorate, the Director's Office, and the Laboratory Counsel, they were combined for the purposes of analysis into one group called Support.

The response rates for the three organizations are presented in Table 3.1. The response rate is computed by dividing the number of surveys returned by the number of employees in that organization who were randomly selected to complete the survey. Both the LANL and Johnson Controls Organizations had comparable response rates (45.4 percent and 50.9 percent, respectively). The Mason \& Hanger Organization had a somewhat lower response rate, 36.2 percent. Also included in this table are the total number of individuals employed by each of the three organizations. This allows one to compute the percent of the total employee population who completed the survey in each organization. This is an important percentage due to the low response rates obtained, as a minimum of ten percent of each organization was needed to ensure statistical accuracy. This criterion was met for each of the three organizations.

Table 3.1. Response Rate by Organization and Percent of the Total Employee Population that Rate Represents for the Los Alamos Site

\begin{tabular}{|c|c|c|c|c|c|}
\hline Organization & $\begin{array}{l}\text { Number } \\
\text { Responses }\end{array}$ & $\begin{array}{l}\text { Number } \\
\text { Employees } \\
\text { Selected }\end{array}$ & $\begin{array}{l}\text { Response } \\
\text { Rate }\end{array}$ & $\begin{array}{c}\text { Total } \\
\text { Number } \\
\text { Employees }\end{array}$ & $\begin{array}{c}\% \text { Total } \\
\text { Employee } \\
\text { Population }\end{array}$ \\
\hline $\begin{array}{l}\text { Los Alamos National } \\
\text { Laboratory }\end{array}$ & 769 & 1693 & 45.40 & 7100 & 10.8 \\
\hline Mason and Hanger & 51 & 141 & 36.20 & 427 & 11.9 \\
\hline Johnson Controls & 147 & 289 & 50.90 & 1457 & 10.1 \\
\hline Unknown & 70 & -- & -- & $\cdots$ & -- \\
\hline TOTAL: & 1036 & 2123 & 48.80 & 8984 & 11.5 \\
\hline
\end{tabular}

LANL employees were also given five staff classifications on the demographic sheet in which to categorize themselves. Table 3.2 contains the LANL staff classifications as well as the acronyms for each as used in this report. Also presented in this table are the percent of the total LANL sample each staff classification represents. The Technical Staff Classification comprises the largest percent of the total LANL. sample, 46.7 percent. The General Staff Classification constitutes the smallest percentage of the total sample of LANL employees (3.3 percent).

Johnson Controls employees were given six staff classifications in which to classify themselves. Table 3.3 presents each of these classifications and the abbreviations for each of them as used in this report. The Craft Employee Staff Classification comprises the largest percentage of the total Johnson Controls sample (53.7 percent). The smallest percentage ( 3.4 percent) of the total sample of employees were classified in the Non-Exempt - Clerical Staff Classification. 
Table 3.2. Staff Classifications of Los Alamos National Laboratory Respondents

\begin{tabular}{|c|c|c|}
\hline Staff Classification & Number Responses & \% LANL Respondents \\
\hline Technical Staff (TSF) & 359 & 46.7 \\
\hline Specialist Staff (STF) & 86 & 11.2 \\
\hline Technicä! Support (TST) & 158 & 20.5 \\
\hline Office Support (OST) & 113 & 14.7 \\
\hline General (GEN) & 28 & 3.6 \\
\hline Unknown & 25 & 3.3 \\
\hline TOTAL: & 769 & 100.0 \\
\hline
\end{tabular}

Table 3.3. Staff Classifications of Johnson Controls Respondents

\begin{tabular}{||l|c|c||}
\hline \multicolumn{1}{|c|}{ Staff Classification } & Number Responses & $\begin{array}{c}\text { \% Johnson Controls } \\
\text { Respondents }\end{array}$ \\
\hline \hline $\begin{array}{l}\text { Exempt Supervisors/ } \\
\text { Management (ESM) }\end{array}$ & 20 & 13.6 \\
\hline Exempt Technical (ETL) & 17 & 11.6 \\
\hline Exempt Administrative (EAD) & 12 & 8.2 \\
\hline Non-Exempt Clerical (NCL) & 5 & 3.4 \\
\hline $\begin{array}{l}\text { Non-Exempt Technician/ } \\
\text { Drafter (NTD) }\end{array}$ & 7 & 4.8 \\
\hline Craft Employee (CFT) & 79 & 53.7 \\
\hline Unknown & 7 & 4.8 \\
\hline \multicolumn{1}{|c|}{ TOTAL: } & 147 & 100.0 \\
\hline
\end{tabular}

For the Mason \& Hanger Organization, four staff classifications were provided on the background information sh set (Table 3.4). Of the four, the largest number of Mason \& Hanger employees classified themselves into the Support Staff Classification (51.0 percent). The smallest percentage of employees classified themselves into the Department Head and the Secretary Staff Classification ( 7.8 percent for both).

The OS demographics questions used at the Los Alamos Site also provided categories of supervisory levels, specific to each organization, by which an employee could identify him/herself. In order to compute the percent of the total sample which both managers and non-managers comprised, these categories were collapsed into the two large groups of managers and non-managers. As depicted in Table 3.5, Non-Managers comprise approximately 69 percent of the sample at the Los Alamos Site while Managers constitute just over 22 percent of the sample. 
Table 3.4. Staff Classifications of Mason \& Hanger Respondents

\begin{tabular}{||l|c|r||}
\hline \multicolumn{1}{|c|}{ Staff Classification } & Number Responses & $\begin{array}{c}\text { \% Mason \& Hanger } \\
\text { Respondents }\end{array}$ \\
\hline \hline Administrative Specialist (ADM) & 10 & 19.6 \\
\hline Department Head (DHD) & 4 & 7.8 \\
\hline Secretary (SEC) & 4 & 7.8 \\
\hline Support (SPT) & 26 & 51.0 \\
\hline Unknown & 7 & 13.7 \\
\hline & 51 & 100.0 \\
\hline
\end{tabular}

Table 3.5. Supervisory Levels at the Los Alamos Site

\begin{tabular}{|c|c|c|}
\hline Supervisory Level & Number Responses & \% Respondents \\
\hline Managers (MNG) & 229 & 22.1 \\
\hline Non-Manager (NMN) & 710 & 68.5 \\
\hline Unknown & 97 & 9.4 \\
\hline TOTAL: & 1036 & 100.0 \\
\hline
\end{tabular}

Four supervisory levels were pro rided for LANL employees to classify themselves into (Table 3.6). The highest percentage of respondents were classified into the Non-Manager category ( 75 percent). The Division and Above Supervisory Level had the lowest percentage of respondents (4.0 percent).

Table 3.6. Supervisory Levels at the Los Alamos National Laboratory

\begin{tabular}{|c|c|c|}
\hline Supervisory Level & Number Responses & \% Total LANL Sample \\
\hline Division \& Above (D\&A) & 31 & 4.0 \\
\hline Group \& Above (G\&A) & 54 & 7.0 \\
\hline Section Leader (SL) & 91 & 11.8 \\
\hline Non-Manager (NMN) & 577 & 75.0 \\
\hline Unknown & 16 & 2.1 \\
\hline TOTAL: & 769 & 100.0 \\
\hline
\end{tabular}

Table 3.7 presents the six supervisory levels provided for Johnson Controls employees to classify themselves into. The highest percentage of respondents indicated that they were Non-Managers $(63.3$ percent). The smallest percentage of respondents placed themselves into the Superintendent Supervisory Level (1.4 percent). 
Table 3.7. Supervisory Levels at the Johnson Controls Los Alamos Site

\begin{tabular}{||l|c|c||}
\hline \multicolumn{1}{|c|}{ Supervisory Level } & Number Responses & \%ohnson Controls Sample \\
\hline \hline $\begin{array}{l}\text { Operations/Administrative } \\
\text { Management \& Above (OAM) }\end{array}$ & 8 & 5.4 \\
\hline Department Manager (DMN) & 4 & 2.7 \\
\hline Superintendent (SPT) & 2 & 1.4 \\
\hline Supervisor (SUP) & 12 & 8.2 \\
\hline Craft Foreman (CFT) & 20 & 13.6 \\
\hline Non-Manager (NMN) & 93 & 63.3 \\
\hline Unknown & 8 & 5.4 \\
\hline & 147 & 100.0 \\
\hline
\end{tabular}

Table 3.8 depicts the two supervisory levels available on the background information sheet for Mason \& Hanger employees. The largest percentage of Mason \& Hanger respondents were Non-Managers (78.4 percent). Respondents from Mason \& Hanger who were best represented by the Manager classification comprised approximately 14 percent of the sample.

Table 3.8. Supervisory Levels at Mason and Hanger Los Alamos Site

\begin{tabular}{||r|r|r||}
\hline \multicolumn{1}{|c|}{ Supervisory Level } & Number Responses & \% Total \\
Mason and Hanger Sample \\
\hline \hline Manager & 7 & 13.7 \\
\hline Non-Manager & 40 & 78.4 \\
\hline Unknown & 4 & 7.8 \\
\hline TOTAL: & 51 & 100.0 \\
\hline
\end{tabular}

Table 3.9 presents the distribution of the number of years employed at the Los Alamos Site across the entire sample. The largest percentage of individuals had been employed between six and ten years (27 percent). Approximately 10 percent of the sample had been employed at the Los Alamos Site for over 20 years.

The distribution of educational levels across the sample for the Los Alamos Site is presented in Table 3.10. Just over 32 percent of the respondents at the Los Alamos Site have a graduate degree. The educational level which comprised the second largest portion of the sample was some college (16.4 percent).

The modal educational level and mean number of years overall for the respondents at the Los Alamos Site, as well as within each organization are presented in Table 3.11. The modal educational level both overall and within the LANL sample was a Graduate Degree. The Johnson Controls Organization had a modal educational level of Some College. The modal educational level for Mason \& Hanger was a High School 
Degree. Overall, the mean number of years at the Los Alamos Site was just under 12. The employee sample from LANL had the longest tenure at the Los Alamos Site, 12.67 years. Both the John Controls and Mason \& Hanger employee samples had comparable mean number of years at the Los Alamos site, 8.76 and 8.39 years respectively.

Table 3.9. Distribution of Number of Years at the Los Alamos Site

\begin{tabular}{||l|r|r|}
\hline \multicolumn{1}{|c|}{ Years at LANL } & Number Responses & \% Total Sample \\
\hline \hline$<6$ months & 2 & 2.0 \\
\hline $1-5$ years & 221 & 21.0 \\
\hline $6-10$ years & 280 & 27.0 \\
\hline $11-15$ years & 216 & 21.0 \\
\hline $16-20$ years & 139 & 13.0 \\
\hline $21-25$ years & 62 & 6.0 \\
\hline $26-30$ years & 29 & 3.0 \\
\hline$>30$ years & 24 & 2.0 \\
\hline Unknown & 45 & 4.0 \\
\hline
\end{tabular}

Table 3.10. Distribution of Educational Levels at the Los Alamos Site

\begin{tabular}{||l|r|r||}
\hline \multicolumn{1}{|c|}{ Educational Level } & Number Responses & \% Total Sample \\
\hline \hline Some High School & 15 & 1.4 \\
\hline High School Degree & 92 & 8.9 \\
\hline Some Technical School & 76 & 7.3 \\
\hline Technical Degree (2-Year) & 51 & 4.9 \\
\hline Some College & 170 & 16.4 \\
\hline 2-Year College Degree & 65 & 6.3 \\
\hline 4-Year College Degree & 103 & 9.9 \\
\hline Some Graduate Work & 80 & 7.7 \\
\hline Graduate Degree & 333 & 32.1 \\
\hline Unknown & 51 & 4.9 \\
\hline
\end{tabular}


Table 3.11. Modal Educational Level and Mean Number of Years at the Los Alamos Site by Organization

\begin{tabular}{||l|r|c|}
\hline \multicolumn{1}{|c|}{ Organization } & Mean Number Years & Modal Educational Level \\
\hline \hline Overall & 11.77 & 9 \\
\hline LANL & 12.67 & 9 \\
\hline JC & 8.76 & 5 \\
\hline M\&H & 8.39 & 2 \\
\hline Unknown & 9.50 & 3 \\
\hline
\end{tabular}

Education Level:

2 = High School Degree; 3 = Some Technical School; $4=2$-Year Technical Degree; $5=$ Some College; 6 = 2-Year College Degree; $7=4$-Year College Degree; $8=$ Some Graduate Work; $9=$ Graduate Degree. 


\section{ORGANIZATIONAL SURVEY SCALES AND RESULTS}

The Organizational Survey (OS) administered at the Los Alamos Site was comprised of the Organizational Culture Inventory (OCI) (Human Synergistics, 1987), consisting of 12 scales describing different organizational cultural styles, and scales assessing communication processes, commitment to the organization, cohesiveness of work group, coordination of work, overall job satisfaction, perceived hazardous nature of work, attention to safety, and questions concerning environment, safety, and health issues. Each of these scales are discussed in more detail below.

The results from each of these scales are discussed in the sections that follow. First, the overall means on each scale for the entire Los Alamos Site are presented. Then, each organization is compared to every other organization on each scale, and statistically significant differences are presented. Comparisons of generic supervisory level categories follow (e.g., LANL Managers versus Johnson Coutrols Managers). In addition, Managers across all organizations are compared to Non-Managers. Finally, within organization analyses are presented. In thes analyses, groups existing within a given organization are compared to each other (e.g., LANL Directorates).

\subsection{Organizational Survey Scale Descriptions}

\subsubsection{Organizational Culture Inventory}

The philosophy of management, the mission of the organization, and the strategic choices management makes determine the culture of the organizatior (Cooke and Burack, 1987). The aspect of culture most immediately affected by these factors is what is valued by the organization. The extent to which these values are recognized and shared reflects the strength of the organization's culture. Organizational facturs, along with these shared values, influence the operating structures of the organization, it's human resource management practices, and the styles of its managers and supervisors. To the extent that these shared values and behavioral norms can be measured and evaluated, data collection of this type is important in understanding the organizational factors that influence performance.

The Organizational Culture Inventory (OCI) (Human Synergistics, 1987) is a paper-and-pencil diagnostic system for measuring the aspects of organizational culture that have the greatest impact on the activities of members and the functioning of the organization. Respondents are asked to review 120 statements which describe some of the thinking and behavioral styles that members of an organization may be expected to adopt in carrying out their work and in interacting with others. These statements measure 12 different cultural styles, some of which are indicative of a positive and supportive environment, while others are useful in identifying potentiaily dysfunctional environments. All of the styles measured by the OCI are related to, and result from, organizational structural variables, reward systems, managerial styles and philosophies, and other factors that can be changed, at least to some extent, by those in leadership positions.

The 12 organizational culture styles, with examples of the items used to assess each one, are described below.

C1: HUMANISTIC-ENCOURAGING: Organizations which are managed in a participative and personcentered way. Members are expected to be supportive, constructive, and open to influence in their dealings with one another.

- Involving subcrdinates in decisions;

- Showing concern for the needs of others. 
C2: AFFILIATIVE: Organizations which place high priority on constructive personal relations. The members are expected to be friendly, open, and sensitive to the satisfaction of their work group.

- Thinking in terms of the group satisfaction;

- Using good human relations skills.

C3: APPROVAL: Organizations in which conflicts are avoided and personal relations are pleasant, at least superficially. Members feel they should agree with and gain approval of others.

- Staying on the good side of superiors;

- Making sure people accept you.

C4: CONVENTIONAL: Organizations that are conservative, traditional, and bureaucratically controlled. Members are expected to conform, follow rules, and make a good impression.

- Always following policies and practices;

- Avoiding confrontations.

C5: DEPENDENT: Organizations that are hierarchically controlled and non-participative. Centralized decision-making leads members to do only what they are told and to clear all decisions with superiors.

- Accepting goals without questioning them;

- Never challenging superiors.

C6: AVOIDANCE: Organizations that do not reward success but punish failures. Negative rewards leads members to shift responsibility to others and avoid being blamed for mistakes.

- Taking few chances;

- Laying "low" when things get tough.

C7: OPPOSITIONAL: Organizations in which confrontation prevails and negativism is rewarded. Members gain status and influence by being critical and are encouraged to oppose the ideas of others.

- Pointing out flaws;

- Remaining aloof from the situation.

C8: POWER: Non-participative naganizations which are structured on the basis of authority in members' positions. Members expect to take charge, control subordinates, and respond to demands of superiors.

- Demanding loyalty;

- Acting forceful.

C9: COMPETITION: Organizations where winning is valued and rewards are given for out-performing others. Members operate in a "win-lose" framework and work against their peers to be noticed.

- Always trying to be right;

- Out-performing one's peers. 
C10: PERFECTIONISTIC: Organizations in which persistence, hard work, and perfectionism are highly valued. Members feel they must avoid all mistakes, keep track of everything, and work long hours to attain specific objectives.

- Setting unrealistically high goals;

- Viewing work as more important than anything else.

C11: ACHIEVEMENT: Organizations that do things well and value members who set and accomplish their own goals. Members set challenging, but realistic goals, and plan and pursue them with enthusiasm.

- Exploring alternatives before acting;

- Pursuing a standard of excellence.

C12: SELF-ACTUALIZING: Organizations that value creativity, quality over quantity, tasks, and individual growth. Members are encouraged to gain satisfaction from their work, develop themselves, and take on new activities.

- Thinking in unique and independent ways;

- Communicating ideas.

From these twelve scales, three cultural styles are described. The first style is comprised of the Humanistic-Encouraging Scale (C1), the Affiliative Scale (C2), the Achievement Scale (C11), and the SelfActualizing Scale ( $\mathrm{C} 12)$. These scales are considered "Constructive;" in other words, organizations which score high on these four scales tend to promote behaviors which are conducive to the satisfaction of the organizational members.

The second cultural style is the "Passive/Defensive Style." This style is made up of the Approval Scale (C3), the Conventional Scale (C4), the Dependent Scale (C5), and the Avoidance Scale (C6). In organizations which score high on these scales, a culture exists which leads employees of the organization to act and react in a defensive way and at the same time, act in a way which does not pose a threat to one's own security within that organization.

A third cultural style is made up of the Oppositional Scale (C7), the Power Scale (C8), the Competitive Scale (C9), and the Perfectionistic Scale (C10). Organizations which score high on these scales often expect members to act in a way that is both forceful and which protects one's position and status. In other words, members adopt an "Aggressive/Defensive Style" in order to be successful within the organization.

\subsubsection{Communication Scales}

Communication is a critical process for effective operations in any organization. However, because it is a process rather than a variable, it is very difficult to measure. The scales used in the questionnaire administered at the Los Alamos Site were developed by Roberts and O'Reilly (1974). They have been administered to various organizations with good reliability and success in analyzing several facets of the communication process.

Four communication scales were administered and are described below. The range on each scale is from a low score of 1 to a high score of 7 . 
TRUST:

Freedom to discuss the problems and difficulties in the job with an immediate supervisor without jeopardy.

ACCURACY: $\quad$ Perception of the accuracy of information received from other organizational levels (superior, same, and subordinate levels).

INTERACT: $\quad$ Desirability of frequent contact with others in the organization (superiors, same, and subordinate).

SATISFAC: $\quad$ Overall satisfaction with the communication process in the organization.

\subsubsection{Commitment Scale}

The Commitment Scale is defined as the relative strength of an individual's identification with and involvement in a particular organization (Mowday \& Steers, 1979). This commitment extends to the goals of the organization and the desire to maintain membership in the organization to facilitate these goals. The range on this scale is from a low score of 1 (low commitment) to a high score of 7 (high commitment).

\subsubsection{Cohesion Scale}

The Cohesion Scale is very similar to the Commitment Scale except that it is defined as the relative strength of an individual's identification with and involvement in a particular work group (Seashore, 1954; Price \& Muller, 1972). The range on this scale is from a low score of 1 (weak cohesiveness) to a high score of 7 (strong cohesiveness).

\subsubsection{Coordination Scale}

The Coordination Scale assesses the employee's perception of the degree to which the subunits of an organization operate according to the requirements of each other and of the total organization (Georgopoulos \& Mann, 1962). The range on this scale is from a low score of 1 (low coordination) to a high score of 7 (high coordination).

\subsubsection{Job Satisfaction}

The Job Satisfaction Scale (Kunin, 1955) refers to employees' overall satisfaction with their jobs. While it is not able to point to specific aspects of the working environment which people are satisfied or dissatisfied with, it can help to determine if employee satisfaction is something which needs further consideration by management. The scale ranges from a low score of 1 (very dissatisfied) to a high score of 7 (very satisfied).

\subsubsection{Hazard Scale}

The Hazard Scale is used to identify people's perception of the hazardous nature of their work (K.H. Roberts, 1990, personal communication). The scale ranges from a low score of 1 (not hazardous) to a high score of 7 (very hazardous). 


\subsubsection{Safety Scale}

The Safety Scale, developed by researchers at the University of California at Berkeley (K. H. Roberts, 1989, personal communication), is used to assess an individual's perception of the importance of safety to success in an organization. Safety is defined as operating in a manner to ensure that the probability of making a mistake is low, because the consequences of making a mistake are high. Organizations typically viewed as operating in this manner are nuclear reactors, naval aircraft carriers and air traffic control centers. The safety scale consists of 40 items which range from a low score of 1 (does not help at all) to a high score of 7 (helps a great deal).

\subsubsection{Environment, Safety, and Health Questions}

The administration of the Organizational Survey (OS) at the Los Alamos Site included four questions pertaining to enviro ument, safety and health issues. Each question ranges from a low score of 1 (not at all or little) to a high score of 7 (very likely or a lot).

The first environmental, safety and health question deals with the likelihood of serious offsite environmental damages/consequences due to improper or substandard performance by a work group. The second question deals with the likelihood of serious onsite environmental damages/consequences due to improper or substandard performance by a work group. The third environmental, safety, and health question asks employees to assess the amount of emphasis they believe management places on environmental issues. Finally, the fourth question asks employees for their perception of how well informed they are of potential risks in their work environment.

\subsection{Overall Results on the OS Scales for the Los Alamos Site}

\subsubsection{Organizational Culture Inventory Results}

The overall mean scores on the twelve OCI scales for the entire sample of the Los Alamos Site employees who responded to the Organizational Survey (OS) are depicted in Figure 4.1. The scales are identified by number and are described in the preceding section. The scores represent the mean score for the entire sample where the score 1 equals not at all and the score 5 equals to a great extent.

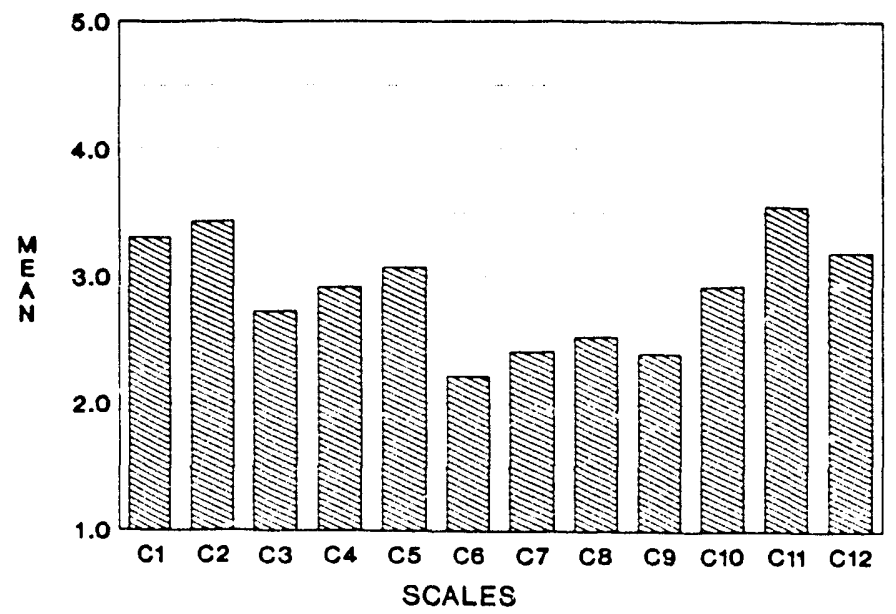

Figure 4.1. Overall means for the los alamos site on the OCI scales 
Based on the sample of the Los Alamos Site employees who responded to the OS, the organizational profile reflected on the $\mathrm{OCI}$ is best described by the Constructive Cultural Style (Humanistic - Encouraging (C1), Affiliative (C2), Achievement (C11), and Self-Actualizing (C12)). In addition, there is a tendency to deal with issues in a passive-defensive manner as exemplified by the relatively high mean scores on the Approval (C3), Conventional (C4), and Dependent (C5) Scales. This indicates that respondents believe that the behaviors which are important to success in the organization are primarily those which are constructive in nature (i.e., "Using good human relations skills," "Pursuing a standard of excellence"). However, members also expressed the sentiment that behaviors such as "Accepting goals without questioning them" are important to success at the Los Alamos Site. Additionally, the mean score obtained on the Perfectionistic (C10) Scale indicates that employees believe persistence, hard work, and perfectionism are valued by the Los Alamos Site.

\subsubsection{Communication Scales Results}

Figure 4.2 depicts the overall mean values on the four communication scales obtained for the Los Alamos Site sample. The survey respondents scored higher on the Perceived Accuracy of Communication Scale than on the Trust in Communication Scale. The sample of the Los Alamos Site employees also had a fairly high desire for interaction and communication with others in the organization, as represented by the mean score on the Desire for Interaction-Communication Scale. The Los Alamos Site employees had a moderate amount of satisfaction with the communication processes at the site.

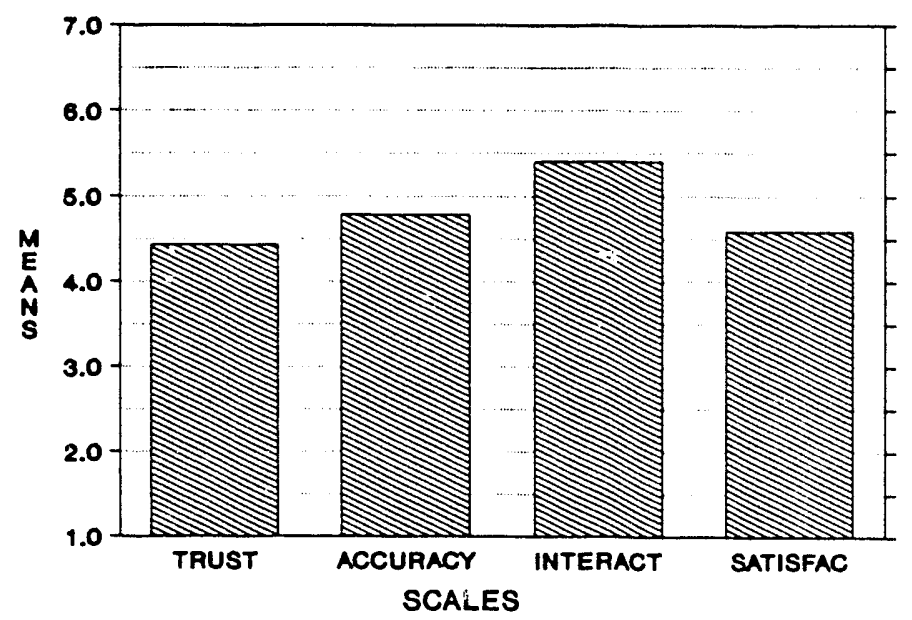

Figure 4.2. Overall mean values for the Los Alamos site on the communication scales

\subsubsection{Results for Additional Scales}

Figure 4.3 presents the results for the Commitment, Cohesion, Hazard, Coordination, Safety, and Job Satisfaction Scales for the Los Alamos Site sample. Respondents indicated a moderate amount of commitment to their organizations, and a higher amount of cohesion within their own working groups. Respondents did not, on average, perceive there to be a very high hazardous aspect to their work, however, they did indicate that those attributes which are important to safety are helpful to them in doing their job well. Perceptions of coordination among working units were low, below the scale midpoint value of 4 . Employees at the Los Alamos Site also indicated a moderaiely high amount of job satisfaction. 


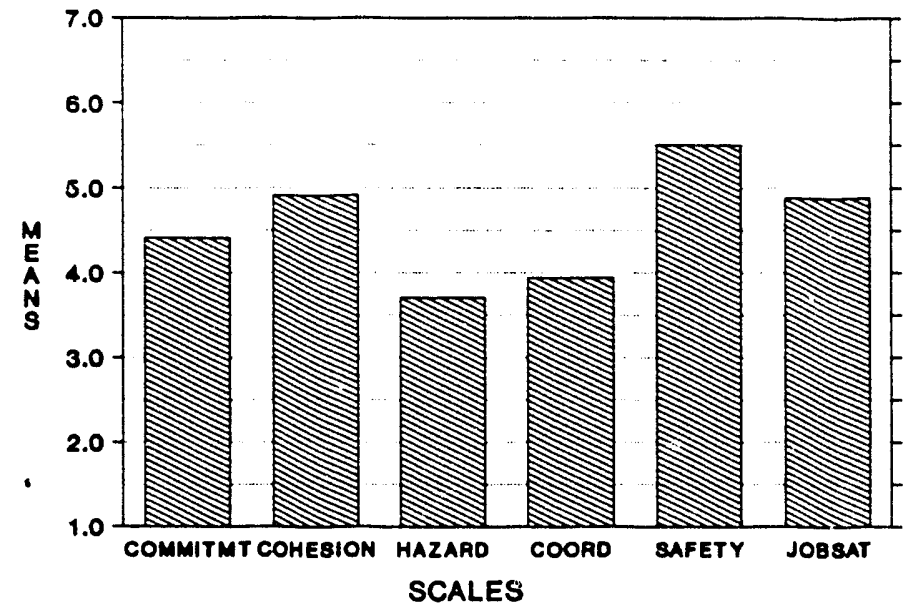

Figure 4.3. Overal! mean values for the Los Alamos site on the additional scales

\subsubsection{Environment, Safety, and Health Questions Results}

Respondents from the Los Alamos Site sample did not perceive there to be a high potential for either off or onsite environmental consequences (Figure 4.4). This is consistent with the relatively low perception of the hazardous nature of work, as indicated by the Hazard Scale (see Section 4.2.3). The perception for onsite consequences was slightly higher than that for offsite consequences. Despite this, the Los Alamos Site respondents indicated that management places a high amount of emphasis on environmental issues and that the employees who work at the Los Alamos Site are well-informed of potential risks associated with their jobs. The respondents indicated a slightly higher amount of employee awareness than management emphasis on environment, safety, and health issues relevant to the Los Alamos Site.

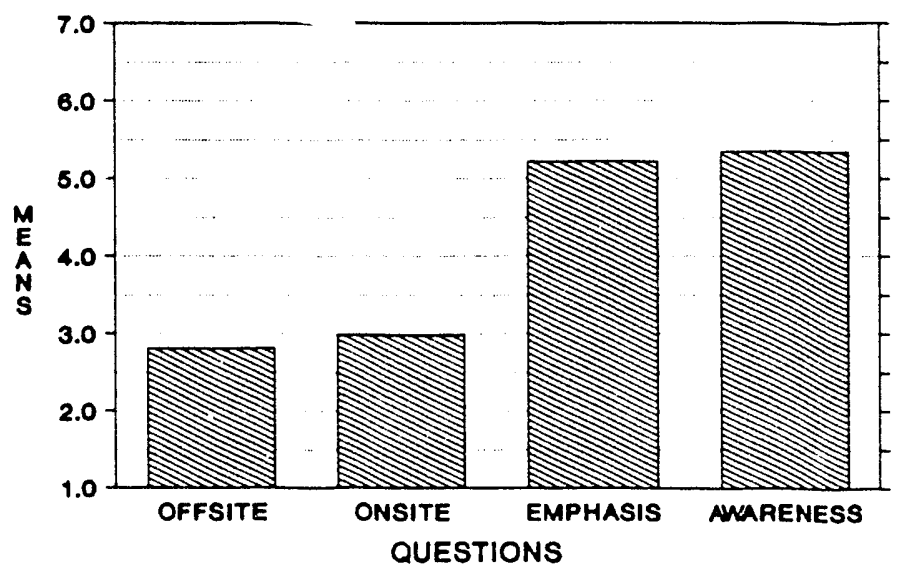

Figure 4.4. Overall mean values for the Los Alamos site on the environment, safety, and health questions

\subsubsection{Summary}

The overall profile of the Los Alamos Site obtained from the survey sample respondents is oniy somewhat useful. Its usefulness is limited by the fact that the Los Alamos Site actually consists of three different organizations, each with their own management structure and set of policies and practices. It is more 
useful, therefore, to examine the overall profiles for each of the individual organizations. The profiles for each organization represented in the Los Alamos Site sample, on each scale are contained in Appendix A. The figures in this appendix present the mean values obtained for each organization compared to the overall mean values obtained for the Los Alamos Site on each of the scales. A discussion of the statistically significant differences between each organization on the OS scales is presented below.

\subsection{Differences Between Organizations on the OS Scales}

\subsubsection{Differences Between Organizations on the OCI}

Statistically significant differences between the Los Alamos Site organizations were obtained on only one OCI scale: the Dependent Scale. As seen in Figure 4.5, the Mason \& Hanger Organization had the highest mean value on this scale and was statistically significantly different from both the Johnson Controls and the LANL Organizations. The LANL Organization had the lowest mean value on this scale.

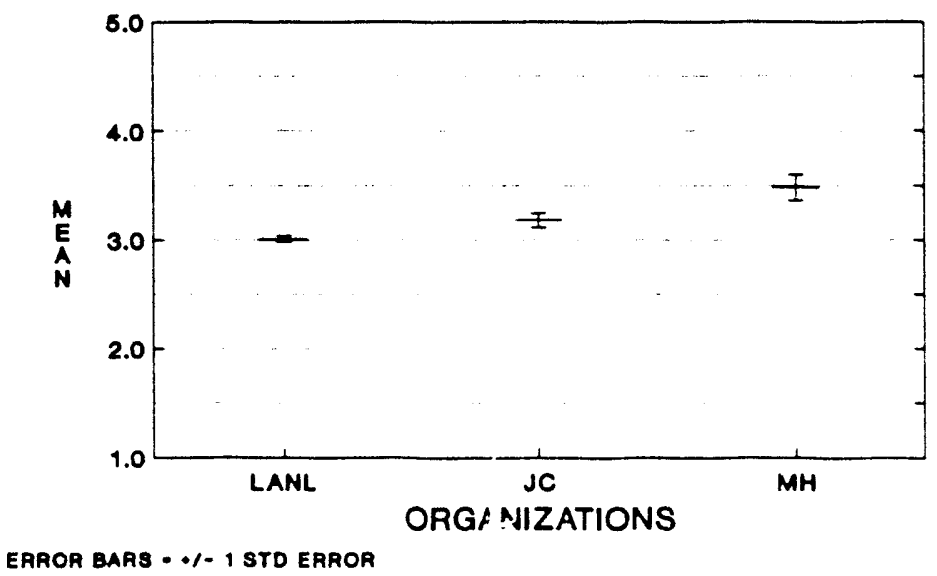

Figure 4.5. Significant differences between organizations on the dependent scale

Appendix B presents the mean values obtained for each organization on each of the scales on the OS.

\subsubsection{Differences Between Organizations on the Communication Scales}

Statistically significant differences between organizations at the Los Alamos Site occurred on three of the four Communication Scales: Communication - Trust; Communication - Accuracy; and Communication - Interaction. Figure 4.6 presents the statistically significant differences between organizations on the Communication - Trust Scale. The LANL Organization had the highest mean value on this scale and was statistically significantly different from the Mason \& Hanger Organization. No other statistically significant differences between organizations were obtained on this scale.

On the Communication - Accuracy Scale, the LANL Organization had the highest mean value and was statistically significantly different from both the Johnson Controls and Mason \& Hanger Organizations (Figure 4.7). The Mason \& Hanger Organization had the lowest mean value on this scale.

Statistically significant differences between organizations on the Communication - Interaction Scale are presented in Figure 4.8. The LANL Organization had the highest mean value on this scale and was 
statistically significantly different from the Johnson Controls Organization. No other statistically significant differences between organizations exist on this scale.

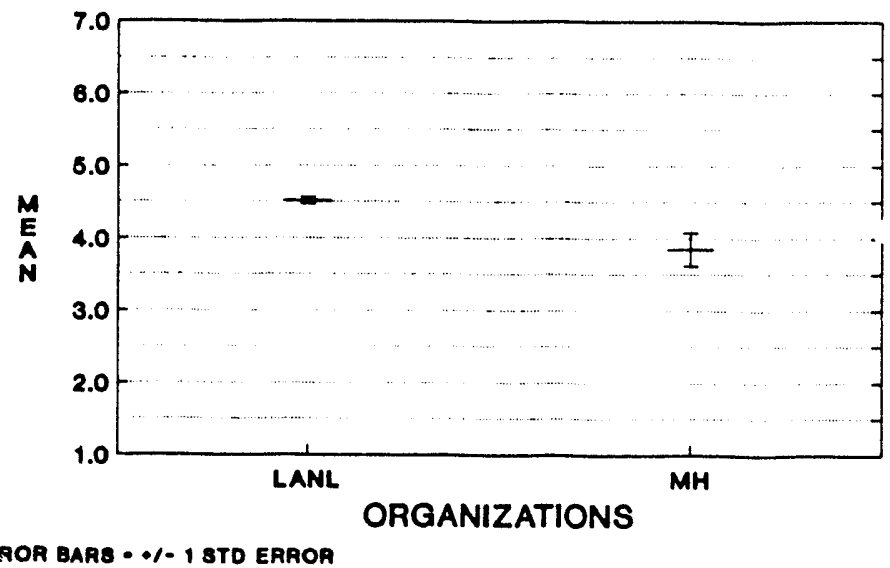

Figure 4.6. Significant differences between organizations on the communication-trust scale

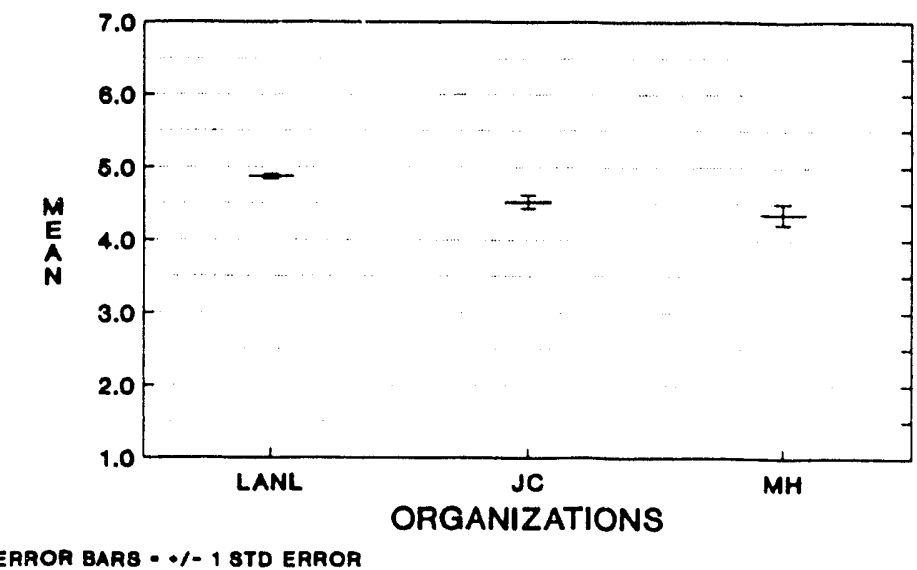

Figure 4.7. Significant differences between organizations on the communication-accuracy scale

\subsubsection{Differences Between Organizations on the Additional Scales}

Statistically significant differences between organizations on the Commitment Scale are presented in Figure 4.9. The LANL Organization had the highest mean value on this scale and was statistically significantly different from the Mason \& Hanger Organization. No other statistically significant differences between the organizations were obtained on this scale.

Figure 4.10 presents the statistically significant differences obtained between organizations on the Hazard Scale. The LANL Organization had the lowest mean value on this scale and was statistically significantly different from both the Johnson Controls, which had the highest mean value on this scale, and the Mason \& Hanger Organizations. 


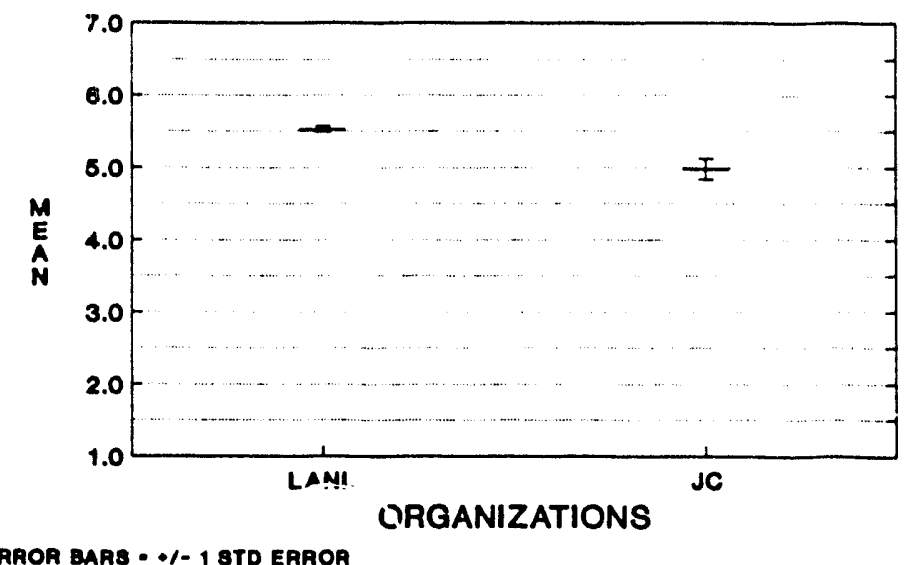

Figure 4.8. Significant differences between o:ganizations on the communication-interaction scale

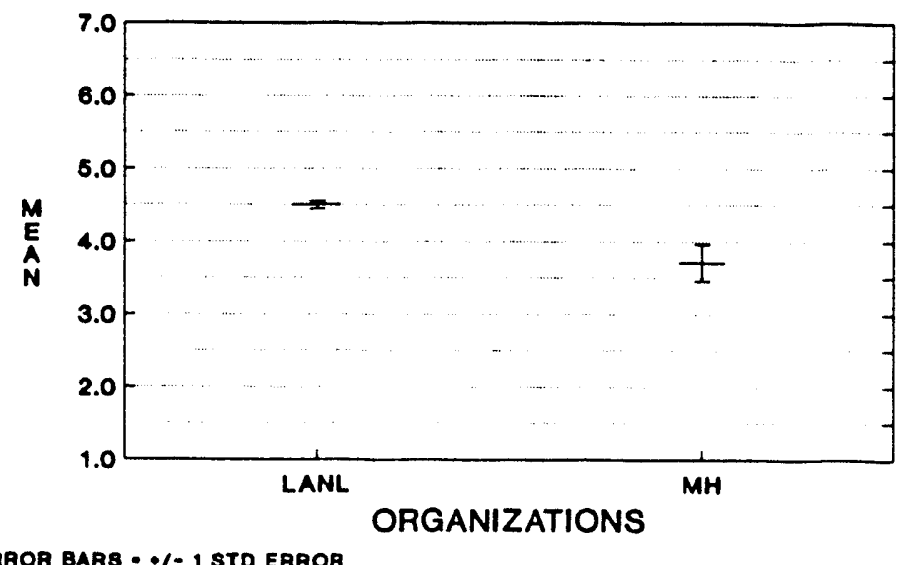

Figure 4.9. Significant differences between organizations on the commitment scale

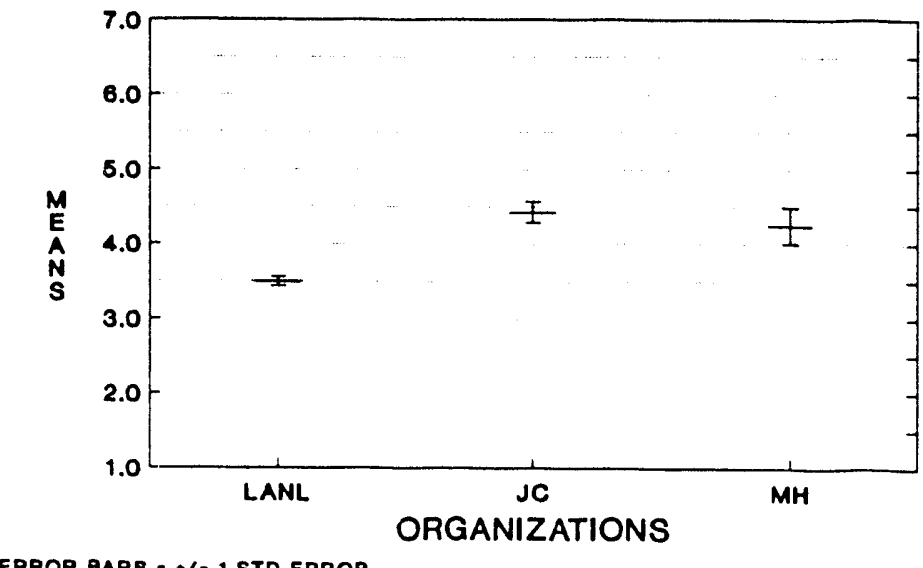

Figure 4.10. Significant differences between organizations on the hazard scale 
Differences between organizations at the Los Alamos Site on the Coordination Scale are presented in Figure 4.11. The LANL Organization had the highest mean on this scale and was statistically significantly differently from both the Johnson Controls and the Mason \& Hanger Organizations. The Mason \& Hanger Organization had the lowest mean value on this scale. No other statistically significant differences between organizations at the Los Alamos Site were obtained on this scale.

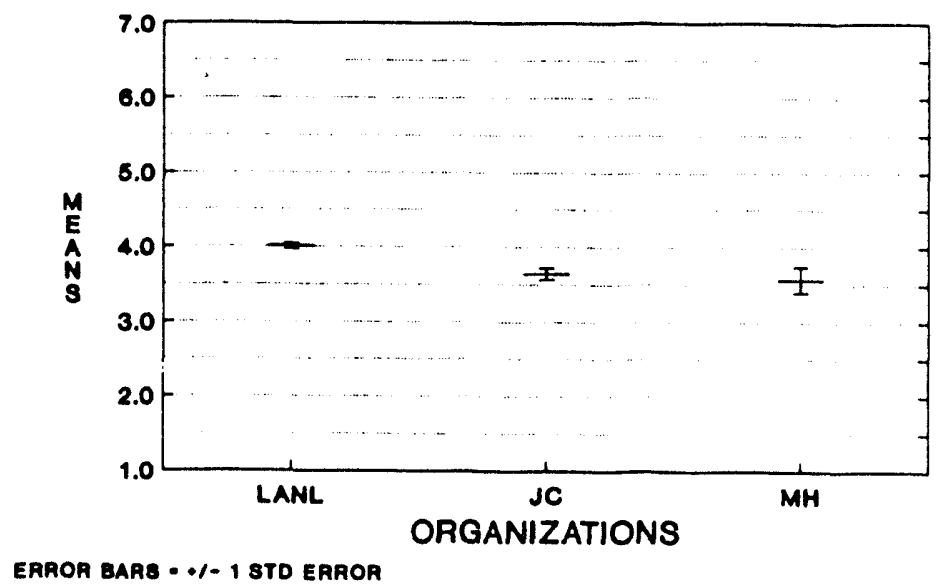

Figure 4.11. Significant differences between organizations at the Los Alamos site on the coordination scale

\subsubsection{Differences Between Organizations on the Environment, Safety, and Health Questions}

Statistically significant differences between organizations at the Los Alamos Site on the Offsite Environmental Consequences Question are presented in Figure 4.12. The LANL Organization had the lowest mean value on this question and was statistically significantly different from both the Johnson Controls and the Mason \& Hanger Organizations. The Johnson Controls Organization had the highest mean value on this question. No other statistically significant differences between organizations were obtained on this question.

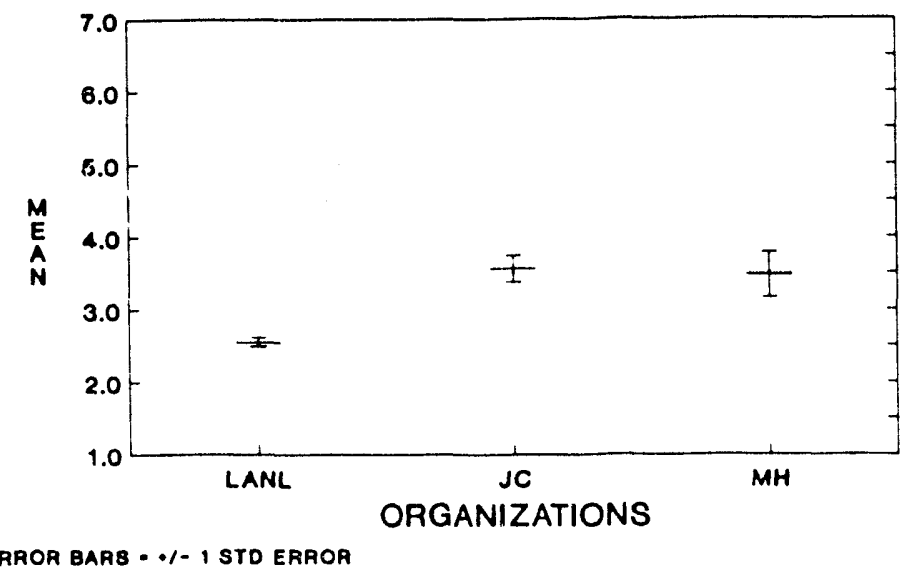

Figure 4.12. Significant differences between organizations on the offsite environmental consequences question 
The LANL Organization also had a statistically significantly lower mean on the Onsite Environmental Consequences Question than both the Johnson Controls and the Mason \& Hanger Organizations (Figure 4.13). The Johnson Controls Organization had the highest mean value on this question of the three organizations at the Los Alamos Site.

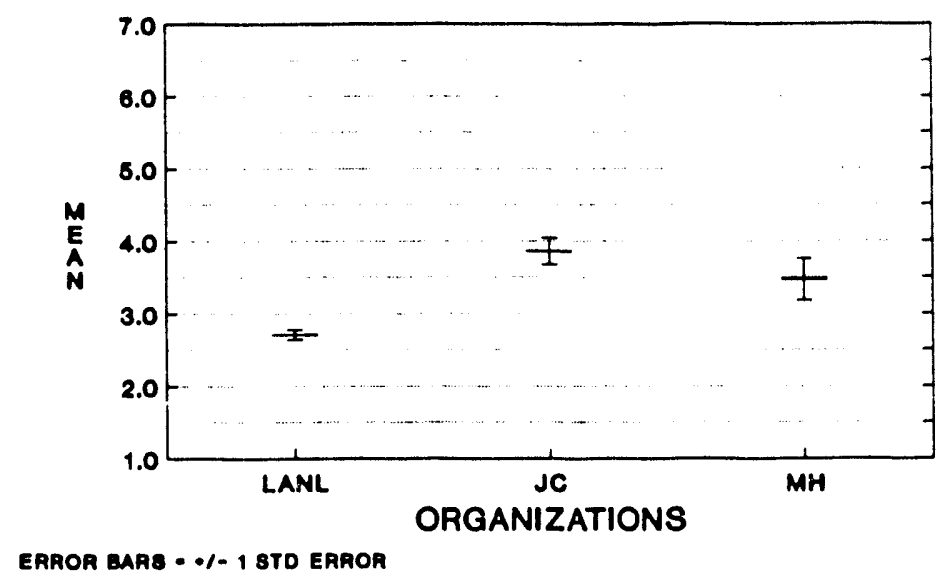

Figure 4.13. Significant differences between organizations on the onsite environmental consequences question

Statistically significant differences between organizations on the management emphasis question are depicted in Figure 4.14. The Mason \& Hanger Organization had the lowest mean value on this question and was statistically significantly different from both the LANL and the Johnson Controls Organizations. The LANL Organization had the highest mean value on this question.

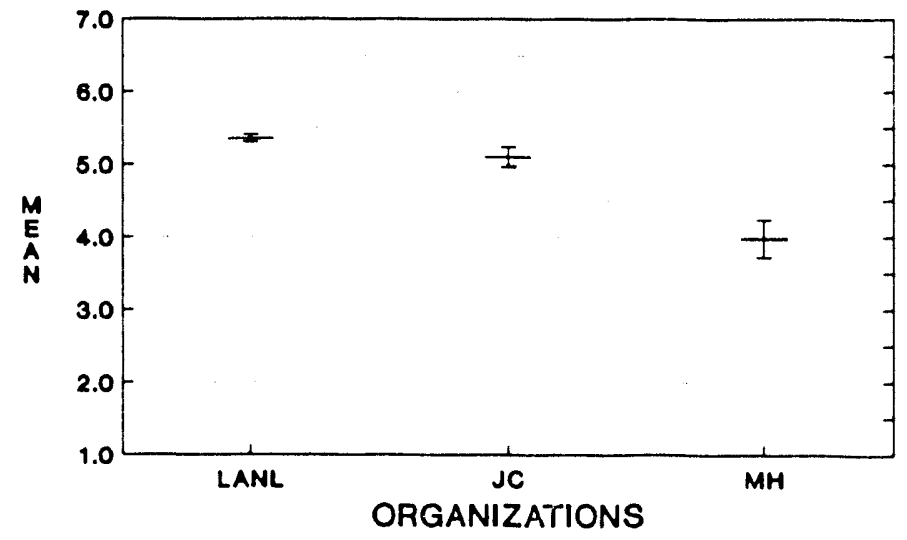

ERAOR BARB - */- 1 STO ERAOR

Figure 4.14. Significant differences between organizations on the management emphasis question

Figure 4.15 presents the statistically significant differences between organizations at the Los Alamos Site on the Employee Awareness Question. Every organization was statistically significantly different from every other organization on this question. The LANL Organization had the highest mean value on this question, while the Mason \& Hanger Organization had the lowest value. 


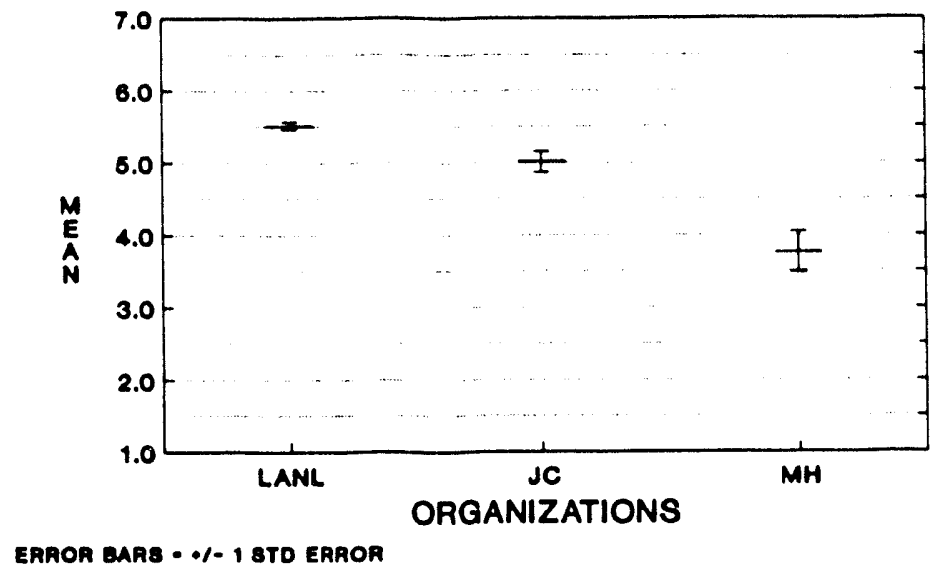

Figure 4.15. Significant differences between organizations on the employee awareness question

\subsubsection{Summary}

Examination of the statistically significant differences which were obtained between the Los Alamos Site organizations on the OS yields some interesting insights. One of the more obvious results is the lack of statistically significant differences between the three organizations on the OCI scales. The only statistically significant difference obtained was on the Dependent (C5) Scale. This indicates that the culture which exists at the Los Alamos Site is fairly homogeneous. Statistically significant differences were found between organizations on three of the Communication Scales, and all the differences obtained involved the LANL Organization having a statistically significantly higher mean value than the other Los Alamos Site Organizations. The LANL Organization also had low mean values on those scales/questions which relate to the perceived hazardous nature of work (i.e., hazard, offsite environmental consequences, onsite environmental consequences).

\subsection{Differences Between Supervisory Levels on the OS Scales}

Although each organization supplied supervisory levels specific to their own organization on the background information sheet, it was possible to create generic categories of manager and non-manager employees. This allowed managers of all organizations to be grouped together and compared to nonmanagers. The section which follows describes this comparison.

\subsubsection{Differences Beiviven Managers and Non-Managers on the OCI Scales}

Statistically significant differences between managers and non-managers on the HumanisticEncouraging (C1) Scale are presented in Figure 4.16. Managers had a statistically significantly higher mean score on this scale than non-managers. No statistically significant differences between managers and nonmanagers were obtained on the Affiliative (C2) Scale. The mean values for managers and non-managers on this scale are contained in Appendix C.

Figure 4.17 presents the statistically significant differences between managers and non-managers on the Approval (C3) Scale. Non-managers had a statistically significantly higher mean value on this scale than did managers. 


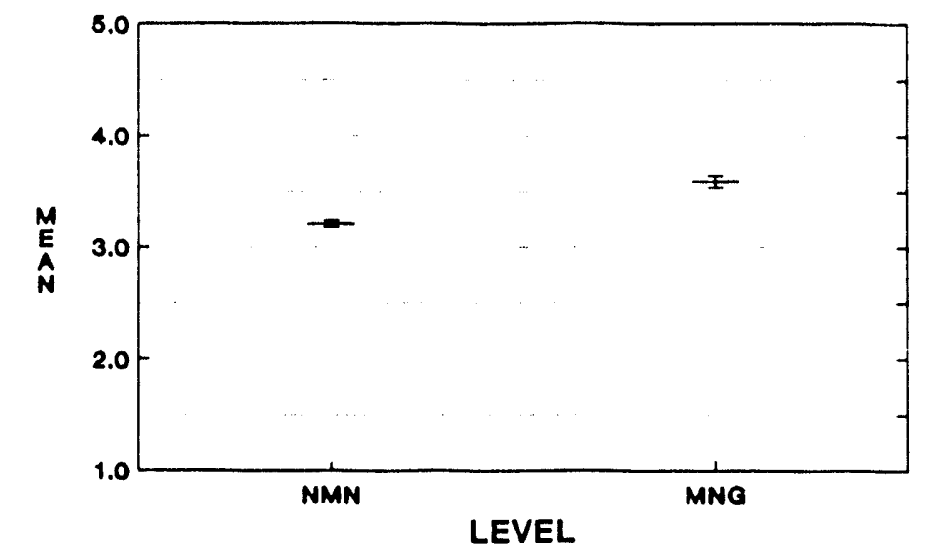

ERROA DAPQ - */- 1 STO EAROR

Figure 4.16. Significant differences between managers and non-managers on the humanisticencouraging scale

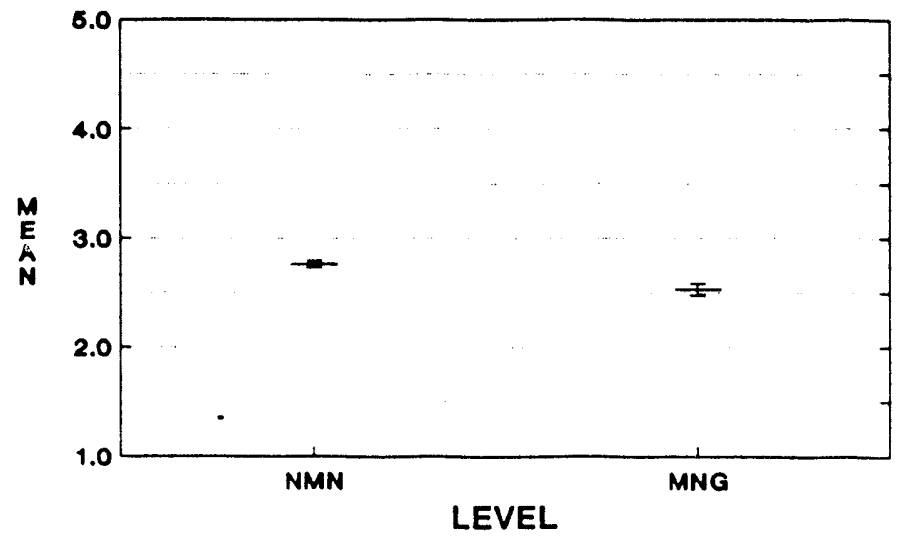

ERROA BARB - */- 1 STO ERAOR

Figure 4.17. Significant differences between managers and non-managers on the approval scale

Statistically significant differsaces between managers and non-managers on the Conventional (C4) Scale are presented in Figure 4.18. Managers had a statistically significantly lower mean value on this scale than non-managers.

On the Dependent (C5) Scale, non-managers had a statistically significantly higher mean value than did the managers. This difference is depicted in Figure 4.19. No statistically significant differences between managers and non-managers at the Los Alamos Site were obtained on the Avoidance (C6), Oppositional (C7), Power (C8), Competitive (C9), or Perfectionistic (C10) Scalus. The mean values on each of these scales for managers and non-managers are contained in Appendix $\mathrm{C}$.

Statistically significant differences between managers and non-managers on the Achievement (C11), and the Self-Actualizing (C12) Scales are presented in Figures 4.20 and 4.21, respectively. In both instances, non-managers had statistically significantly lower mean values than managers. 


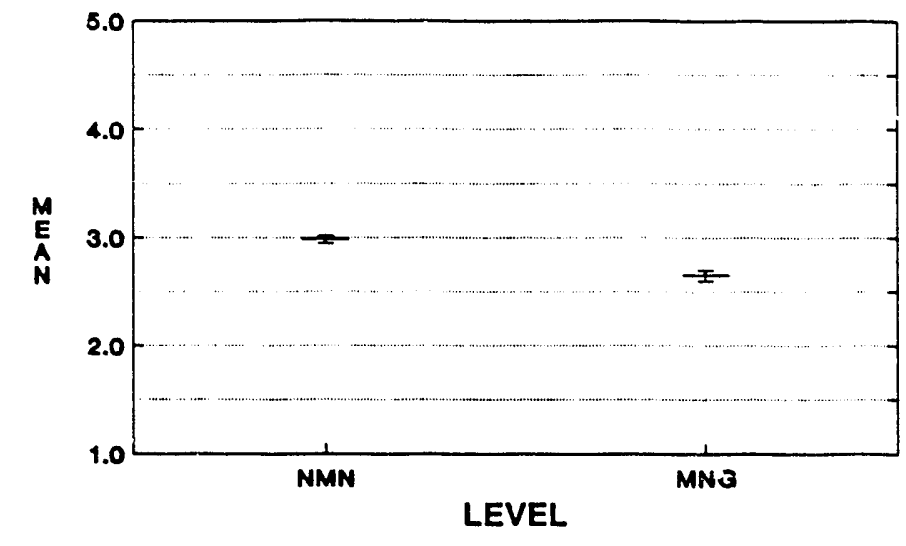

ERROR BARB - * - I STD ERROR

Figure 4.18. Significant differences between managers and non-managers on the conventional scale

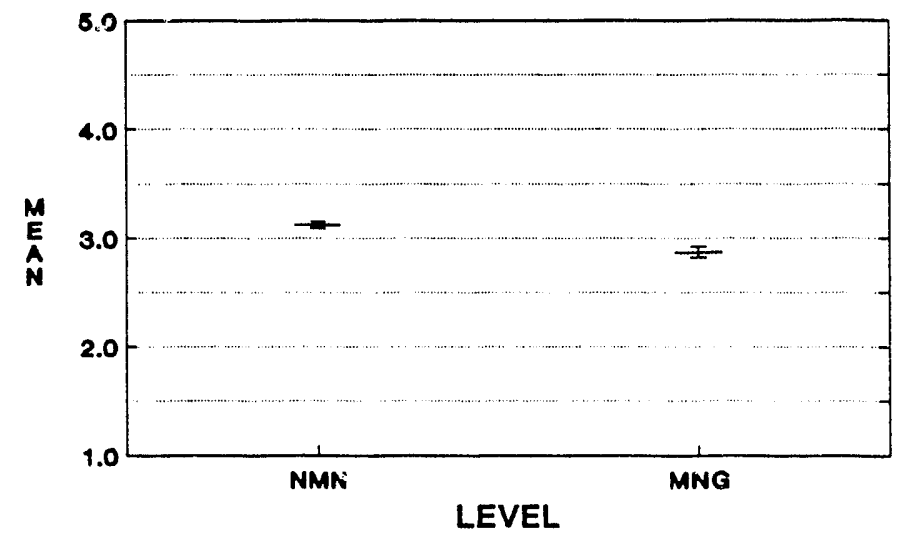

ERROR BARS - - /- 1 STD ERPOR

Figure 4.19. Significant differences between managers and non-managers on the dependent scale

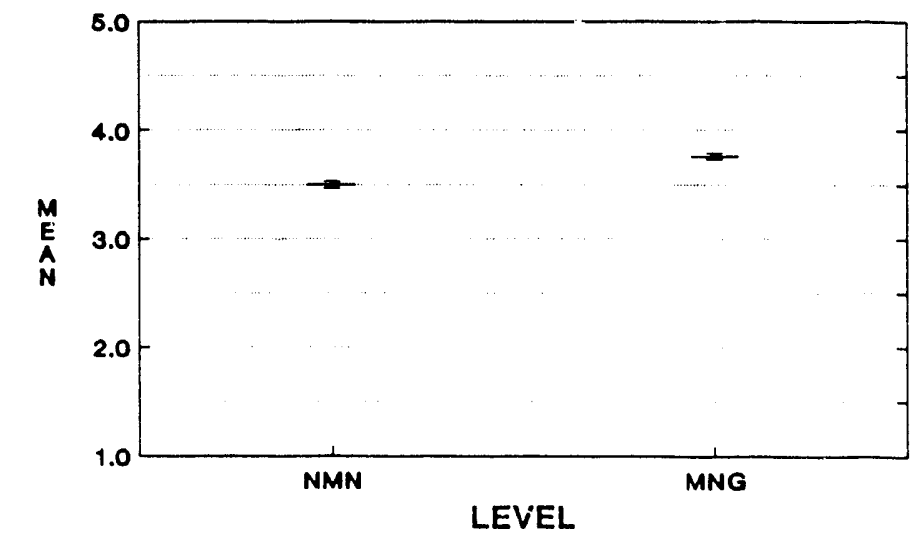

ERROR BARS - *1- 1 STD ERROR

Figure 4.20. Significant differences between managers and non-managers on the achievement scale 


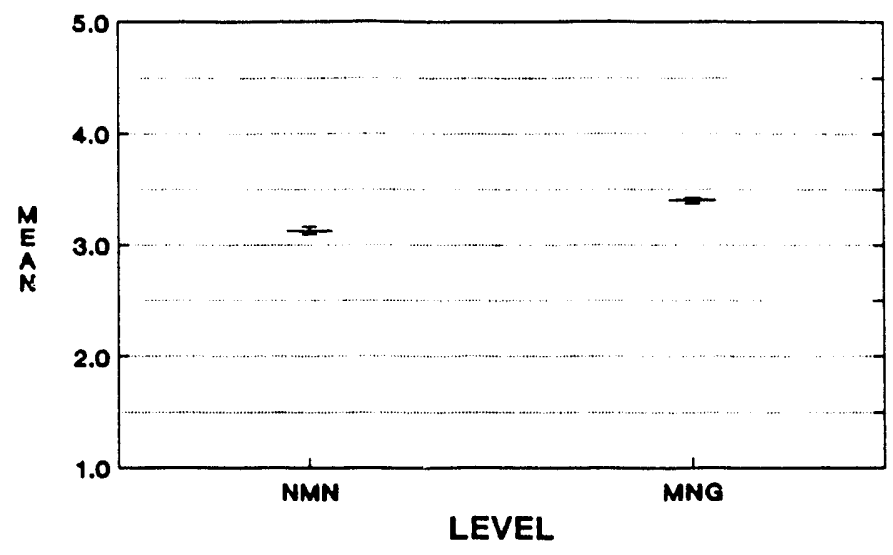

ERAOR DARS - * - 1 STD EAROR

Figure 4.21. Significant differences between managers and non-managers on the self-actualizing scale

\subsubsection{Differences Between Managers and Non-Managers on the Communication Scales}

Statistically significant differences between managers and non-managers occurred on two of the Communication Scales: Communication - Accuracy and Communication - Interaction. On both of these scales, managers had statistically significantly higher mean values than non-managers. These differences are depicted in Figures 4.22 and 4.23 , respectively.

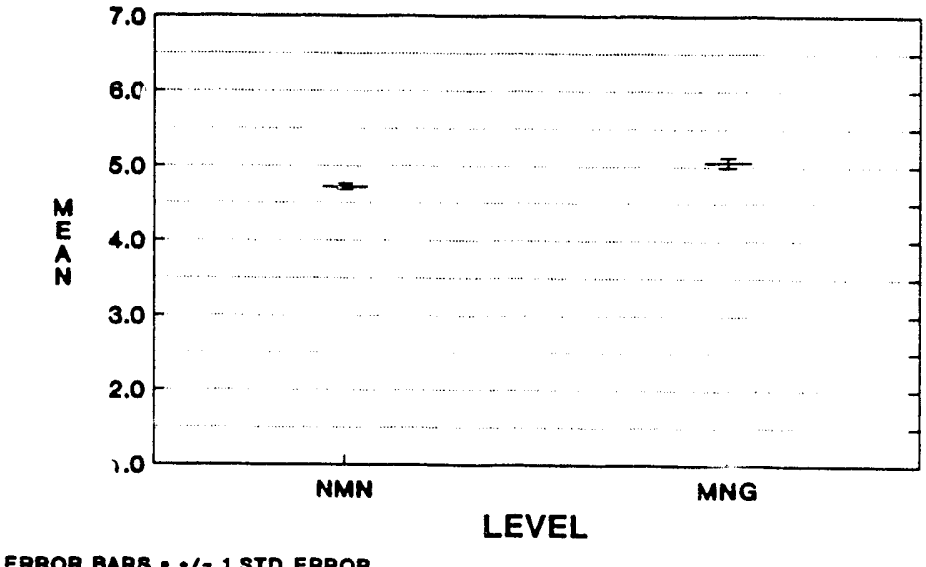

Figure 4.22. Significant differences between managers and non-managers on the communication-accuracy scale

\subsubsection{Differences Between Managers and Non-Managers on the Additional Scales}

Statistically significant differences between managers and non-managers on the Commitment Scale are depicted in Figure 4.24. Non-Managers had a statistically significantly lower mean value on this scale than managers. 


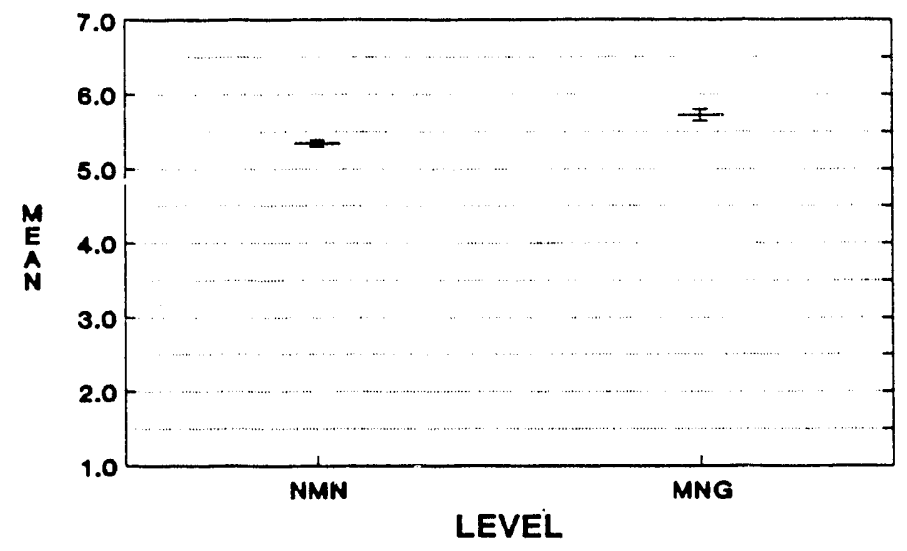

ERROR BAR8 - -1- 1 STO ERAOR

Figure 4.23. Significant differences between managers and non-managers on the communication-interaction scale

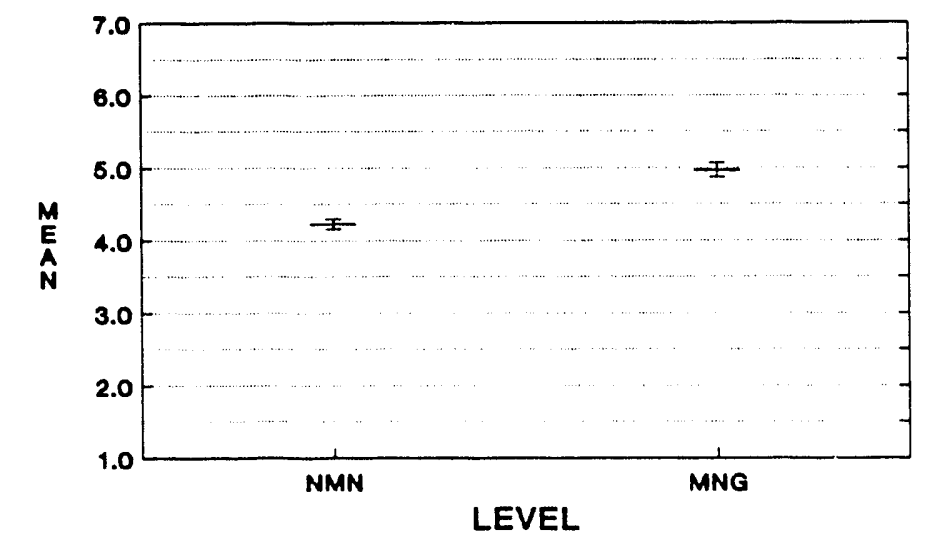

ERROR BARS - - / - 1 STD ERROR

Figure 4.24. Significant differences between managers and non-managers on the commitment scale

Figure 4.25 presents the statistically significant differences between managers and non-managers on the Cohesion Scale. Managers had a statistically significantly higher mean value on this scale than nonmanagers.

No statistically significant differences were obtained between managers and non-managers on the Hazard Scale. However, as shown in Figure 4.26, managers had a statistically significantly higher mean value on the Safety Scale than did non-managers.

No statistically significant differences were obtained between managers and non-managers on either the Coordination or the Job Satisfaction Scales. Appendix $C$ contains the mean values for these two groups on these, as well as on all other, scales. 


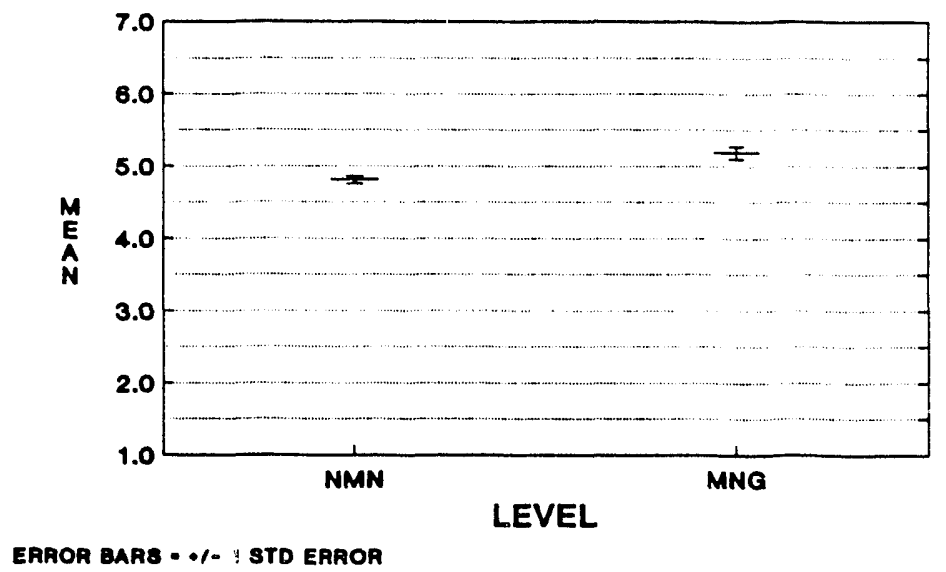

Figure 4.25. Significant differences between managers and non-managers on the cohesion scale

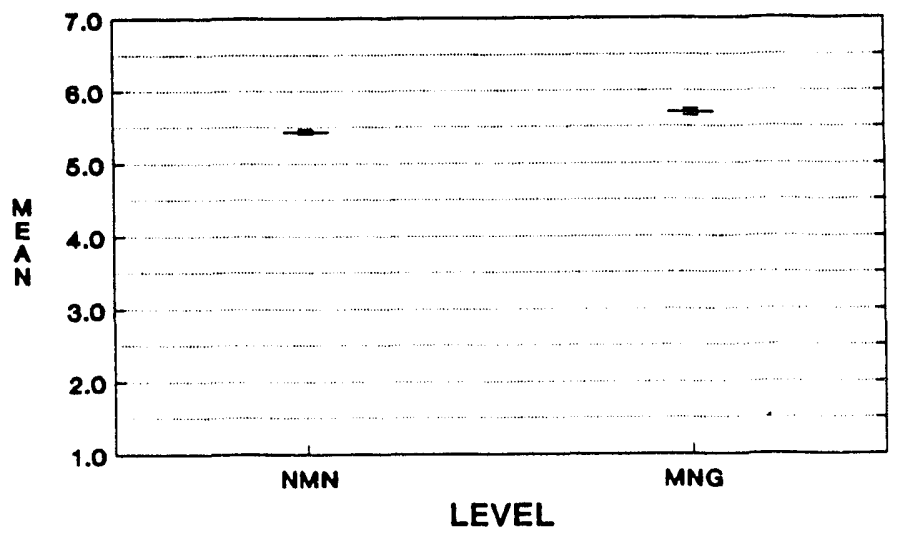

ERROR BARS - */- 1 STD ERROR

Figure 4.26. Significant differences between managers and non-managers on the safety scale

\subsubsection{Differences Between Managers and Non-Managers on the Environment, Safety, and Health Questions}

Statistically significant differences were obtained between managers and non-managers on two of the Environment, Safety, and Health Questions: Management Emphasis on Environmental Issues, and Employee Awareness of Risks in their Work Environment. The mean values for managers and non-managers on both the Off- and Onsite Environmental Consequences Questions are contained in Appendix C.

Figure 4.27 presents the statistically significant differences between managers and non-managers on the Management Emphasis Question. Managers had a statistically significantly higher mean value on this question than non-managers.

Statistically significant differences between managers and non-managers on the employee awareness question are depicted in Figure 4.28. Non-Managers had a statistically significantly lower mean value on this question than managers. 


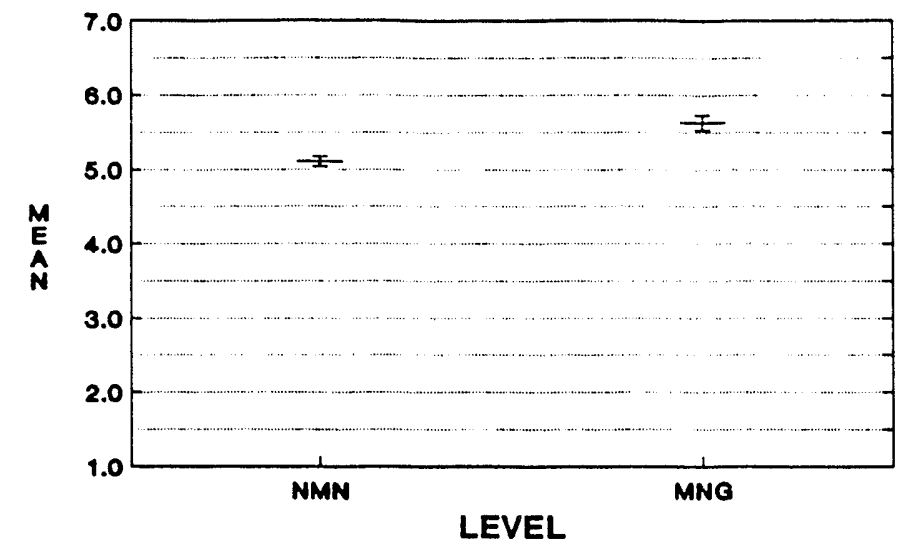

ERAOR BARB - •/- 1 STD ERROA

Figure 4.27. Signiticant differences between managers and non-managers on the management emphasis question

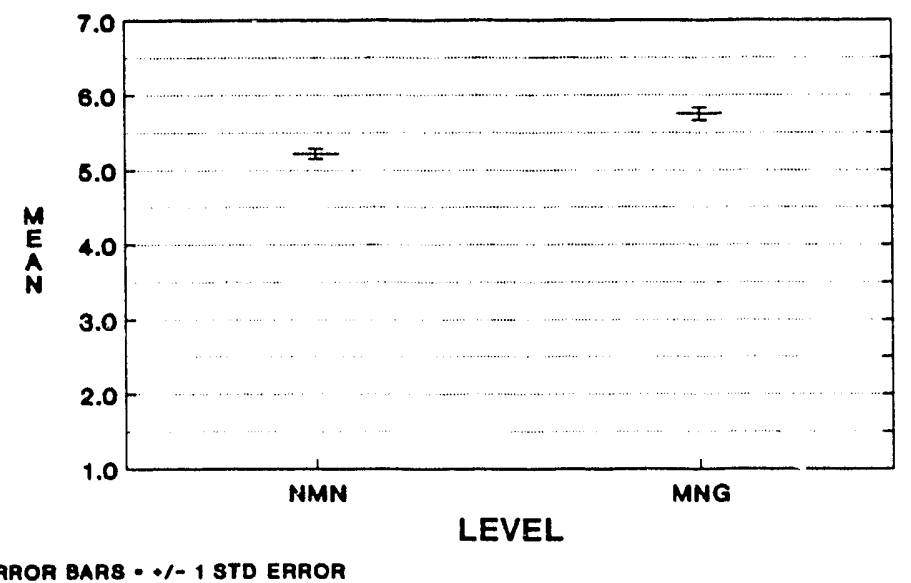

Figure 4.28. Significant differences between managers and non-mänagers on the employee awareness question

\subsubsection{Summary}

The results obtained in the comparison of the Los Alamos Site managers to ron-managers are consistent with the literature and with results obtained at other DOE facilities.

\subsection{Differences Between Organizations' Managerial Employees on the OS Scales}

Comparisons were made of managerial and non-managerial employees across the three organizations surveyed at the Los Alamos Site. This sections discusses the results for the managerial employees while the following section discusses the results for the non-managerial employees. 


\subsubsection{Differences Between Organizations' Managerial Employees on the OCI Scales}

No statistically significant differences between organizations' managerial employees at the Los Alamos Site were obtained on the OCI Scales. Appendix D contains the mean values for the managers of each organization on each of the scales.

\subsubsection{Differences Between Organizations' Managerial Employees on the Communication Scales}

Statistically significant differences between organizations' managerial employees were obtained on one of the Communication Scales: Communication-Interaction. As depicted in Figure 4.29, the LANL Managers had a statistically significantly higher mean value on this scale than the Johnson Controls Managers. The mean values obtained for the organizations' managerial employees on each of the other scales are contained in Appendix D.

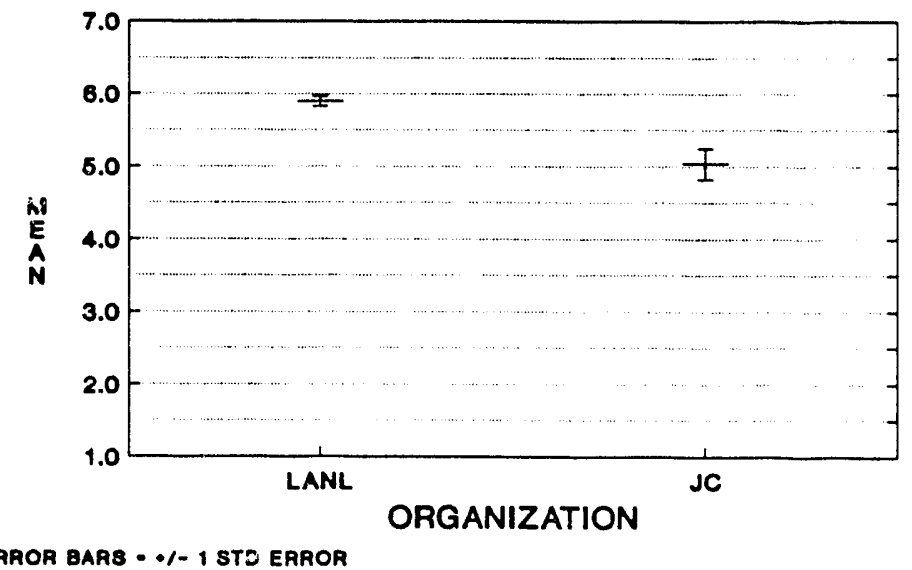

Figure 4.29. Significant differences between organizations' managerial employees on the communication-interaction scale

\subsubsection{Differences Between Organizations' Managerial Employees on the Additional Scales}

No statistically significant differences were obtained between the managerial employees of the three organizations at the Los Alamos Site on any of the additional scales. Appendix D contains the mean values for each organizations' managerial employees on each of the additional scales.

4.5.4 Differences Between Organizations' Managerial Employees on the Environment, Safety, and Health Questions

No statistically significant differences were obtained between the managerial employees of the three organizations at the Los Alamos Site on any of the Environment, Safety, and Health Questions. Appendix $D$ contains the mean values for each organizations' managerial employees on each of the Environment, Safety, and Health Questions.

\subsubsection{Summary}

Only one statistically significant difference was obtained between the managerial employees of the three organizations. The lack of statistically significant differences may be attributable to the disparity in the 
number of managerial employees at each organization (i.e., LANL had 174 respondents, while Mason \& Hanger had only seven managerial employees who responded to the survey).

\subsection{Differences Between Organizations' Non-Managerial Employees on the OS Scales}

\subsubsection{Differences Between Organizations' Non-Managerial Employees on the OCI Scales}

No statistically significant differences between the Los Alamos Site Organizations' Non-Managerial Employees occurred on any of the OCI Scales. The mean values obtained for the non-managerial employees at each organization on each of the OCI Scales are contained in Appendix E.

\subsubsection{Differences Between Organizations' Non-Managerial Employees on the Communication Scales}

Statistically significant differences between the non-managerial employees at the three organizations' surveyed at the Los Alamos Site occurred on every Communication Scale except the CommunicationSatisfaction Scale. The mean values for each organizations' non-managerial employees on the Communication-Satisfaction Scale can be found in Appendix E.

Figure 4.30 presents the statistically significant differences between the organizations' non-managerial employees on the Communication-Trust Scale. The LANL non-managerial employees had a statistically signiricantly higher mean value on this scale than the Mason \& Hanger non-managerial employees.

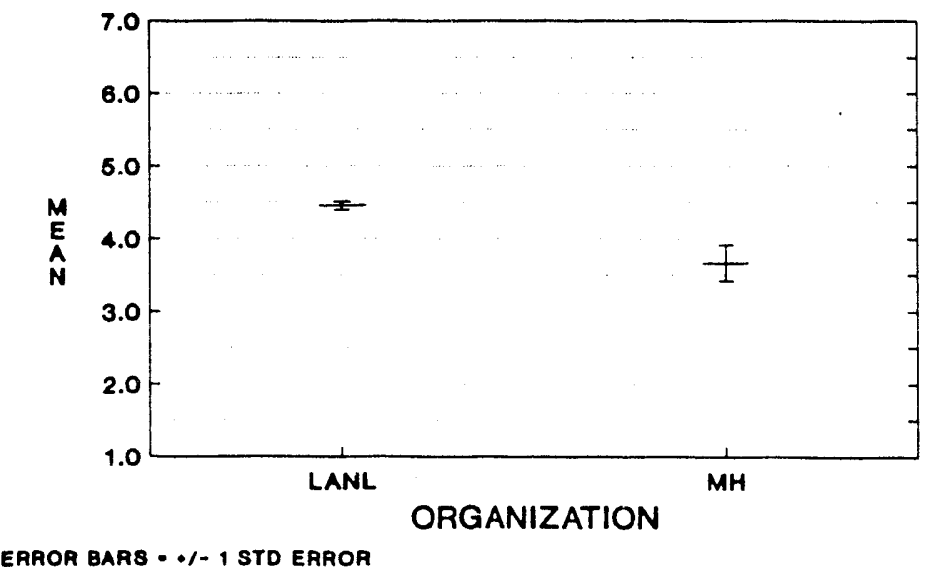

Figure 4.30. Significant differences between organizations' non-managerial employees on the communication-trust scale

Figure 4.31 presents the statistically significant differences between the organizations' non-managerial employees on the Communication-Accuracy Scale. The LANL Non-Managerial employees had a statistically significantly higher mean value on this scale than the Mason \& Hanger Non-Managerial employees.

Statistically significant differences tween hie organizations' non-managerial employees on the Communication-Interaction Scale are depicted in Figure 4.32. The LANL Non-Managerial employees had a statistically significantly higher mean value on this scale than the Johnson Controls Non-Managerial employees. 


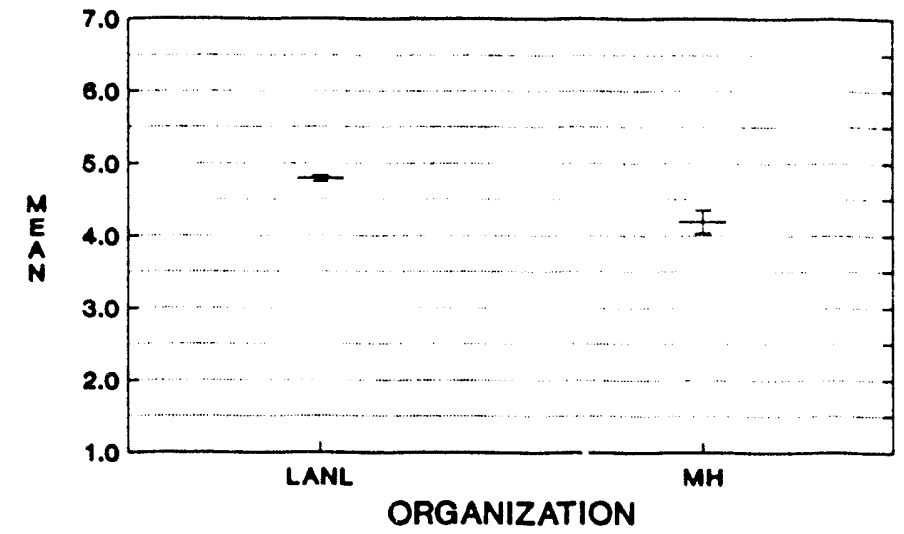

ERAOR BARS - */- 1 STD EAROR

Figure 4.31. Significant differences between organizations' non-managerial employees on the communication-accuracy scale

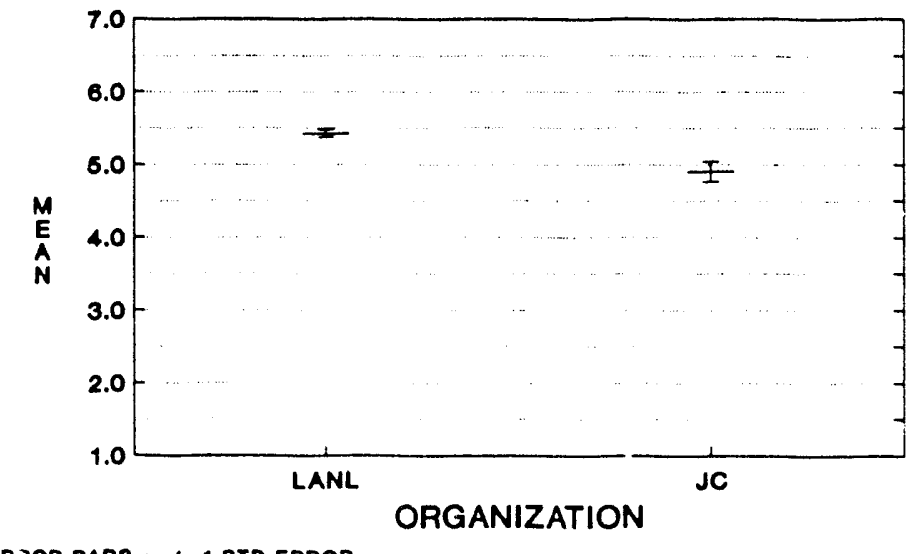

Figure 4.32. Significant differences between organizations' non-managerial employees on the communication-interaction scale

\subsubsection{Differences Between Organizations' Non-Managerial Employees on the Additional Scales}

Statistically significant differences between organizations' non-managerial employees on the Commitment Scale are depicted in Figure 4.33. The LANL Non-Managerial employees had a statistically significantly higher mean value on this scale than the Mason \& Hanger Non-Managerial employees.

No statistically significant differences between the non-managerial employees of the three organizations at the Los Alamos Site were obtained on the Cohesion Scale. Appendix E contains the mean value for the non-managerial employees of each organization on this scale.

Statisticaliy significant differences between the organizations' non-managerial employees on the Hazard Scale are depicted in Figure 4.34. The LANL Non-Managerial employees had the lowest mean value on this scale and were statistically significantly different from both the Johnson Controls and the Mason \& Hanger Non-Managerial employees. The Non-Managerial employees at the Johnson Controls organization had the highest mean value on this scale. 


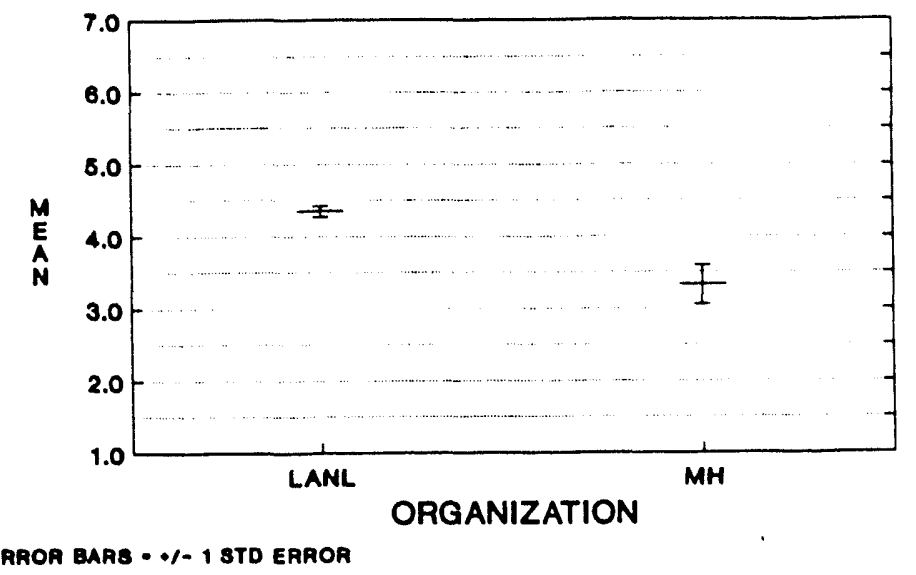

Figure 4.33. Significant differences between organizations' non-managerial employees on the commitment scale

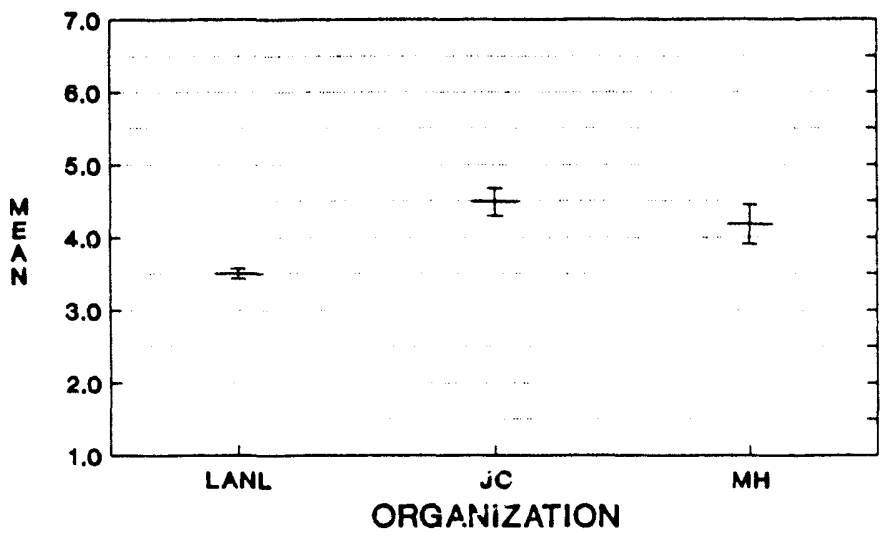

ERROA BARS - */- 1 STD ERROR

Figure 4.34. Significant differences between organizations' non-managerial employees on the hazard scale

No statistically significant differences between the non-managerial employees of the three Los Alamos Site organizations were obtained on the Safety Scale. Appendix E contains the mean values for the nonmanagers at each organization on this scale.

Figure 4.35 depicts the statistically significant differences between the non-managerial employees at the three organizations on the Coordination Scale. The LANL Non-Managerial employees had the lowest mean value on this scale and were statistically significantly different from both the Johnson Controls and the Mason \& Hanger Non-Managerial employees. The Johnson Controls Non-Managerial employees had the highest mean value on the Coordination Scale.

No statistically significant differences were obtained between the non-managerial employees of the three organizations surveyed at the Los Alamos Site on the Job Satisfaction Scale. Appendix E presents the mean values of each organizations' managerial employees on this scale. 


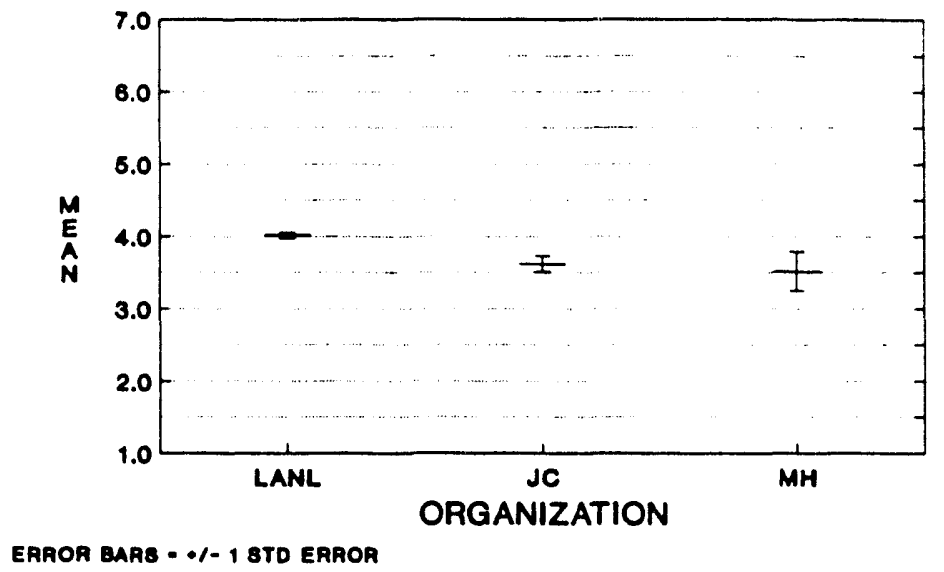

Figure 4.35. Significant differences between organizations non-managerial employees on the coordination scale

\subsubsection{Differences Between Organizations' Non-Managerial Employees on the Environment, Safety, and Health Questions}

Statistically significant differences between organizations' non-managerial employees were obtained on each of the environment, safety, and health questions. As depicted in Figure 4.36, the LANL NonManagerial employees had a statistically significantly lower mean value on the Offsite Consequences Question than both the Johnson Controls Non-Managerial employees, who had the highest mean value on this question, and the Mason \& Hanger Non-Managerial employees.

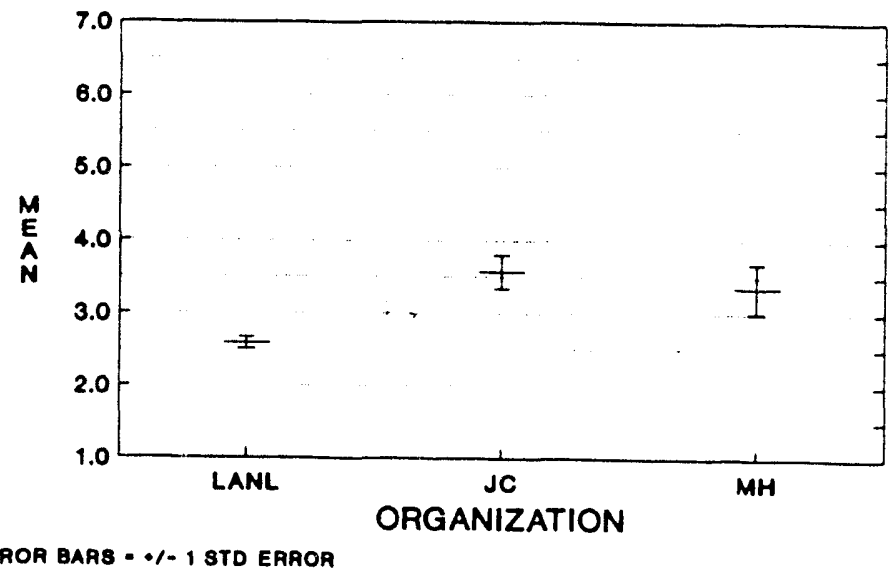

Figure 4.36. Significant differences between organizations' non-managerial employees on the offsite environmental consequences question

On the Onsite Environmental Consequences Question, the LANL Non-Managerial employees had a statistically significantly lower mean value than the Johnson Controls Non-Managerial employees (Figure 4.37). 


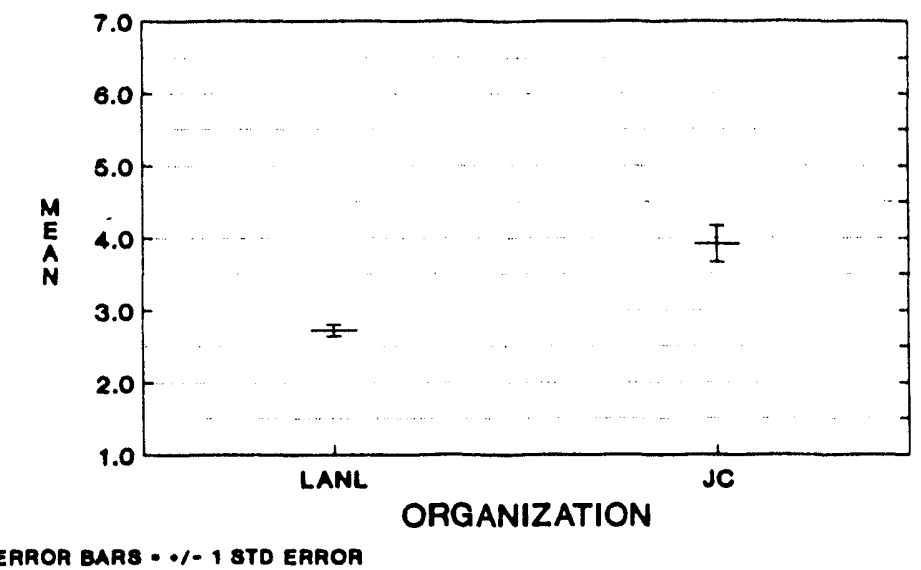

Figure 4.37. Significant differences between organizations' non-managerial employees on the onsite environmental consequences question

The statisticaily significant differences between the non-managerial employees of the three organizations surveyed at the Los Alamos Site on the Management Emphasis Question are depicted in Figure 4.38. The Mason \& Hanger Non-Managerial employees had a mean score that was statistically significantly lower than the mean score obtained for both the LANL Non-Managerial employees, who had the highest mean value on this question, and the Johnson Controls Non-Managerial employees.

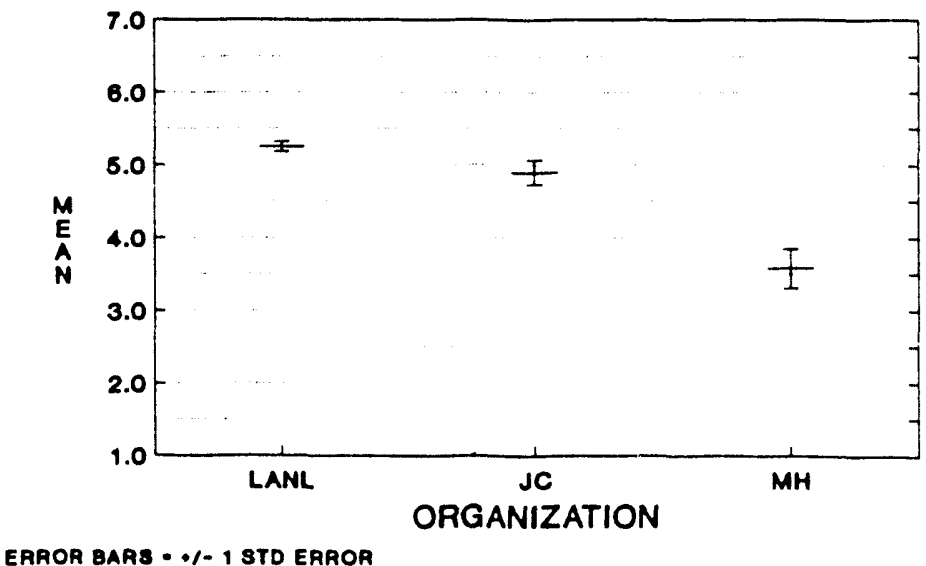

Figure 4.38. Significant differences between organizations' non-managerial employees on the management emphasis question

Statistically significant differences between organizations' non-managerial employees on the Employee Awareness Question are presented in Figure 4.39. The LANL Non-Managerial employees had the highest mean value on this question and were statistically significantly different from both the Johnson Controls and the Mason \& Hanger Non-Managerial employees. The Mason \& Hanger Non-Managerial employees had the lowest mean value on this question and were statistically significantly different from both the Johnson Controls and LANL Non-Managerial employees. 


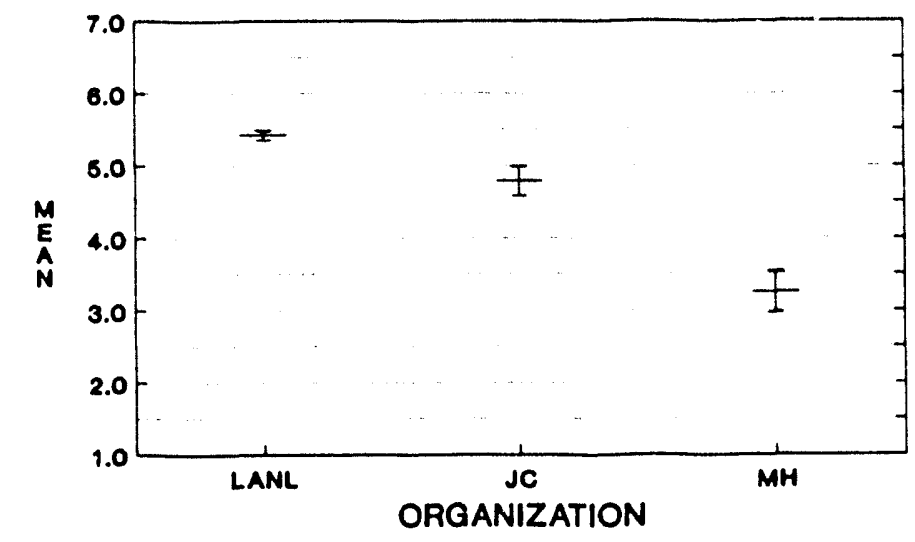

EAMON DAAE - */- 1 OTD ERROR

Figure 4.39. Significant differences between organizations' non-managerial employees on the employee awareness question

\subsubsection{Summary}

The differences obtained between the non-managerial employees of the three organization surveyed at the Los Alamos Site correspond well to those obtained when the three organizations were compared using all employees.

\subsection{Differences Within the LANL Organization on the OS Scales}

This section discusses the statistically significant differences obtained within the LANL Organization on the OS Scales. Specifically, differences between (?) directorates within the LANL Organization; (b) staff classifications within the LANL Organization; and (c) supervisory levels within the LANL Organization, are discussed. Note that for the analyses in which the LANL Directorates were compared to one another, the At Large/Center for National Security Studies, the Director's Office, the Human Resources, and the Laboratory Counsel Directorates were combined into one group called Support. This combination was necessary due to the small number of individuals in each group.

\subsubsection{Differences Between the LANL Directorates on the OS Scales}

\subsubsection{Differences Between the LANL Directorates on the OCI Scales}

No statistically significant differences were obtained between the LANL directorates on the Humanistic-Encouraging $(\mathrm{Cl})$ Scale. The mean values obtained for each directorate on this as well as every other scale are contained in Appendix F. In addition, Appendix $G$ contains figures which compare the overall mean values obtained for the LANL Organization on the OCI Scales, to the mean values obtaincd for each Directorate on the OCI Scales.

Statistically significant differences between the LANL Directorates on the Affiliative (C2) Scale are depicted in Figure 4.40. The Support Directorate had the highest mean value on this scale and was statistically significantly different from the Defense Research and Applications, Nuclear Weapons Technology, and Research Directorates. The Defense Research and Applications Directorate had the lowest mean value on this scale. The Controller Directorate had a statistically significantly higher mean value than both the 
Defense Research and Applications, and New Weapons Technology Directorates. No other statistically significant differences between LANL Directorates were found on this scale.

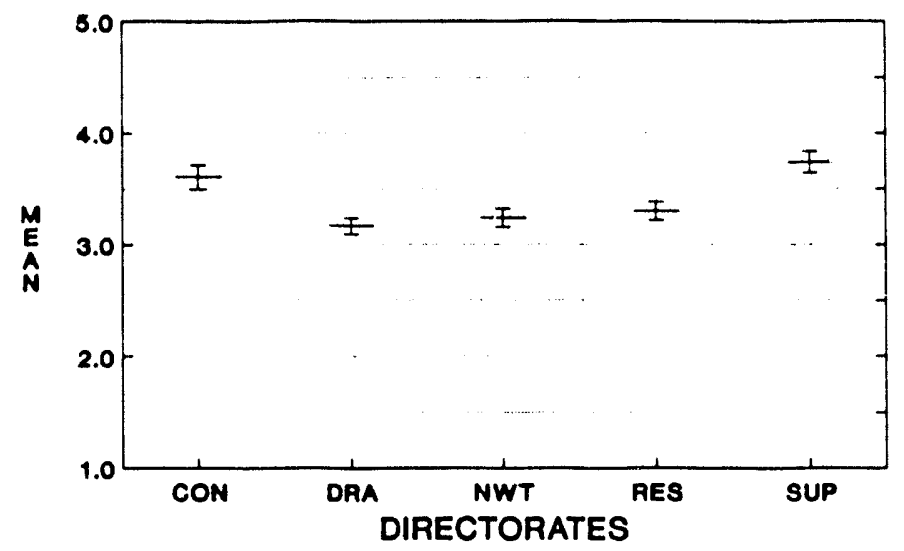

EAROR BARS - ./ 1 STD EAROR

Figure 4.40. Significant differences between LANL directorates on the affiliative scale

Statistically significant differences between the LANL directorates on the Approval (C3) Scale are depicted in Figure 4.41. The Controlier Directorate had the highest mean value on this scale and was statistically significantly different from the Defense Research and Applications, and the Energy and Technology Directorates. The Energy and Technology Directorate had the lowest mean value on this scale. The Support Group also had a statistically significantly higher mean value on this scale than the Energy and Technology Directorate. No other statistically significant differences between the LANL Directorates were obtained on this scale.

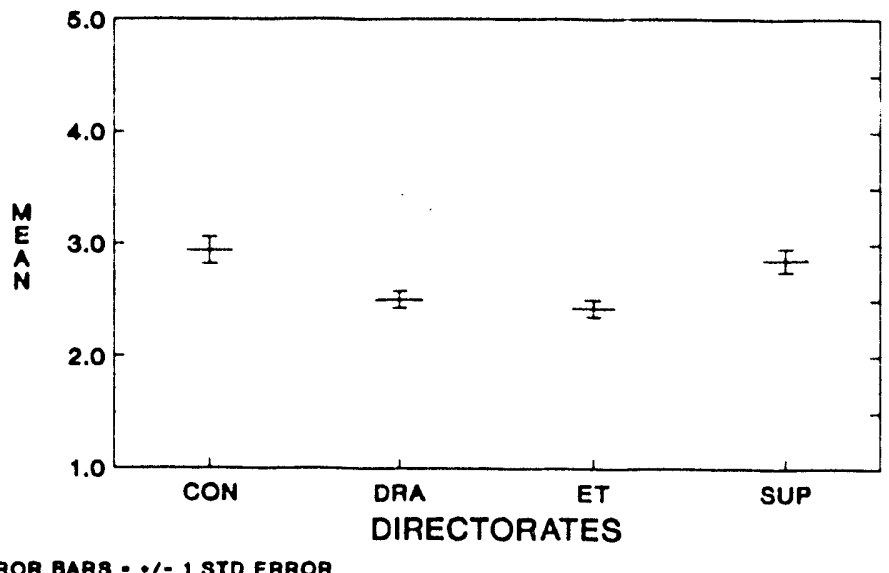

ERROR BAAS - •/- 1 STD ERROR

Figure 4.41. Significant differences between LANL directorates on the approval scale

Figure 4.42 presents the statistically significant differences between the LANL Directorates on the Conventional Scale (C4). The Controller Directorate had the highest mean value on this scale and was statistically significantly different from the Defense Research and Applications, the Energy and Technology 
and the Nuclear Weapons and Technology Directorates. The Energy and Technology Directorate had the lowest mean value on this scale. The Operations Directorate had a statistically significantly higher mean value on this scale than the Energy and Technology Directorate.

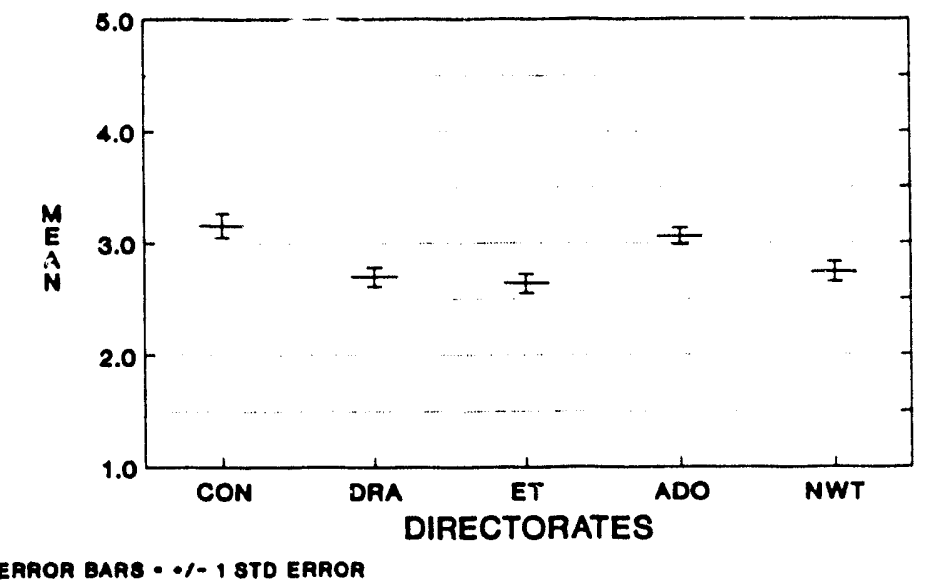

Figure 4.42. Significant differences between LANL directorates on the conventional scale

The statistically significant differences obtained on the Dependent (C5) Scale between the LANL Directorates are presented in Figure 4.43. The Controller Directorate had the highest mean value on this scale and was statistically significantly different from the Chemistry and Materials, the Defense Research and Applications, and the Energy and Technology Directorates. The Energy and Technology Directorate had the lowest mean value on this scale and was also statistically significantly different from tise Operations and Support Directorates, as well as from the Controller Directorate. No other statistically significant differences between the LANL Directorates were present on this scale.

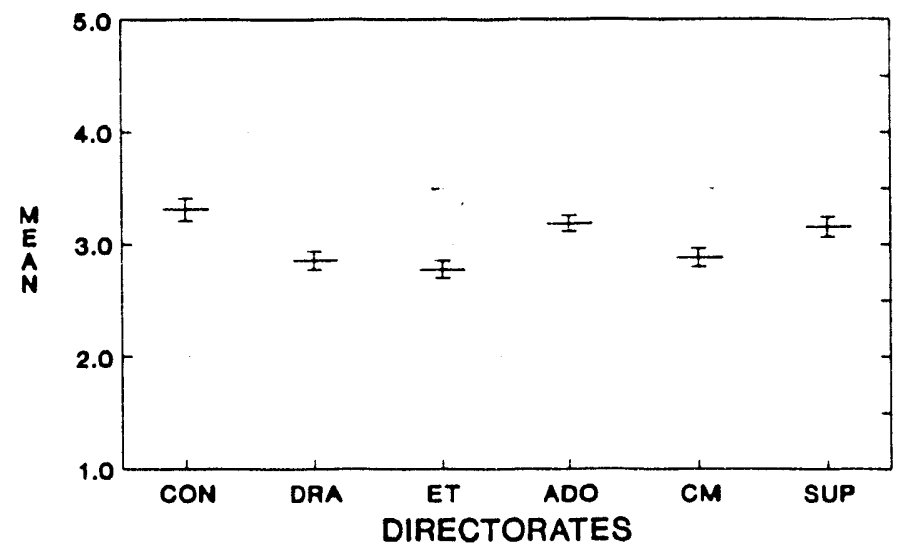

ERROR BAR8 - */- 1 STD ERROR

Figure 4.43. Significant differences between LANL directorates on the dependent scale

The Controller Directorate had the highest obtained mean value on the Avoidance (C 4 ) Scale (Figure 4.44) and was statistically significantly different from the Lefense Research and Applications, Energy and Technology, Chemistry and Materials, and Nuciear Weapons Technology Directorates. The Energy and 
Technology Directorate, which had the lowest mean value on this scale, was also statistically significantly different from the Research and Support Directorates. No other statistically significant differences between the LANL Directorates were present on this scale.

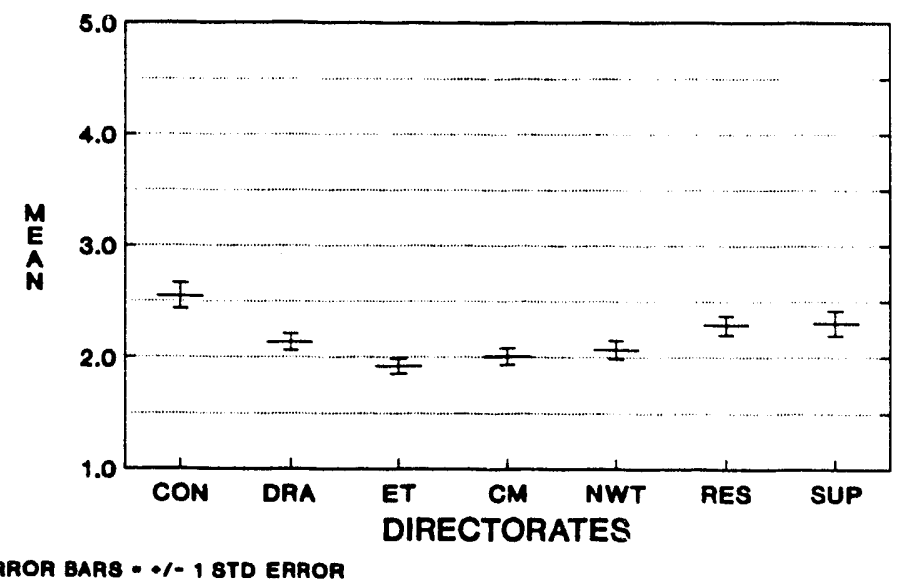

Figure 4.44. Significant differences between LANL directorates on the avoidance scale

No statistically significant differences were obtained between the LANL Directorates on the Oppositional (C7) Scale. Appendix F contains the mean values obtained for each directorate on each of the OS scales.

Presented in Figure 4.45 are the statistically significant differences obtained between the LANL Directorates on the Power (C8) Scale. The Controller Directorate had the highest mean value on this scale and was statistically significantly different from the Defense Research and Applications, Energy and Technology, Chemistry and Materials, and Nuclear Weapons Technology Directorates. In addition, the Energy and Technology Directorate, which had the lowest mean value, had a statistically significantly lower mean value on this scale than the Sipport Directorate.

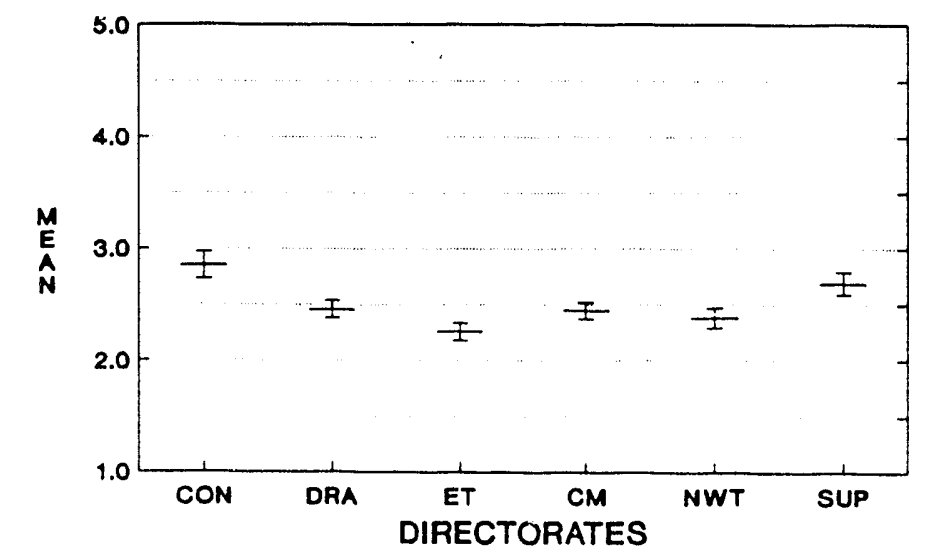

ERROR BARS - - / 1 STD ERROR

Figure 4.45. Significant differences between LANL directorates on the power scale 
No statistically significant differences were obtained between the LANL Directorates on any of the remaining OCI Scales (i.e., Competition (C9), Perfectionisi. _ . -), Achievement (C11), or Self-Actualizing (C12) Scales). Appendix F contains the mean values obtained for each LANL Directorate on each of these scales.

\subsubsection{Differences Between the LANL Directorates on the Communication Scales}

Statistically significant differences between the LANL Directorates were found on only one of the Communication Scales: Trust. The mean values for the LANL Directorates on all other Communication Scales are contained in Appendix F. In addition, Appendix $\mathrm{H}$ contains figures which compare the mean values obtained for each LANL Directorate to the overall mean values for the 1 ANL Organization on the Communication Scales.

Figure 4.46 presents the statistically significant differences obtained between the LANL Directorates on the Communication-Trust Scale. The Energy and Technology Directorate had the highest mean value on this scale and was statistically significantly different from both the Controller and Operations Directorates. The Controller Directorate had the lowest mean value on this scale.

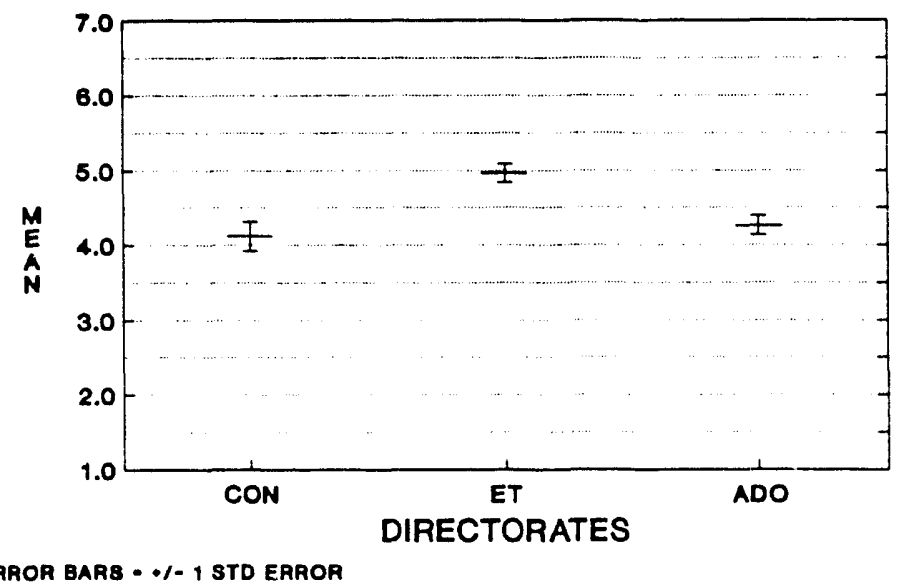

Figure 4.46. Significant differences between LANL directorates on the communication-trust scale

\section{4:i.1.3 Differences Between the LANL Directorates on the Additional Scales}

Statistically significant differences between the LANL Directorates were obtained on two of the additional scales: Commitment and Hazard. The mean values for each LANL Directorate on each of the other additional scales are contained in Appendix F. Appendix I contains figures which compare the mean value obtained for the overall LANL Organization to the mean values obtained for each directorate on each of the additional scales.

Statistically significant differences between the LANL Directorates on the Commitment Scale are presented in Figure 4.47. The Energy and Technology Directorate had the highest mean value on this scale and, along with the Nuclear Weapons Technology Directorate, was statistically significantly different from both the Controller and Operations Directorates. No other statistically significant differences between directorates were obtained on this scale. 


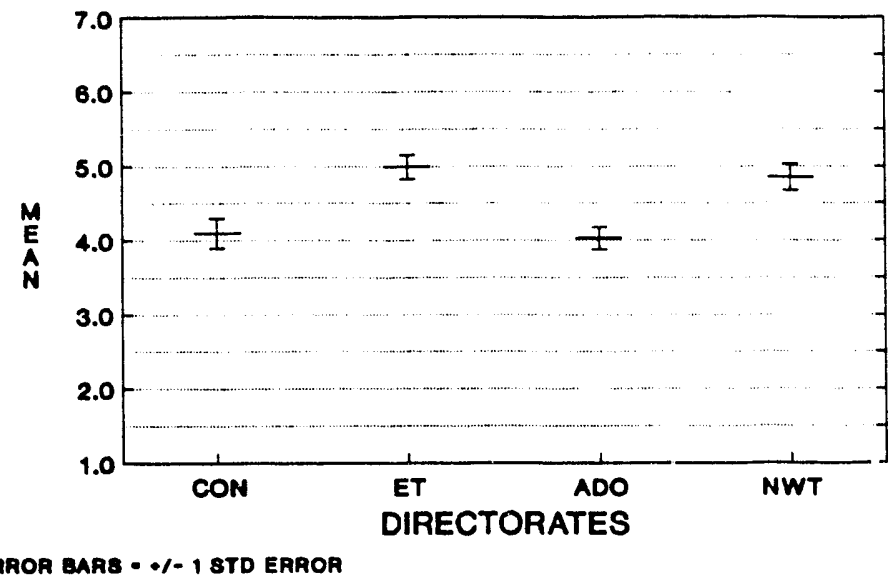

Figure 4.47. Significant differences between LANL directorates on the commitment scale

Figure 4.48 presents the statistically significant differences obtained between the LANL Directorates on the Hazard Scale. The Chemistry and Materials Directorate had the highest mean value on this scale and, along with the Nuclear Weapons Technology Directorate, was statistically significantly different from the Research, Defense Research and Applications, Energy and Technology, Support, and Controller Directorates. The Controller Directorate had the lowest mean value on this scale. Other statistically significant differences between directorates on this scale are presented in Appendix F.

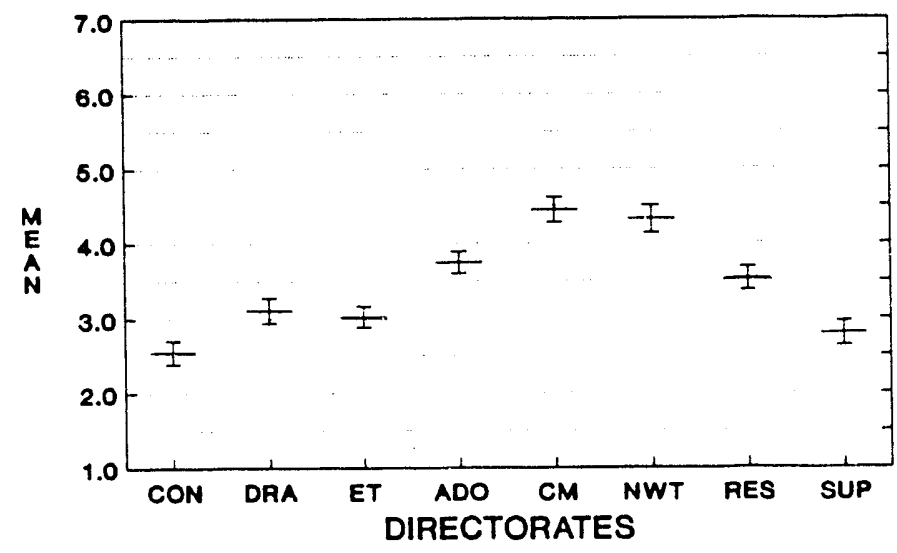

ERAOR BARS - *1- 1 STD ERROR

Figure 4.48. Significant differences between LANL directorates on the hazard scale

\subsubsection{Differences Between the LANL Directorates on the Environment, Safety, and Health Questions}

Statistically significant differences between the LANL Directorates were found on each of the Environment, Safety, and Health Questions. Appendix J presents figures which compare the mean value obtained for the overall LANL Organization to the mean values obtained for each LANL Directorate on the Environment, Safety, and Health Questions. 
Figure 4.49 presents the statistically significant differences obtained between the LANL Directorates on the Offsite Environmental Consequences Question. The Chemistry and Materials Directorate had the highest mean value on this question, and along with the Nuclear Weapons Technology and Operations Directorates, was statistically significantly different from the Controller, Energy and Technology, and Support Directorates. Both the Support and Controller Directorates had the lowest mean values on this question. Other statistically significant differences between the LANL Directorates on this question can be found in Appendix F.

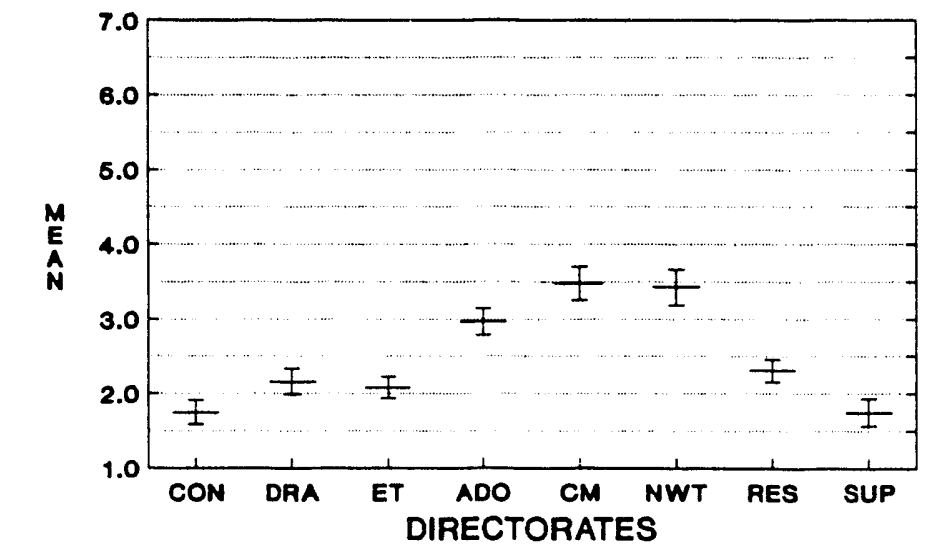

ERROR BARS - */- 1 STO ERROR

Figure 4.49. Significant differences between LANL directorates on the offsite environmental consequences question

On the Onsite Environmental Consequences Question, the Chemistry and Materials Directorate again had the highest mean value and was statistically significantly different from every other LANL Directorate except the Nuclear Weapons Technology Directorate (Figure 4.50). The Controller Directorate had the lowest mean value on this question, and in addition to being significantly different from the Chemistry and Materials Directorate, was statistically significantly different from the Nuclear Weapons Technology, Operations, and Research Directorates. Additional statistically significant differences between LANL Directorates on the Onsite Environmental Consequences Question are contained in Appendix F.

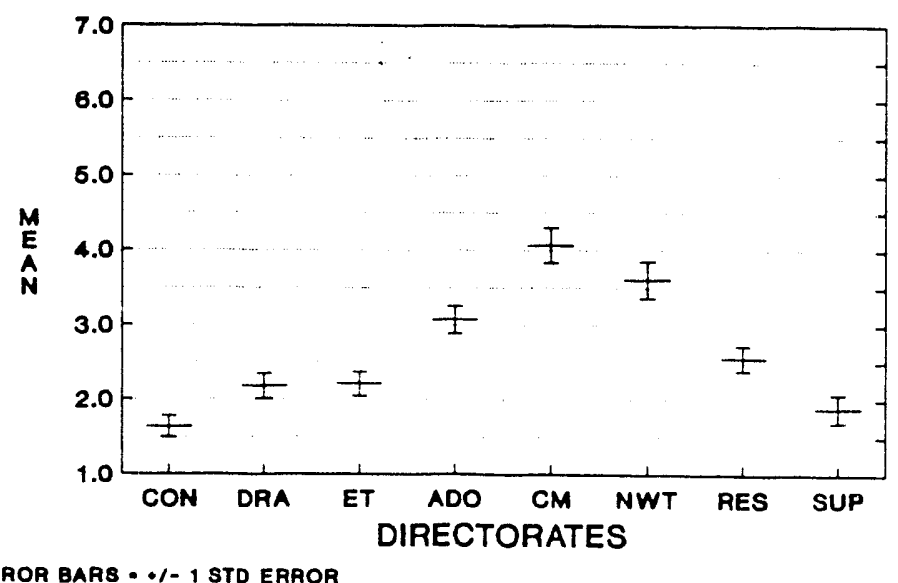

Figure 4.50. Significant differences between LANL directorates on the onsite environmental consequences question 
Figure 4.51 depicts the statistically significant differences obtained between the LANL Directorates on the Management Emphasis Question. The Controller Directorate had the lowest mean value on this question and was statistically significantly different from the Energy and Technology, Chemistry and Materials, and Nuclear Weapons Technology Directorates. The Chemistry and Materials Directorate had the highest mean value on this question. No other statistically significant differences between the LANL Directorates were obtained on this question.

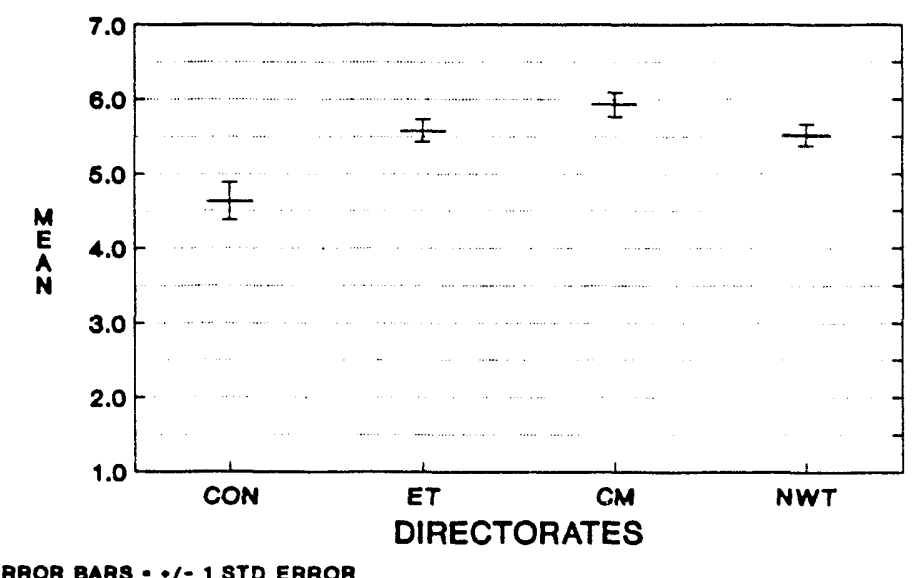

Figure 4.51. Significant differences between LANL directorates on the management emphasis question

A similar result was found when the LANL Directorates were compared to one another on the Employee Awareness Question (Figure 4.52). The Controller Directorate again had the lowest obtained mean value and was statistically significantly different from the Nuclear Weapons Technology, Chemistry and Materials, and Energy and Technology Directorates. For this question, however, the Nuclear Weapons Technology Directorate had the highest mean value.

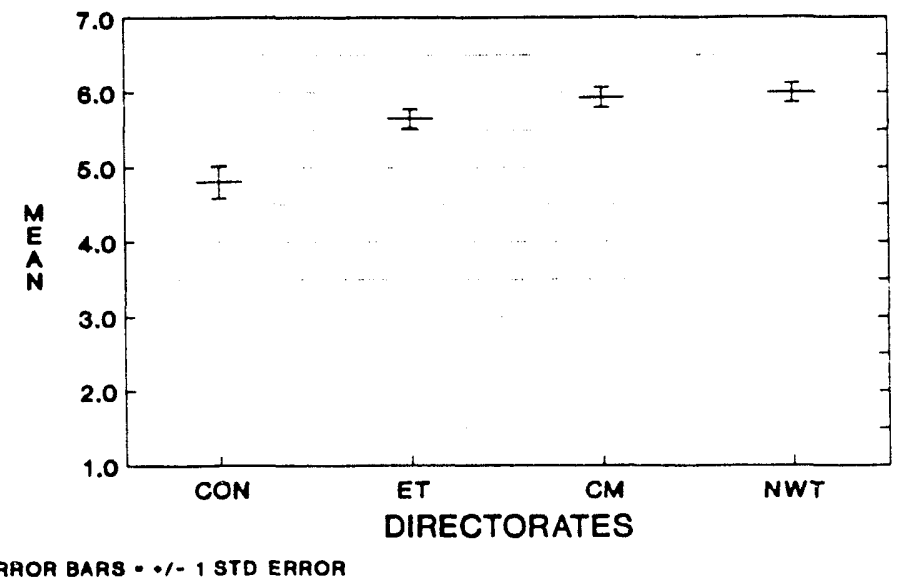

Figure 4.52. Significant differences between LANL directorates on the employee awareness question 


\subsubsection{Summary}

The statistically significant differences obtained between the LANL Directorates suggest that the directorates can actually be clustered into two larger groups based on similarities in scale scores. In one group is the Controller Directorate, which was involved in every statistically significant difference obtained between the LANL Directorates. They tended to score higher than other directorates on those scales which make up the Passive-Defensive Cultural Style (i.e., Approval (C3), Conventional (C4), Dependent (C5), and Avoidance (C6) Scales). In addition, they had the perception that their work involves a low amount of hazard as well as a low potential for both on and offsite environmental consequences. Interestingly, they had a mean score on the Affiliative (C2) Scale of the OCI, one of the scales which is indicative of a constructive cultural style, that was higher than that obtained for some of the other directorates which had lower passive-defensive scale scores. The directorates which exhibited profiles similar to that exhibited by the Controller Directorate were the Support and Operations Directorates. The Operations Directorate however, tended to perceive a greater potential for both on and offsite environmental consequences.

At the other end of the spectrum were the Energy and Technology, Defense Research and Applications, Chemistry and Materials, and Nuclear Weapons Technology Directorates.

These directorates scored lower on the passive-defensive scales and had a tendency towards a higher perception of management emphasis on environmental issues, as well as employee awareness of these same issues. In addition, both the Chemistry and Materials and Nuclear Weapons Technology Directorates had high mean values on those scales which were indicative of more hazardous woik.

\subsubsection{Differences Between the LANL Staff Classifications on the OS Scales}

\subsubsection{Differences Between the LANL Staff Classifications on the OCI Scales}

Figure 4.53 depicts the statistically significant differences obtained between the LANL Staff Classifications on the Humanistic-Encouraging (C1) Scale. The Technical Support Staff Classification had the lowest mean value on this scale and was statistically significantly different from both the Specialist Staff and the Office Support Staff Classifications. The Office Support Staff Classification had the highest mean value on this question. No other statistically significant differences between the LANL Staff Classifications were obtained on this scale.

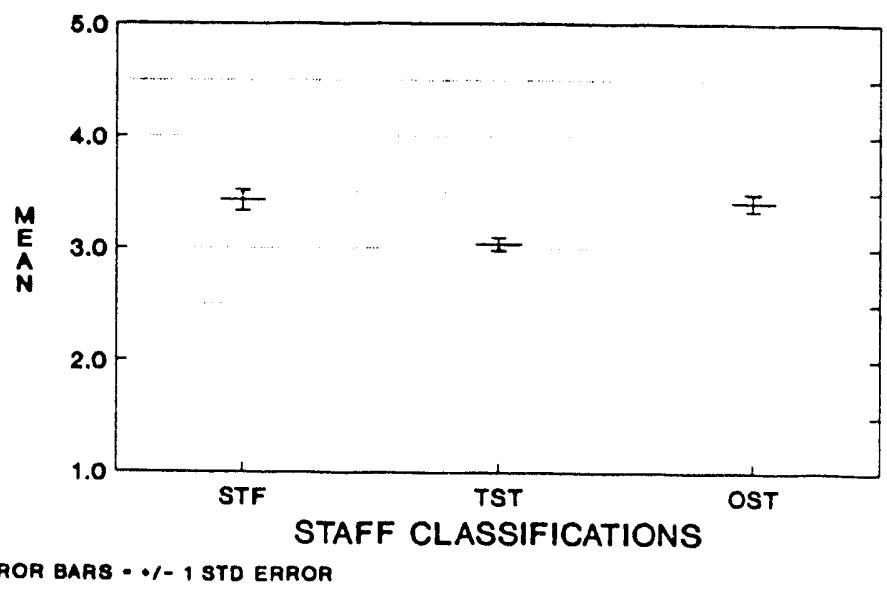

Figure 4.53. Significant differences between LANL staff classifications on the humanisticencouraging scale 
The statistically significant differences between the LANL Staff Classifications on the Affiliative (C2) Scale are depicted in Figure 4.54. The Office Support, which had the highest mean value on this scale, and General Staff Classifications were statistically significantly different from the Technical Staff and Technical Support Staff Classifications, both of which had the lowest mean values. No other statistically significant differences between LANL Staff Classifications were obtained on this scale.

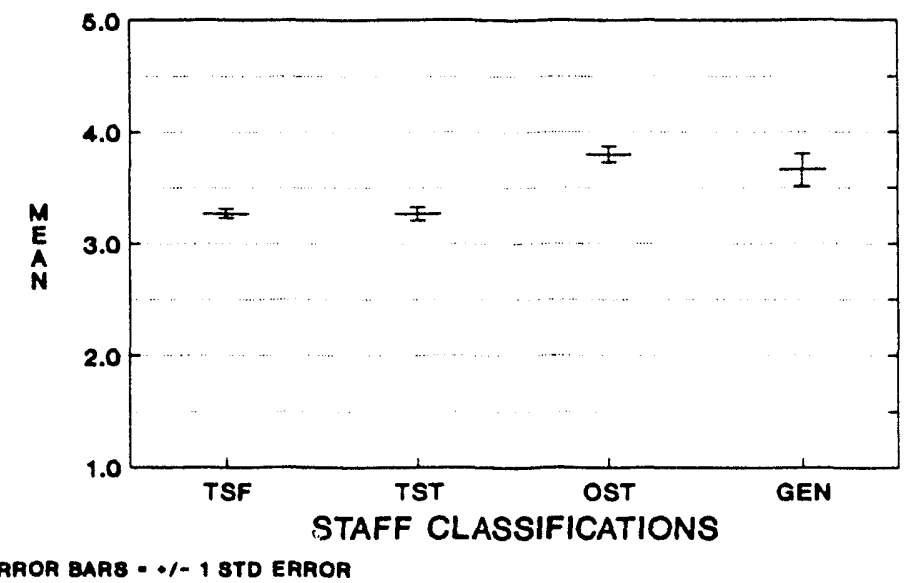

Figure 4.54. Significant differences between LANL staff classifications on the affiliative scale

On the Approval (C3) Scale, the General Staff Classification had a statistically significantly higher mean value than the Technical Staff, which had the lowest mean value, the Specialist Staff, and the Technical Support Staff Classifications (Figure 4.55). Other statistically significant differences between the LANL Staff Classifications on this scale are presented in Appendix K.

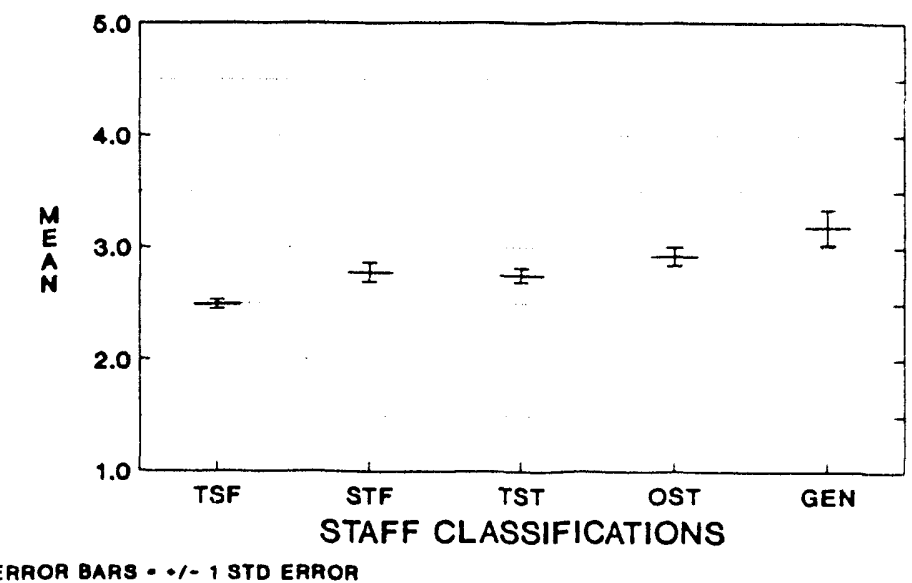

Figure 4.55. Significant differences between LANL staff classifications on the approval scale

On the Conventional (C4) Scale, the Technical Staff Staff Classification had the lowest mean value and was statistically significantly different from the Technical Support, Office Support, and General Staff Classifications (Figure 4.56). The General Staff Classification had the highest mean value on this scale. 


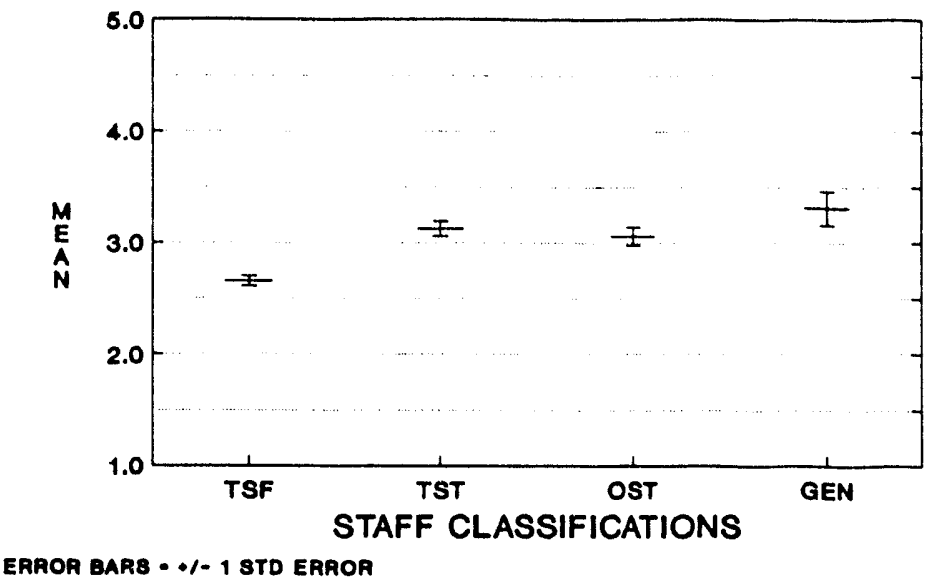

Figure 4.56. Significant differences between LANL staff classifications on the conventional scale

The statistically significant differences between the LANL Staff Classifications on the Dependent (C5) Scale are presented in Figure 4.57. The Technical Staff Staff Classification had the lowest mean value on this scale and was statistically significantly different from the Technical Support, Office Support, and General Staff Classifications. The General Staff Classification had the highest mean value on this scale and was also statistically significantly different from the Specialist Staff Staff Classification.

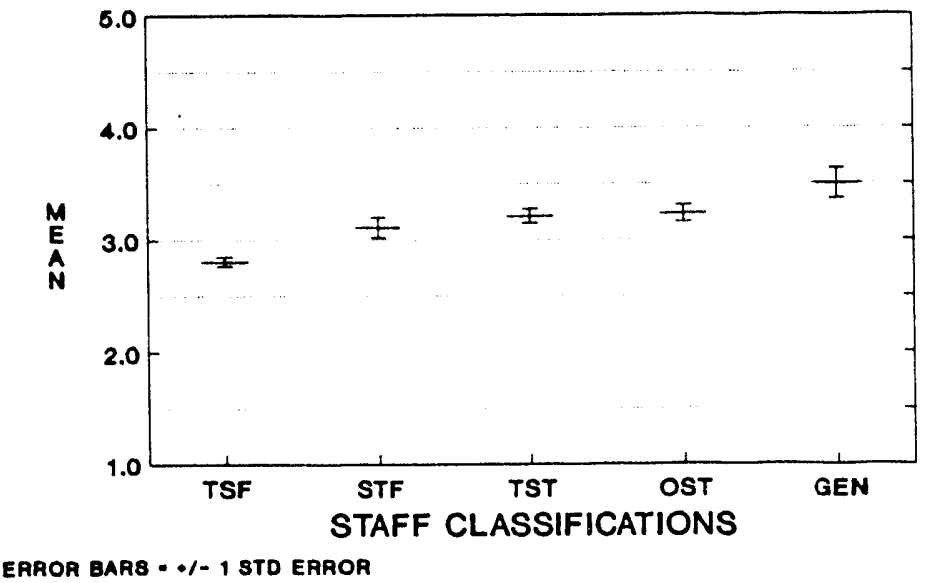

Figure 4.57. Significant differences between LANL staff classifications on the dependent scale

No statistically significant differences were obtained between the LANL Staff Classifications on the Avoidance (C6), Oppositional (C7), Power (C8), or Competition (C9) Scales. The mean value obtained for each LANL Staff Classification on each of these scales are contained in Appendix K.

Statistically significant differences between the LANL Staff Classifications on the Perfectionistic (C10) Scale are presented in Figure 4.58. The General Staff Classification had the highest mean value on this scale and was statistically significantly different from every other LANL Staff Classification. The Technical Staff Staff Classification had the lowest mean value on this question. 


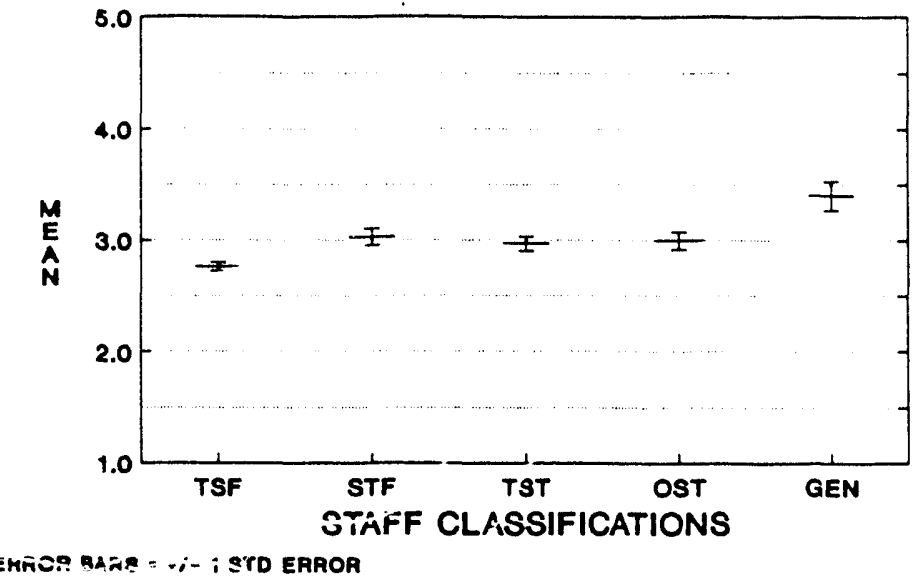

Figure 4.58. Significant differences between LANL staff classifications on the perfectionistic scale

No statistically significant differences were found between the LANL Staff Classifications on either the Achievement $(\mathrm{C} 11)$ or Self-Actualizing (C12) Scales. Appendix K contains the mean values obtained for each staff classification on both of these scales.

\subsubsection{Differences Between the LANL Staff Classifications on the Communication Scales}

Statistically significant differences between the LANL Staff Classifications were obtained on two of the four Communication Scales: Communication-Accuracy, and Communication-Interaction. The mean values obtained for each staff classification on the other Communication Scales (Trust and Satisfaction) are contained in Appendix K.

Figure 4.59 presents the statistically significant differences obtained between the LANL Staff Classifications on the Communication - Accuracy Scale. The Technical Staff Staff Classification had the highest mean value on this scale and was statistically significantly different from the Technical Support and General Staff Classifications. The General Staff Classification had the lowest mean value on this scale and was statistically significantly different from the Specialist Staff and Office Support, as well as from the Technical Staff, Staff Classifications.

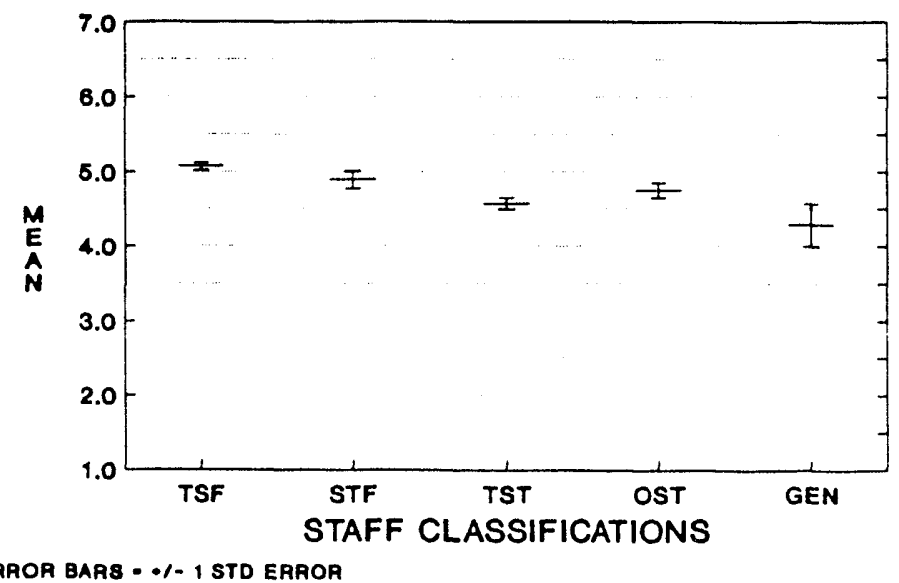

Figure 4.59. Significant differences between LANL staff classifications on the communication-accuracy scale 
Statistically significant differences between the LANL Staff Classifications on the CommunicationInteraction Scale are presented in Figure 4.60. The Technical Support Staff Classification had the lowest mean value on this scale and was statistically significantly different from the Technical Staff and Specialist Staff Staff Classifications. The Specialist Staff Staff Classification had the highest mean value on this scale and was statistically significantly different from the General, as well as from the Technical Support, Staff Classifications.

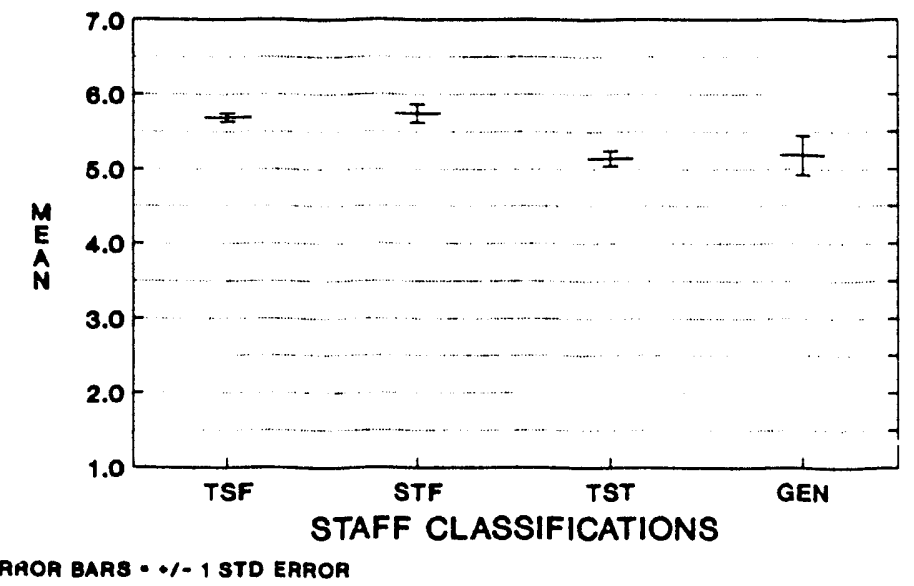

Figure 4.60. Significant differences between LANL staff classifications on the communicationinteraction scale

\subsubsection{Differences Between the LANL Staff Classifications on the Additional Scales}

Statistically significant differences between the LANL Staff Classifications were obtained on only one of the additional scales: the Hazard Scale. The mean values obtained for each of the LANL Staff Classifications on the other additional scales are contained in Appendix K.

Figure 4.61 depicts the statistically significant differences obtained between the I,ANL Staff Classifications on the Hazard Scale. The Technical Support Staff Classification had the highest mean value on this scale and was statistically significantly different from every other LANL Staff Classification. The Specialist Staff Staff Classification had the lowest mean value on this scale and was statistically significantly different from the Technical Staff, as well as from the Technical Support, Staff Classifications. Other statistically significant differences obtained between the LANL Staff Classifications on the Hazard Scale are presented in Appendix K.

\subsubsection{Differences Between the LANL Staff Classifications on the Environment, Safety, and Health Questions}

Statistically significant differences between the LANL Staff Classifications were obtained on two of the four Environment, Safety, and Health Questions: Onsite Environmental Consequences and Offsite Environmental Consequences Questions. The mean values for the LANL Staff Classifications on both the Management Emphasis and the Employee Awareness Questions are presented in Appendix K. 


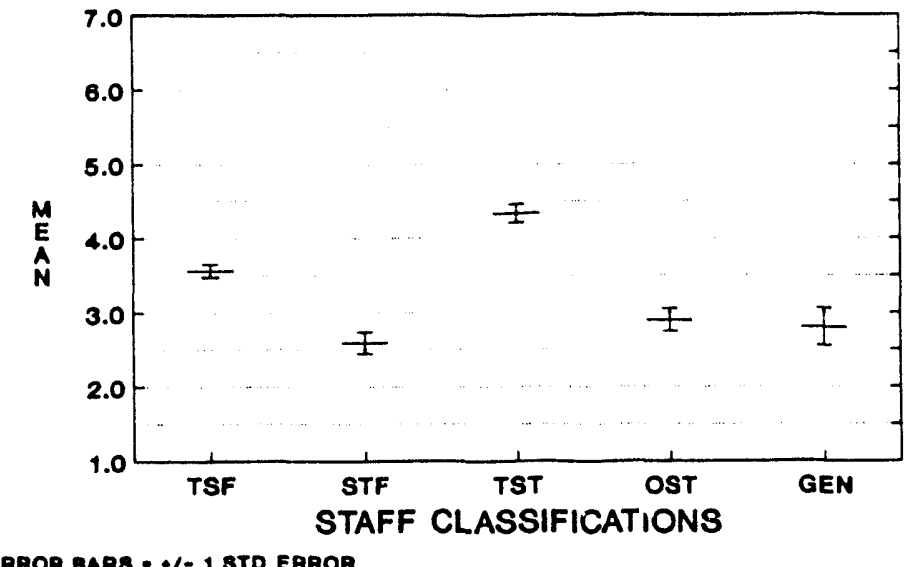

Figure 4.61. Significant differences between LANL staff classifications on the hazard scale

Figure 4.62 presents the statistically significant differences obtained between the LANL Staff Classifications on the Offsite Environmental Consequences Question. The Specialist Staff Staff Classification had the lowest mean value on this question, and was statistically significantly different from the Technical Support and Office Support Staff Classifications. The Technical Support Staff Classification had the highest mean value on this question and was statistically significantly different from the General, as well as from the Specialist Staff, Staff Classifications.

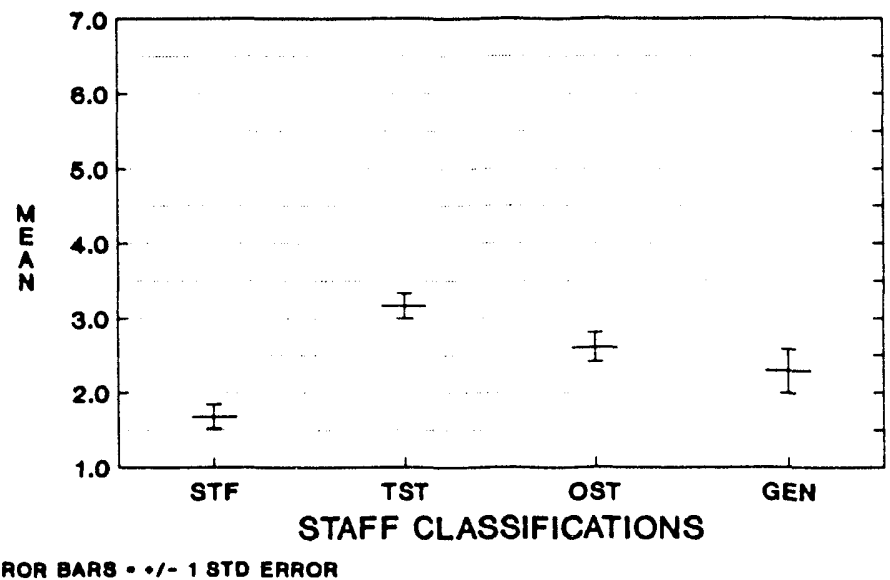

Figure 4.62. Significant differences between LANL staff classifications on the offsite environmental consequences question

Statistically significant differences between the LANL Staff Classifications on the Onsite Environmental Consequences Question are presented in Figure 4.63. The Technical Support, which had the highest mean value on this question, and Technical Staff Staff Classifications wcre statistically significantly different from both the Specialist Staff, which had the lowest mean value on this question, and General Staff Classifications. 


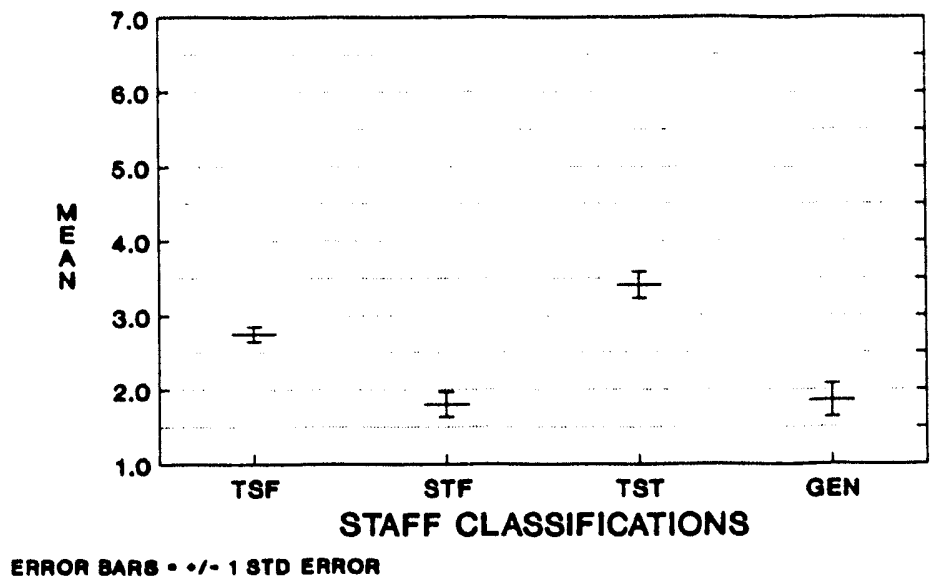

Figure 4.63. Significant differences between LANL staff classifications on the onsite environmental consequences question

\subsubsection{Summary}

Both the Technical Staff and Specialist Staff Staff Classifications exhibited profiles on the OCI which were low on those scales which comprise the passive-defensive cultural style, while the Office Support and General Staff Classifications exhibited profiles which were higher on these same scales. In addition, the General Staff Classification differed from every other staff classification on the Perfectionistic (C10) Scale, scoring statistically significantly lower. Both the Technical Staff and Specialist Staff Staff Classificatious had higher mean values on the Communication-Accuracy and Communication-Interaction Scales. The Technical Support and General Staff Classifications scored lower on these same scales.

\subsubsection{Differences Between the LANL Supervisory Levels on the OS Scales}

The demographics sheet utilized included four categories of supervisory levels for LANL respondents to categorize themselves into. This section discusses the results obtained when these four levels were compared on each of the OS Scales. In addition, analyses were conducted in which three of the supervisory levels were combined into one group called managers and compared to the non-manager category. This section will also present the results of these analyses.

\subsubsection{Differences Between the LANL Supervisory Levels on the OS Scales}

Statistically significant differences between the four LANL Supervisory Levels on the HumanisticEncouraging (C1) Scale are presented in Figure 4.64. The Non-Manager Level had a statistically significantly lower mean value on this scale than every other supervisory level in the LANL Organization. The Division and Above Level had the highest mean value on this scale.

When the three supervisory levels were combined into one group called managers and compared to non-managers on the Humanistic-Encouraging (C1) Scale, the managers had a statistically significantly higher mean value than the non-managers. This difference is depicted in Figure 4.65. 


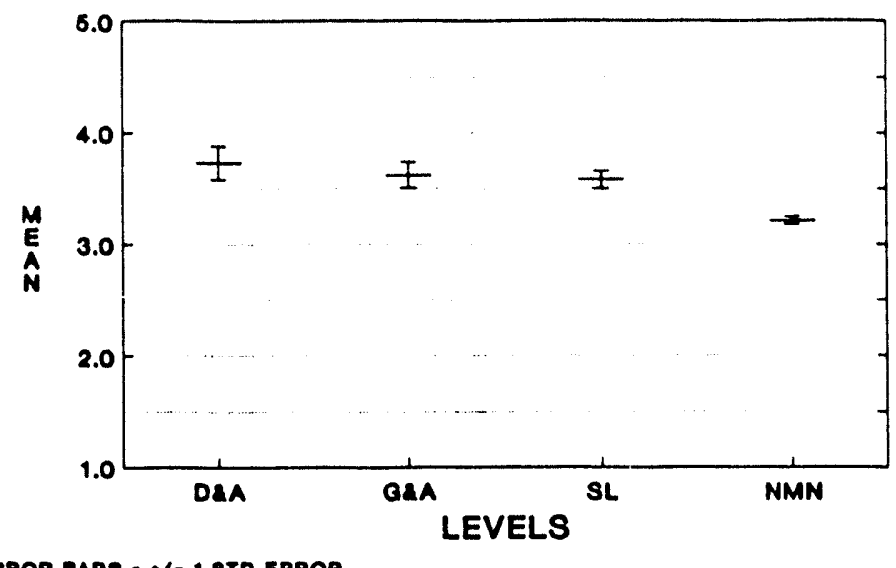

EHAOR DARS - -1- 1 STO EAROA

Figure 4.54. Significant differences between LANL supervisory levels on the humanistic-encouraging scale

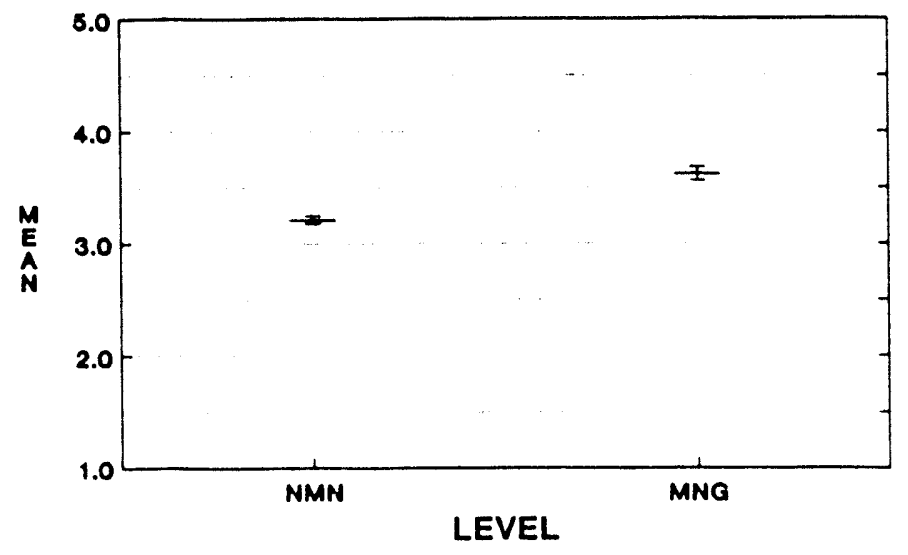

ERROR BARB - ./. I STO EAROR

Figure 4.65. Significant differences between LANL managers and non-managers on the humanistic-encouraging scale

No statistically significant differences were obtained between the LANL Supervisory Levels or between the LANL managers and non-managers on the Affiliative (C2) Scale. Appendix L contains the mean values obtained for each of the LANL Supervisory Levels on this scale. Appendix M contains the mean values obtained for LANL managers and non-managers on this scale.

Statistically significant differences between the LANL Supervisory Levels on the Approval (C3) Scale are presented in Figure 4.66. The Division and Above Level had a statistically significantly lower mean value on this scale than the Non-Manager Level.

When the three supervisory levels were collapsed into one group of managers and compared to nonmanagers, the managers had a statistically significantly lower mean value on this scale than the non-managers. This difference is depicted in Figure 4.67.

Figure 4.68 presents the statistically significant differences obtained be ween the LANL Supervisory Levels on the Conventional (C4) Scale. The non-managers had the highest mean value on this scale and were 
statistically significantly different from both the Division and Above, and Group and Above Supervisory Levels. The Division and Above Supervisory Level had the lowest mean value on this scale.

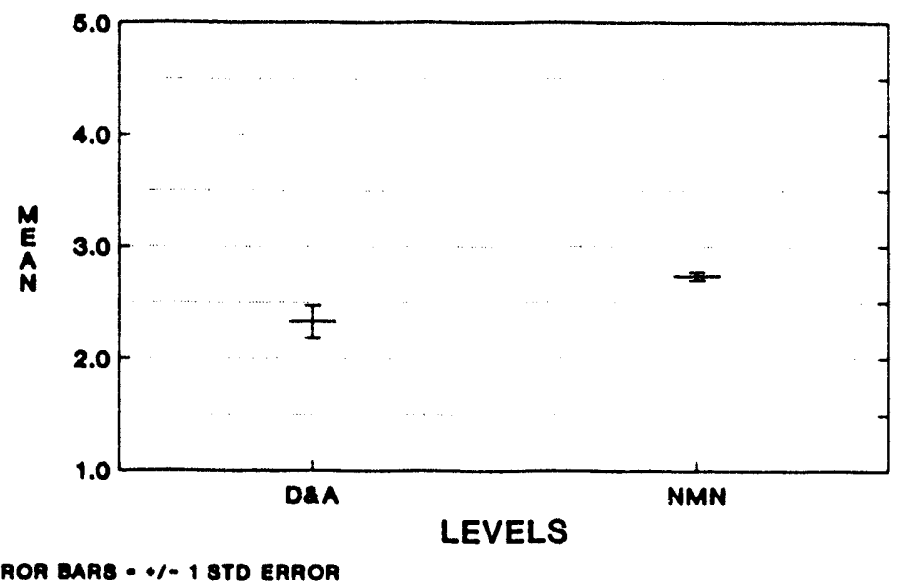

Figure 4.66. Significant differences between LANL supervisory levels on the approval scale

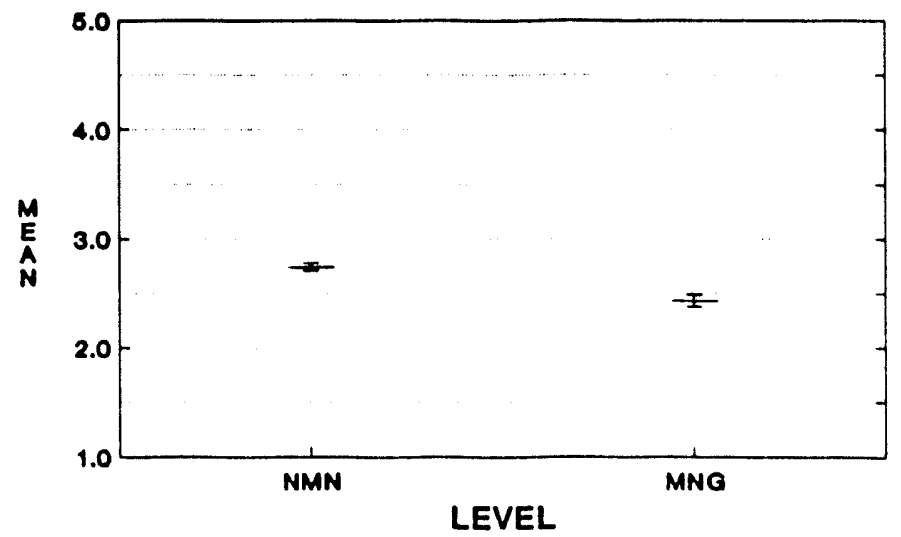

ERAOA BARB - * 1 STO ERROR

Figure 4.67. Significant differences between LANL managers and non-managers on the approval scale

Statistically significant differences between the manager group (formed from the three levels of supervisors) and non-manager group on the Conventional (C4) scale are presented in Figure 4.69. The nonmanagers had a statistically significantly higher mean value on this scale than the managers.

Figure 4.70 presents the statistically significant differences between the LANL Supervisory Levels on the Dependent (C5) Scale. The non-managers had the highest mean value on this scale and were statistically significantly different from both the Division and Above, which had the lowest mean value, and Group and Above Supervisory Levels. 


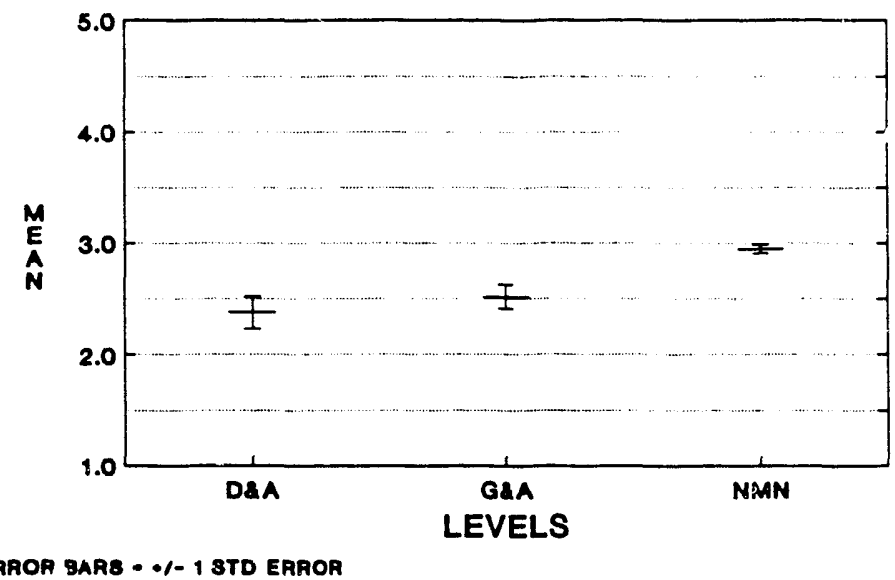

Figure 4.68. Significant differences between LANL supervisory levels on the conventional scale

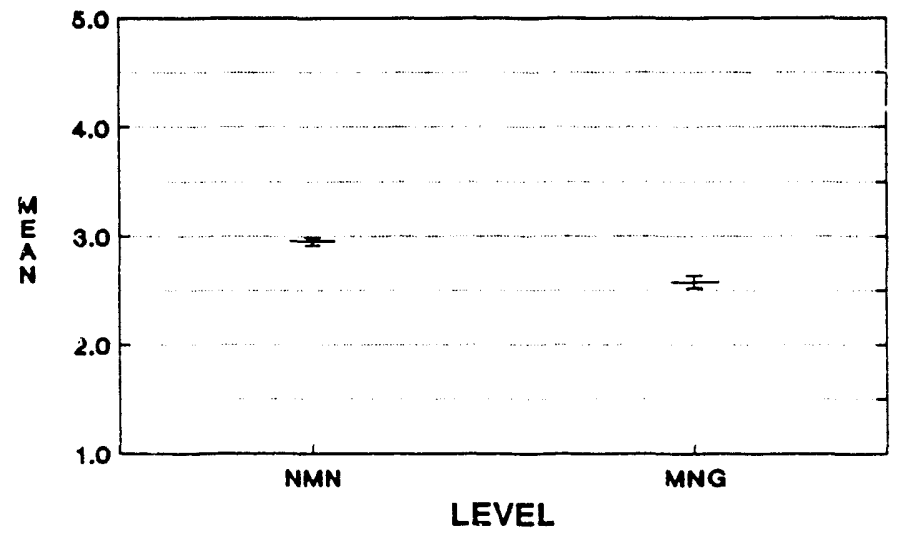

ERROR BARS - *1- 1 STO ERROA

Figure 4.69. Significant differences between LANL managers and non-managers on the conventional scale

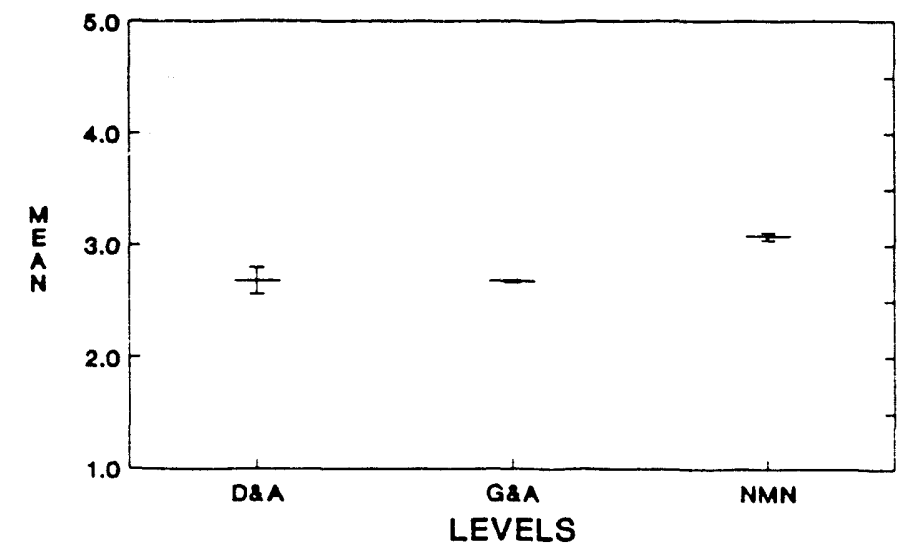

ERAOR BARS - -1- 1 STD ERROR

Figure 4.70. Significant differences between LANL supervisory levels on the dependent scale 
When the three levels of supervisors at LANL were collapsed into one group of managers and sompared to the non-managers on the Dependent (C5) Scale, the non-managers had a statistically significantly higher mean value than the managers. This difference is depicted in Figure 4.71.

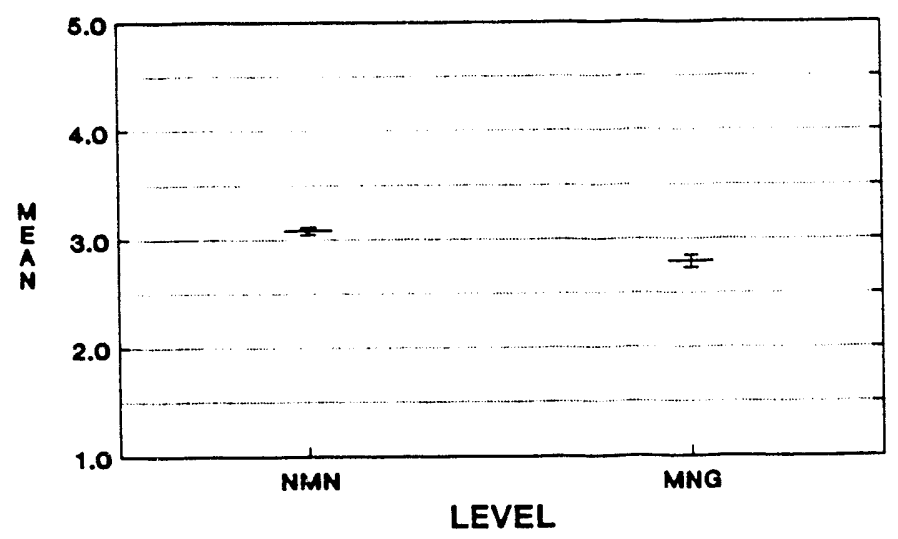

ERPOR BARS - •/- 1 STD ERROR

Figure 4.71. Significant differences between LANL managers and non-managers on the dependent scale

No statistically significant differences were obtained when the LANL Supervisory Levels were compared on the Avoidance (C6), Oppositional (C7), Power (C8), Competition (C9), or Perfectionistic (C10) Scales. The mean values obtained for each level on each of these scales are contained in Appendix L. Additionally, no statistically significant differences were found on these same scales when the three levels of supervisors were combined into one group called rnanagers and compared to the non-managers. Appendix $M$ contains the mean values obtained for both managers and non-managers on these scales.

Statistically significant differences between the LANL Supervisory Levels on the Achievement (C11) Scale are presented in Figure 4.72. The Division and Above Level had the highest mean value on this scale and was statistically significantly different from the Non-Manager level.

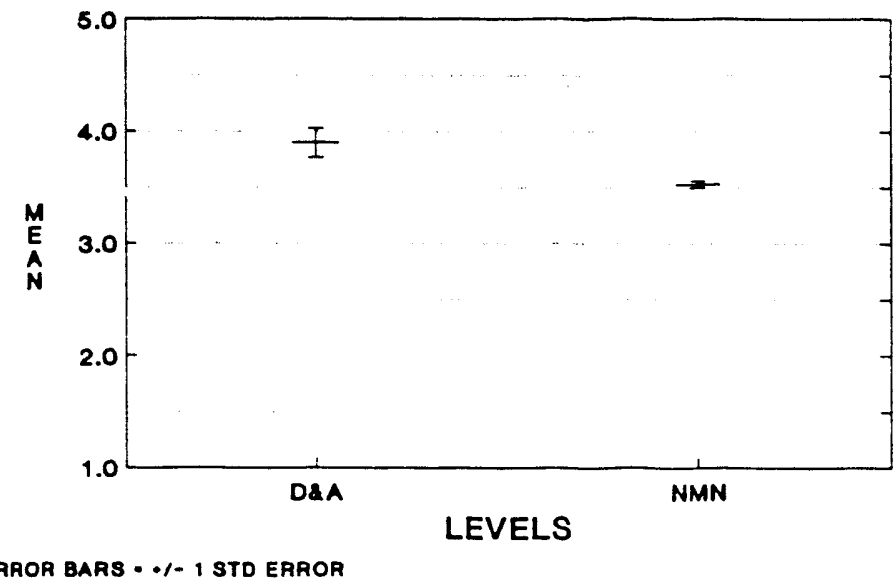

Figure 4.72. Significant differences between LANL supervisory levels on the achievement scale 
Figure 4.73 presents the statistically significant differences obtained when the three supervisory levels were combined into one group of managers and compared to non-managers on the Achievement (C11) Scale. The non-managers had a statistically significantly lower mean value on this scale than the managers.

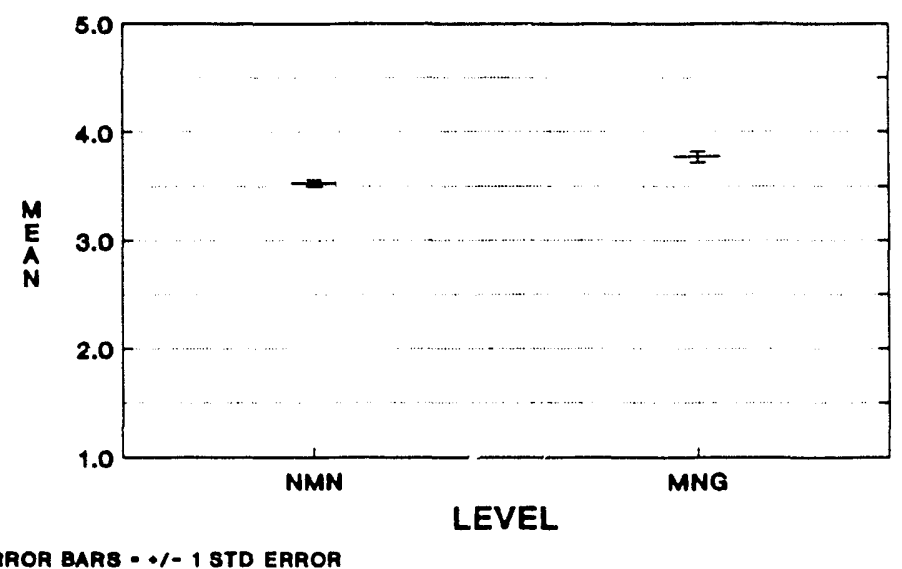

Figure 4.73. Significant differences between LANL managers and non-managers on the achievement scale

Statistically significant differences between the LANL supervisory levels on the Self-Actualizing $(\mathrm{C} 12)$ Scale are depicted in Figure 4.74. The Non-Manager Level had the lowest mean value on this scale and was statisticaily significantly different from the Division and Above Level.

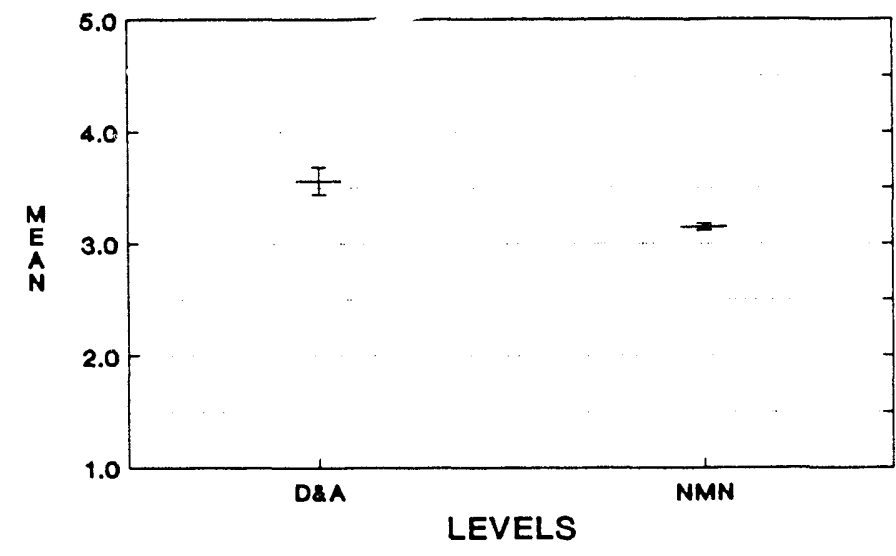

ERROR BARS - */- 1 STD ERROR

Figure 4.74. Significant differences between LANL supervisory levels on the self-actualizing scale

When the three levels of supervisors were combined into one group called managers and compared to non-managers on the Self-Actualizing (C12) Scale, managers had a statistically significantly higher mean value than non-managers. This difference is presented in Figure 4.75 . 


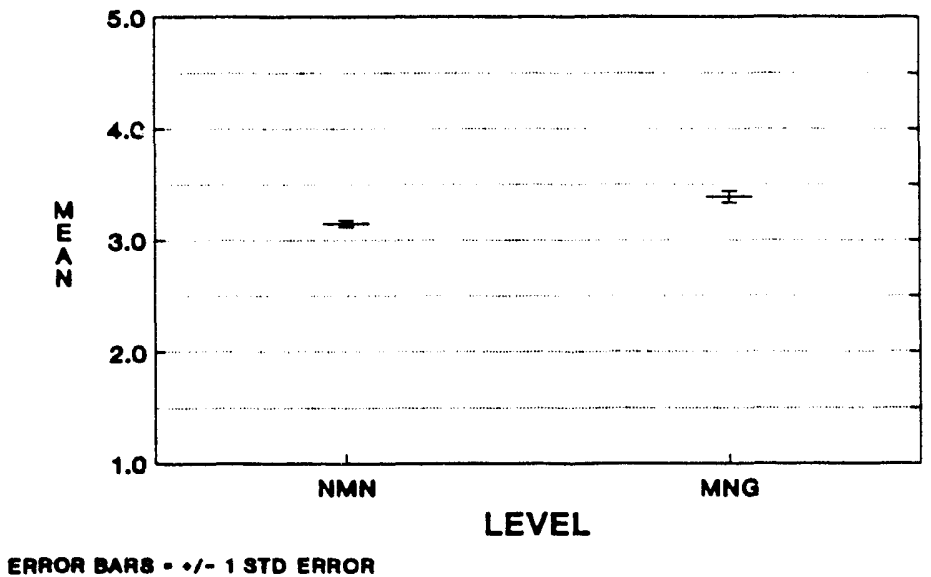

Figure 4.75. Significant differences between LANL managers and non-managers on the self-actualizing scale

\subsubsection{Differences Between the LANL Supervisory Levels on the Communication Scales}

Statistically significant differences between the LANL Supervisory Levels and between managers and non-managers were obtained on two of the four Communication Scales, Communication-Accuracy and Communication-Interaction. The mean results obtained for the LANL Supervisory Levels and for the LANL Managers and Non-Managers on the Communication-Trust and the Communication-Satisfaction Scales are contained in Appendices $L$ and $M$, respectively. Figure 4.76 presents the statistically significant differences found between LANL Supervisory Levels on the Communication-Accuracy Scale. The Division and Above Level had a statistically significantly higher mean value on this scale than the Non-Manager Level.

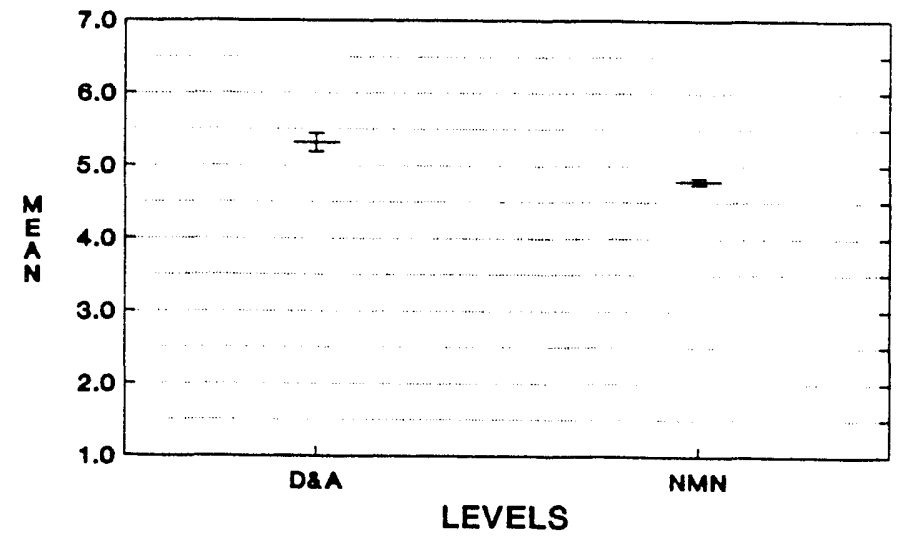

ERROR BARS - -/ - 1 STO ERROR

Figure 4.76. Significant differences between LANL supervisory levels on the communication-accuracy scale

Statistically significant differences between the LANL managers and non-managers on the Communication-Accuracy Scale are depicted in Figure 4.77. The managers had a statistically significantly higher mean value on this scale than the non-managers. 


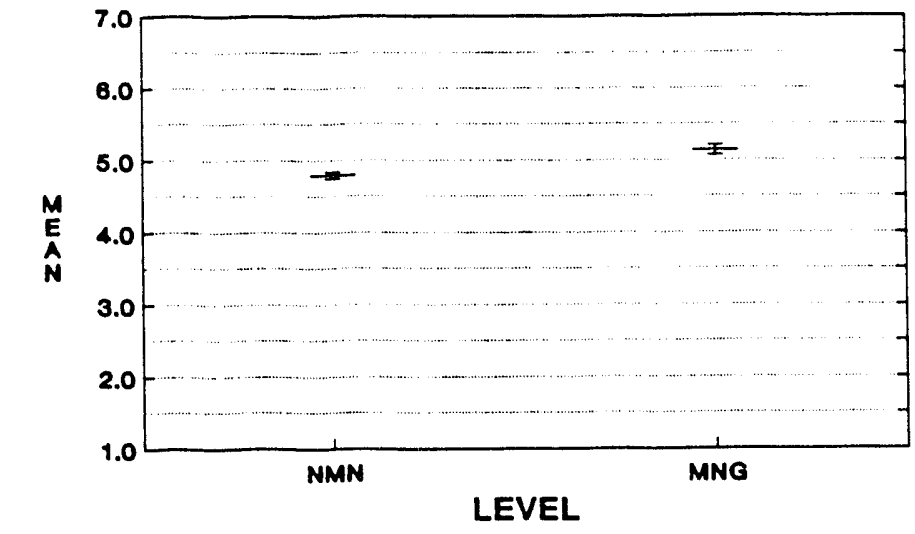

ERROR BARS - */- 1 STO ERROR

Figure 4.77. Significant differences between LANL managers and non-managers on the communication-accuracy scale

Statistically significant differences between the LANL Supervisory Levels on the CommunicationInteraction Scale are depicted in Figure 4.78. The Division and Above Level had a statistically significantly higher mean value on this scale than the Non-Manager Level.

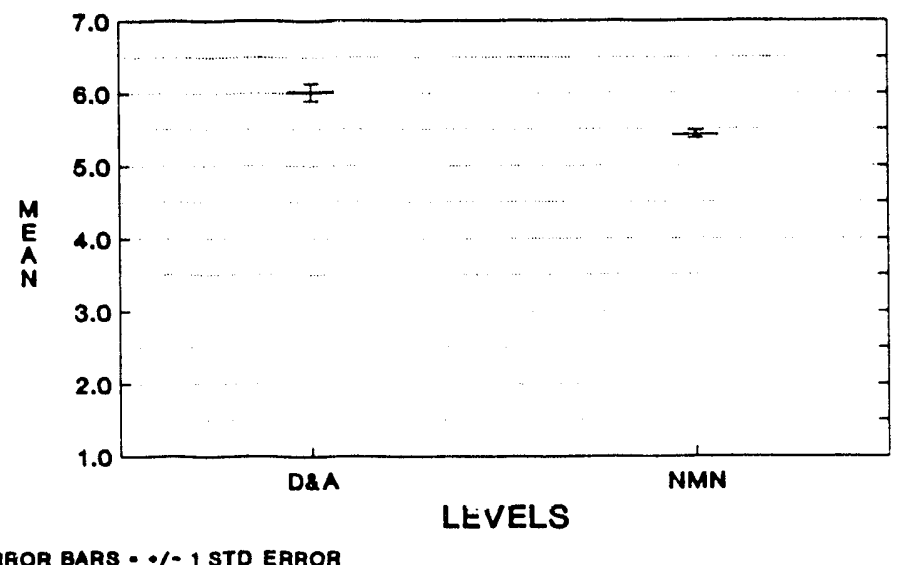

Figure 4.78. Significant differences between LANL supervisory levels on the communication-interaction scale

Figure 4.79 presents the statistically significant differences obtained on the Communication Interaction Scale when the three supervisory levels were combined into one group and compared to the nonmanager level. The managers had a statistically significantly higher mean value on this scale than the nonmanagers.

\subsubsection{Differences Between the LANL Supervisory Levels on the Additional Scales}

Statistically significant differences between the LANL Supervisory Levels on the Commitment Scale are depicted in Figure 4.80. The Division and Above Level had a statistically significantly higher mean value on this scale than the Non-Manager Level. 


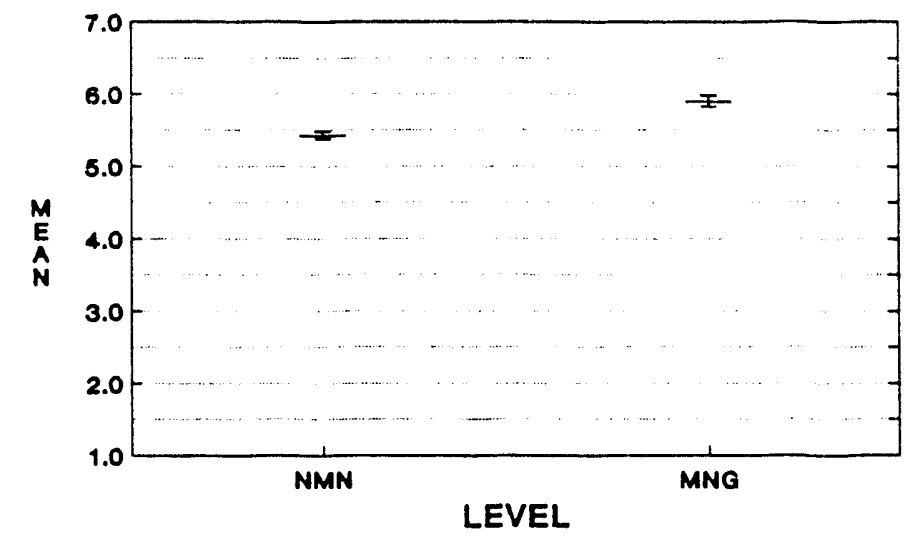

EAROR BARB - - 1 - 8 TO ERAOR

Figure 4.79. Significant differences between LANL managers and non-managers on the communication-interaction scale

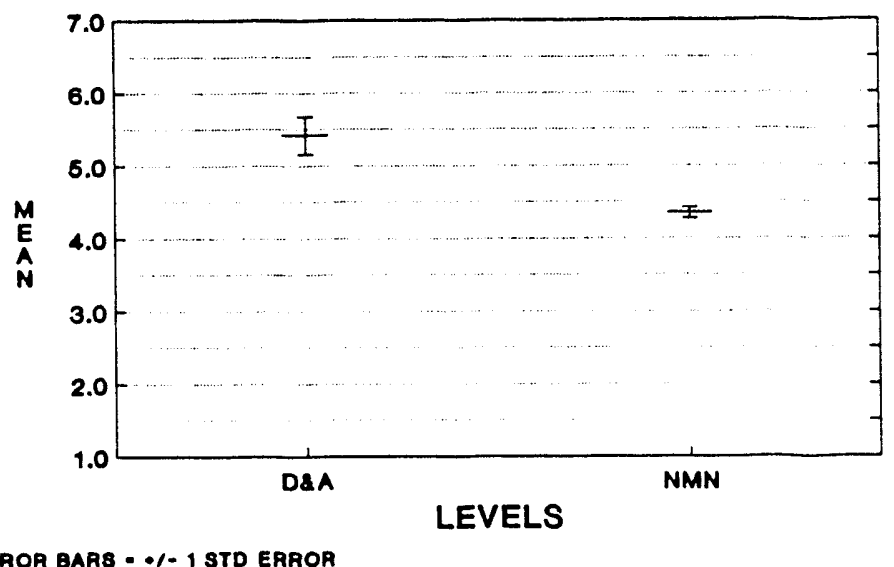

Figure 4.80. Significant differences between LANL supervisory levels on the commitment scale

When the three supervisory levels were combined into one group called managers and compared to the non-managers on the Commitment Scale, the managers had a statistically significantly higher mean value on this scale than the non-managers. Figure 4.81 depicts this result.

Statistically significant differences between the LANL Supervisory Levels on the Cohesion Scale are depicted in Figure 4.82. The Group and Above Level had a statistically significantly higher mean value on this scale than the Non-Manager Level.

Figure 4.83 presents the statistically significant differences on the Cohesion Scale when the three supervisory levels were combined into one group called managers and compared to the non-managers. The non-managers had a statistically significantly lower mean value on this scale than the managers.

No statistically significant differences between the LANL Supervisory Levels were obtained on any of the other additional scales (i.e., Hazard, Coordination, Job Satisfaction). Appendix L contains the mean values obtained for each level on each of these scales. 


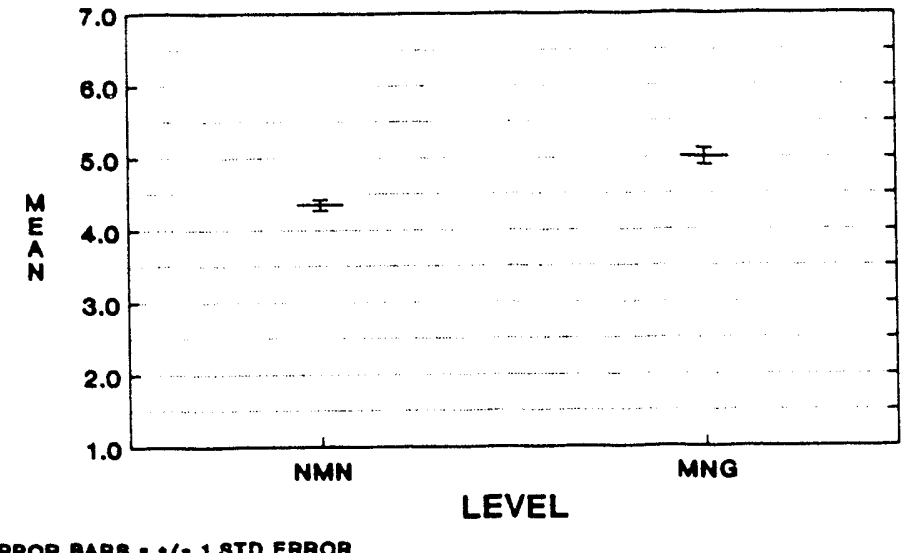

ERAOP BARS - -1- 1 STD ERROA

Figure 4.81. Significant differences between LANL managers and non-managers on the commitment scale

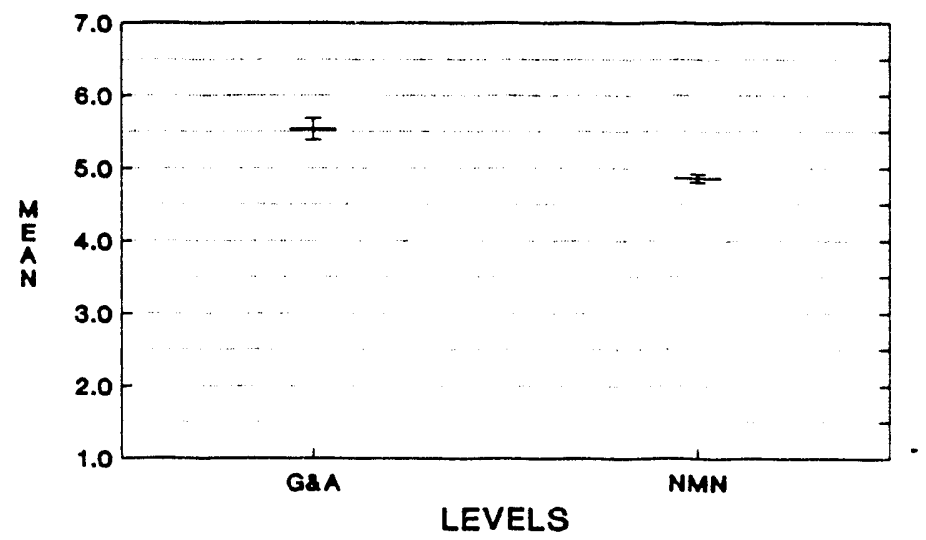

ERAOR BARB - - / 1 STO ERAOR

Figure 4.82. Significant differences between LANL supervisory levels on the cohesion scale

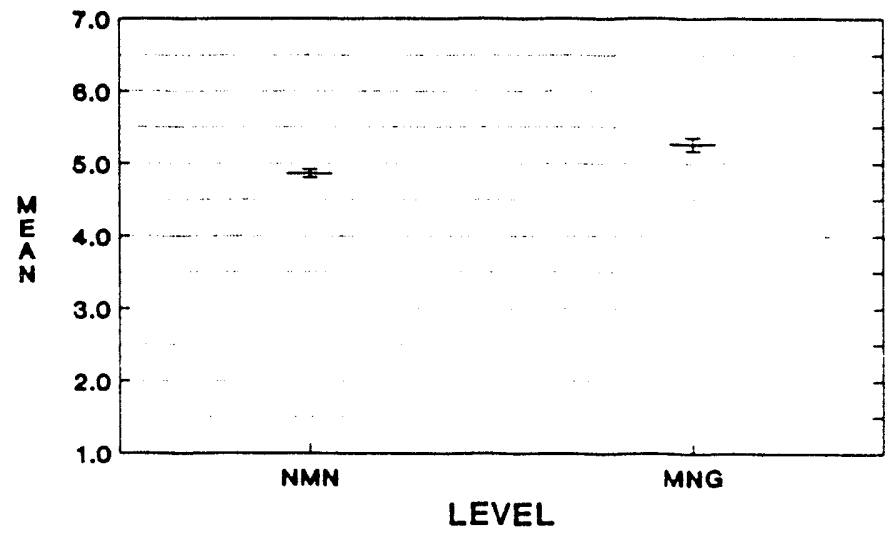

ERAOR BARS - - / I STO ERROR

Figure 4.83. Significant differences between LANL managers and non-managers on the cohesion scale 
No statistically significant differences were found on either the Hazard, Coordination, or Job Satisfaction Scales when the three levels of supervisors were combined into one group called managers and compared to the non-managers. The mean values for each of the groups on these scales are contained in Appendix M.

However, when the group of managers (comprised of the three supervisory levels) were compared to the group of non-managers on the Safety Scale, the non-managers had a statistically significantly lower mean value on this scale than the managers. These results are presented in Figure 4.84.

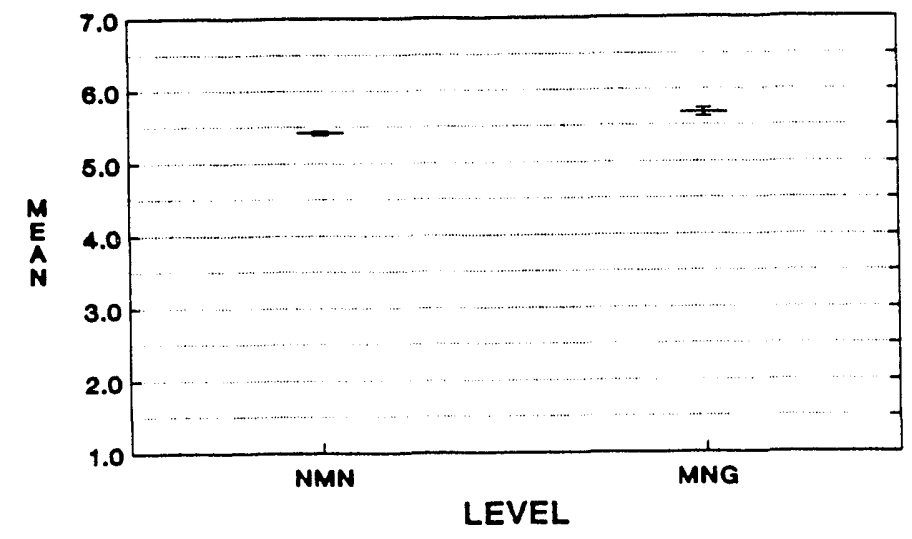

ERROR BARS - •/- 1 BTD ERAOR

Figure 4.84. Significant differences between LANL managers and non-managers on the safety scale

\subsubsection{Differences Between the LANL Supervisory Levels on the Environment, Safety, and Health Questions}

No statistically significant differences were obtained on any of the Environment, Safety, and Health Questions when the LANL Supervisory Levels were compared to one another. The results obtained for each level on each of the four questions are contained in Appendix L.

When the three levels of supervisors at LANL were combined into one group called managers and compared to the group of non-managers, statistically significant differences were obtained only on the Employee Awareness Environment, Safety, and Health Question. The mean values obtained for managers and non-managers on the other three Environment, Safety, and Health Questions are contained in Appendix M.

Figure 4.85 presents the statistically significant differences obtained between managers and nonmanagers on the Employee Awareness Question. The non-managers had a statistically significantly lower mean value on this question than the managers.

\subsubsection{Summary}

The statistically significant differences obtained on the analyses involving LANL Supervisory Levels and Managers versus Non-Managers are consistent with the literature and with results obtained at other DOE facilities. One interesting result is the lack of statistically significant differences found between Section Leaders and Non-Managers. On only one scale were statistically significant differences obtained between these two groups, on the Humanistic-Encouraging ( $\mathrm{Cl}$ ) Scale. In addition, the differences obtained on the 
OCI Scales as well as on the Communication Scales and additional scales suggest that the Non-Manager LANL employees scored lower on those scales which make up the "constructive" cultural style, and higher on those scales which make up the "passive-defensive" cultural style. No statistically significant differences were found between supervisory levels on the $\mathrm{OCI}$ scales which comprise the "aggressive-defensive" cultural style.

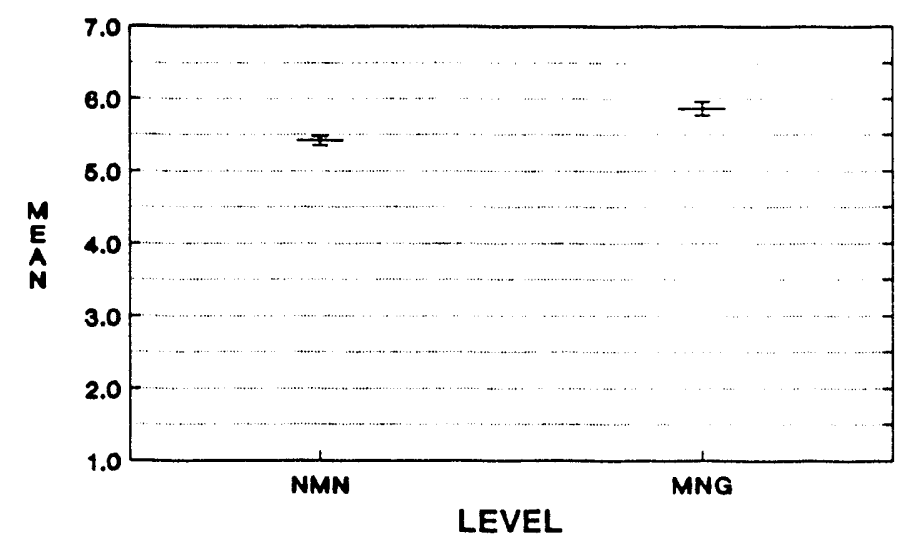

ERAOR BARB $\cdots /-1$ STD ERROR

Figure 4.85. Significant differences between LANL managers and non-managers on the employee awareness question

\subsection{Differences Within the Johnson Controls Organization on the OS Scales}

This section discusses the statistically significant differences obtained within the Johnson Controls Organization on the OS Scales. Specifically, differences between (a) departments within the Johnson Controls Organization; (b) staff classifications within the Johnson Controls Organization; and (c) supervisory levels within the Johnson Controls Organization, are discussed. Note that while six supervisory levels were provided for Johnson Controls employees on the background information sheet, most did not have enough respondents to allow meaningful statistical analyses to be conducted. For this reason, the five levels of supervisors were combined into one group called managers and compared to the supervisory level of non-manager for all analyses of supervisory level.

\subsubsection{Differences Between the Johnson Controls Departments on the OS Scales}

Two departments were provided on the background information sheet for Johnson Controls employees to categorize themselves into: Operations and Administration.

\subsubsection{Differences Between the Johnson Controls Departments on the OS Scales}

No statistically significant differences were obtained between the two Johnson Controls Departments on any of the OCI Scales. Appendix N contains the mean values obtained by each department on each of the OCI Scales, as well on all other scales in the OS. Additionally, Appendix O contains figures which compare the mean value obtained by each Johnson Controls Department to the overall mean value obtained for the Johnson Controls Organization on the OCI Scales. 


\subsubsection{Differences Between the Johnson Controls Departments on the Communication Scales}

No statistically significant differences were obtained between the two Johnson Controls Departments on any of the Communication Scales. Appendix $N$ contains the mean values obtained by each Johnson Controls Department on each of the Communication Scales. Additionally, Appendix P presents figures which compare the mean value obtained by each Johnson Controls Department to the overall mean value obtained for the Johnson Controls Organization on the Communication Scales.

\subsubsection{Differences Between the Johnson Controls Departments on the Additional Scales}

Statistically significant differences between the Johnson Controls Departments occurred on only one of the additional scales: the Hazard Scale. Appendix $N$ contains the mean values obtained for each department on this as well as on all other scales. Appendix $\mathrm{Q}$ presents figures which compare the mean values for the overall Johnson Controls Organization to the mean values obtained for each Johnson Controls Departments on the additional scales.

Figure 4.86 depicts the statistically significant differences obtained between the Johnson Controls Departments on the Hazard Scale. The Operations Department had a statistically significantly higher mean value on this scale than the Administration Department.

\subsubsection{Differences Between the Johnson Controls Departments on the Environment, Safety, and Health} Questions

Statistically significant differences between the Johnson Controls Departments occurred on one of the Environment, Safety, and Health Questions: Onsite Environmental Consequences. The mean values obtained for the other Environment, Safety, and Health Questions for the Johnson Controls Departments can be found in Appendix N. Appendix $\mathrm{R}$ contains the mean values for the overall Johnson Controls Organization compared to the mean values obtained for each Johnson Controls Department on the Environment, Safety, and Health Scales.

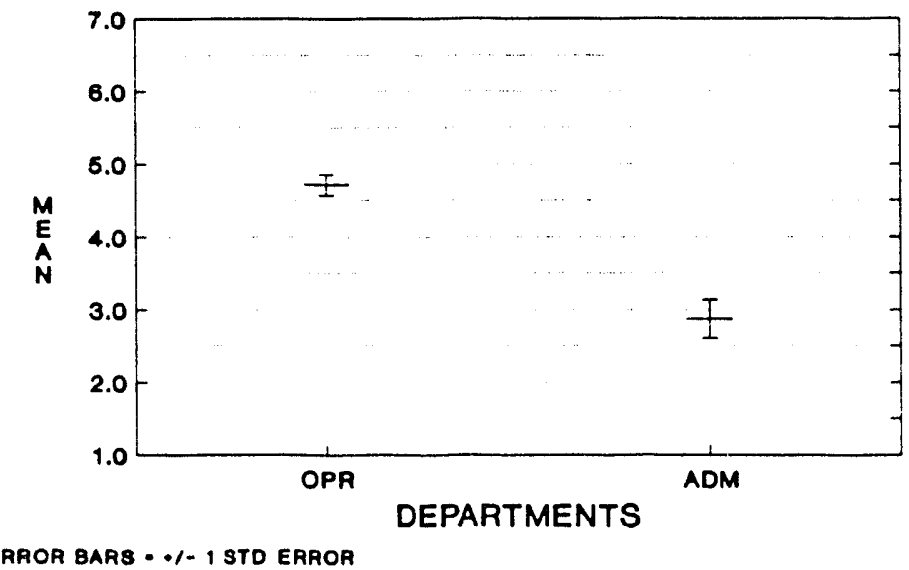

Figure 4.86. Significant differences between Johnson Controls departments on the hazard scale 
Figure 4.87 presents the statistically significant differences between the Johnson Controls Departments on the Onsite Environmental Consequences Question. The Operations Department had a statistically significantly higher mean value on this question than the Administration Department.

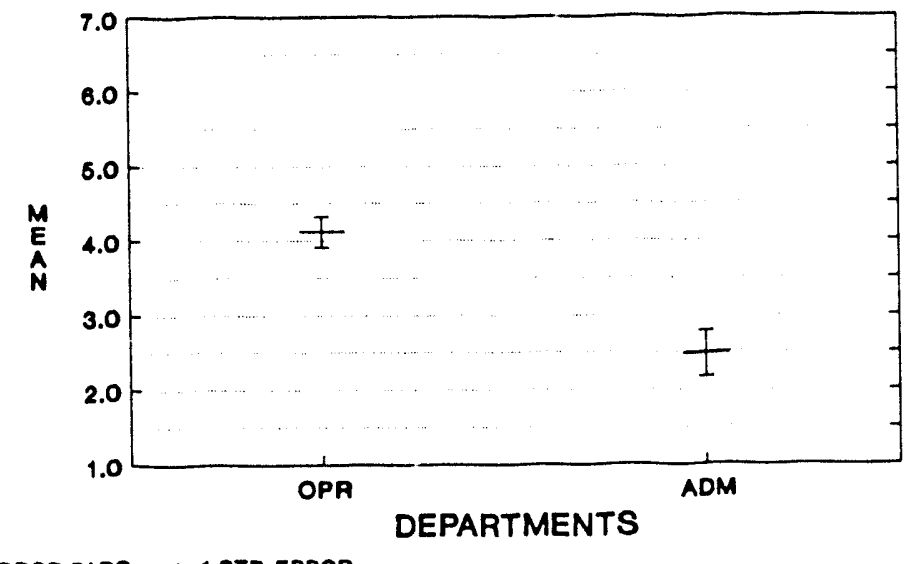

Figure 4.87. Significant differences between Johnson Controls departments on the onsite environmental consequences question

\subsubsection{Summary}

Very few statistically significant differences existed between the departments in the Johnson Controls Organization. Those which did exist make sense in that they appear related to the potential hazard associated with work at Johnson Controls.

\subsubsection{Differences Between Johnson Controls Staff Classifications on the OS Scales}

\subsubsection{Differences Between Johnson Controls Staff Classifications on the OCI Scales}

Statistically significant differences between the Johnson Controls Staff Classifications were obtained on only one of the OCI Scales: the Conventional (C4) Scale. The mean values obtained for each staff classification on the OCI Scales, as well as on all scales of the OS, are contained in Appendix S.

Figure 4.88 presents the statistically significant differences which were obtained between the Johnson Controls Staff Classifications on the Conventional (C4) Scale. The Non-Exempt Technical/Drafter Staff Classification had the highest mean value on this scale and was statistically significantly different from the Exempt Technical Staff Classification. No other statistically significant differences between the Johnson Controls Staff Classifications were obtained on this scale.

\subsubsection{Differences Between the Johnson Controls Staff Classifications on the Communication Scales}

No statistically significant differences between the Johnson Controls Staff Classifications were obtained on any of the Communication Scales. Appendix $S$ contains the me::n values obtained for each staff classification on each of the Communication Scales. 


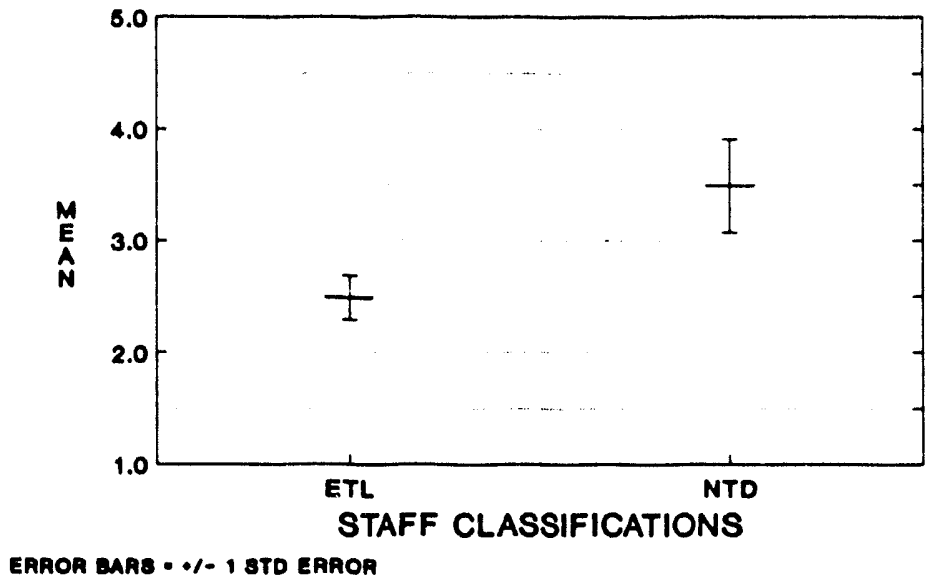

Figure 4.88. Significant differences between Johnson Controls staff classifications on the conventional scale

\subsubsection{Differences Between the Johnson Controls Staff Classifications on the Additional Scales}

Statistically significant differences between the Johnson Controls Staff Classifications were found on one of the additional scales: the Hazard Scale. The mean values obtained for each staff classification on all other additional scales are contained in Appendix S.

Statistically significant differences between the Johnson Controls Staff Classifications on the Hazard Scale are presented in Figure 4.89. The Craft Employee Staff Classification had the highest mean value on this scale and was statistically significantly different from the Exempt Administration Staff Classification. No other statistically significant differences between the Johnson Controls Staff Classifications were obtained on this scale.

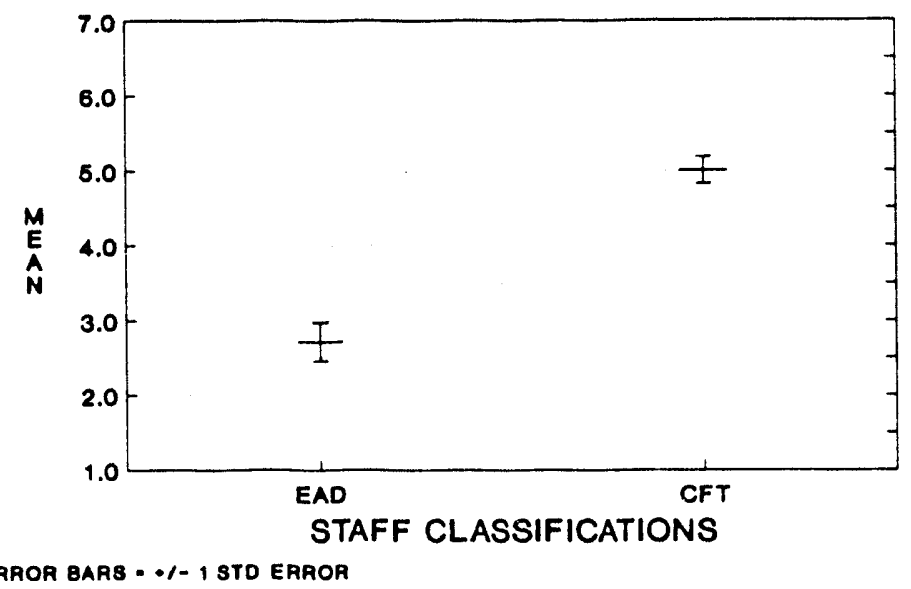

Figure 4.89. Significant differences between Johnson Controls staff classifications on the hazard scale 
4.8.2.4 Differences Between the Johnsor. Controls Staff Classifications on the Environment, Safety, and Health Questions

No statistically significant differences were obtained between any of the Johnson Controls Staff Classifications on any of the Environment, Safety, and Health Questions. Appendix S contains the mean values obtained for each staff classificaiton on cach of the four Environment, Safety, and Health Questions.

\subsubsection{Summary}

Statistically significant differences between Johnson Controls Staff Classifications were obtained on only two of the OS Scales. Thus, it appears that the various staff classifications at the Johnson Controls Organization have similar perceptions about the expectations placed on them as well as similar attitudes about their working environment.

\subsubsection{Differences Between the Johnson Controls Managers and Non-Managers on the OS Scales}

\subsubsection{Differences Between the Johnson Controls Managers and Non-Managers on the OS Scales}

No statistically significant differences were obtained between the managers and non-managers of the Johnson Controls Organization on any of the OCI Scales. Appendix T contains the mean values obtained for both managers and non-managers at Johnson Controls on each of the OCI Scales.

\subsubsection{Differences Between the Johnson Controls Managers and Non-Managers on the Communication Scales}

No statistically significant differences were obtained between the managers and non-managers of the Johnson Controls Organization on any of the Communication Scales. Appendix $\mathrm{T}$ contains the mean values obtained for Johnson Controls Managers and Non-Managers on each of the Communication Scales.

\subsubsection{Differences Between the Johnson Controls Managers and Non-Managers on the Additional Scales}

Statistically significant differences between the managers and non-managers of the Johnson Controls Organization were present on only one of the additional scales: Job Satisfaction. The mean values obtained for managers and non-managers on all other additional scales can be found in Appendix $\mathrm{T}$.

Figure 4.90 presents the statistically significant differences obtained between managers and nonmanagers of the Johnson Controls Organization on the Job Satisfaction Scale. Managers had a statistically significantly higher mean value on this scale than did non-managers.

4.8.3.4 Differences Between the Johnson Controls Managers and Non-Managers on the Environment, Safety, and Health Questions

No statistically significant differences were obt:ined between the Johnson Controls Managers and Non-Managers on any of the Environment, Safety, and Hcalth Questions. The mean values obtained for both managers and non-managers on each of these questions are presented in Appendix $\mathrm{T}$. 


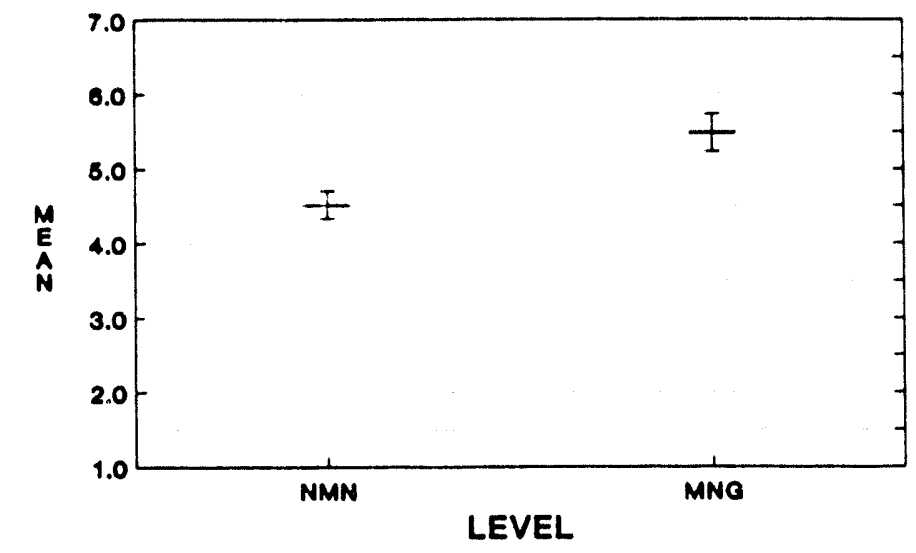

EAMOR DAค8 - *- 1 STO EAROA

Figure 4.90. Significant differences between managers and non-managers at Johnson Controls on the job satisfaction scale

\subsubsection{Summary}

The few statistically significant differences obtained between managers and non-managers on the OS Scales, could be indicative of a fairly homogeneous organizational culture within the Johnson Controls Organization.

\subsection{Differences Within the Mason \& Hanger Organization on the OS Scales}

\subsubsection{Differences Between the Mason \& Hanger Departments on the OS Scales}

Two Mason \& Hanger Departments were included on the background information sheet for Mason \& Hanger employees to classify themselves into. These departments are: Field and Staff.

\subsubsection{Differences Between the Mason \& Hanger Departments on the OS Scales}

Statistically significant differences between the Mason \& Hanger Departments were present on one of the OCI Scales: the Humanistic - Encouraging (C1) Scale. The inean values obtained on all other OCI Scales for each of the Mason \& Hanger Departments are presented in Appendix U. In addition, Appendix $\mathrm{V}$ contains figures which compare the mean values obtained for the overall Mason \& Hanger Organization to the mean values obtained for each Mason \& Hanger Department on the OCI Scales.

Figure 4.91 presents the statistically significant differences between the Mason \& Hanger Departments on the Humanistic - Encouraging (C1) Scale. The Field Department had a statistically significantly lower mean value on this scale than the Staff Department.

\subsubsection{Differences Between the Mason \& Hanger Departments on the Communication Scales}

Statistically significant differences between the Mason \& Hanger Departments were obtained on two of the Communication Scales: Communication-Trust, and Communication-Accuracy. The mean values on the other Communication Scales for each Mason \& Hanger Department are presented in Appendix U. In addition, Appendix $W$ contains figures which compare the mean value obtained for the overall Mason \& 
Hanger Organization to the mean values obtained for each Mason \& Hanger Department on the Communication Scales.

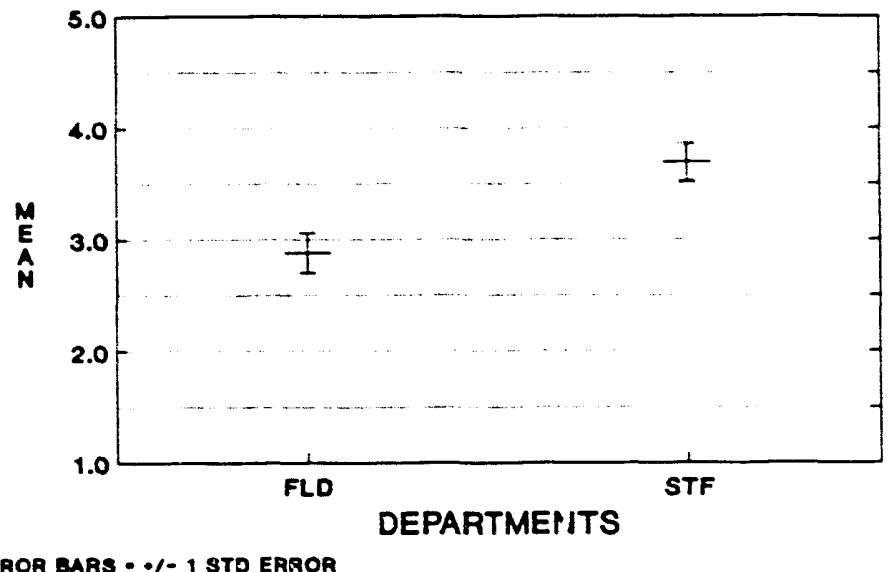

Figure 4.91. Significant differences between Mason \& Hanger departments on the humanisticencouraging scale

The statistically significant differences obtained between the Mason \& Hanger Departments on the Communication-Trust Scale are depicted in Figure 4.92. The Field Department had a statistically significantly lower mean value on this scale than the Staff Department.

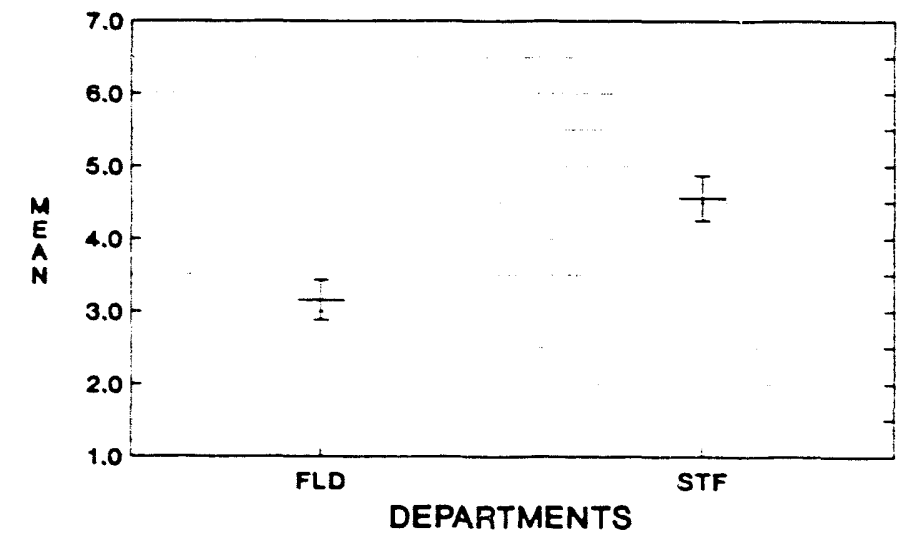

ERROR BARS - * - I STD, ERROA

Figure 4.92. Significant differences between Mason \& Hanger departments on the communication-trust scale

Figure 4.93 presents the statistically significant differences obtained between the Mason \& Hanger Denartments on the Communication - Accuracy Scale. Once again, the Field Department had the lowest obtained mean value on this scale and was statistically significantly different from the Staff Department. 


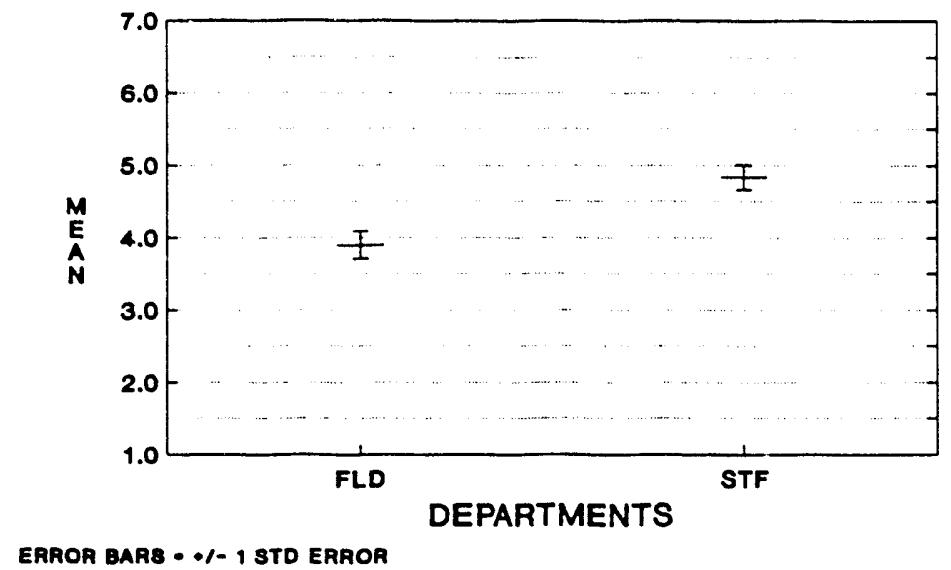

Figure 4.93. Significant differences between Mason \& Harger departments on the communication-accuracy scale

\subsubsection{Differences Between the Mason \& Hanger Departments on the Additional Scales}

Statistically significant differences between the Mason \& Hanger Departments were obtained on only one of the additional scales: the Job Satisfaction Scale. The mean values obtained for each department on every other additional scale are contained in Appendix U. Appendix X contains figures which compare the mean value obtained for the overall Mason \& Hanger Organization to tie mean values obtained for each Mason \& Hanger Department on the additional scales.

Figure 4.94 presents the statistically significant differences obtained between the Mason \& Hanger Departments on the Job Satisfaction Scale. Once again, the Field Department had a statistically significantly lower mean value on this scale than the Staff Department.

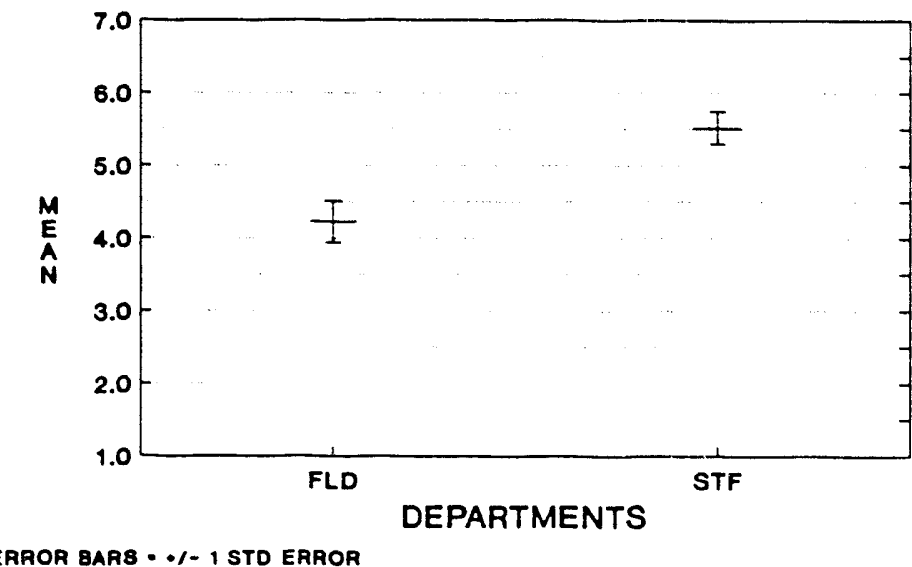

Figure 4.94. Significant differences between Mason \& Hanger departments on the job satisfaction scale 
4.9.1.4 Differences Between the Mason \& Hanger Departments on the Environment, Safety, and Health Questions

No statistically significant differences were obtained between the Mason \& Hanger Departments on any of the Environment, Safety, and Health Questions. Appendix U contains the mean values obtained for each department on each of the questions. Appendix Y presents figures which compare the mean values obtained for the overall Mason \& Hanger Organization to the mean values obtained for each Mason \& Hanger Department on the Environment, Safety, and Health Questions.

\subsubsection{Summary}

Yhile there were only four statistically significant differences obtained on the OS Scales between the two departments at Mason \& Hanger, the differences indicate that the Field Department has a profile which appears less constructive, satisfied, and trusting than the one exhibited by the Staff Department.

\subsubsection{Differences Between the Mason \& Hanger Staff Classifications on the OS Scales}

Four categories of staff classifications were provided on the background information sheet for Mason \& Hanger employees to classify themselves into. No statistically significant differences were found between the Mason \& Hanger Staff Classifications on any of the OS Scales. Appendix Z contains the mean values obtained for each staff classification on each of the OS Scales. The lack of statistically significant differences between the Mason \& Hanger Staff Classifications may be partially attributable to a large discrepancy in the number or respondents between the staiff classifications.

\subsubsection{Differences Between the Mason \& Hanger Supervisory Levels on the OS Scales}

Two levels of supervisors were available on the hackground information sheet for Mason \& Hanger respondents to classify themselves into: Managers and Non-Managers. No statistically significant differences were obtained between these two levels or any of the OS Scales. Appendix AA contains the mean values obtained for each supervisory level on each of the scales of the OS. 


\section{CONCLUSIONS}

While the overall mean values obtained for the Los Alamos Site on the OCI scales indicated a predominantly constructive cultural style, this is only somewhat useful, as it is limited by the fact that three separate organizations actually exist at the Los Alamos Site. It is more useful, therefore, to compare the profiles exhibited by each of the three organizations and note the differences and similarities which are present.

Statistically significant differences between the three Los Alamos Site organizations were obtained on only one of the OCI scales - the Dependent (C5) Scale. This lack of statistically significant differences between organizations on the $\mathrm{OCI}$ scales indicates that the three organizations do, in fact, have fairly homogeneous cultures.

Statistically significant differences between the three organizations did occur on three of the four communications scales. In all three instances, the LANL Organization had the highest mean value, indicating communications may be less of a problematic area at LANL than at the Mason \& Hanger or Johnson Controls Organizations. Mason \& Hanger employees appeared to have less faith in the communication processes which exist within their organization, as evidenced by the Communication-Trust and Communication-Accuracy Scales. Within Johnson Controls, desirability of interaction with others in the organization appeared to be an issue.

In addition, on those scales which relate to the hazardous or consequential nature of one's work, the LANL Organization had lower obtained mean values than the other two organizations at the Los Alamos Site. The Johnson Controls Organizations had the highest obtained mean values on these scales.

Differences obtained between managers and non-managers at the Los Alamos site were consistent with the literature as well as with results obtained at other DOE sites. Managers tended to exhibit a more constructive profile, were more committed to the organization, were more satisfied with their jobs, and generally had favorable attitudes regarding the communication processes which exist in their organization. Non-managers, on the other hand, scored statistically significantly different from managers on these same scales (they had lower obtained mean values) and were higher on those scales which constitute the passivedefensive cultural style. Non-managers also scored lower on the communication scales of Accuracy and Interaction as well as on the Commitment, Cohesion, and Safety Scales, and the Management Emphasis and Employee Awareness Questions.

Only one statistically significant difference occurred when the managers from each organization were compared to one another. The lack of statistically significant differences here may be partially attributable to the discrepancy in the number of manager respondents at each organization. The statistically significant differences obtained between the non-manager employees of each organization correspond closely to those obtained when the organizations at the Los Alamos Site were compared to one another on the OS Scales.

Within the LANL Organization, statistically significant differences between directorates divided the directorates into two main groups. In one group were these directorates which scored lower on the scales related to the perceived hazardous nature of one's work. Specifically, these included the Controller, Energy \& Technology, and Support Directorates. These directorates also scored high on those scales which comprise the passive-defensive cultural style and low on the Commitment and Communication-Trust Scales and on the Management Emphasis and Employee Awareness Questions. 
On the other hand, the Nuclear Weapons Technology and Chemistry and Materials Directorates scored higher on those scales which were concerned with the perceived hazardous nature of one's work, but lower on the scales which comprised the passive-defensive cultural style. These directorates also scored higher on the Management Emphasis and Employee Awareness Questions.

The differences between the supervisory levels at LANL were consistent with the literature and with results found at other DOE facilities. One notable result was the lack of statistically significant differences between the LANL Section Leaders and Non-Managers. In fact, the majority of statistically significant differences between the LANL Supervisory Levels involved the Non-Manager and Division and Above Levels. This may be indicative of a management that is highly centralized.

Few statistically significant differences were obtained between any of the groups at either the Johnson Controls or at the Mason \& Hanger Organizations. The differences which did exist within the Johnson Controls Organization appeared related to the potential for hazard in a particular job function. Thus, the Johnson Controls Organization seems to have a fairly homogeneous culture. At Mason \& Hanger, the culture also appeared somewhat homogeneous; however, the Field Department seemed to be less constructive, satisfied, and trusting than the Staff Department.

It should be reemphasized that the response rate which was obtained at the Los Alamos Site was less than optimal. Over one-half of the individuals randomly selected to complete the survey did not. One possible explanation for this is that the survey administrations were conducted at four different locations, and individuals were assigned to a session based on the beginning letter of their last name. Due to the large physical size of the Los Alamos Site, these central locations may not have been easily accessible to all individuals, thus increasing the likelihood of a low response rate. However, the minimum percentage necessary, ten percent of each organization's population, did in fact complete the survey, providing statistical validity for the results discussed here. 


\section{REFERENCES}

Cooke, R.A., and Burack, E.H., "Measuring Norms and Expectations with the OCI," in Organizational Culture Inventory, Level V Mianual, Chicago: Human Synergistics, 1987, pp. 13-26.

Hays, W.L., Statistics, Fourth Edition, New York: Holt, Rinehart, and Winston, Inc., 1988.

Human Synergistics, Organizational Culture Inventory, Level V, Plymouth, MI, 1987.

Georgopolous, B.S., and Mann, F.C., The Community General Hospital, New York: Macmillan, 1962.

Kunin, J., "The construction of a new type of attitude measure," Personnel Psychology, 8 , i955, pp. 65-78.

Mowday, R., and Steers, R.M., The measurement of organizational commitment, Journal of Vocational Behavior, 14, 1979, pp. 224-247.

Price, J.L., and Muller, Handbook of Organizational Measurement, Lexington, MA: DC Heath and Company, 1972.

Roberts, K.M., and O'Reilly, C.A., "Measuring organizational communications," Journal of Applied Psychology, $\underline{59}$ (3), 1974, pp. 321-326 (copyright pending).

Seashore, S.E., Group Cohesiveness in the Industrial Work Group, Ann Arbor, MI: Survey Research Center, University of Michigan, MI, 1954. 
Appendix A: Overall Means on the OS Scales for the Los Alamos Site Compared to the Overall Means Obtained for Each Organization

Comparison of Means for the LANL Organization and the Los Alamos Site on the $\mathrm{OCl}$ Scales

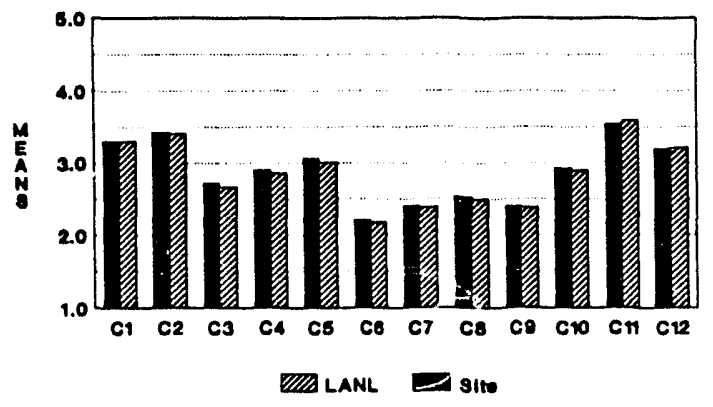

Comparison of Means for the LANL Organization and the Los Alamos Site on the Communication Scales

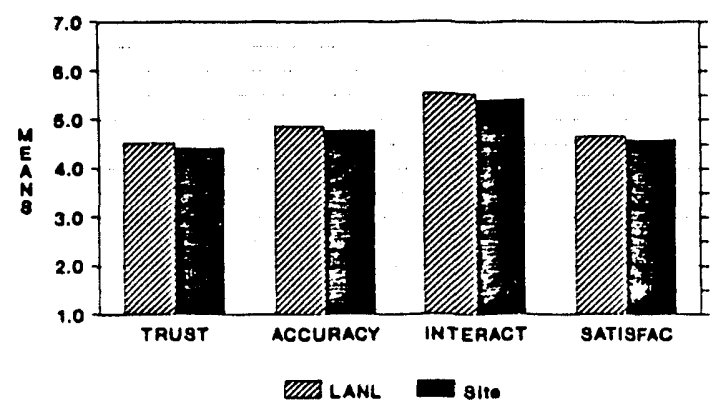

Comparison of Means for the LANL Organization and the Los Alamos Site on the Additional Scales

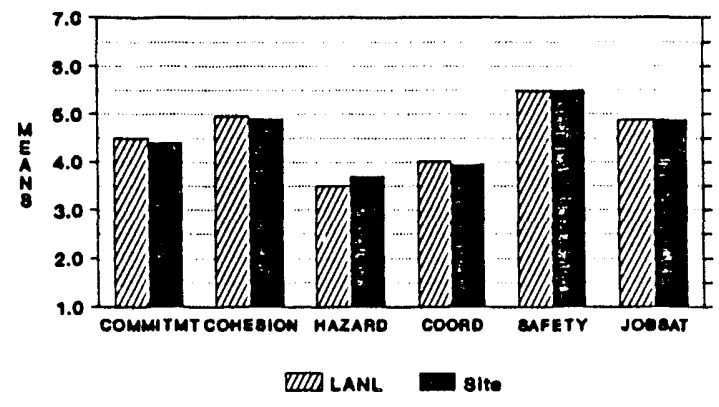

Comparison of Means for the LANL Organization and the Los Alamos Site on the Environment, Safety and Health Questions

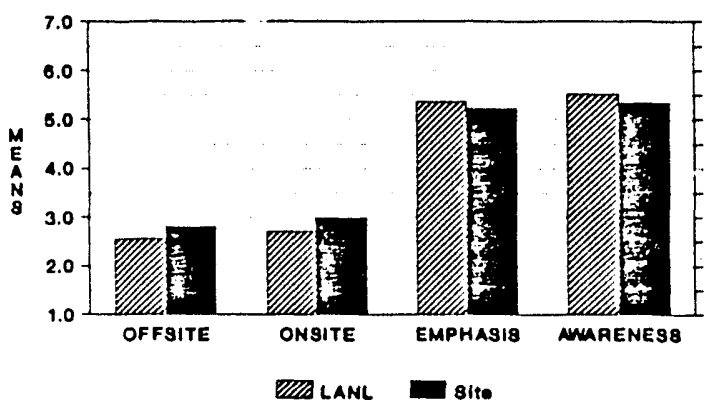


Comparison of Means for Johnson Controls and the Los Alamos Site on the $\mathrm{OCl}$ Scales

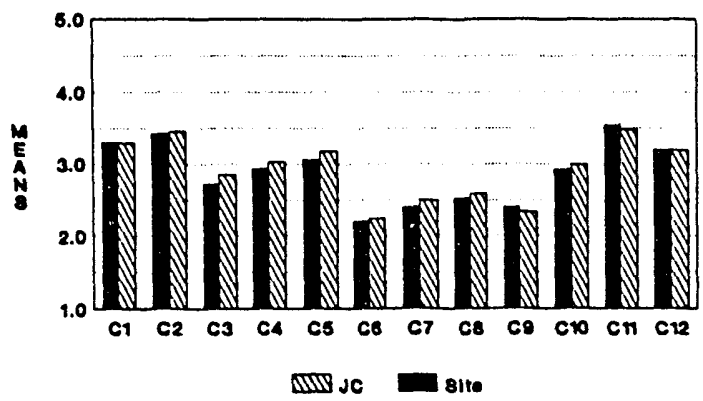

Comparison of Means for Johnson Controls and the Los Alamos Site on the Communication Scales

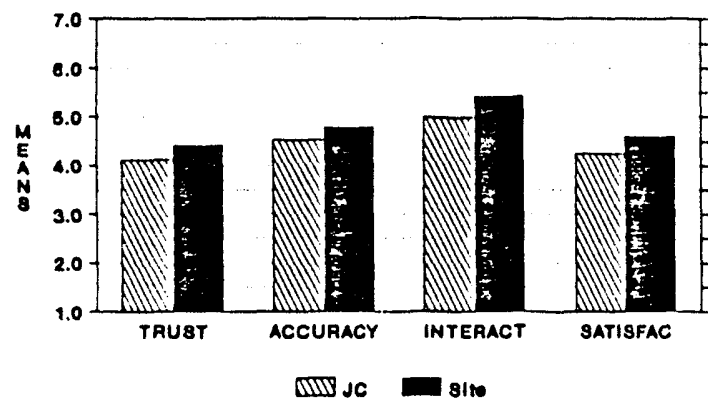

Comparison of Means for Johnson Controls and the Los Alamos Site on the Additional Scales

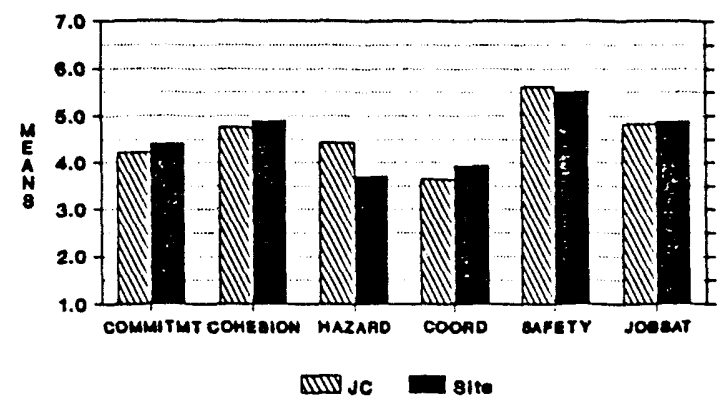

Comparison of Johnson Controls and the Los Alamos site on the Environment, Safety, and Health Questions

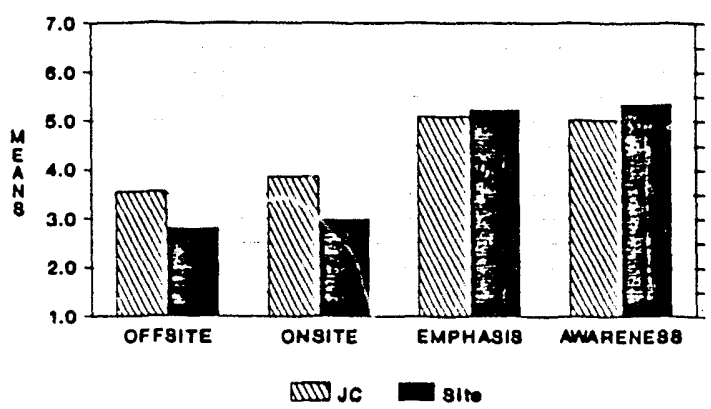


Comparison of Means for Mason and Hanger and the Los Alamos Site on the OCl Scales

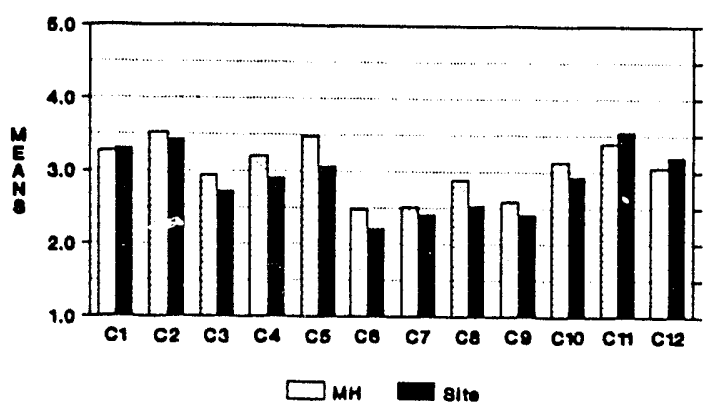

Comparison of Means for Mason and Hanger and the Los Alamos Site on the Communication Scales

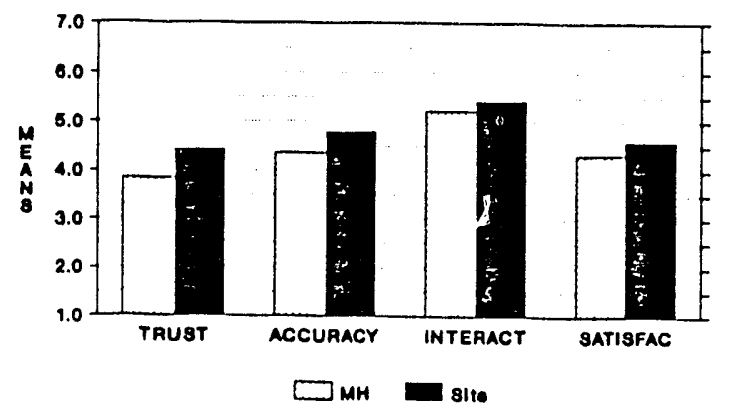

Comparison of Means for Mason and Hanger and the Los Alamos Site on the Additional Scales

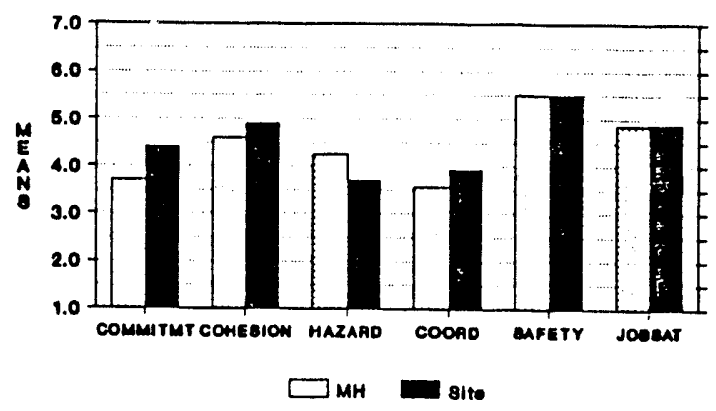

Comparison of Means for Mason and Hanger and the Los Alamos Site on the Environment, Safety, and Health Questions

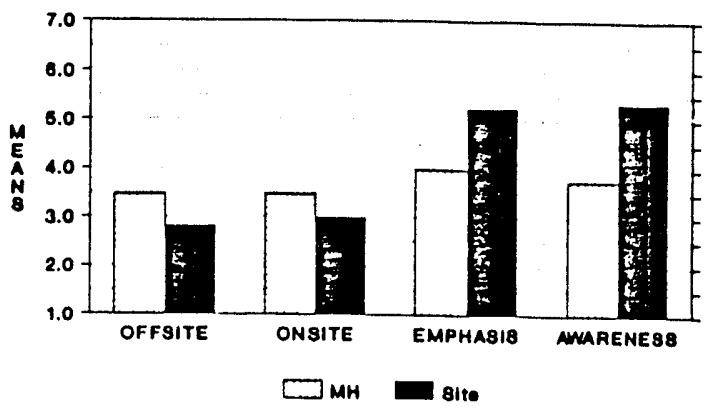




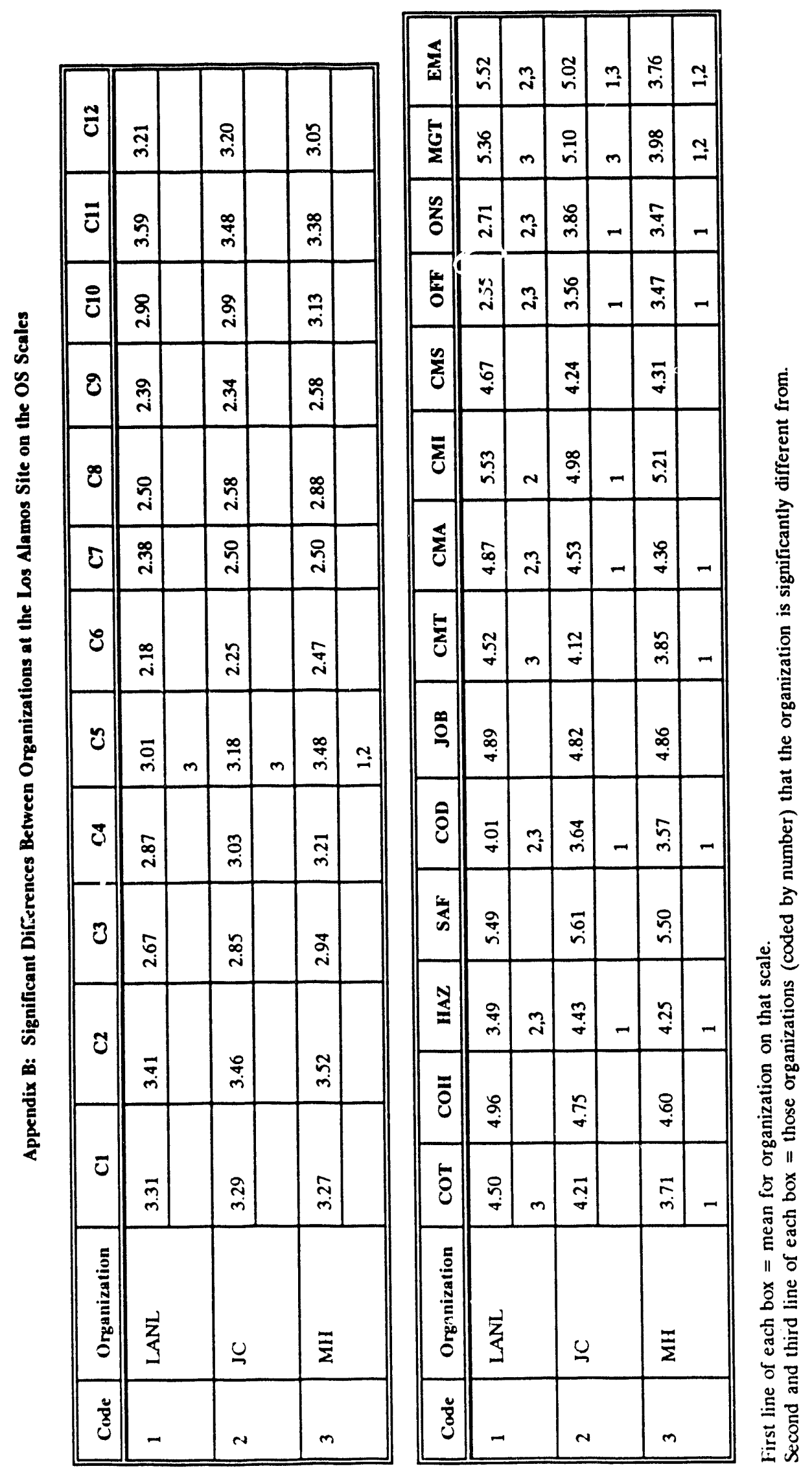




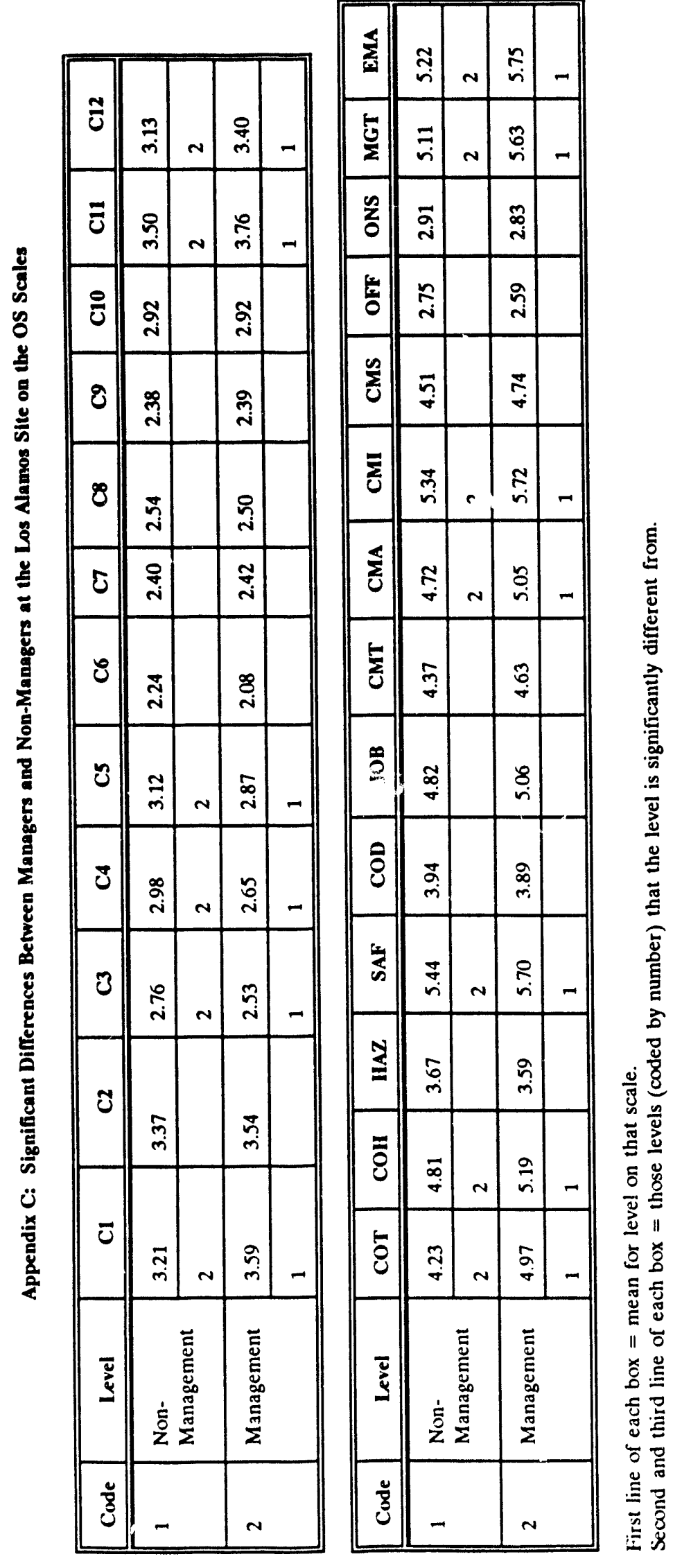




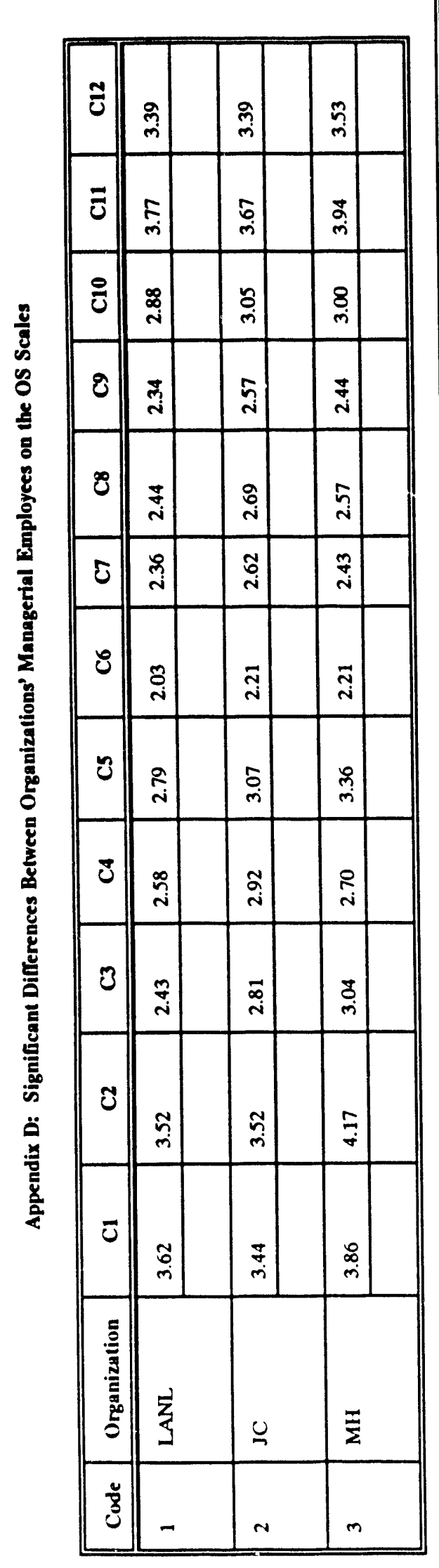

\begin{tabular}{|c|c|c|c|}
\hline 紊 & $\begin{array}{l}\mathscr{D} \\
\stackrel{n}{2}\end{array}$ & $\stackrel{n}{n}$ & $\begin{array}{l}q \\
\dot{n}\end{array}$ \\
\hline$\underline{\underline{2}}$ & $\begin{array}{l}0 \\
\vdots \\
0\end{array}$ & 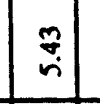 & : \\
\hline$\frac{n}{z}$ & ¿ّ & $\vec{b}$ & $\vec{m}$ \\
\hline 힣 & 染 & $\hat{m}$ & वे \\
\hline in & 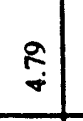 & $\stackrel{\infty}{+}$ & \begin{tabular}{|l|l} 
\\
$\vdots$
\end{tabular} \\
\hline $\bar{z}$ & $\begin{array}{l}8 \\
\dot{5} \\
\end{array}$ & 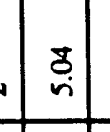 & 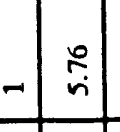 \\
\hline$\frac{1}{i}$ & $\square$ & 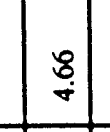 & $\frac{a}{\dot{n}}$ \\
\hline$\frac{1}{\partial}$ & $\stackrel{2}{+}$ & $\stackrel{\circ}{\square}$ & 5 \\
\hline$\stackrel{0}{\bullet}$ & $\overline{9}$ & $\begin{array}{l}\infty \\
\dot{n}\end{array}$ & 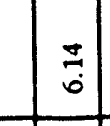 \\
\hline ิे & \begin{tabular}{l}
$\circ$ \\
\hdashline \\
\end{tabular} & 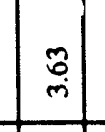 & $\begin{array}{c}5 \\
\vdots \\
\end{array}$ \\
\hline 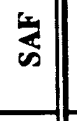 & \begin{tabular}{|c|} 
\\
$\vdots$ \\
\end{tabular} & $\begin{array}{l} \\
\vdots \\
\vdots\end{array}$ & $\begin{array}{l}\infty \\
\infty \\
\end{array}$ \\
\hline$\stackrel{?}{=}$ & 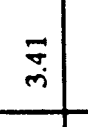 & $\stackrel{\infty}{+}$ & $\stackrel{\infty}{+}$ \\
\hline $\bar{z}$ & \begin{tabular}{|l|l} 
\\
\hdashline
\end{tabular} & $\overrightarrow{7}$ & $\overrightarrow{\dot{n}}$ \\
\hline : & \begin{tabular}{|c|} 
\\
$\dot{n}$
\end{tabular} & 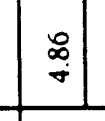 & 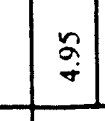 \\
\hline 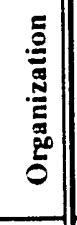 & 妾 & 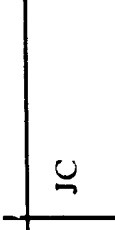 & $\overline{\bar{z}}$ \\
\hline 总 & - & 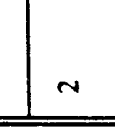 & m \\
\hline
\end{tabular}




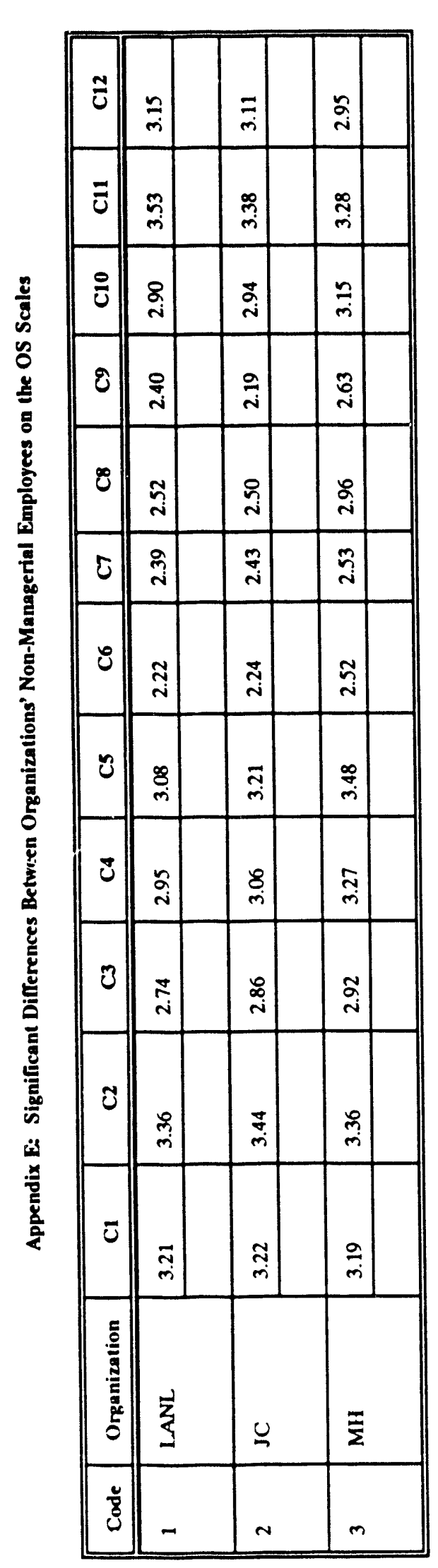

\begin{tabular}{|c|c|c|c|c|c|c|}
\hline$\sum_{i=1}^{1}$ & $\underset{\nabla}{\tilde{G}}$ & $\vec{n}$ & $\frac{9}{6}$ & 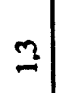 & $\underset{n}{\beth}$ & $\cong$ \\
\hline$\frac{t}{2}$ & 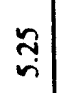 & $m$ & $\stackrel{8}{\circ}$ & $m$ & $\stackrel{\infty}{\grave{m}}$ & $\cong$ \\
\hline$\sum_{0}^{n}$ & $\underset{\sim}{\mathbb{N}}$ & $N$ & $\underset{\sim}{\tilde{m}}$ & - & 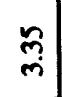 & \\
\hline ثا⿱ & $\stackrel{\infty}{\sim}$ & $\vec{n}$ & $\stackrel{5}{n}$ & - & $\underset{m}{\stackrel{m}{m}}$ & - \\
\hline$\sum_{U}^{\infty}$ & $\underset{+}{\vec{b}}$ & & 8 & & $\stackrel{0}{9}$ & \\
\hline $\bar{z}$ & $\stackrel{q}{\dot{q}}$ & $N$ & $\overrightarrow{7}$ & - & $\overline{\bar{n}}$ & \\
\hline$\sum_{0}^{\leq}$ & $\stackrel{2}{+}$ & $m$ & $\tilde{\sim}$ & & $\stackrel{g}{\dot{\sigma}}$ & - \\
\hline$\sum$ & $\stackrel{\circ}{+}$ & $m$ & $\stackrel{\varrho}{-}$ & & $\underset{\dot{m}}{5}$ & - \\
\hline 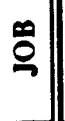 & $\stackrel{\infty}{\underset{\sim}{+}}$ & & $\tilde{\tilde{\tau}}$ & & $\stackrel{\curvearrowleft}{\sigma}$ & \\
\hline ชิ & $\underset{+}{\sigma}$ & $\vec{n}$ & $\tilde{i}$ & - & $\begin{array}{r}\tilde{n} \\
\tilde{n}\end{array}$ & - \\
\hline$\frac{1}{n}$ & $\underset{\sim}{\mathfrak{r}}$ & & $\stackrel{n}{n}$ & & $\stackrel{q}{n}$ & \\
\hline 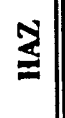 & 昜 & $\stackrel{m}{i}$ & $\stackrel{g}{q}$ & - & $\stackrel{\infty}{+}$ & - \\
\hline$\overline{8}$ & $\stackrel{\infty}{\infty}$ & & $\stackrel{?}{+}$ & & $\underset{+}{f}$ & \\
\hline 8 & $\tilde{q}$ & m & $\underset{\substack{\infty \\
\text { mi }}}{ }$ & & $\stackrel{m}{m}$ & \\
\hline 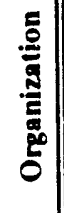 & 安 & & 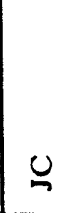 & & $\bar{\Sigma}$ & \\
\hline 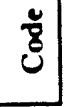 & - & & $N$ & & $m$ & \\
\hline
\end{tabular}




\begin{tabular}{|c|c|c|c|c|c|c|c|c|c|c|c|c|c|c|c|c|}
\hline$\overline{0}$ & 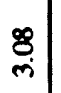 & & $=$ & & 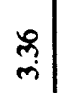 & & 8 & & $\stackrel{m}{m}$ & & ఫ్ & & $\stackrel{=}{m}$ & & $\tilde{m}$ & \\
\hline $\bar{u}$ & $\underset{\dot{m}}{\vec{q}}$ & & $\bar{n}$ & & $\stackrel{\infty}{\stackrel{\infty}{m}}$ & & $\frac{F}{m}$ & & $\underset{\dot{m}}{8}$ & & $\overrightarrow{\dot{p}}$ & & $\stackrel{m}{m}$ & & $\stackrel{\infty}{\circ}$ & \\
\hline 인 & స్తి & & $\stackrel{\sim}{\infty}$ & & $\underset{\mathbf{N}}{\mathbf{N}}$ & & 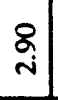 & & $\begin{array}{c}\infty \\
\sim \\
\sim\end{array}$ & & $\underset{\infty}{\infty}$ & & $\begin{array}{c}\infty \\
i \\
i\end{array}$ & & $\begin{array}{l}8 \\
\dot{m}\end{array}$ & \\
\hline 8 & 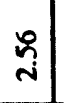 & & 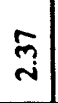 & & $\stackrel{\mathrm{N}}{\mathrm{N}}$ & & 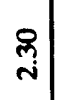 & & $\sqrt[n]{n}$ & & $\stackrel{m}{\mathbf{N}}$ & & $\stackrel{g}{i}$ & & $\tilde{\tilde{N}}$ & \\
\hline$\ddot{0}$ & $\underset{\sim}{\infty}$ & 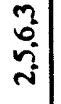 & 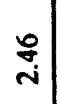 & - & 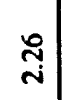 & $\stackrel{\infty}{=}$ & $\stackrel{\mathscr{n}}{n}$ & & $\stackrel{n}{\sim}$ & - & $\underset{⿱ 亠 凶}{\sim}$ & -1 & nี & & ì & $m$ \\
\hline 5 & $\bar{n}$ & & 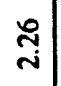 & & 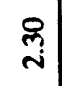 & & $\underset{\sim}{\stackrel{N}{i}}$ & & $\underset{\sim}{\grave{n}}$ & & $\underset{i}{\stackrel{O}{i}}$ & & $\underset{\sim}{\sim}$ & & $\stackrel{0}{i}$ & \\
\hline 8 & $\underset{\sim}{n}$ & $\begin{array}{l}m \\
n \\
0 \\
i \\
0\end{array}$ & $\underset{\sim}{\Delta}$ & - & $\tilde{\sigma}$ & $\stackrel{0}{-0}$ & $\underset{\sim}{\mathbb{N}}$ & & $\vec{i}$ & - & $\underset{i}{5}$ & -1 & స్తి & $m$ & $\vec{n}$ & $m$ \\
\hline 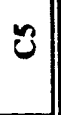 & $\bar{m}$ & $\begin{array}{c}n \\
\mathfrak{i} \\
n\end{array}$ & $\stackrel{\circ}{\stackrel{\infty}{i}}$ & - & $\stackrel{\infty}{i}$ & $\begin{array}{l}\infty \\
\stackrel{-}{-} \\
-\end{array}$ & $\frac{a}{m}$ & $m$ & $\underset{\sim}{\infty}$ & - & $\stackrel{\sim}{\sim}$ & & $\begin{array}{l}8 \\
\dot{m}\end{array}$ & & $\stackrel{0}{\stackrel{m}{m}}$ & $m$ \\
\hline $\bar{U}$ & $\stackrel{\oplus}{\oplus}$ & רֶ. & $\stackrel{R}{i}$ & - & $\underset{\sim}{\vec{d}}$ & $\stackrel{\square}{-}$ & $\underset{m}{8}$ & $m$ & $\underset{\infty}{\stackrel{\sim}{\sim}}$ & & $\begin{array}{l}\pi \\
i\end{array}$ & -1 & 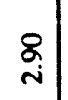 & & $\vec{a}$ & \\
\hline 3 & $\vec{\alpha}$ & $\stackrel{m}{m}$ & $\overline{\mathbf{n}}$ & - & $\underset{\sim}{\stackrel{m}{i}}$ & $\stackrel{\infty}{-}$ & $\stackrel{\infty}{\stackrel{\infty}{N}}$ & & $\hat{్}$ & & : 2 & & $\begin{array}{l}\vec{b} \\
\text { in }\end{array}$ & & 迸 & $m$ \\
\hline$\tilde{U}$ & $\begin{array}{l}\vec{b} \\
\dot{n}\end{array}$ & స్ & $\stackrel{\Rightarrow}{m}$ & $\vec{\infty}$ & $\tilde{m}$ & & $\stackrel{\sim}{\vec{m}}$ & & $\underset{j}{\frac{\pi}{0}}$ & & $\underset{\sim}{\mathbb{m}}$ & $\vec{\infty}$ & 足 & $\infty$ & $\frac{T}{\dot{m}}$ & గั \\
\hline $\bar{U}$ & $\underset{m}{\infty}$ & & $\frac{\infty}{\infty}$ & & 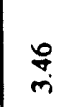 & & $\frac{\infty}{\dot{m}}$ & & $\vec{m}$ & & $\underset{m}{m}$ & & $\underset{\sim}{\sim}$ & & $\overrightarrow{\dot{m}}$ & \\
\hline | & zo & & 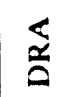 & & 5 & & $\stackrel{\circ}{\gtrless}$ & & $\sum$ & & $\sum_{z}^{5}$ & & $\mathscr{\mathscr { d }}$ & & 官 & \\
\hline 5 & - & & $N$ & & $m$ & & $\nabla$ & & $r$ & & 0 & & $r$ & & $\infty$ & \\
\hline
\end{tabular}




\begin{tabular}{|c|c|c|c|c|c|c|c|c|}
\hline 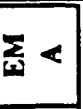 & \begin{tabular}{l|l|l}
85 \\
$\square$
\end{tabular} & \begin{tabular}{|l|} 
\\
\\
$n$
\end{tabular} & \begin{tabular}{l|l}
5 & \\
&
\end{tabular} & 菩 & \begin{tabular}{|l|l}
2 & -1 \\
\end{tabular} & - & \begin{tabular}{|l|}
7 \\
7
\end{tabular} & \begin{tabular}{l|} 
\\
\\
2
\end{tabular} \\
\hline$\frac{5}{2}$ & \begin{tabular}{l|l}
8 \\
8
\end{tabular} & 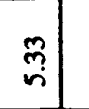 & 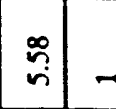 & . & $\mid-$ & $\tilde{n}-$ & $\bar{n}$ & 㓓 \\
\hline 势 & $\mid$ & \begin{tabular}{l|l}
$\stackrel{\infty}{*}$ & $:$
\end{tabular} & $\bar{\nabla}: \dot{0}$ & ( & 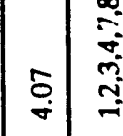 & $\underset{్}{\infty}$ & $\stackrel{\circ}{\circ}$ & 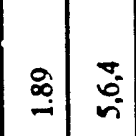 \\
\hline ث: & $\begin{array}{l}\Omega \\
\end{array}$ & $\stackrel{\circ}{2}$ & 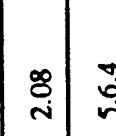 & $D_{0}^{\circ}$ & 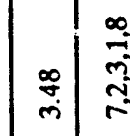 & $=$ & जे & : \\
\hline$z$ & ฐ & $\$$ & 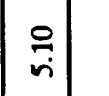 & 9 & $\stackrel{\infty}{\square}$ & 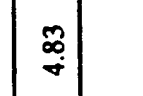 & 5 & $\$$ \\
\hline ह & مُ & . & $\left|\begin{array}{l}0 \\
\vdots \\
i\end{array}\right|$ & $\begin{array}{l}0 \\
\end{array}$ & 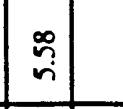 & \begin{tabular}{|l|} 
\\
\\
0
\end{tabular} & : & $\tilde{n}$ \\
\hline$\frac{5}{\bar{y}}$ & 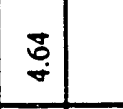 & a & \begin{tabular}{|l|} 
\\
$\vdots$ \\
\end{tabular} & $F$ & \begin{tabular}{|l|l|} 
\\
\hdashline \\
\hdashline
\end{tabular} & $\stackrel{\infty}{:}$ & \begin{tabular}{|l} 
\\
\end{tabular} & $\overrightarrow{\dot{n}}$ \\
\hline $\bar{z}$ & 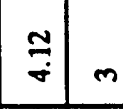 & $\frac{1}{3}$ & $:=$ & $:$ & 5 & 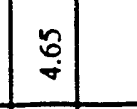 & 5 & $\approx$ \\
\hline ळ & $q$ & $g$ & $\div$ & $\mid$ & $\mid$ & $\approx$ & $\approx$ & $\frac{n}{n}$ \\
\hline ठิ & 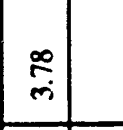 & 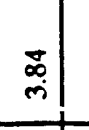 & $\exists$ & : & 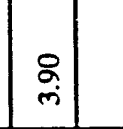 & 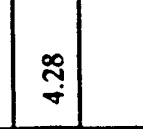 & 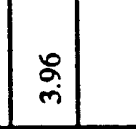 & 8 \\
\hline 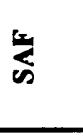 & 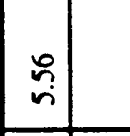 & 咅 & \begin{tabular}{|l|l|}
$\vec{n}$ \\
\end{tabular} & \begin{tabular}{|l|} 
\\
iे \\
\end{tabular} & 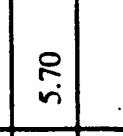 & $\hat{\hat{n}}$ & 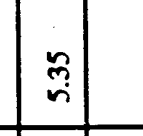 & 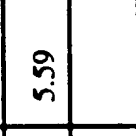 \\
\hline$\cong$ & 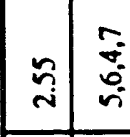 & $=$ & $\because$ & $\underset{\sim}{ \pm}$ & 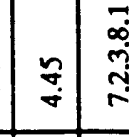 & $\widetilde{\sim}$ & $\widetilde{n}$ & 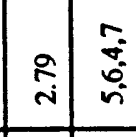 \\
\hline $\bar{z}$ & 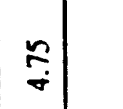 & $\mid$ & zin & 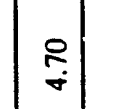 & 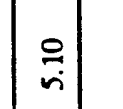 & $\frac{n}{n}$ & 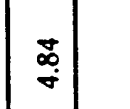 & $\mid$ \\
\hline 8 & $\begin{array}{lll} \\
\end{array}$ & $\%$ & $g=$ & $:=$ & 7 & $\stackrel{\varpi}{\square}:$ & 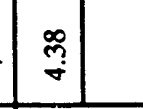 & 5 \\
\hline $\begin{array}{l}\frac{\bar{z}}{\underline{\underline{z}}} \\
\underline{\underline{\underline{\underline{z}}}}\end{array}$ & $z$ & 音 & 豆 & 主 & $\bar{E}$ & 点 & \begin{tabular}{|l|} 
凅 \\
\end{tabular} & 5 \\
\hline है & - & N & $=$ & + & $n$ & $\circ$ & 1 & $\infty$ \\
\hline
\end{tabular}




\section{Appendix G: Mean Values for the Overall LANL Organization Compared to the Mean Values Obtained for Each LANL Directorate on the OCI}

COMPARISON OF OVERALL LANL TO THE CONTROLLER DIRECTORATE ON THE OCI SCALES

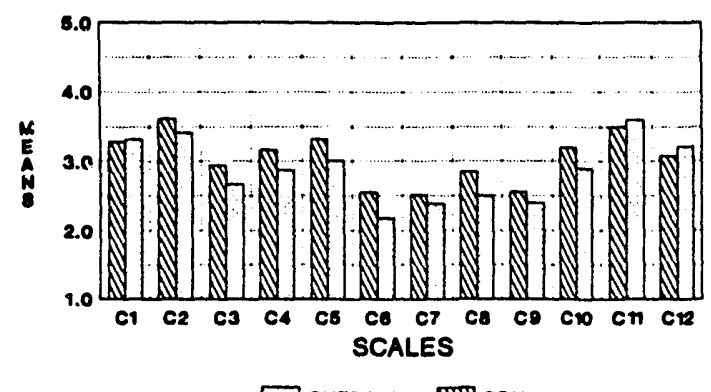

$\square$ OVERALL TON

COMPARISON OF OVERALL LANL TO THE DIRECIOR'S OFFICE ON THE OCI SCALES

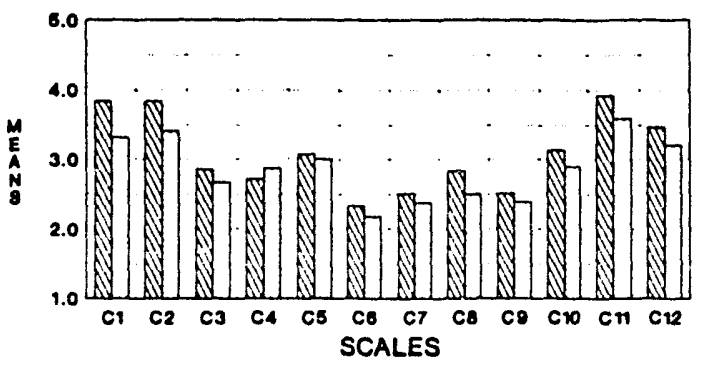

$\square$ OVERALL IIJU OIn
COMPARISON OF OVERALL LANL TO THE HUMAN RESOURCES DIRECTORATE ON THE OCI SCALES

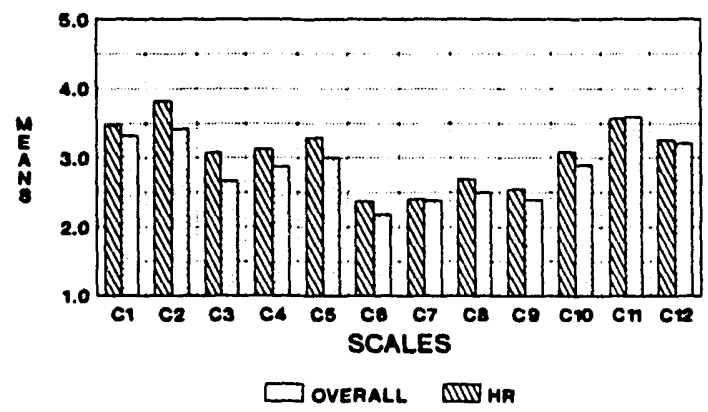

COMPARISON OF OVERALL LANL TO THE LABORATORY COUNSEL OFFICE ON THE OCI SCALES

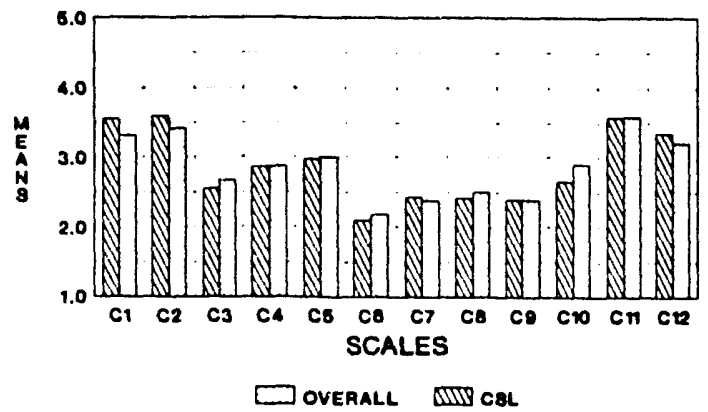


COMPARISON OF OVERALL LANL TO THE DEFENSE RESEARCH AND APPLICATIONS DIRECTORATE ON THE OCI SCALES

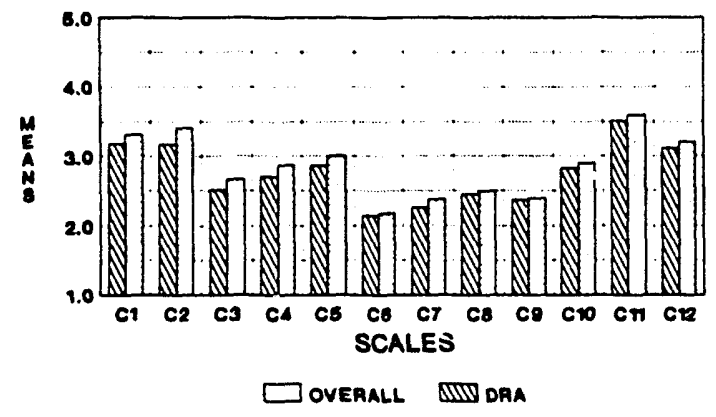

COMPARISON OF OVERALL LANL TO THE AT LARGE AND THE CNSS DIRECTORATE ON THE OCI SCALES

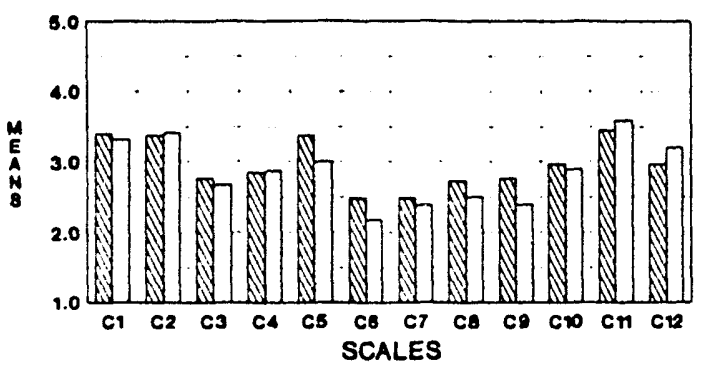

$\square$ OVERALL CUIO CNE
COMPARISON OF OVERALL LANL TO THE ENERGY AND TECHNOLOGY DIRECTORATE ON THE OCI SCALES

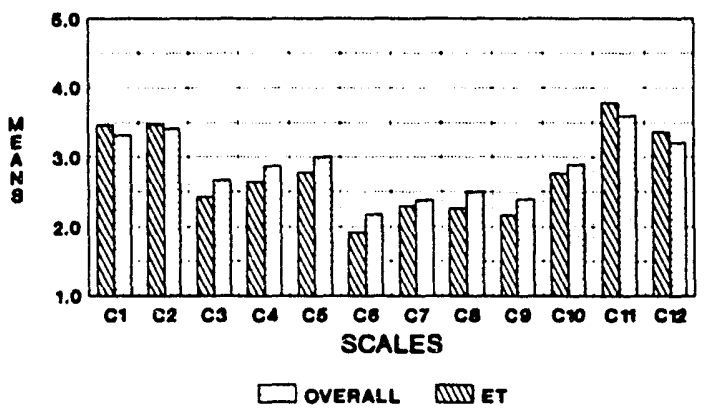

COMPARISON OF OVERALL LANL TO THE CHEMISTRY \& MATERIALS DIRECTORATE ON THE OCI SCALES

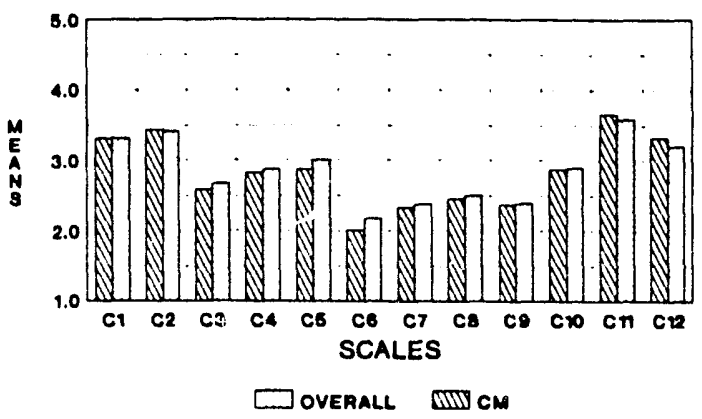


COMPARISON OF OVERALL LANL TO THE OPERATIONS DIRECTORATE ON THE OCI SCALES

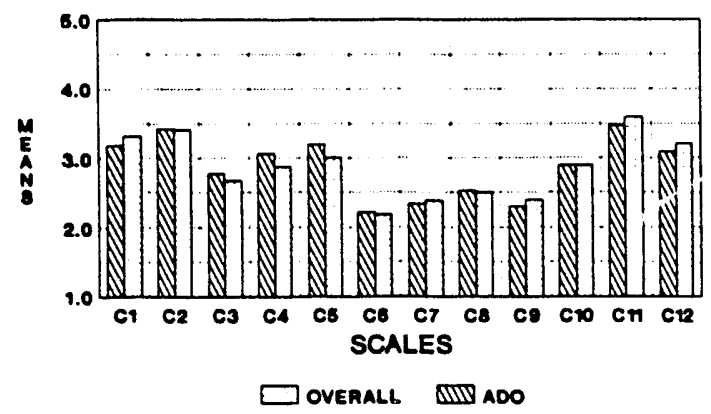

COMPARISON OF OVERALL LANL TO THE RESEARCH DIRECTORATE ON THE OCI SCALES

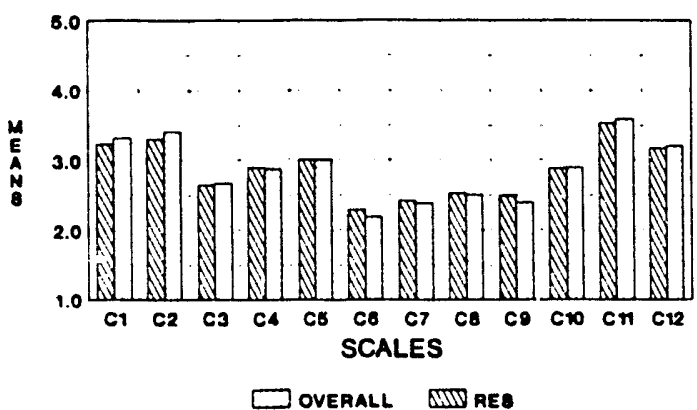

COMPARISON OF OVERALL LANL TO THE NUCLEAR WEAPONS TECHNOLOGY DIRECTORATE ON THE OCI SCALES

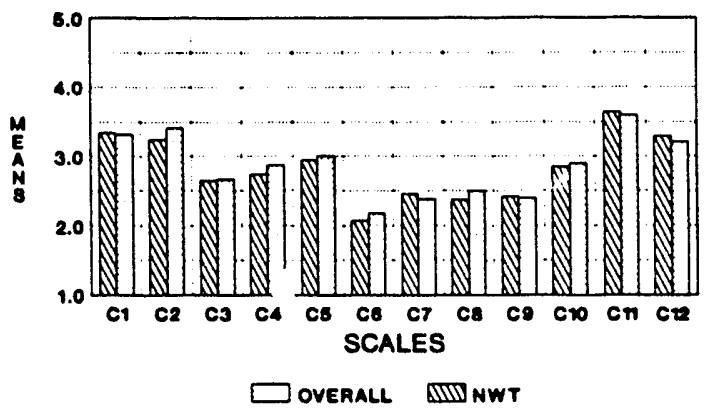


Appendix H: Mean Values for the Overall LANL Organization Compared to the Mean Values Obtained for Each LANL Directorate on the Communication Scales
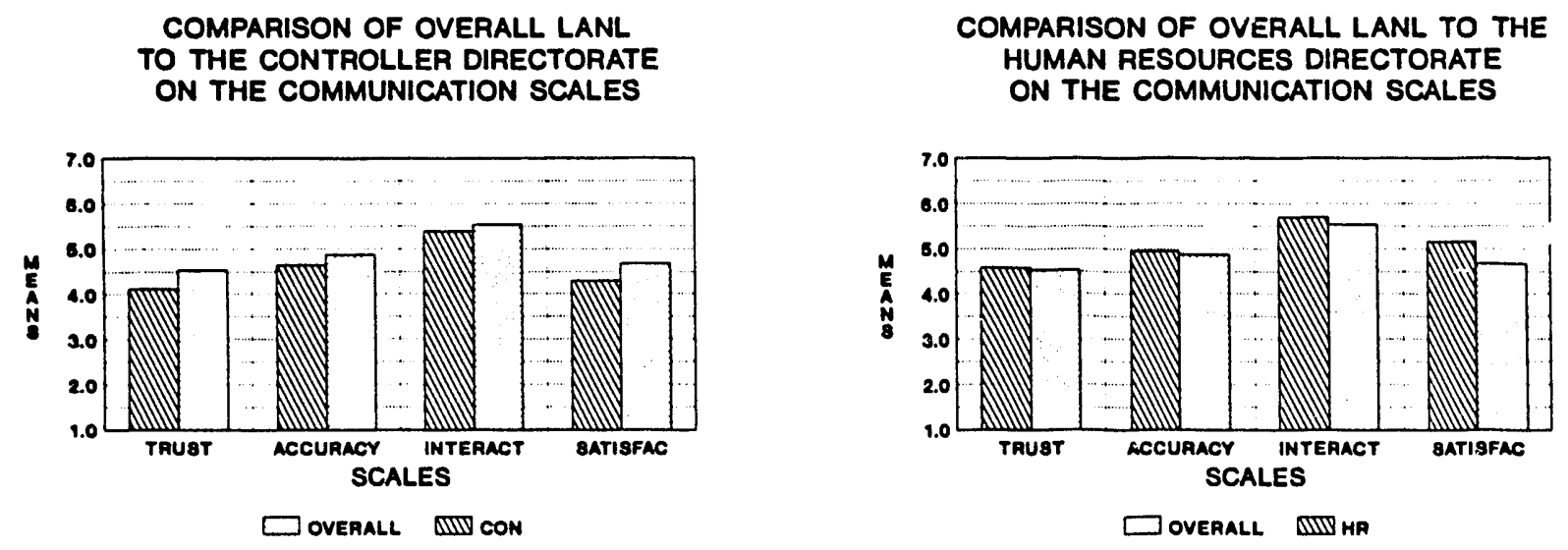

COMPARISON OF OVERALL LANL TO THE DIRECTOR'S OFFICE ON THE COMMUNICATION SCALES

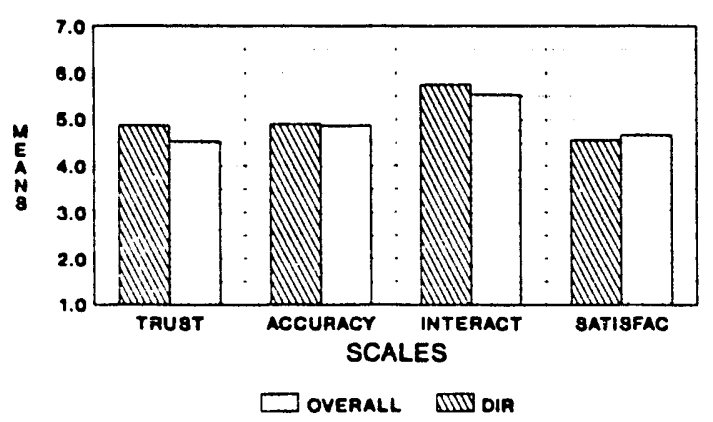

COMPARISON OF OVERALL LANL TO THE LABORATORY COUNSEL DIRECTORATE ON THE COMMUNICATION SCALES

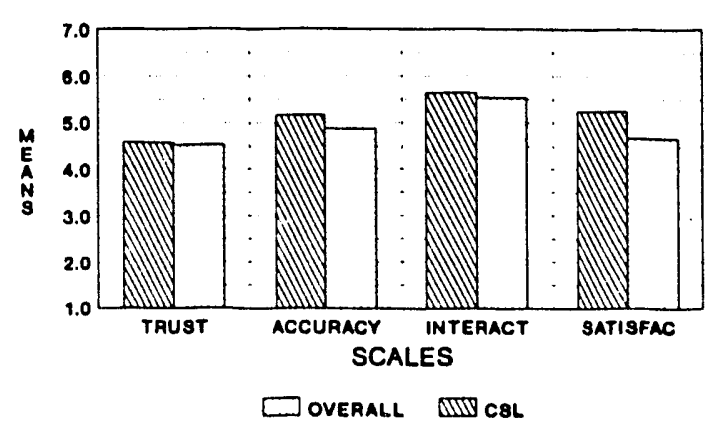

$\mathrm{H}-1$ 
COMPARISON OF OVERALL LANL TO THE DEFENSE RESEARCH AND APPLICATIONS DIRECTORATE ON THE COMMUNICATION SCALES

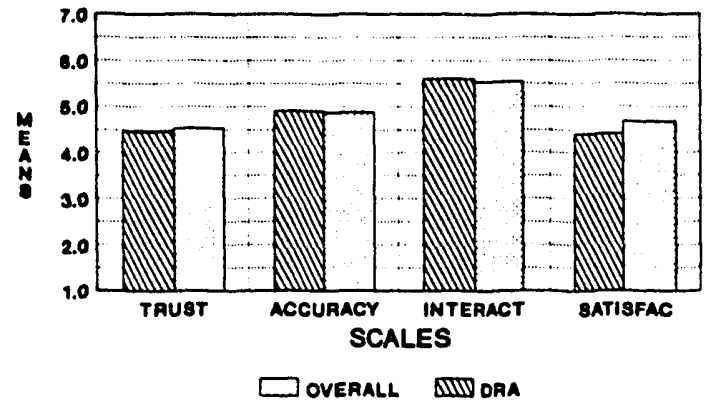

COMPARISON OF OVERALL LANL TO THE OPERATIONS DIRECTORATE ON THE COMMUNICATION SCALES

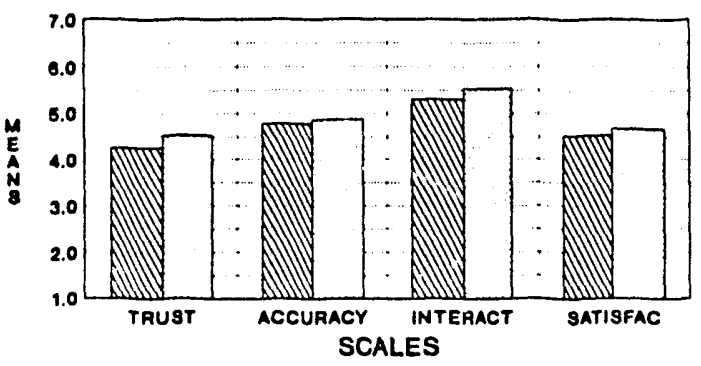

OVERALL AIII ADO
COMPARISON OF OVERALL LANL TO THE ENERGY AND TECHNOLOGY DIRECTORATE ON THE COMMUNICATION SCALES

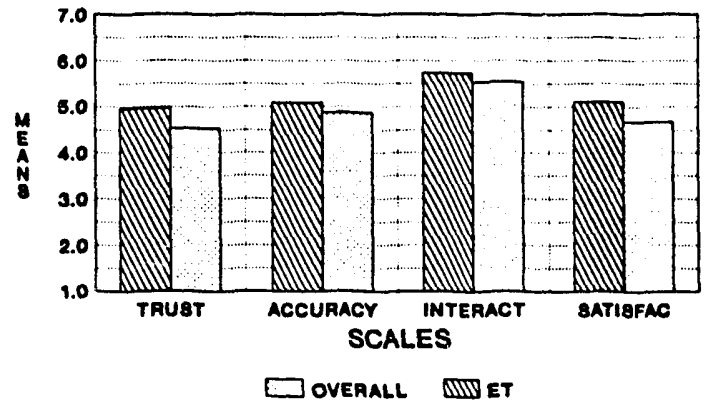

COMPARISON OF OVERALL LANL TO THE AT LARGE \& CNSS DIRECTORATE ON THE COMMUNICATION SCALES

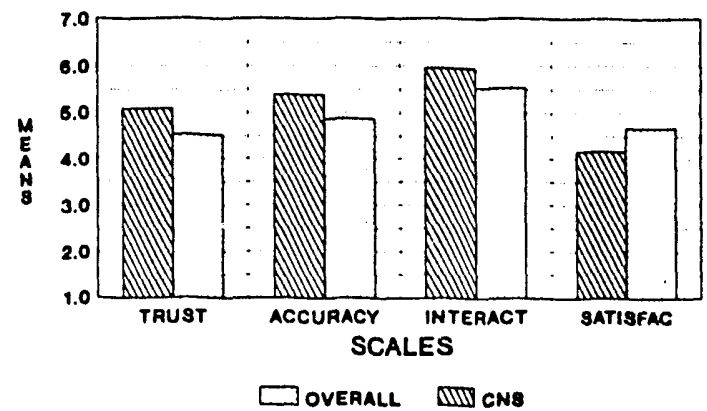


COMPARISON OF OVERALL LANL TO THE CHEMISTRY AND MATERIALS DIRECTORATE ON THE COMMUNICATION SCALES

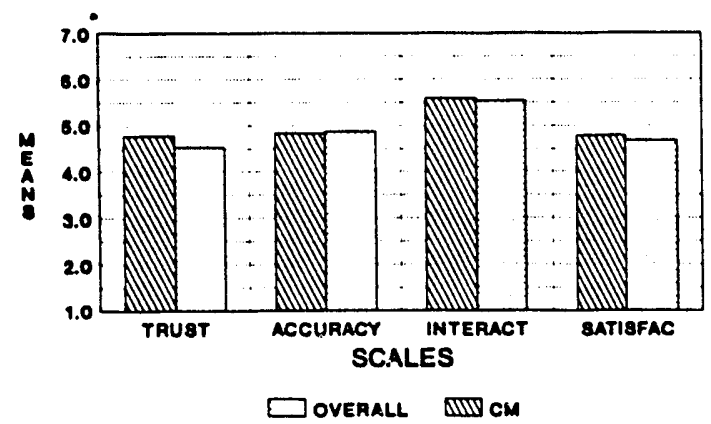

COMPARISON OF OVERALL LANL TO THE RESEARCH DIRECTORATE ON THEE COMMUNICATION SCALES

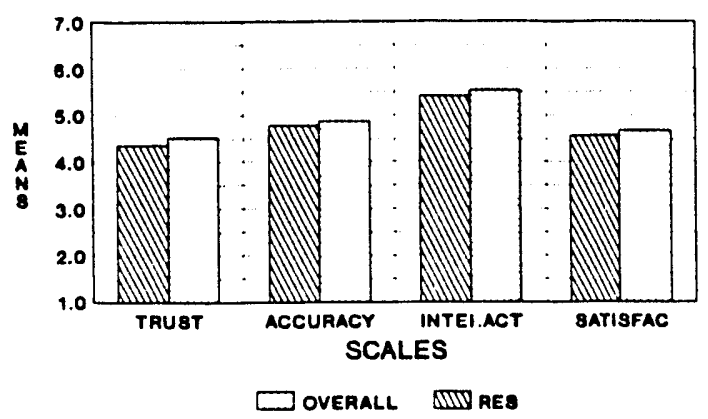

COMPARISON OF OVERALL LANL TO THE NUCLEAR WEAPONS TECHNOLOGY DIRECTORATE ON THE COMMUNICATION SCALES

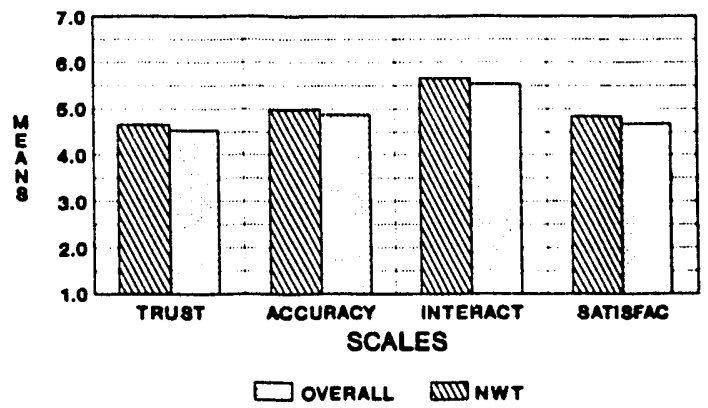


Appendix I: Mean Values for the Overall LANL Organization Compared to the Mean Values Obtained for Each LANL Directorate on the Additional Scales

\section{COMPARISON OF OVERALL LANL TO THE CONTROLLER DIRECTORATE ON THE ADDITIONAL SCALES}

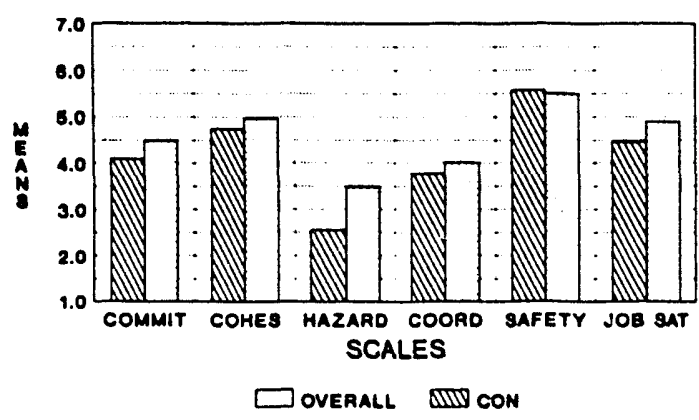

COMPARISON OF OVERALL LANL TO THE DIRECTOR'S OFFICE ON THE ADDITIONAL SCALES

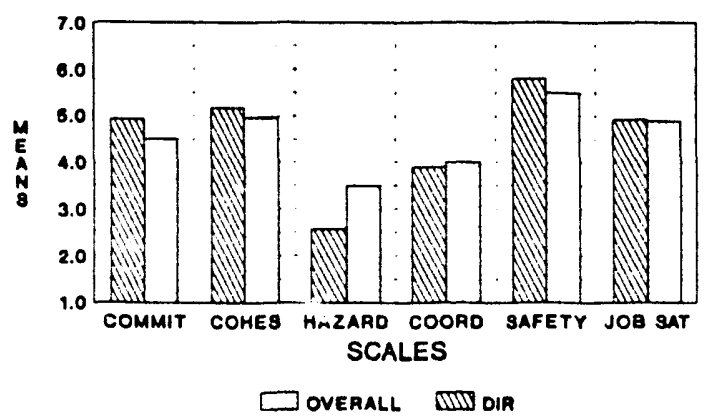

COMPARISON OF OVERALL LANL TO THE HUMAN RESOURCES DIRECTORATE ON THE ADDITIONAL SCALES

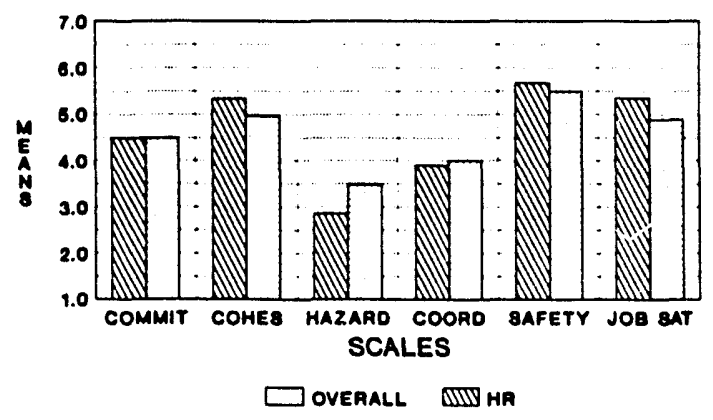

COMPARISON OF OVERALL LANL TO THE LABORATORY COUNSEL DIRECTORATE ON THE ADDITIONAL SCALES

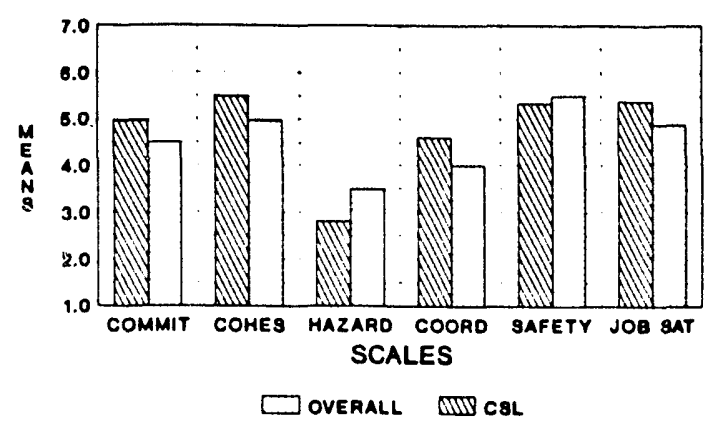


COMPARISON OF OVERALL LANL TO THE DEFENSE RESEARCH AND APPLICATIONS DIRECTORATE ON THE ADDITIONAL SCALES

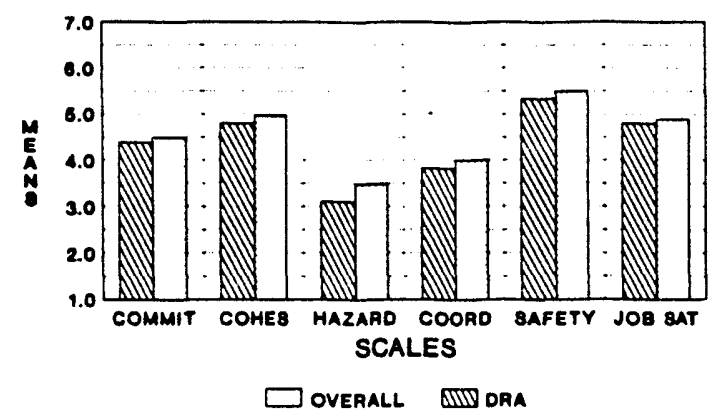

COMPARISON OF OVERALL LANL TO THE OPERATIONS DIRECTORATE ON THE ADDITIONAL SCALES

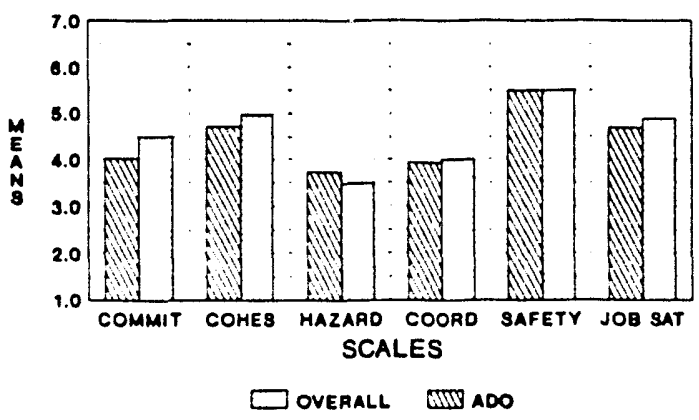

COMPARISON OF OVERALL LANL TO THE ENERGY AND TECHNOLOGY DIRECTORATE ON THE ADDITIONAL SCALES

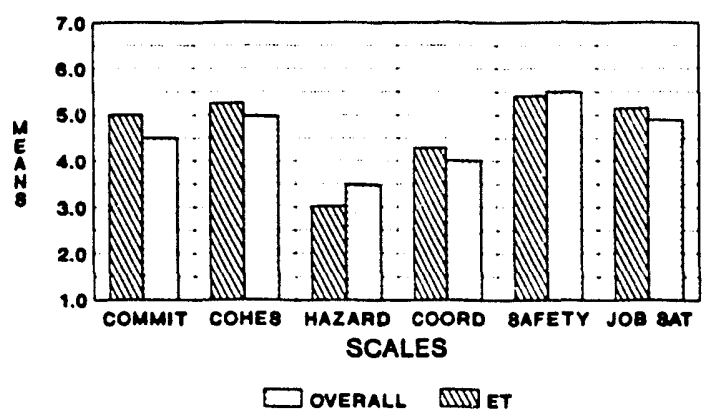

COMPARISON OF OVERALL LANL TO THE AT LARGE \& CNSS DIRECTORATE ON THE ADDITIONAL SCALES

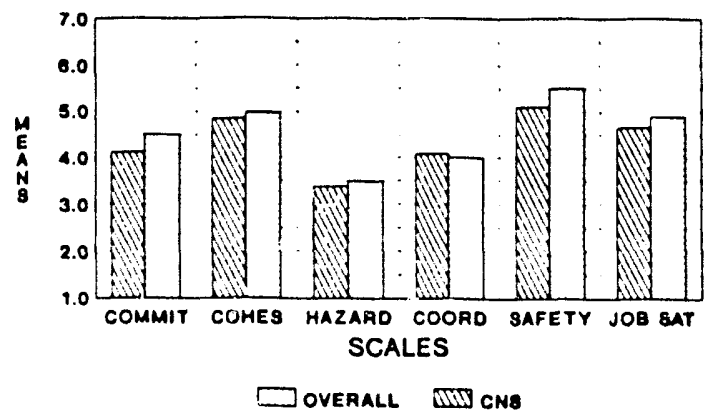


COMPARISON OF OVERALL LANL TO THE CHEMISTRY AND MATERIALS DIRECTORATE ON THE ADDITIONAL SCALES

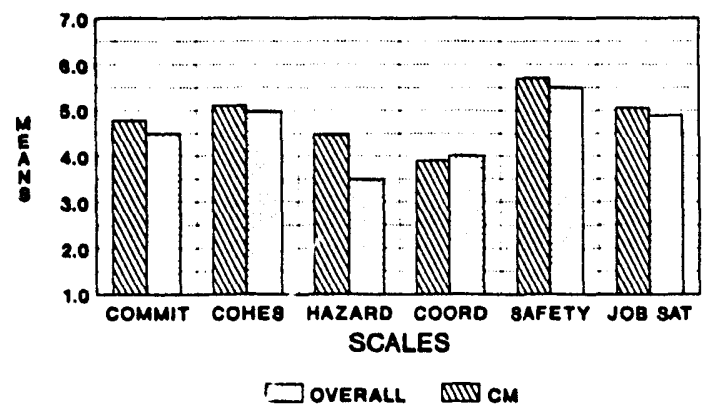

COMPARISON OF OVERALL LANL TO THE RESEARCH DIRECTORATE ON THE ADDITIONAL SCALES

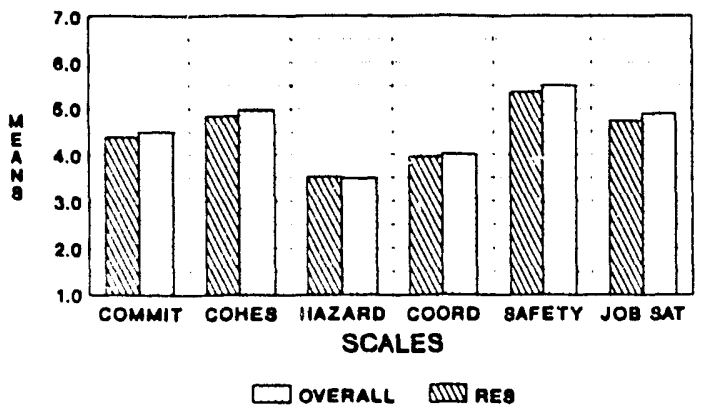

COMPARISON OF OVERALL LANL TO THE NUCLEAR WEAPONS TECHNOLOGY DIRECTORATE ON THE ADDITIONAL SCALES

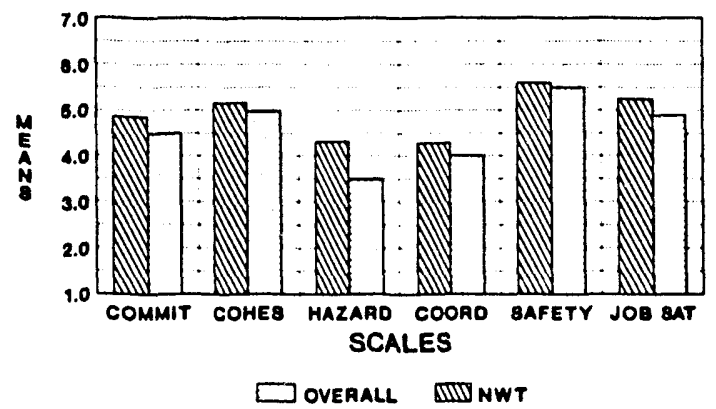


Appendix J: Mean Values for the Overall LANL Organization Compared to the Mean Values Obtained for Each LANL Directorate on the Environment, Safety, and Health Questions

COMPARISON OF OVERALL LANL TO THE CONTROLLER ON THE ENVIRONMENT, SAFETY, \& HEALTH QUESTIONS

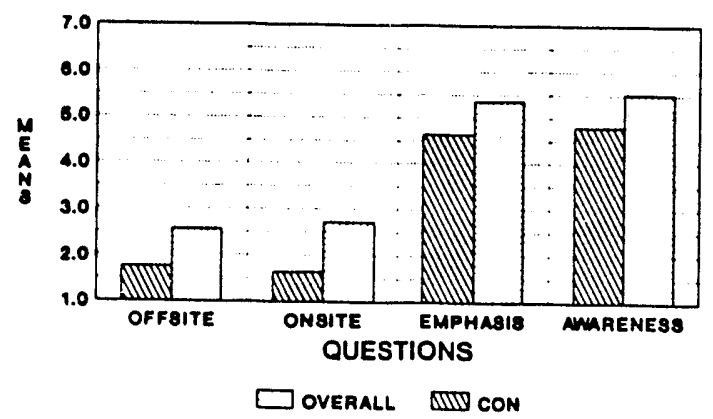

COMPARISON OF OVERALL LANL TO THE DIRECTOR'S OFFICE ON THE ENVIRONMENT, SAFETY, \& HEALTH QUESTIONS

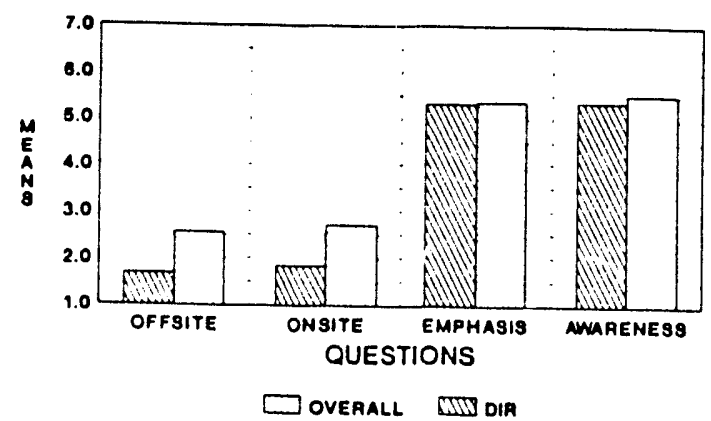

COMPARISON OF OVERALL LANL TO THE HUMAN RESOURCES ON THE ENVIRONMENT, SAFETY, \& HEALTH QUESTIONS

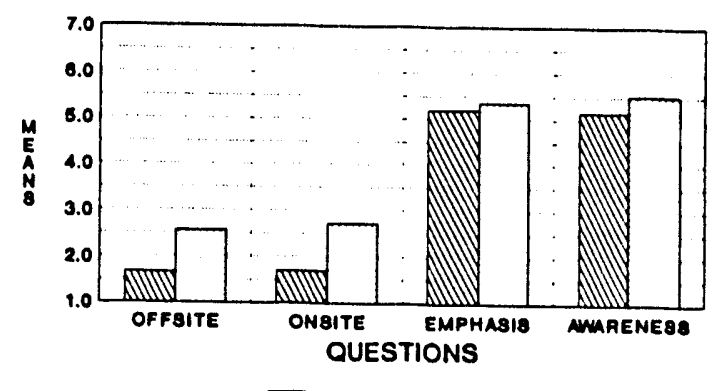

$\square$ OVERALL UIITH
COMPARISON OF OVERALL LANL TO THE LABORATORY COUNSEL ON THE ENVIRONMENT, SAFETY, \& HEALTH QUESTIONS

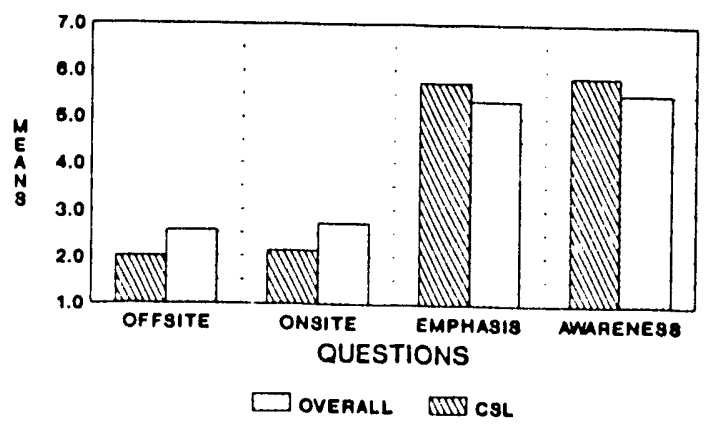


COMPARISON OF OVERALL LANL TO THE DEFENSE RESEARCH \& APPLICATION DIRECTORATE ON ENVIRONMENT SAFETY HEALTH QUESTIONS

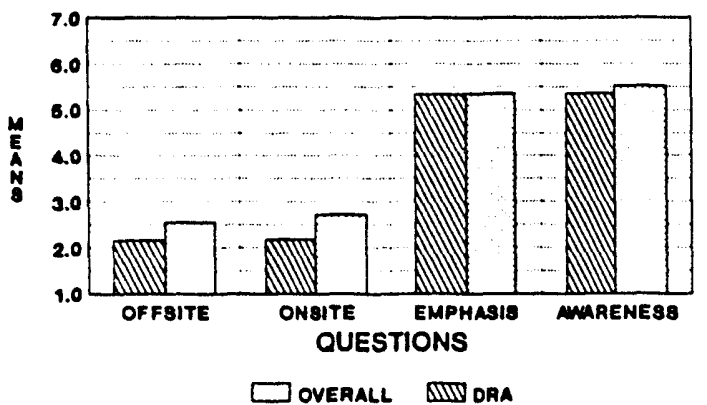

COMPARISON OF OVERALL LANL TO THE OPERATIONS DIRECTORATE ON THE ENVIRONMENT, SAFETY, \& HEALTH QUESTIONS

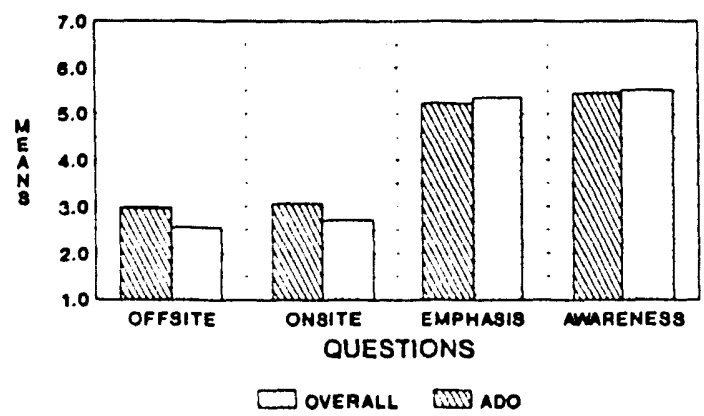

COMPARISON OF OVERALL LANL TO THE ENERGY AND TECHNOLOGY DIRECTORATE ON THE ENVIRONMENT, SAFETY, \& HEALTH QUESTIONS

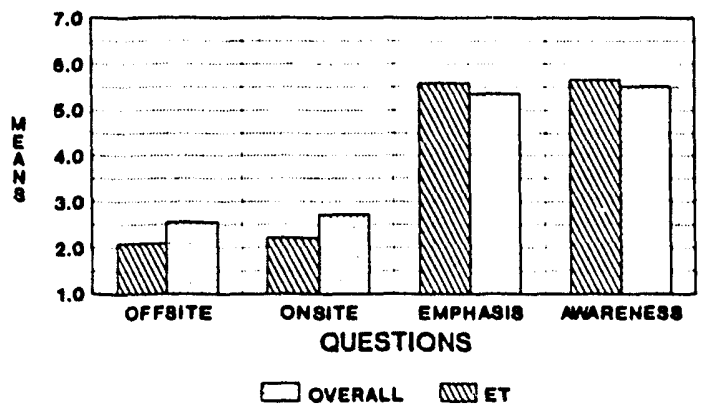

COMPARISON OF OVERALL LANL TO THE AT LARGE \& CNSS DIRECTORATE ON THE ENVIRONMENT, SAFETY, \& HEALTH QUESTIONS

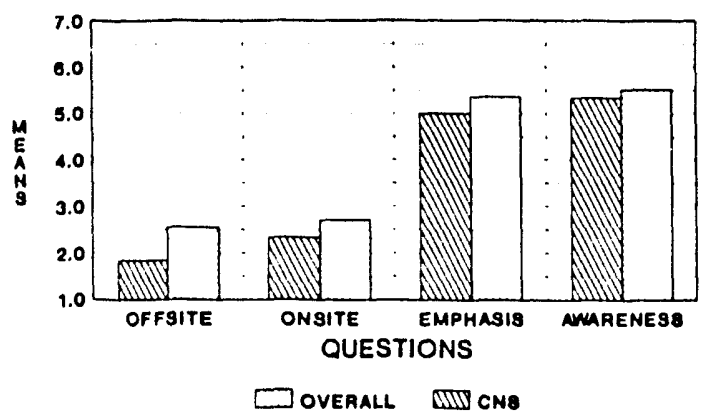


COMPARISON OF OVERALL LANL TO THE CHEMISTRY \& MATERIALS DIRECTORATE ON THE ENVIRONMENT, SAFETY, \& HEALTH QUESTIONS

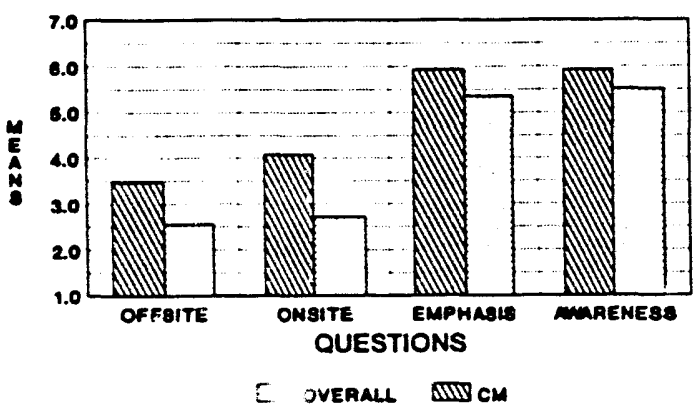

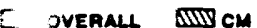

COMPARISON OF OVERALL LANL TO NUCLEAR WEAPONS TECHNOLOGY DIRECTORATE ON THE ENVIRONMENT, SAFETY, \& HEALTH QUESTIONS

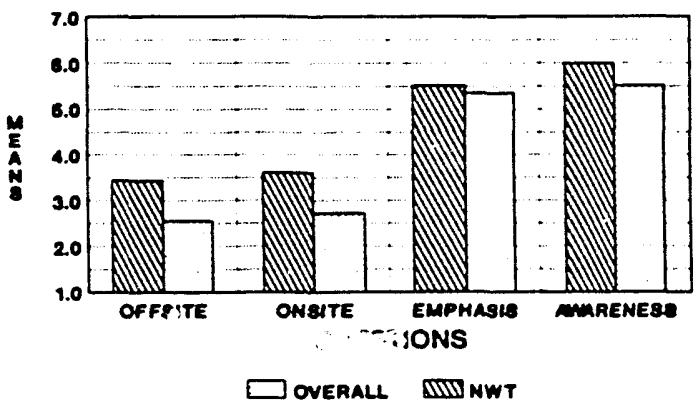

COMPARISON OF OVERALL LANL TO THE RESEARCH DIRECTORATE ON THE ENVIRONMENT, SAFETY, \& HEALTH QUESTIONS

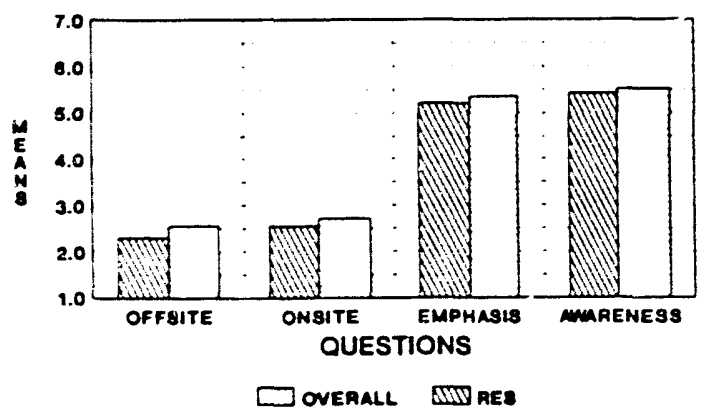




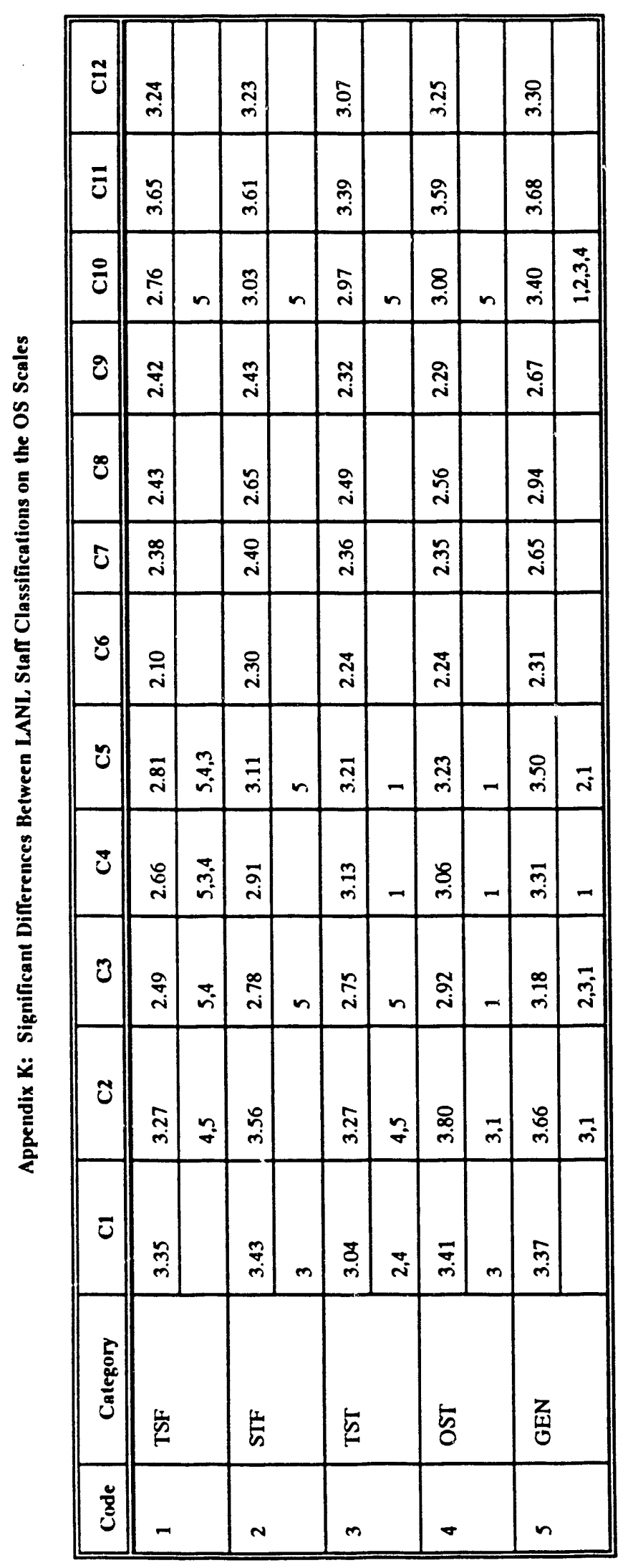




\begin{tabular}{|c|c|c|c|c|c|c|c|c|c|c|}
\hline$\sum_{i=2}$ & $\begin{array}{l}\mathbb{N} \\
\dot{n}\end{array}$ & & $\underset{\sim}{\stackrel{\approx}{i}}$ & & $\bar{m}$ & & $\stackrel{\infty}{\stackrel{m}{n}}$ & & స్ & \\
\hline$\frac{5}{2}$ & $\stackrel{\varnothing}{n}$ & & $\underset{n}{\sigma}$ & & $\frac{\infty}{\sim}$ & & $\overrightarrow{\dot{v}}$ & & $\underset{n}{t}$ & \\
\hline$\sum_{0}^{n}$ & $\stackrel{\sim}{i}$ & $\tilde{n}$ & $\stackrel{\infty}{\infty}$ & $\stackrel{m}{=}$ & $\vec{j}_{\dot{m}}$ & $\tilde{\sim}$ & $\sqrt[5]{n}$ & & $\stackrel{\circ}{\circ}$ & $\dddot{m}$ \\
\hline$\frac{5}{0}$ & $\stackrel{\infty}{\stackrel{\infty}{\sim}}$ & & $\stackrel{\infty}{\circ}$ & $\dot{m}$ & $\frac{\circ}{m}$ & $\tilde{n}$ & $\vec{i}$ & $N$ & స్సి & $m$ \\
\hline$\sum_{j}^{\infty}$ & $\underset{\sim}{\stackrel{\sim}{*}}$ & & $\stackrel{b}{0}$ & & 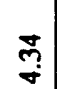 & & $\underset{\sim}{\stackrel{a}{+}}$ & & $\stackrel{\circ}{*}$ & \\
\hline $\bar{z}$ & $\underset{\dot{p}}{\hat{n}}$ & $m$ & $\frac{\pi}{n}$ & ñ & $\frac{\vec{V}}{n}$ & $\vec{N}$ & ڤn & & $\frac{\infty}{n}$ & $\sim$ \\
\hline$\sum_{U}^{\leq}$ & $\stackrel{5}{n}$ & $\stackrel{n}{m}$ & $\underset{\sim}{\stackrel{\leftrightarrow}{+}}$ & $n$ & $\tilde{n}$ & - & $\stackrel{n}{\sigma}$ & $n$ & స్ণ & $\stackrel{\bar{s}}{\Im}$ \\
\hline $\bar{z}$ & $\begin{array}{l}2 \\
\dot{0}\end{array}$ & & $\frac{n}{\sigma}$ & & $\underset{\sim}{\mathbb{\sim}}$ & & $\stackrel{\infty}{+}$ & & $\underset{8}{8}$ & \\
\hline$\stackrel{\infty}{\underline{0}}$ & $\underset{\square}{\circ}$ & & $\underset{\sigma}{\sigma}$ & & $\underset{\sim}{\stackrel{\overbrace{}}{\sigma}}$ & & $\underset{\sim}{\tilde{C}}$ & & $\underset{\sim}{\sim}$ & \\
\hline ठิ & $\begin{array}{c}5 \\
+\end{array}$ & & $\underset{\sim}{\mathbb{N}}$ & & $\begin{array}{l}\infty \\
\infty \\
m\end{array}$ & & $\underset{+}{\stackrel{\infty}{+}}$ & & $\underset{f}{\stackrel{f}{F}}$ & \\
\hline 孚 & $\stackrel{m}{\vec{v}}$ & & n̊ & & $\underset{v}{v_{i}}$ & & $\begin{array}{l}\tilde{\sigma} \\
\dot{n}\end{array}$ & & $\stackrel{\overbrace{}}{n}$ & \\
\hline$\geqq$ & $\begin{array}{c}\tilde{n} \\
\boldsymbol{c}_{i}\end{array}$ & $\begin{array}{l}n \\
n \\
m\end{array}$ & $\stackrel{\check{n}}{\sim}$ & $\vec{m}$ & $\stackrel{\vec{m}}{+}$ & 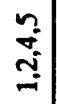 & 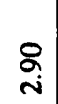 & $m$ & $\underset{\substack{\infty \\
\text { D }}}{ }$ & $\bar{m}$ \\
\hline$\overline{8}$ & $\begin{array}{l}8 \\
\text { ni }\end{array}$ & & $\underset{n}{\infty}$ & & $\vec{\sigma}$ & & $\underset{\sim}{\delta}$ & & $\underset{+}{\stackrel{\circ}{\circ}}$ & \\
\hline 8 & $\begin{array}{l}\infty \\
\stackrel{\infty}{*}\end{array}$ & & $\stackrel{g}{+}$ & & $\stackrel{m}{\rightarrow}$ & & $\bar{n}$ & & 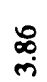 & \\
\hline 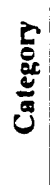 & $\frac{1}{\omega}$ & & $\frac{5}{5}$ & & 5 & & 5 & & 㿿 & \\
\hline Uू & - & & $N$ & & $m$ & & $\nabla$ & & $n$ & \\
\hline
\end{tabular}



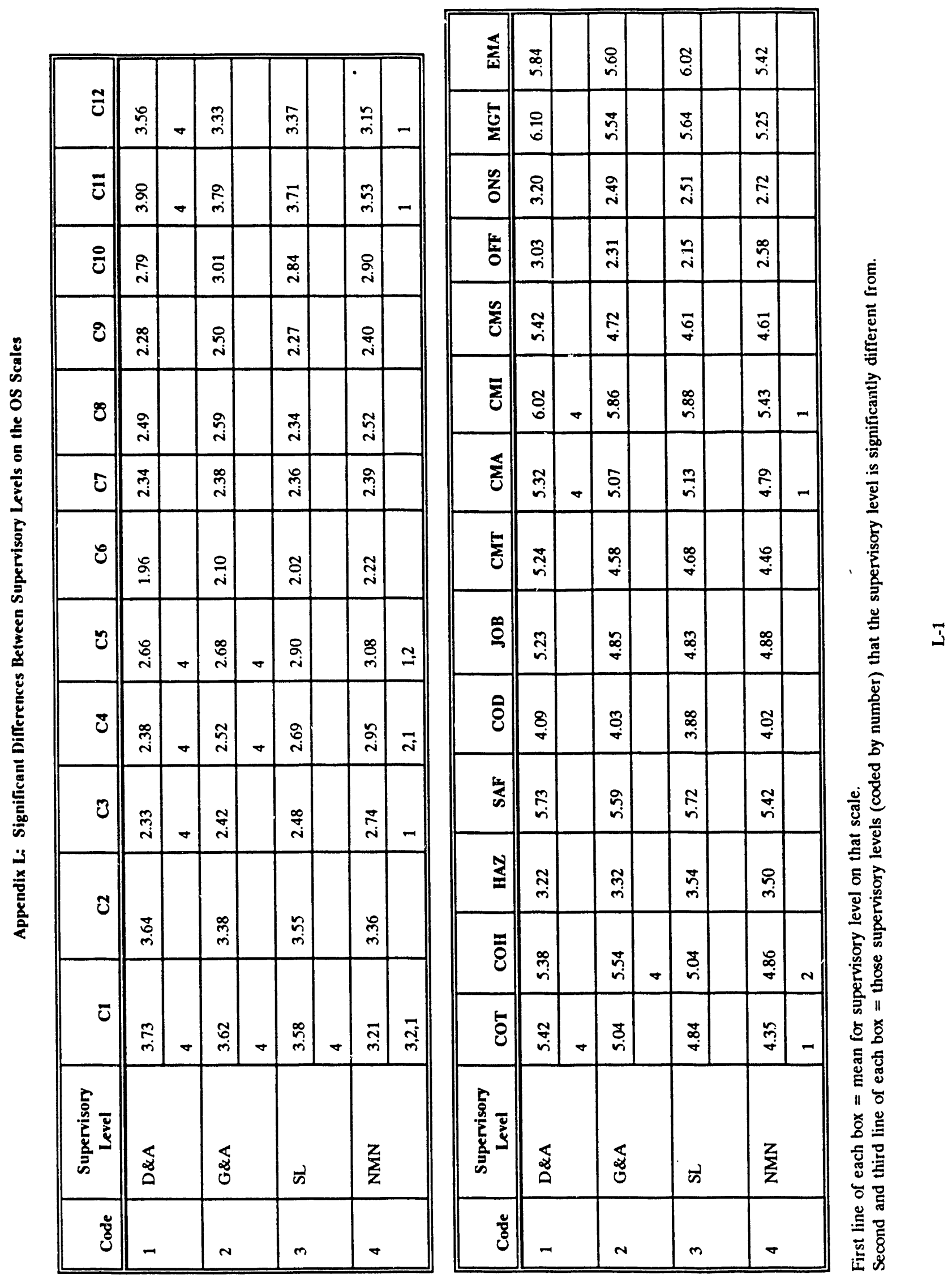


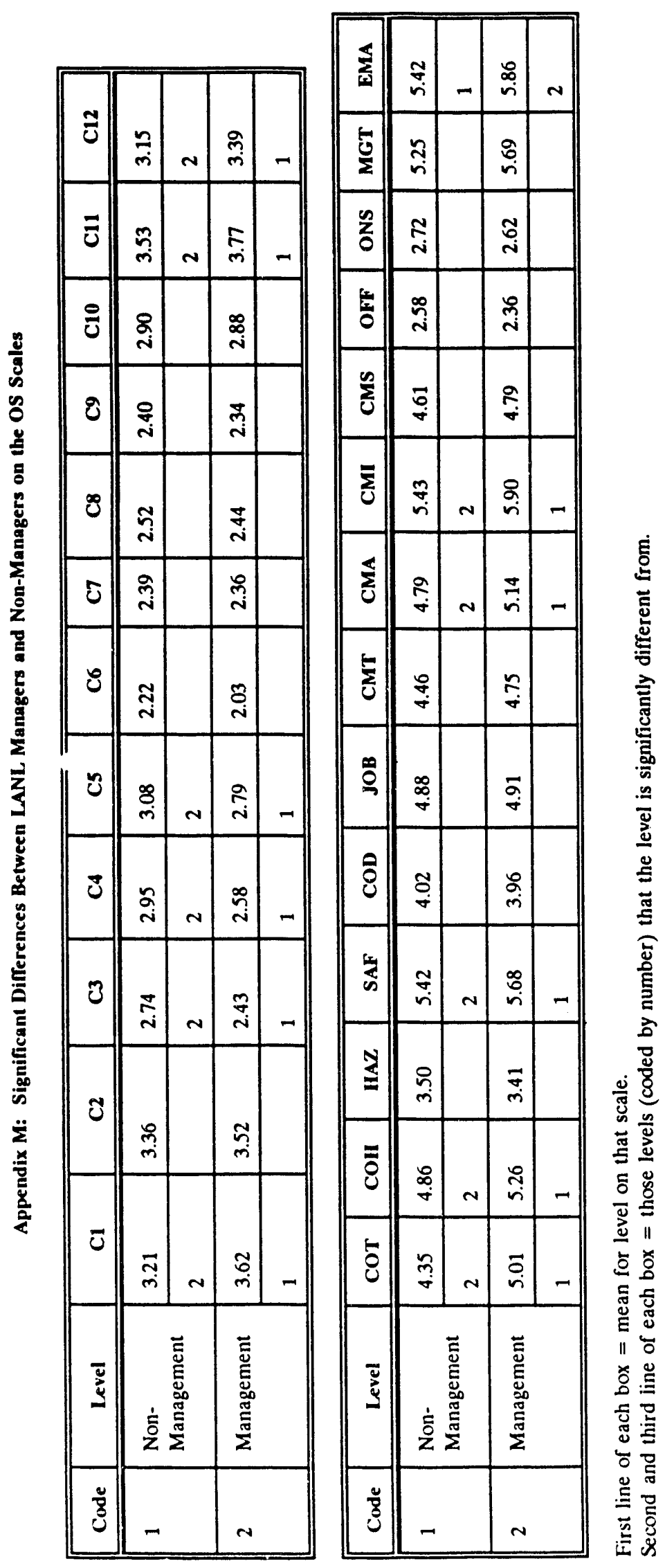




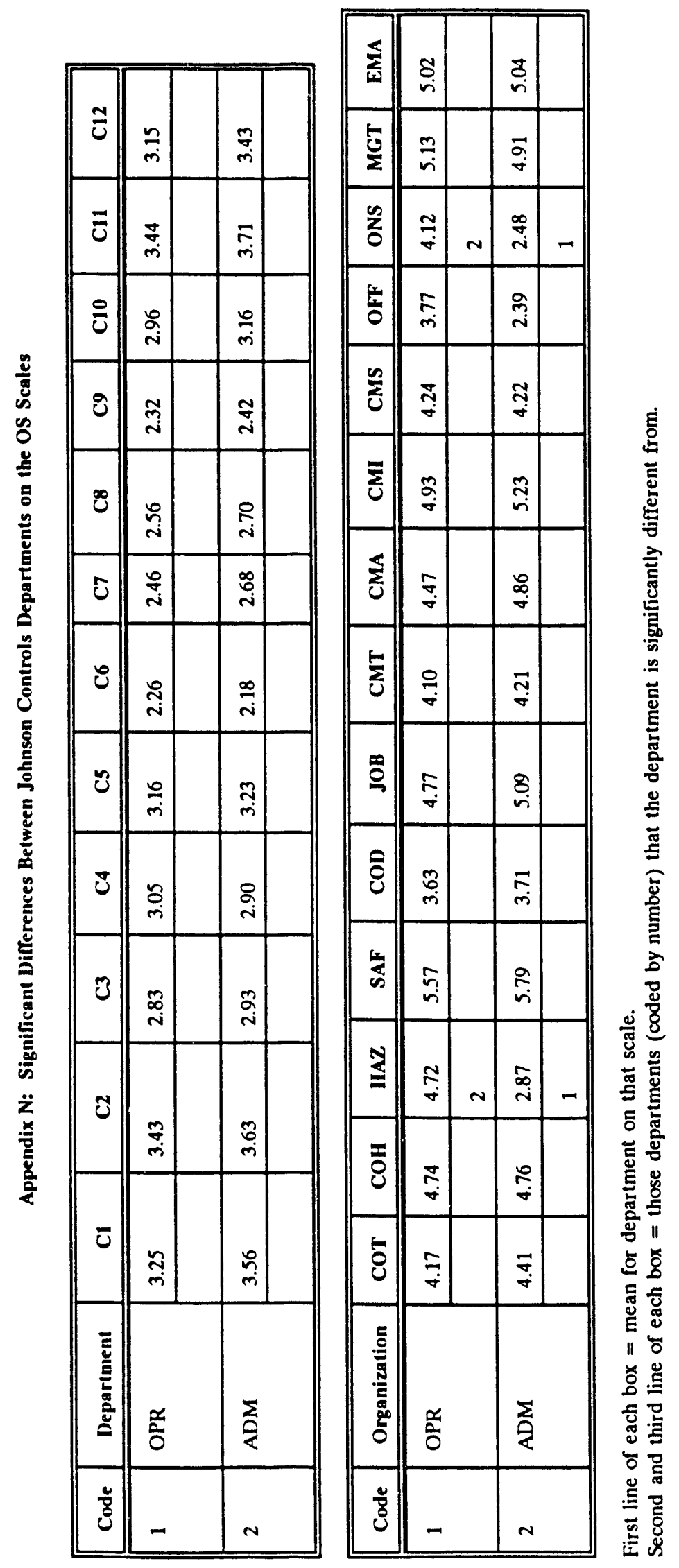


Appendix P: Mean Values for the Overall Johnson Controls Organization Compared to the Mean Values Obtained for Each.Juhnson Controls Department on the Communication Scales

COMPARISON OF OVERALL JOHNSON CONTROLS TO THE ADMINISTRATION DEPARTMENT ON THE OCI SCALES

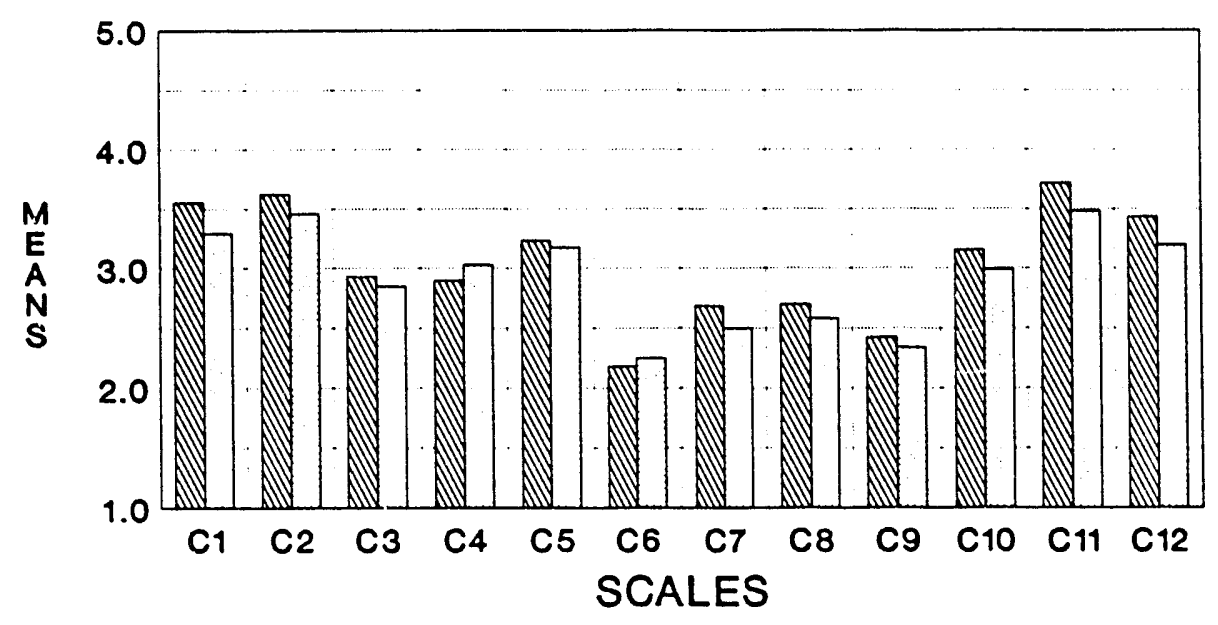

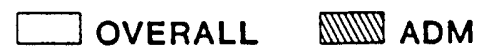

COMPARISON OF OVERALL JOHNSON

CONTROLS TO THE OPERATIONS

DEPARTMENT ON THE OCI SCALES

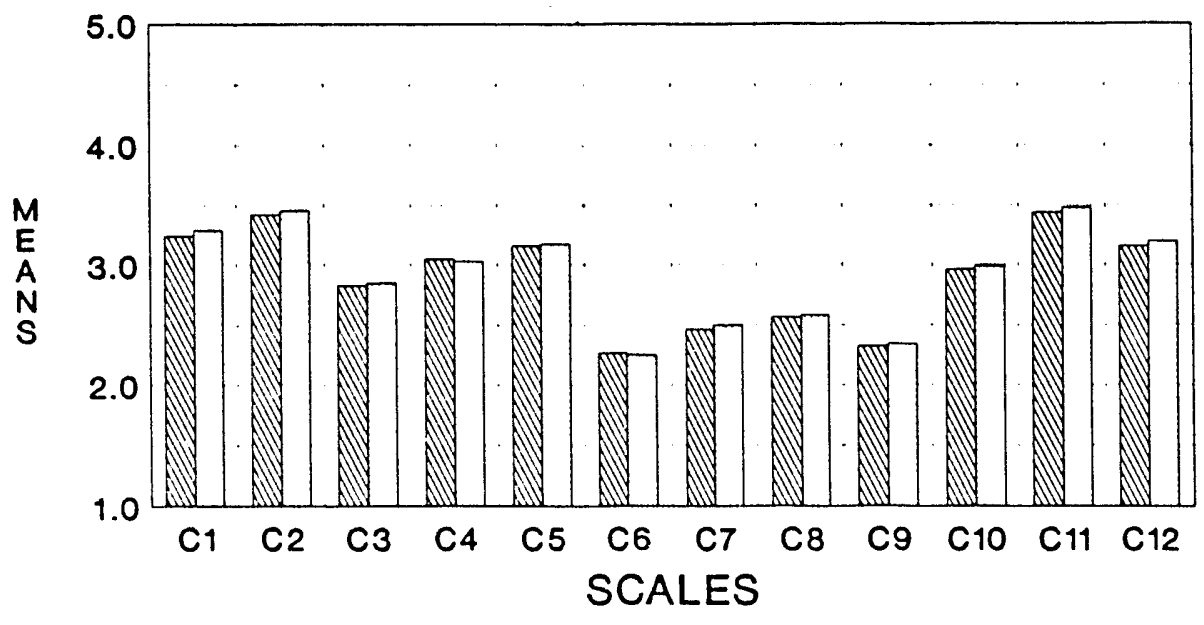

$\square$ OVERALL $\quad$ MUIU⿴囗十⺝ OPR

P-1 
COMPARISON OF OVERALL JOHNSON CONTROLS TO THE ADMINISTRATION DEPARTMENT ON THE COMMUNICATION SCALES

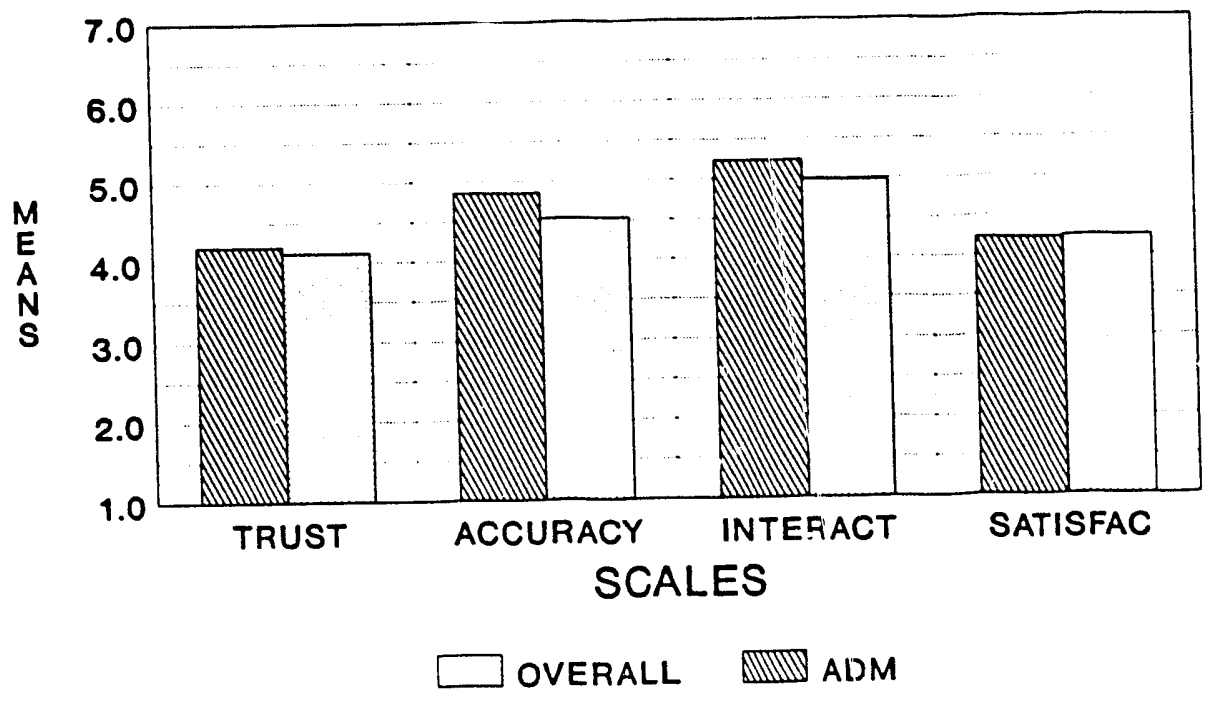

COMPARISON OF OVERALL JOHNSON CONTROLS TO THE OPERATIONS DEPARTMENT ON THE COMMUNICATION SCALES

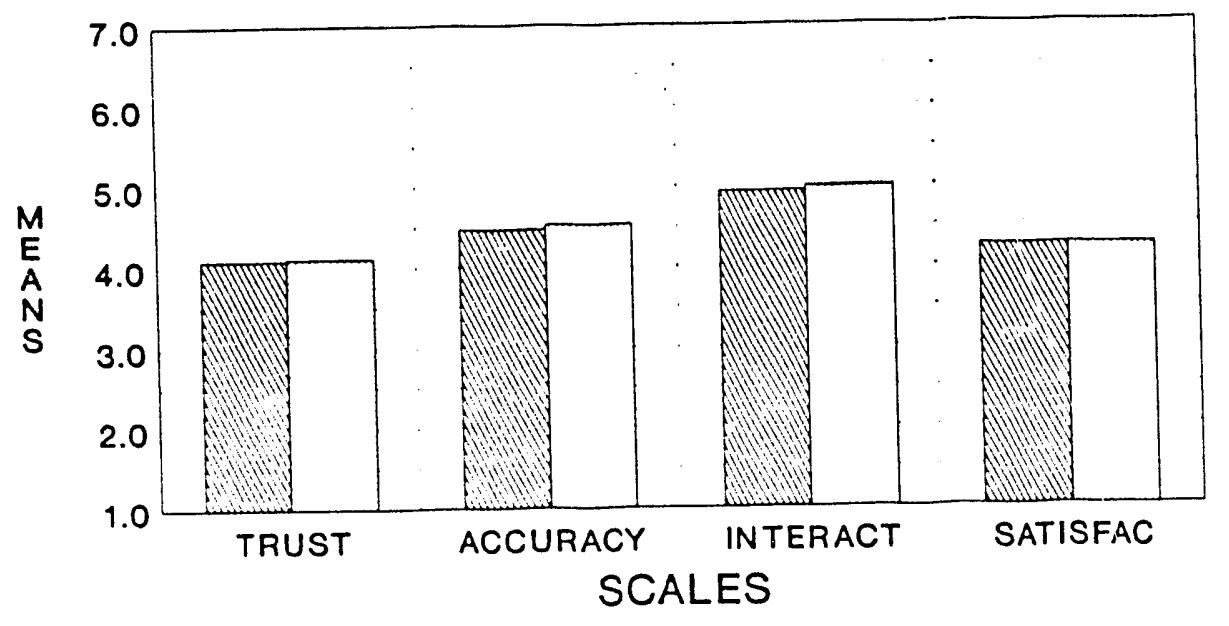

$\square$ OVERALL OPR 
Appendix Q: Mean Values for the Overall Johnson Controls Organization Compared to the Mean Values Obtained for Each Johnson Controls Department on the Additional Scales

COMPARISON OF OVERALL JOHNSON CONTROLS TO THE ADMINISTRATION DEPARTMENT ON THE ADDITIONAL SCALES

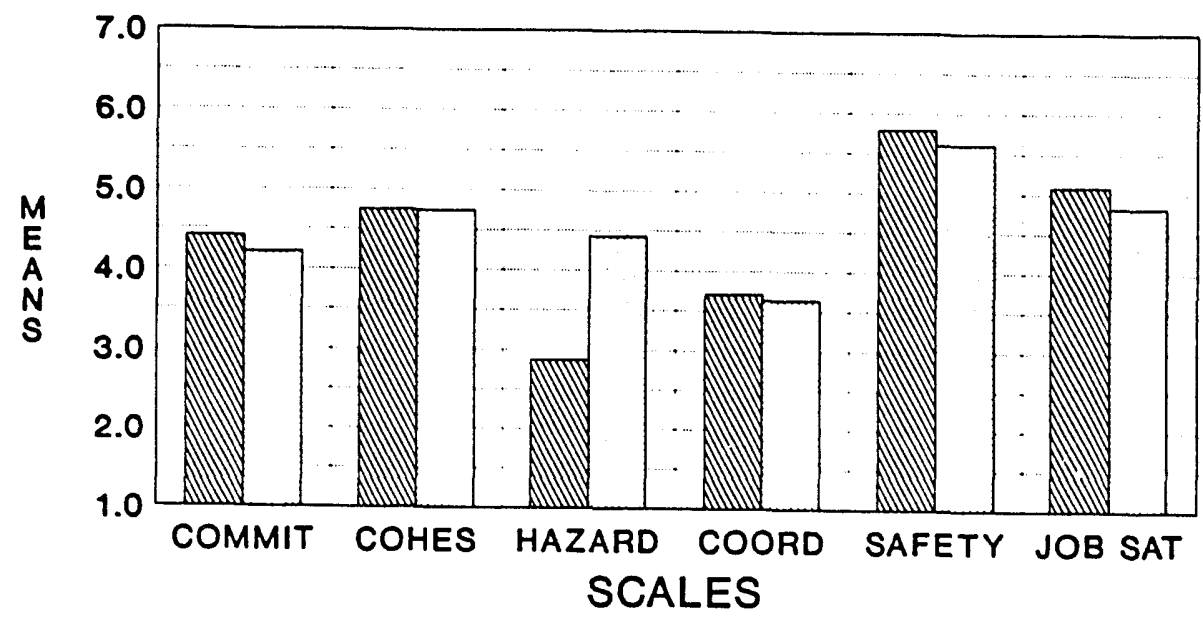

OVERALL $\$$ ADIII ADM

COMPARISON OF OVERALL JOHNSON CONTROLS TO THE OPERATIONS DEPARTMENT ON THE ADDITIONAL SCIALES

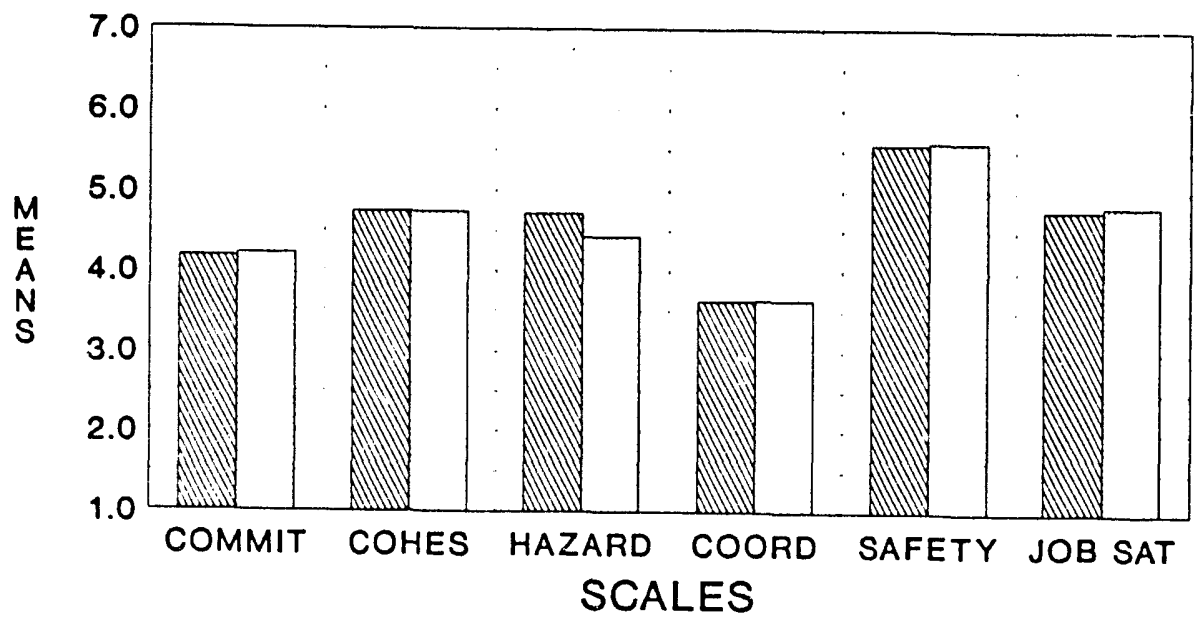

OVERALL RIIIIJ OPR

Q-1 
Appendix R: Mean Values for the Overall Johnson Controls Organization Compared to the Mean

- Values Obtained for Each Johnson Controls Department on the Environment, Safety, and Health Questions

COMPARISON OF OVERALL JOHNSON CONTROLS TO THE ADMINISTRATION DEPARTMENT ON THE ENVIRONMENT, SAFETY, \& HEALTH QUESTIONS

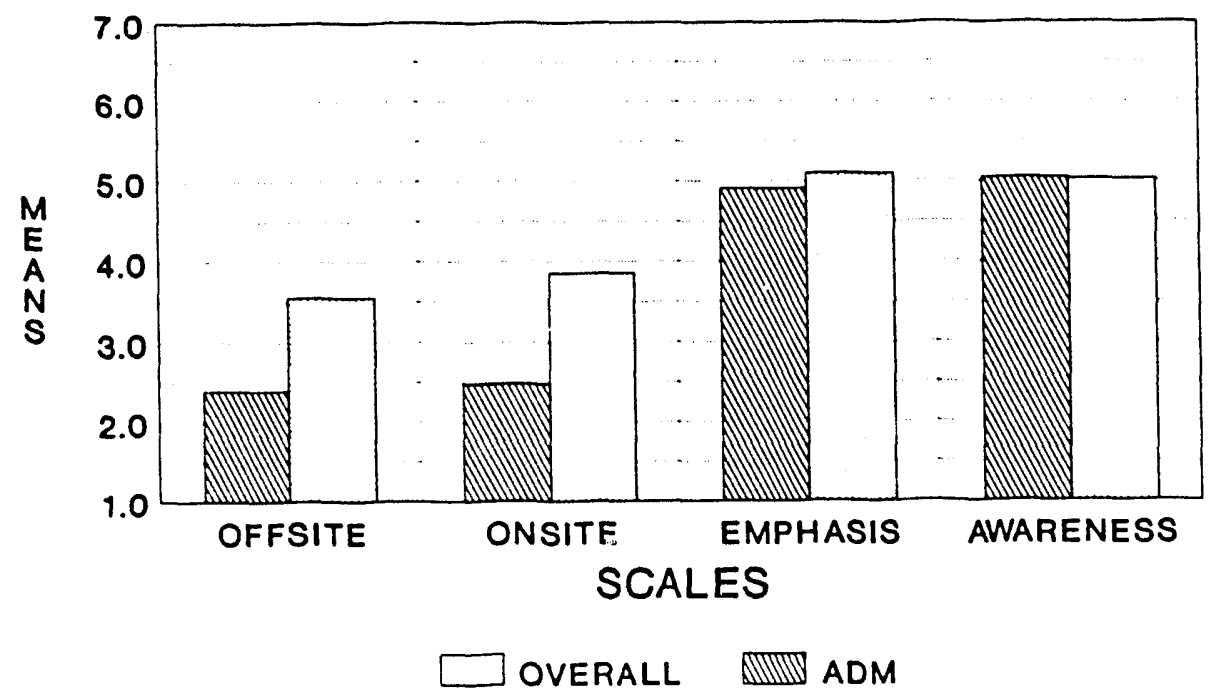

COMPARISON OF OVERALL JOHNSON CONTROLS

TO THE OPERATIONS DEPARTMENT ON THE ENVIRONMENT, SAFETY, \& HEALTH QUESTIONS

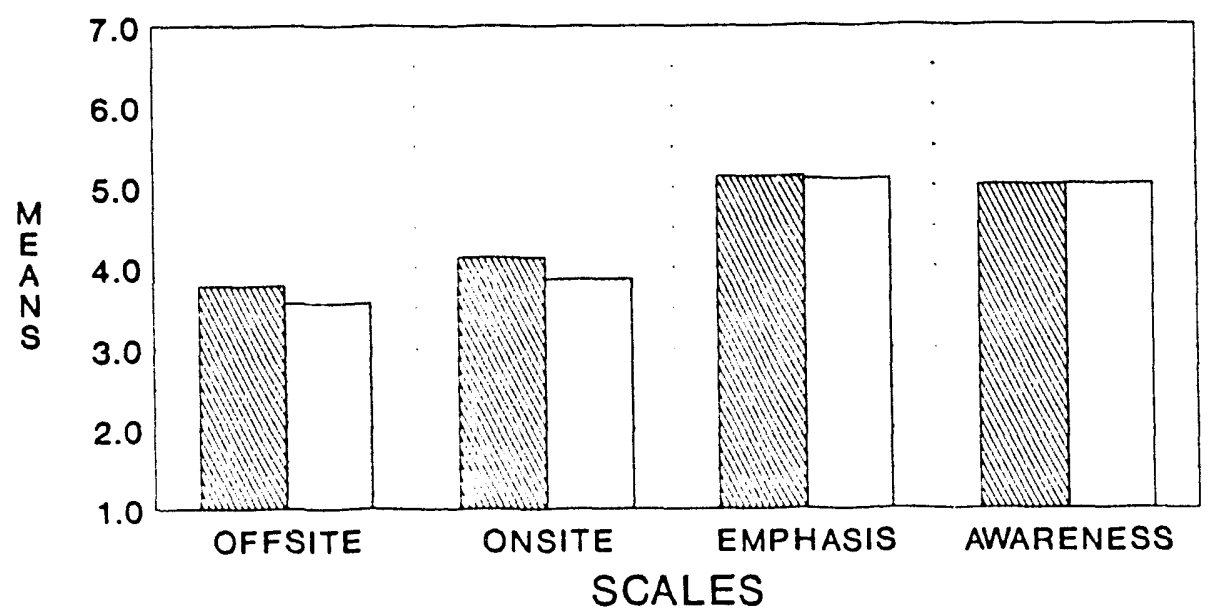

OVERALL OPR

R-1 


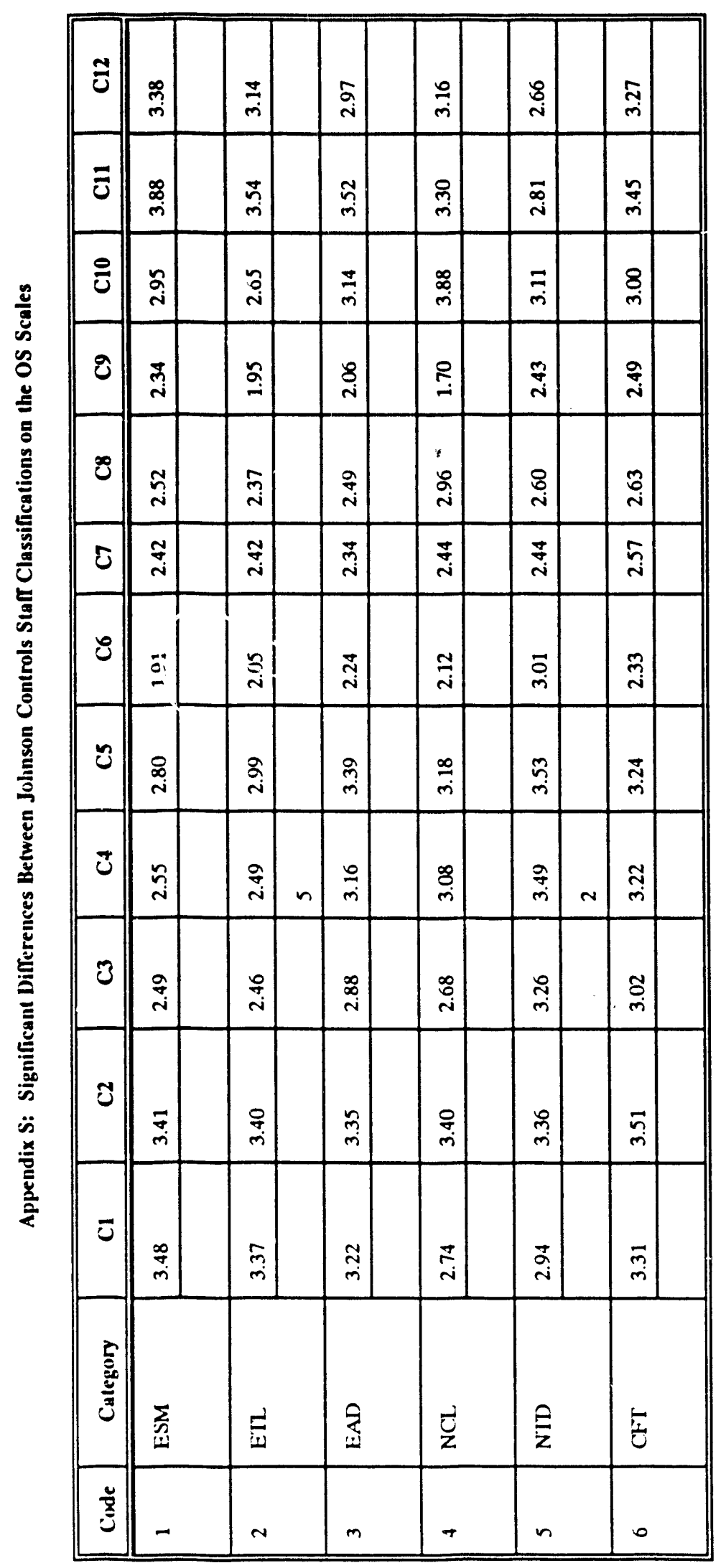




\begin{tabular}{|c|c|c|c|c|c|c|c|c|}
\hline$\sum_{x=1}^{5}$ & $\stackrel{\beth}{n}$ & $\overrightarrow{\vec{n}}$ & $\vec{b}$ & & $\stackrel{8}{8}$ & $\stackrel{m}{m}$ & $\bar{a}$ & \\
\hline 5 & $\underset{8}{8}$ & $\underset{n}{8}$ & $\underset{\sim}{\sim}$ & & 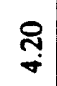 & స్లి & $\frac{7}{n}$ & \\
\hline$\frac{n}{z}$ & $\stackrel{\bar{m}}{m}$ & $\stackrel{n}{\rightarrow}$ & $\underset{i}{i}$ & & శ్రి & $\underset{\sim}{\stackrel{m}{\sim}}$ & $\underset{\forall}{\stackrel{\sim}{*}}$ & \\
\hline 竞 & $\underset{\sim}{\infty}$ & 胥 & $\underset{\mathrm{N}}{8}$ & & $\underset{m}{8}$ & $\underset{\mathrm{m}}{8}$ & $\underset{\dot{m}}{\stackrel{a}{b}}$ & \\
\hline$\sum_{U}^{n}$ & $\stackrel{R}{\stackrel{R}{+}}$ & $\underset{+}{8}$ & $\underset{\sim}{\stackrel{\sim}{*}}$ & & $\underset{m}{\stackrel{P}{m}}$ & $\underset{+}{8}$ & $\underset{+}{7}$ & \\
\hline $\bar{\Sigma}$ & 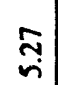 & $\underset{\sim}{\mathbb{n}}$ & $\begin{array}{l}\vec{u} \\
\dot{v}\end{array}$ & & $\stackrel{\overbrace{}}{乛}$ & స్ & $\stackrel{2}{\dot{r}}$ & \\
\hline$\sum_{0}^{\$}$ & $\underset{7}{ซ}$ & $\begin{array}{l}0 \\
0 \\
0\end{array}$ & $\underset{g}{\sigma}$ & & $\stackrel{\tilde{m}}{\vec{\sigma}}$ & $\stackrel{?}{+}$ & $\stackrel{5}{\square}$ & \\
\hline$\sum_{j}^{2}$ & $\frac{\pi}{\dot{\sigma}}$ & $\begin{array}{l}0 \\
+ \\
+\end{array}$ & 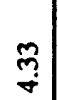 & & $\underset{\sim}{\sim}$ & ڤ̊ำ & $\underset{+}{Z}$ & \\
\hline 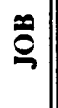 & $\underset{n}{n}$ & $\underset{\sim}{\tilde{\sigma}}$ & $\underset{\sim}{\stackrel{\sim}{*}}$ & & $\underset{+}{8}$ & $\underset{m}{m}$ & $\underset{+}{2}$ & \\
\hline$\widehat{\overline{\mathrm{U}}}$ & $\stackrel{\sim}{m}$ & $\stackrel{n}{\vec{m}}$ & $\underset{m}{\vec{m}}$ & & p్లై & 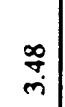 & $\underset{i}{\vec{m}}$ & \\
\hline$\frac{1}{n}$ & $\begin{array}{l}\infty \\
\dot{n}\end{array}$ & $\tilde{n}$ & $\begin{array}{l}\tilde{n} \\
n\end{array}$ & & $\underset{n}{\stackrel{\sim}{n}}$ & $\stackrel{\vec{n}}{\mathfrak{n}}$ & $\begin{array}{l}: \\
\dot{n}\end{array}$ & \\
\hline$\stackrel{3}{a}$ & $\stackrel{8}{:}$ & $\underset{+}{\stackrel{\leftrightarrow}{+}}$ & $\underset{\sim}{\mathbb{N}}$ & 0 & $\underset{8}{8}$ & $\sqrt[5]{n}$ & $\vec{b}$ & $m$ \\
\hline$\overline{0}$ & $\begin{array}{l}\overrightarrow{\tilde{n}} \\
\text {. }\end{array}$ & $\stackrel{9}{\rightarrow}$ & $\frac{n}{\dot{\sigma}}$ & & $\underset{+}{\stackrel{N}{\sigma}}$ & 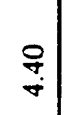 & $\begin{array}{l}a \\
\dot{\sigma}\end{array}$ & \\
\hline 8 & $\stackrel{P}{+}$ & $\begin{array}{l}\vec{a} \\
\dot{m}\end{array}$ & 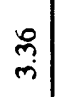 & & $\begin{array}{l}\hat{\infty} \\
\tilde{n}\end{array}$ & $\frac{\Xi}{m}$ & $\begin{array}{l}0 \\
+ \\
+\end{array}$ & \\
\hline 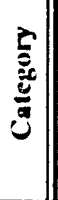 & 忿 & $\vec{n}$ & 蛋 & & $\underset{\mathbf{z}}{\mathbf{z}}$ & $\stackrel{e}{z}$ & $\tilde{U}$ & \\
\hline క气 & - & $N$ & $m$ & & $\vec{\nabla}$ & $n$ & 0 & \\
\hline
\end{tabular}




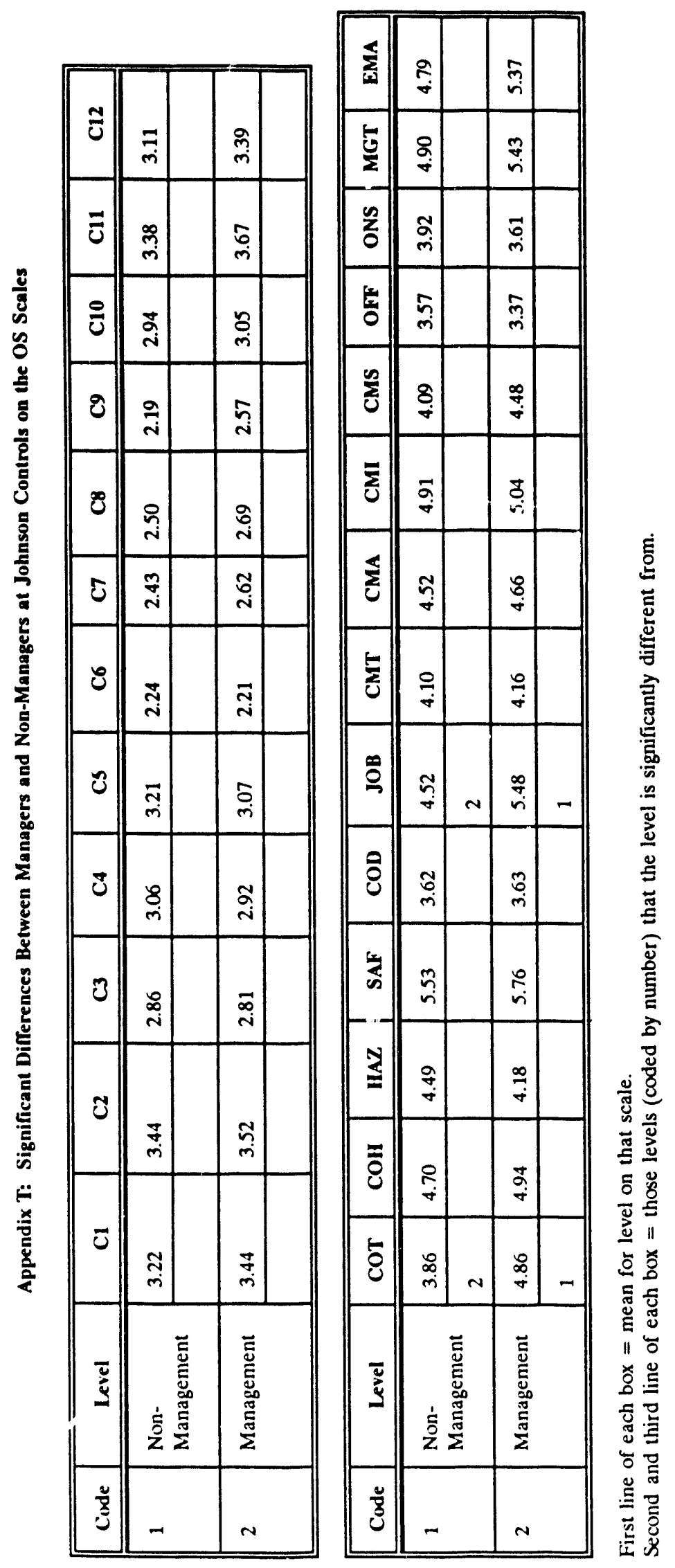



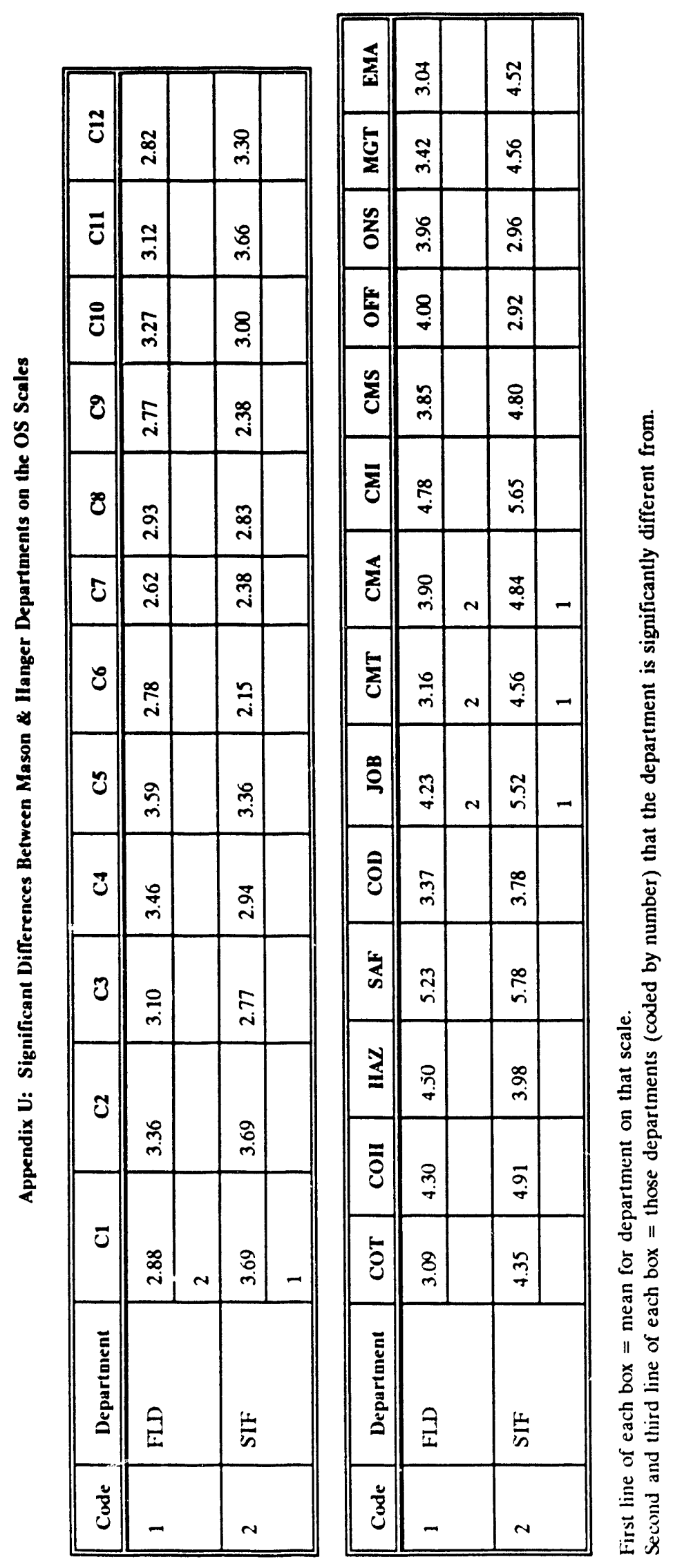
Appendix V: Mean Values for the Overall Mason \& Hanger Organization Compared to the Mean Values Obtained for Each Mason \& Hanger Department on the OCI Scales

COMPARISON OF OVERALL MASON

AND HANGER TO THE FIELD

DEPARTMENT ON THE OCI SCALES

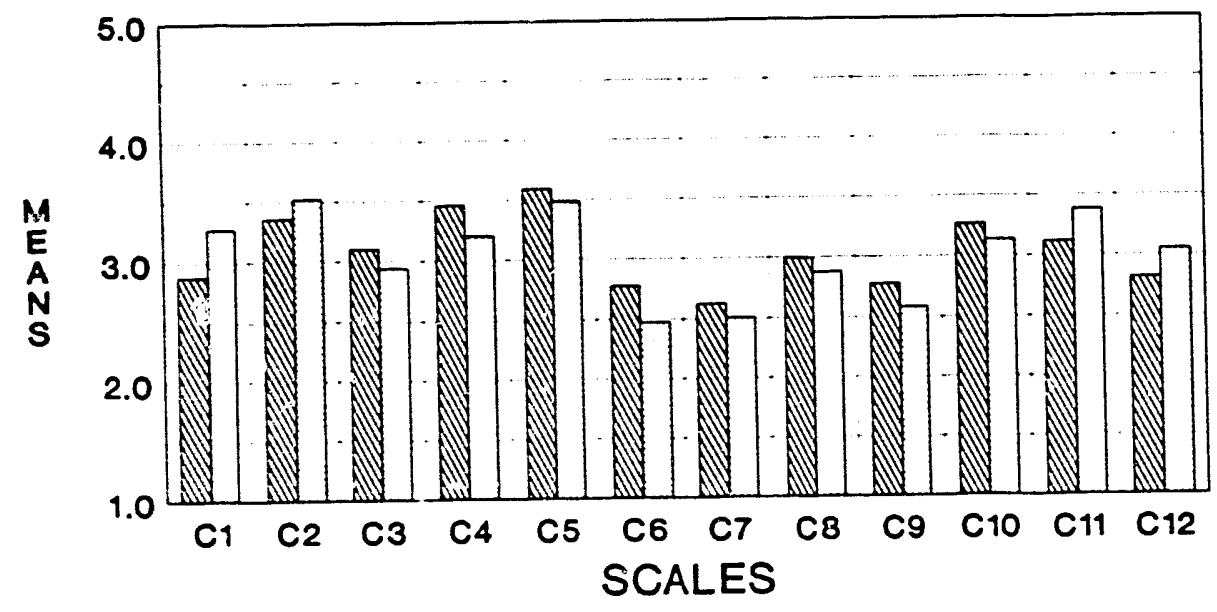

$\square$ OVERALL $\quad$ MUTil FLD

COMPARISON OF OVERALL MASON

AND HANGER TO THE STAFF

DEPARTMENT ON THE OCI SCALES

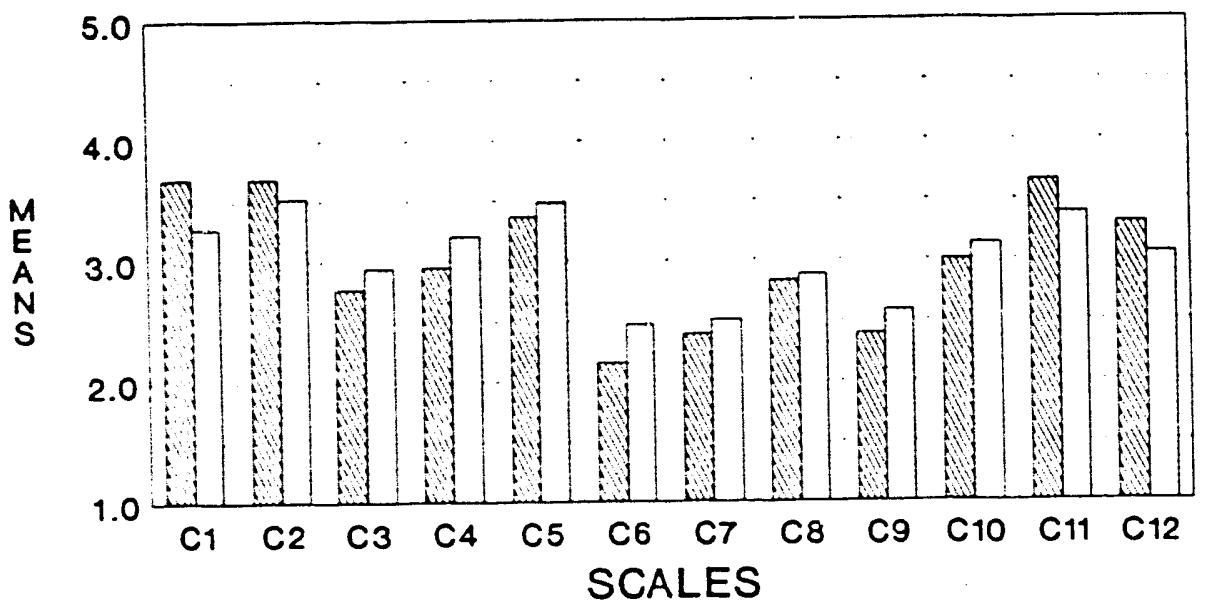

Doverall STF 
Appendix W: Mean Values for the Overall Mason \& Hanger Organization Compared to the Mean Values Obtained for Each Mason \& Hanger Department on the Communication Scales

\section{COMPARISON OF OVERALL MASON \\ AND HANGER TO THE FIELD DEPARTMENT ON THE COMMUNICATION SCALES}

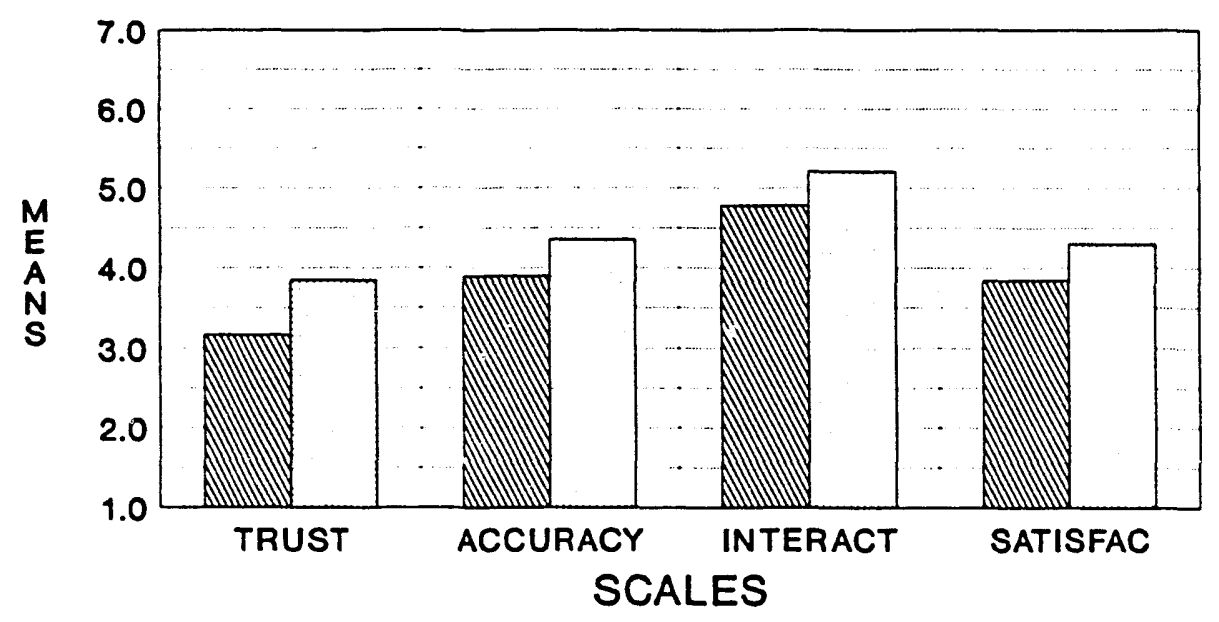

$\square$ OVERALL $\quad \mathbb{R}$ ADM

\section{COMPARISON OF OVERALL MASON \\ AND HANGER TO THE STAFF DEPARTMENT \\ ON THE COMMUNICATION SCALES}

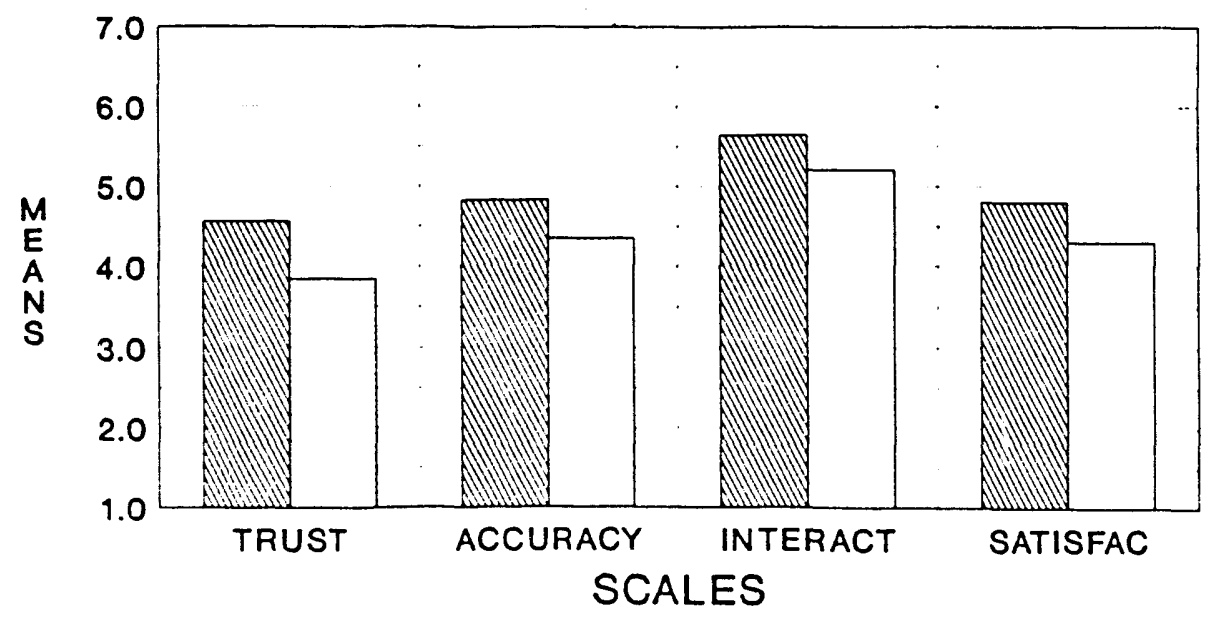

$\square$ OVERALL MIVIJ STF

W-1 
Appendix X: Mean Values for the Overall Mason \& Hanger Organization Compared to the Mean Values Obtained for Each Mason \& Hanger Department on the Additional Scales

COMPARISON OF OVERALL MASON AND HANGER TO THE FIELD DEPARTMENT ON THE ADDITIONAL SCALES

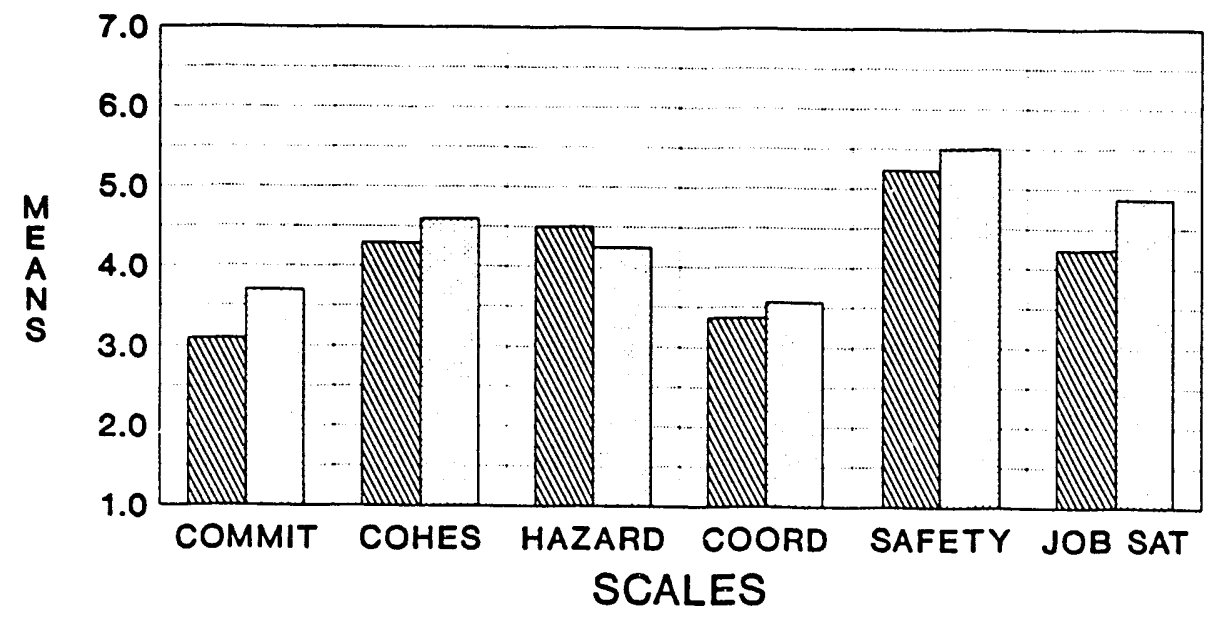

OVERALL $\quad$ MTMW FLD

COMPARISON OF OVERALL MASON AND HANGER TO THE STAFF DEPARTMENT ON THE ADDITIONAL SCALES

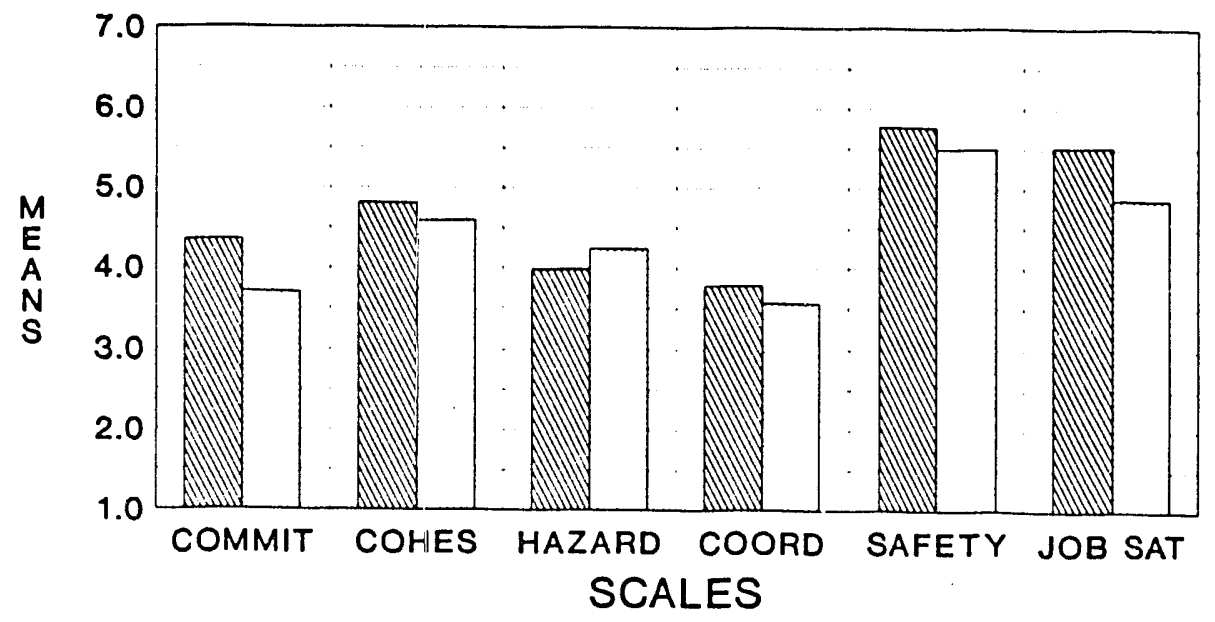

$\square$ OVERALL $\quad$ STITH STF

$\mathrm{X}-1$ 
Appendix Y: Mean Values for the Overall Mason \& Hanger Organization Compared to the Mean Values Obtained for Each Mason \& Hanger Department on the Environment, Safety, and Health Questions

COMPARISON OF OVERALL MASON AND HANGER TO THE FIELD DEPARTMENT ON THE ENVIRONMENT, SAFETY, \& HEALTH QUESTIONS

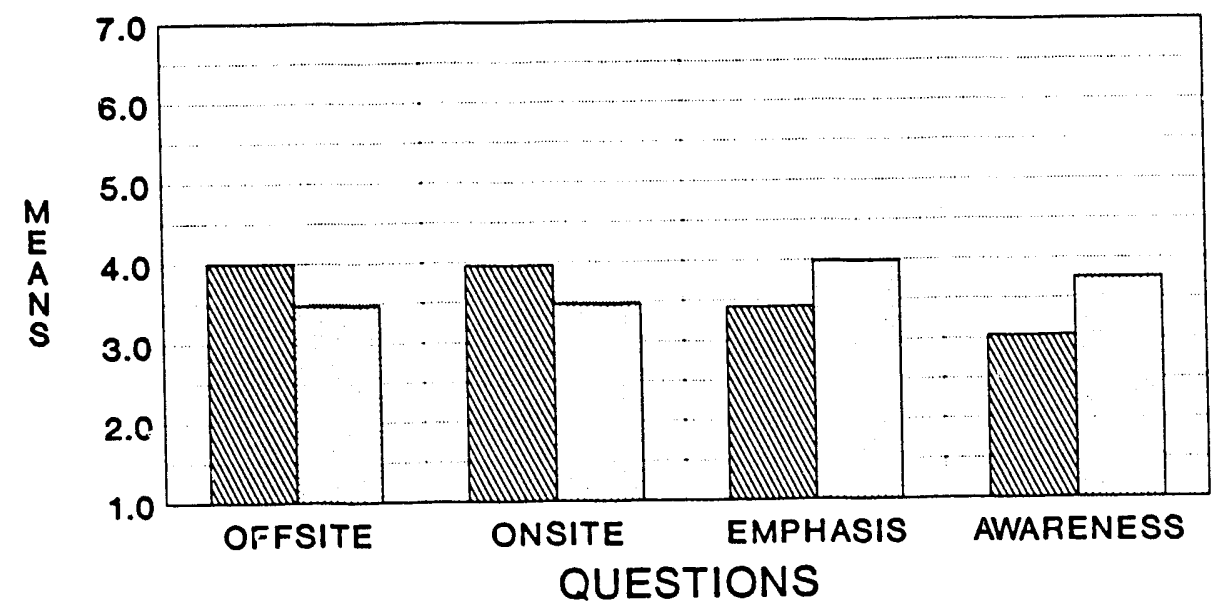

$\square$ OVERALL $\quad$ MUTH

COMPARISON OF OVERALL MASON AND HANSESR TO THE STAFF DEPARTMENT ON THE ENVIRONMENT, SAFETY, \& HEALTH QUESTIONS

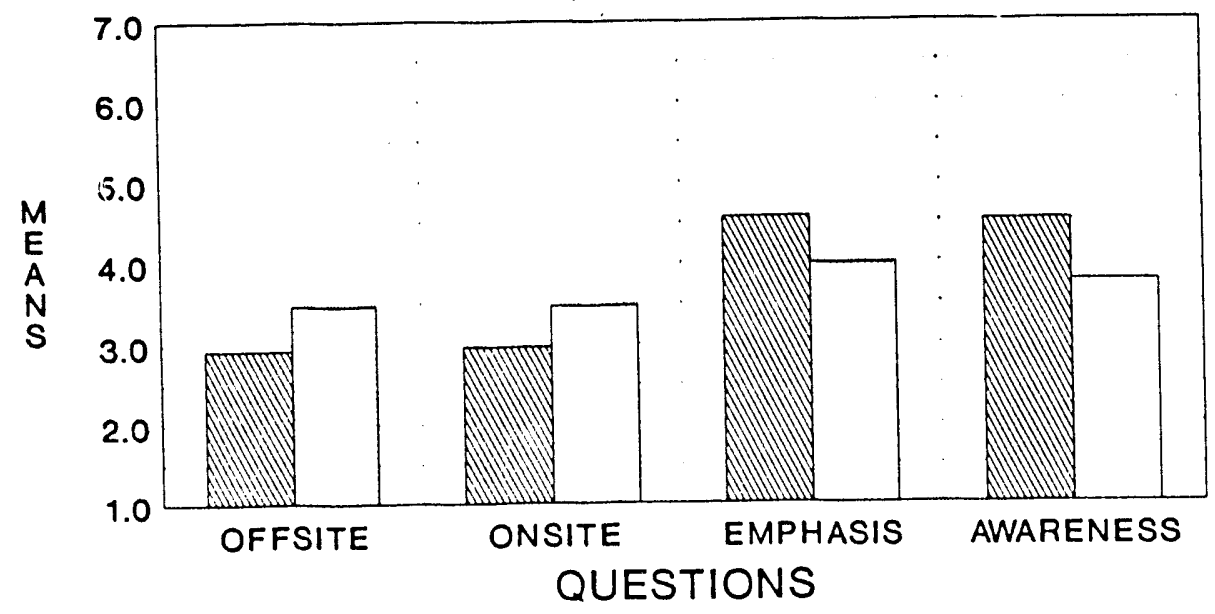

$\square$ OVERALL MUITH STF 


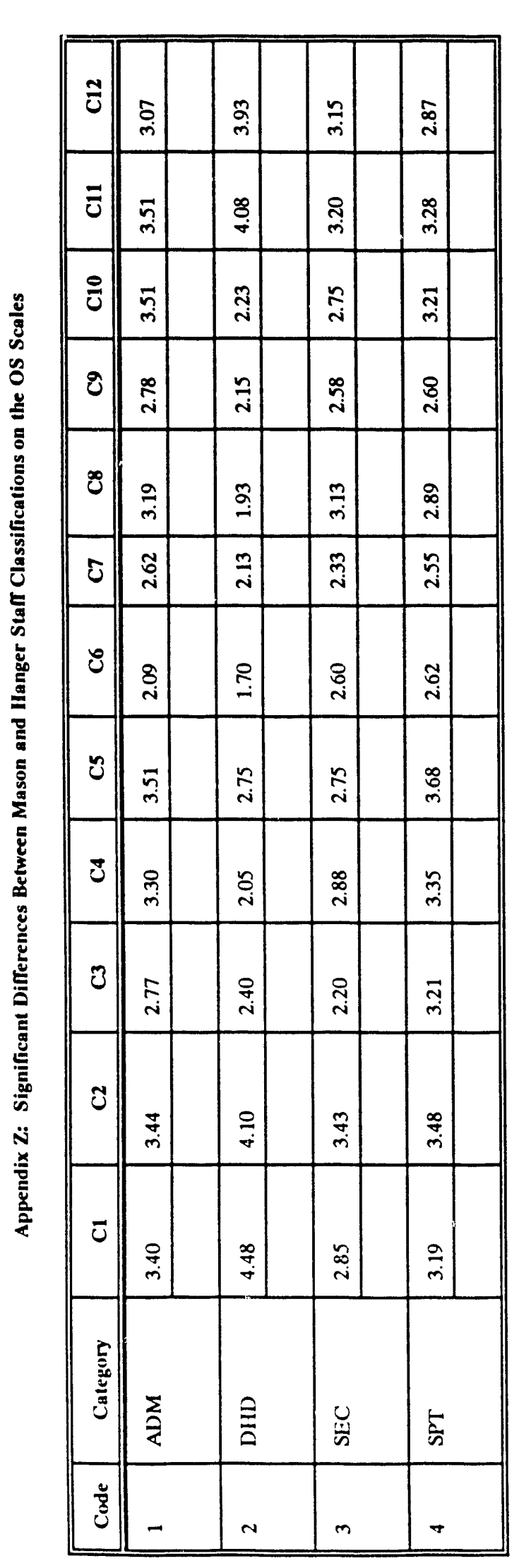

\begin{tabular}{|c|c|c|c|c|c|}
\hline$\sum_{i=1}^{\mathbb{1}}$ & $\begin{array}{l}\stackrel{\infty}{\infty} \\
\text { r. }\end{array}$ & 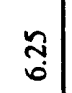 & $\underset{+}{8}$ & 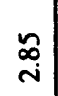 & \\
\hline 5 & $\stackrel{\wp}{*}$ & $\underset{+}{\stackrel{\sim}{+}}$ & $\underset{\sim}{\stackrel{\sim}{*}}$ & 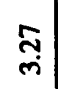 & \\
\hline $\begin{array}{l}n \\
z \\
0\end{array}$ & 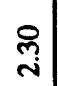 & ஜ̂ & $\underset{m}{\stackrel{n}{m}}$ & $\underset{\dot{m}}{\tilde{m}}$ & \\
\hline 동 & থ্লে & $\begin{array}{l}8 \\
+\end{array}$ & $\underset{m}{\stackrel{n}{m}}$ & $\underset{\sim}{\tilde{m}}$ & \\
\hline$\sum_{U}^{\infty}$ & శ్ণి & 8 & $\stackrel{8}{\circ}$ & $\underset{+}{8}$ & \\
\hline $\bar{z}$ & $\stackrel{n}{n}$ & $\underset{F}{\mathcal{F}}$ & 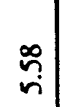 & $\overrightarrow{\dot{n}^{\prime}}$ & \\
\hline 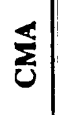 & $\underset{+}{F}$ & $\underset{i}{8}$ & $\underset{\sim}{\sim}$ & $\stackrel{\leftrightarrow}{\leftrightarrow}$ & \\
\hline$\sum$ & $\stackrel{\infty}{\overrightarrow{+}}$ & $\begin{array}{c}8 \\
i\end{array}$ & $\underset{⿱}{+}$ & $\stackrel{\infty}{\dot{m}}$ & \\
\hline$\stackrel{\infty}{\varrho}$ & ల్ల & $\underset{0}{8}$ & $\begin{array}{l}\approx \\
\hat{v}\end{array}$ & $\stackrel{f}{+}$ & \\
\hline$\overline{0}$ & $\stackrel{8}{\circ}$ & $\underset{+}{F}$ & $\underset{\sim}{\stackrel{\vartheta}{*}}$ & స్లి & \\
\hline$\dot{s}$ & $\stackrel{\vec{r}}{\dot{n}}$ & $\stackrel{m}{n}$ & $\vec{a}$ & $\begin{array}{l}\text { Pे } \\
\text { vi }\end{array}$ & \\
\hline$\stackrel{3}{3}$ & $\stackrel{\infty}{\circ}$ & $\begin{array}{l}\infty \\
\stackrel{\infty}{+} \\
\dot{\sigma}\end{array}$ & $\vec{m}$ & $\stackrel{?}{+}$ & \\
\hline $\bar{\delta}$ & $\stackrel{\infty}{\sim}$ & ષ્ત્ & $\stackrel{\sim}{\sigma}$ & $\stackrel{\infty}{\rightarrow}$ & \\
\hline 5 & $\underset{+}{\sigma}$ & $\underset{\sim}{\sim}$ & $\underset{n}{n}$ & $\underset{\sim}{\tilde{n}}$ & \\
\hline 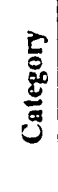 & $\sum_{\text {\& }}$ & $\stackrel{\Xi}{\Xi}$ & 岂 & $\bar{\hbar}$ & \\
\hline క్ & - & $\sim$ & $m$ & $\sigma$ & \\
\hline
\end{tabular}




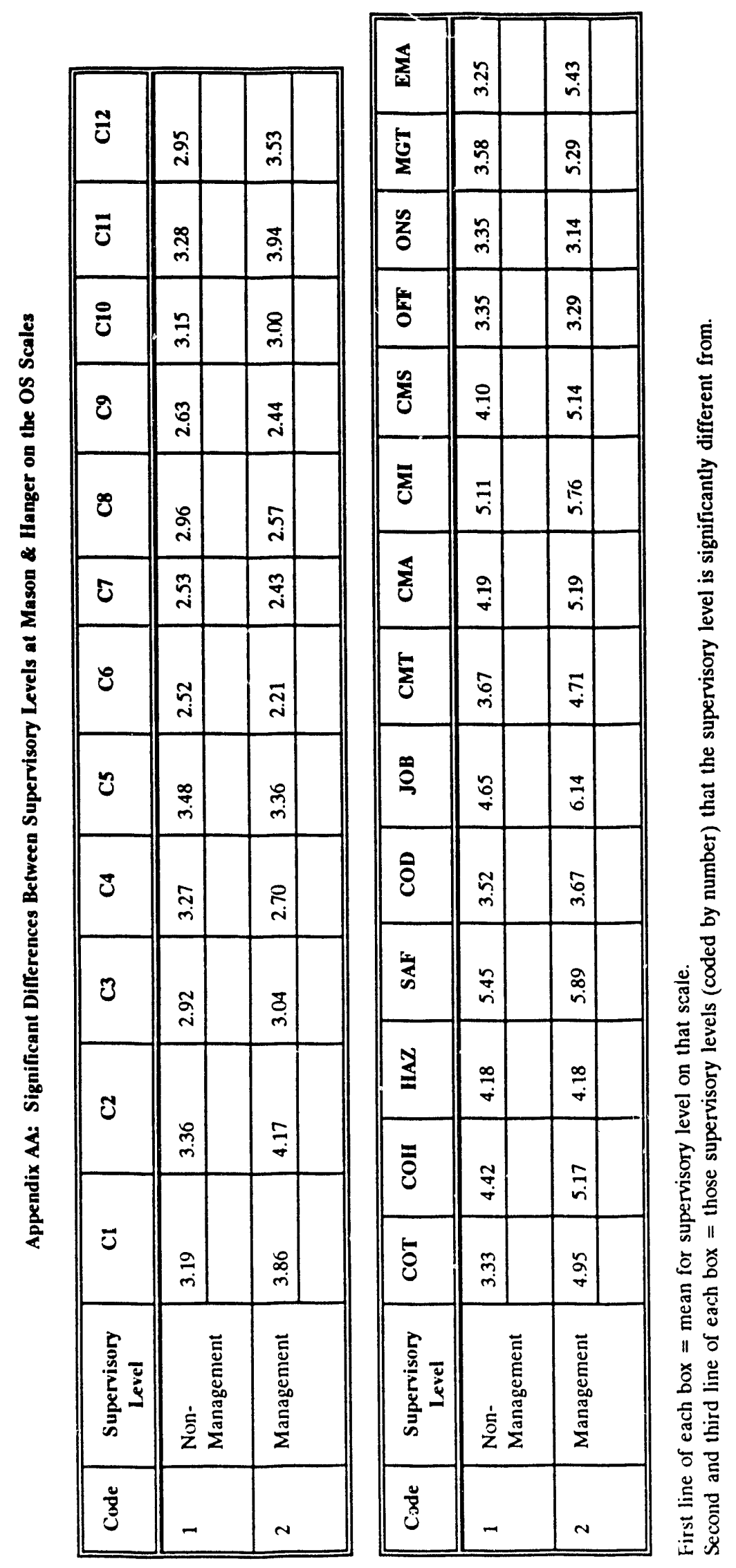

安 

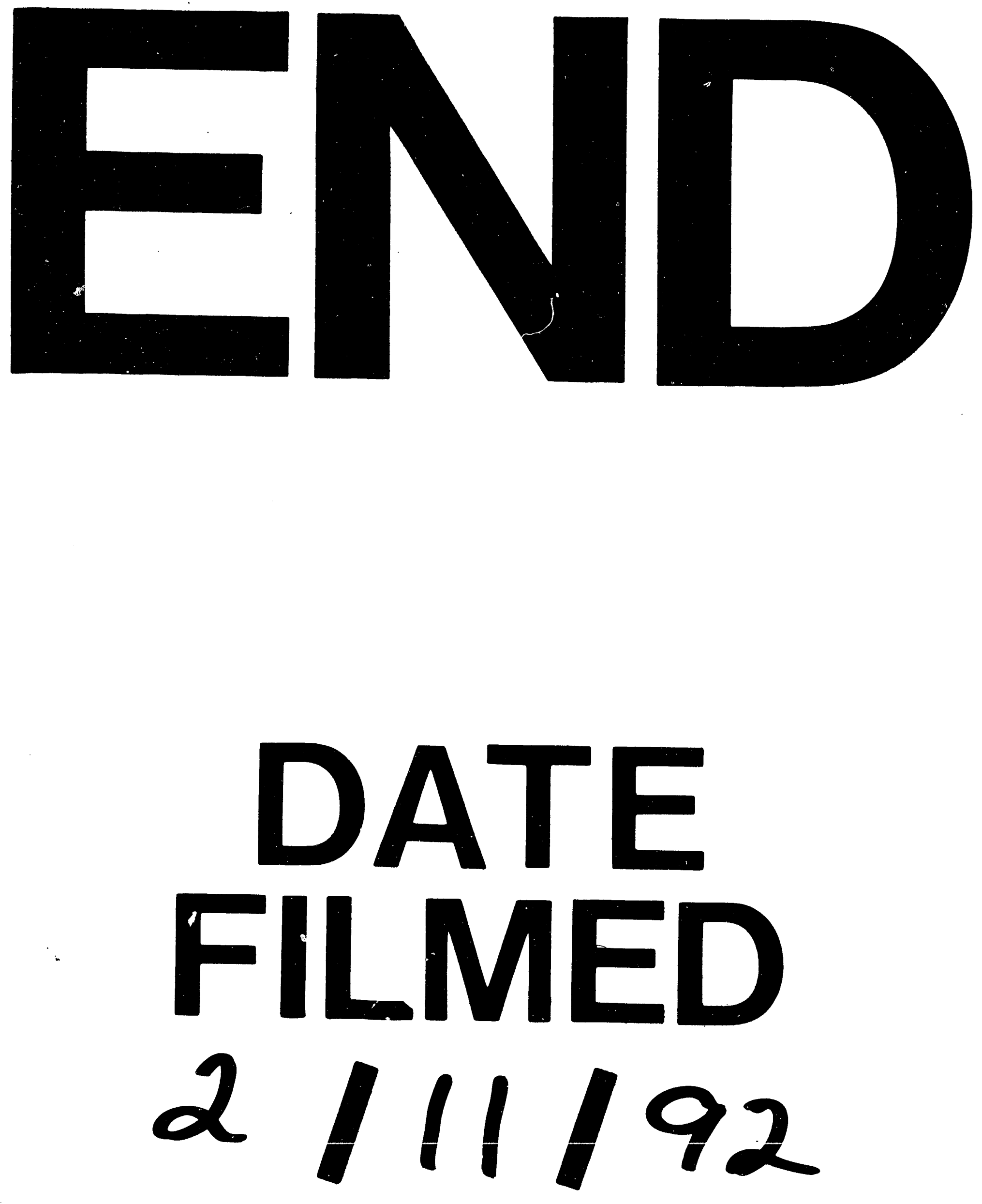
